qQE

821

P78

1890

INVZ 



\title{
Beiträge zur Naturkunde Preussens
}

\author{
heransgegeben
}

von der

Physikalisch-0ekonomischen Gesellschaft zu Königsberg.

\author{
- उद्धश 7. हैं \\ Die \\ Trilobiten-Fauna \\ der \\ Ost- und Westpreussischen Diluvialgeschiebe \\ von \\ J. F. Pompecki.
}

Mit 6 lithographierten Tafeln.

Königsberg in Pr.

In Kommission bei Wilhelm Koch.

1890. 


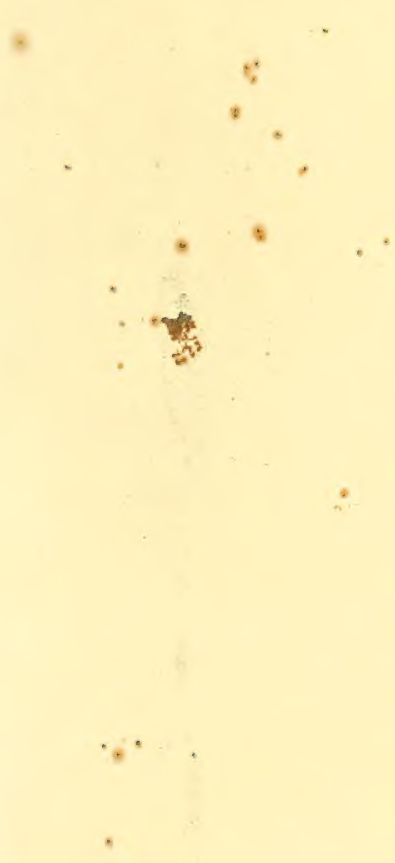

is dis +

$\therefore \quad y$

- 3. 

Voplegende Arbeit soll den Zweck erfüllen, den Sammlern von Diluvialgeschieben unserer Provinzen ein bequemes Hilfsmittel zur Bestimmung der in denselben gefundenen Trilobiten u liefern. Sie soll es dabei überflüsig machen, a uf die bisher zum Bestimmen dieser Trilobiten unumgänglich notwendigen Specialwerke zurückgehen zu müssen, welche sich der Sammelnde in der Regel nicht anzuschaffen vermag. Sie soll also, indem sie auf solche Weise das Bestimmen der gefundenen Dinge ermöglicht, überhaupt zum weiteren Sammeln anregen.

Um dem gedachten Zwecke vollständig zu dienen, sind neben genauen Beschreibungen sämmtlicher, mir aus unseren Geschieben bekannten Trilobitenformen, soweit es irgend thunlich war, auch Abbildungen aller Formen gegeben.

Das Material, auf welches ich meine Untersuchungen stützte, gehört den Sammlungen des Mineralogischen Instituts der Universität Königsberg, des Provinzial-Museums zu Königsberg, der Herren Dr. Vanhöffen-Wehlau, Dr. Gagel-Königsberg, Dr. Kiesow-Danzig, Lehrer Zinger-Pr. Holland und Konrektor Seydler-Braunsberg. pflichtet:

Zu ganz besonderem Danke für Unterstützungen bei der vorliegenden Arbeit bin ich ver-

Dem Direktor des hiesigen Mineralogischen Instituts, Herrn Prof. Dr. Branco, welcher mich mit der Ausführung der vorliegenden Arbeit betraute und mir in liebenswürdigster Weise die Sammlungen des Mineralogischen Instituts zur Verfügung stellte. Herrn Prof. Dr. Branco verdanke ich ausserdem vielfache Unterstïtzungen bei der oft sehr schwierigen Beschaffung der einschlagenden Litteratur;

Herrn Prof. Dr. Jentzsch, durch welchen mir die reichhaltigen Sammlungen und die wertvolle Bibliothek des Provinzial-Museums zu Königsberg zugänglich wurden;

Herrn Prof. Dr. Chun für die Ueberweisung der Litteratur über Trilobiten aus der Bibliothek des hiesigen Zoologischen Instituts;

Ferner den Herren Dr. Vanhöffen, Dr. Gagel, Dr. Haas e, welche mir ihre Unterstützung in dankenswertester Weise zu teil werden liessen; den Herren Dr. Kiesow, Lehrer Zinger und Konrektor Seydler, welche mich ihre wertyollen Trilobitensammlungen benutzen liessen.

Herr Prof. Lindström in Stockholm war so liebenswürdig, mir auf mehrere an ihn gerichtete Fragen in bezug auf einzelne zweifelhafte Geschiebe und Arten gütige Auskunft zu erteilen, wofür ich ihm an dieser Stelle meinen wärmsten Dank ausspreche.

Königsberg, im Juli 1890.

Die Trilobiten der palaeozoischen Diluvialgeschiebe der Provinzen Ost- und Westpreussen sind bereits mehrfach in der Litteratur der Geologie und Palaeontologie der Norddeutschen Tiefebene erwähnt worden. Ausser den Arbeiten von Jentzsch ${ }^{1}$ ) Nötling, $\left.{ }^{2}\right)$ Römer, ${ }^{3}$ ) Kiesow, ${ }^{4}$ ) welche die Trilobiten nur insoweit berücksichtigten, als

1) Jentzsch: "Uebersicht der silurischen Geschiebe Ost- und Westpreussens." Zeitschr. d. d. geol. Ges. 1880. Bd. XXXII.

2) Nötling: „Die Cambrischen und silurischen Geschiebe der Provinzen Ost- und Westpreussen." Jahrb. d. K. pr. geol. Landesanstalt 1882. pag. $261 \mathrm{ff}$.

3) Römer: "Lethaea erratica." Dames u. Kayser. Pal, Abhandl. Bd. II. 1884-85.

4) Kiesow: "Ueber Sil. u. Devon. Geschiebe Westpreussens." Schr. d. Naturforsch. Ges. z. Danzig. N. F. Bd. VI. H. I. 
sie zur Alters- und Heimatbestimmung der einzelnen Geschiebe wichtig sind, erschien im Jahre 1874 eine Arbeit Steinhardts, ${ }^{1}$ ) welche sämtliche, damals aus dem Gebiete unserer Provinzen bekannten Trilobitenformen umfasste. Die Arbeit Steinhardts kann heute, nachdem die Erforschung der russischen und skandinavischen Trilobitenfaunen durch Schmidt, Holm und Lindström so wesentlich gefördert ist, kaum mehr als ausreichendes Hilfsmittel zum Bestimmen unserer Trilobitenformen genügen. Ausserdem ist seit dem Erscheinen der Steinhardt'schen Arbeit das Trilobitenmaterial aus den Geschieben unserer Provinzen so erheblich angewachsen, dass wir jetzt eine Fauna von über 140 Formen haben, währendt Steinhardts Arbeit nur 49 Arten enthält.

Der Gang der vorliegenden Arbeit soll nun der sein, dass im Anschluss an Nötlings Geschiebearbeit in einem "Petrographischen Teile" diejenigen trilobitenführenden Geschiebe einer Betrachtung unterzogen werden, welche mir seit dem Erscheinen von Nötlings Arbeit als neu bekannt geworden sind, resp. solche, deren Verbreitungsbezirk sich durch neuere Erfunde als ein anderer erweist, als der von Nötling angegebene.

An diesen "Petrographischen Teil" knüpft sich der "Palaeontologische Teil", in welchem die sämtlichen, mir bekannten Trilobitenformen aus unseren Provinzen untersucht und beschrieben werden. Die Familien der Phacopiden, Cheiruriden, Lichiden, Mllaeniden konnten mit Hilfe der wichtigen Arbeiten Schmidts ${ }^{2}$ ) und Holms ${ }^{3}$ ) ohne grössere Schwierigkeiten bearbeitet werden; bei anderen, so namentlich bei der Familie der Asaphiden, über die es bis jetzt eine zum Teil nur mangelhafte Litteratur giebt, sah ich mich mehrfach genötigt, neue Arten aufzustellen.

In bezug auf das Alter der Trilobiten kommen in den Provinzen Ost- und Westpreussen nur Geschiebe vom Alter des Cambrium und Silur in betracht. Eine einzige typisch devonische Form, Phacops latifrons, liegt mir in einem angeblich aus Ostpreussen stammendem Stücke vor; doch da mir aus den Heimatsgebieten unserer Geschiebe weder diese Form, noch ein derartiges Gestein, wie das des betreffenden ostpreussischen Stückes bekannt ist, erwähne ich diese Art nur mit aller Reserve. (S. S. 9.)

Was die Heimat unserer Trilobiten anbetrifft, so ist diese, wie die aller unserer palaeozoischen Geschiebe auf die Ostseeprovinzen Russlands, auf Schweden und auf ein jetzt vom Meere bedecktes Mittelgebiet, das "Balticum", zurückzuführen. Auf dieses Balticum beziehe ich Formen, welche bis jetzt aus Schweden und Russland unbekannt sind, resp. solche, deren Gesteinsmaterial nicht mit dem in den genannten Ländern als anstehend bekannten übereinstimmt. Immerhin ist es möglich, dass Formen unserer Geschiebe, welche bisher noch nirgendwo anstehend gefunden sind, doch noch in Estland oder Schweden gefunden werden; denn so genau sind St. 3. 1874.

1) Steinhardt: „Die bis jetzt in pr. Gesch. gef. Trilobiten." Beiträge zur Naturk. Preussens

2) Fr. Schmidt: „Revision der Ostbaltischen Silurischen Trilobiten", in Mémoires d. 1'Ac. imp. d. sciences de St. Petersb. I. Phacopiden, Cheiruriden, Eucrinuriden. 1882. II. Acidaspiden, Lichiden. 1885. III. (G. Holm) : Mlaeniden. 1886.

3) G. Holm: „De Svenska arterna af Trilobitstägtet Illaenus". Bch. t. K. Svenska Vet.Ak. Staudlingar, 1882. Bd. VII, Nro. 3. 
die Heimatsgebiete unserer Geschiebe wohl kaum schon durchforscht, dass man sagen dürfte: die eine oder die andere Form unserer Geschiebe kommt weder in Russland, noch in Schweden vor, sie muss also auf ein Mittelgebiet bezogen werden. Eine derartige Angabe hat also nach dem jetzigen Standpunkt der Erfahrung nur die Wahrscheinlichkeit nicht aber absolute Gewissheit für sich.

\section{A. Petrographischer Teil.}

\section{Cambrische Geschiebe.}

\section{Schwarzer Stinkkalk mit Agnostus pisiformis Linné. ${ }^{1}$ )}

Nötling erwähnt schwarzen Stinkkalk mit Agn. pisiformis aus Westpreussen. Ausser einem angeblich von Neukuhren stammenden Stücke bereits stark verwitterten Stinkkalkes lag mir noch ein Stück desselben Alters von Schettniehnen bei Braunsberg (Ostpreussen) vor.

Das Heimatsgebiet ist Schweden.

\section{Schwarzer Stinkkalk mit Agnostus pisiformis Linné var. socialis Tullb. und Olenus truncatus Boeck. ${ }^{2}$ )}

Ein sehr grosses Geschiebe kleinkörnigen, schwarzen Stinkkalkes, welches beim Zerschlagen einen ausserordentlich stark bituminösen Geruch verbreitete, war dicht angefüllt mit Resten von Olenus truncatus Boeck und Agn. pisiformis Linné var. socialis Tullb. Beide Formen kamen jedoch nicht mit einander vermischt vor; das Geschiebe liess vielmehr zwei Zonen unterscheiden, eine, in welcher allein O. truncatus - namentlich auf Schichtflächen - in grossen Massen vorkam, und eine zweite, welche ganze Nester von Agn. pisiformis var. socialis enthielt.

Fundort: Bäckermühle bei Marienwerder, Westpreussen.

Heimat: Nach einer Mitteilung des Herrn Prof. Lindström stimmt das Gestein auffallend mit dem Alaunschiefer (Olenusschiefer) Westgotlands überein; Schweden ist daher als Heimat des Geschiebes $2 \mathrm{zu}$ betrachten.

\section{Schwarzer Stinkkalk mit Peltura scarabaeoïdes Wahlenberg und Sphaerophthalmus alatus Boeck.}

Ein plattenförmiges zum Theil sehr feinkörniges Geschiebe schwarzen Stinkkalkes enthielt neben Kopfschildern von Pelt. scarabaeoïdes solche von Sphaer, alatus.

Fundort: Bäckermühle bei Marienwerder, Westpreussen.

Heimat: Das Geschiebe ist auf die in Schweden weit verbreitete obere Zone des Olenusschiefers zurückzuführen. $\left.{ }^{3}\right)^{4}$ )

1) cfr. Nötling. 1. c. pag. 267.

2) Nötling erwähnt l. c. pag. 268 dieses Geschiebe nach einer Mitteilung des Herrn Prof. Jentzsch als typischen Agnostuskalk.

3) Remelé: Unters. üb. d. versteinerungsf. Diluvialgesch. d. Nordd. Flachlandes. St. I, pag. 45, 59, 82.

4) Römer: Leth. erratica. pag. 35. 


\section{3a. Schwarzer Stinkkalk mit Peltura scarabaeoïdes Wahlenberg.}

Ein kleines, plattenförmig spaltendes. Geschiebe, das durch Verwitterung bereits fast ganz braun gefärbt ist, zeigt einzelne Kopfschilder von Pelt. scarabaeoïdes, durch welches Fossil das Geschiebe als demjenigen der No. 3 ungefähr gleichalterig bestimmt wird.

Fundort: Pr. Holland, Ostpreussen.

Heimat: jedenfalls, wie bei No. 3, Schweden.

\section{Untersilurische Geschiebe.}

\section{a) Schichtengruppe B. Fr. Schmidts.}

a) Glaukonitkalk. B .

1. Nötling ${ }^{1}$ ) erwähnt unter No. 5c. seiner Arbeit ein Geschiebe „buntfarbigen, etwas erdigen mürben Glaukonitkalkes mit grossen dunkelgrünen Glaukonitkörnern." Dasselbe sollte nach Nötling enthalten:

\section{Orthisina of parva. \\ Megalaspis sp. \\ Niobe sp.}

Mir lag dasselbe Stück vor: es enthielt neben ganz unbestimmbaren Bruchstücken einer Asaphidenart, die möglicherweise zu Megalaspis gehören kann,

Orthis Christianiae Kjerulf

Amphion priscus n. sp.

Fundort: Belschwitz in Westpreussen.

Heimat: Das Geschiebe ist auf Schweden zurückzuführen. ${ }^{2}$ )

2. Roter Kalk mit Endoceren. In Bezug auf die Nötlingschen ${ }^{3}$ ) Varietäten a und c kann ich die Mitteilung Vanhoeffens, ${ }^{4}$ ) der beide Varietäten auch aus Ostpreussen erwähnt, während sie nach Nötling nur in Westpreussen vorkommen, bestätigen, da neuerdings derartige Geschiebe namentlich in der Umgegend von Königsberg häufiger gefunden worden sind.

Ein der Varietät a Nötlings entsprechendes Geschiebe - braunroter, erdiger ziemlich weicher Kalk, von zahlreichen, bräunlich gefärbten Kluftflächen durchsetzt - enthielt neben Resten von Megalaspis limbata Boeck ein Schwanzschild von

Holometopus? laevis n. sp.

Die Heimat der roten Endocerenkalke ist Schweden, resp. Oeland.

\section{b) Schichtengruppe D. Fr. Schmidts.}

\section{a) Jewesche Schicht D.}

Zu Nötling $10 \mathrm{a}^{5}$ ) erwähne ich ein sehr grosses Geschiebe dichten grauen Kalksteins, der sehr an Echinosphaeritenkalk erinnert; es enthielt:

1) Nötling. 1. c. pag. 271.

2) Römer. 1. c. pag. 36.

3) Nötling. 1. c. pag. 273, 274.

4) Vanhoeffen: "Einige für Ostpreussen neue Geschiebe." Zeitschr. d. d. geol. Ges. Jahrg. 1886. Sep.-Abdr. pag. 2.
5) Nötling l. c. pag. 281. 
Strophomena tenuistriata Murch.

Bellerophon sp.

Monograptus sp.

- Illaenus sp.

Asaphus Branconis n. sp.

Das betr. Geschiebe wurde in Craussen bei Königsberg gefunden. Geschiebe dieser Art sind sowohl in Ost- als Westpreussen nicht selten.

Heimat: Estland.

\section{B) Kegelsche Schicht $\mathbf{D}_{2}$.}

Nötling ${ }^{1}$ ) kennt kein Geschiebe dieses Alters, während sie jetzt in beiden Provinzen mehrfach gefunden sind. Es sind gelbgraue bis braune, ziemlich feste, oft etwas mergelige Kalke mit dunkelbraunen Kluftflächen, welche zahlreiche, allerdings meistens schlecht erhaltene Bruchstücke von Phacops maxima Fr. Schmidt enthalten.

Die Heimat dieser Geschiebe ist Estland.

Nötling erwähnt a. a. O. bei der Besprechung der Kegelschen Schicht eine Mitteilung Schmidts über Phacops Kegelensis Schmidt aus einem ostpr. Geschiebe. Ich hatte Gelegenheit, das betreffende Geschiebe von Kaidau-Ostpreussen zu untersuchen. Dasselbe gehört der Sammlung des hiesigen Provinzialmuseums; es enthält neben Ph. Kegelensis Bruchstücke von Asaphus jevensis Fr. Schmidt und besteht aus hellgrauem dichtem Kalk vom Alter der Jeweschen Schicht D1.

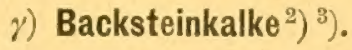

Mehrere Geschiebe dieser Art lagen mir vor:

1. Ein ziemlich grosses Geschiebe typischen Backsteinkalkes enthielt:

Mllaenus jevensis Holm,

Mastopora concava Eichwald,

Murchisonia sp.

Fundort: Nasser Garten bei Königsberg.

2. Ein kleines Geschiebe, welches erst zum teil in Backsteinkalk umgewandelt war und noch einen Kern bläulich grauen, kieseligen Gesteins zeigte, welches lebhaft an das der Lyckholmer Schicht erinnerte; dasselbe enthielt neben Mastopora concava Eichw. das Schwanzschild einer Encrinurusart, welche dem Encrinurus Seebachi Fr. Sehmidt (vergl, pag. 39) nahe steht.

Fundort: Mewe-Westpreussen.

3. Ein weiteres kleines Geschiebe, das bereits ganz in Backsteinkalk umgewandelt war, enthielt eine Glabella von Cheirurus cf. Plautini Fr. Schmidt.

Fundort: Wehlau-Ostpreussen.

Das Alter und die Heimat der Backsteinkalke sind nicht mit Sicherheit zu bestimmen. Die Varietät 1 wird durch Illaenus jevensis sicher als der Jeweschen

1) Nötling 1. c. pag. 284 .

2) cf. Nötling 1. c. pag. 283.

3) cf. Kiesow. Sil. u. Devon. Geschiebe Westpreussens, pag. 11. 
Schicht gleichalterig bestimmt und ontweder auf Estland selbst oder im Nachbargebiet des Balticums zurückgeführt. Für die Varietäten 2 und 3 können weder Alter noch Heimat näher bestimmt werden.

\section{c) Wesenberger Schicht E. Fr. Schmidts.}

Nötling ${ }^{1}$ ) erwähnt unter No. 16 ein kleines Geschiebe „blutroten, sehr harten, splittrigen Kalkes vom Habitus des Wesenberger Gestein " mit Encrinurus sp. Ein ganz ähnliches Geschiebe wurde bei Königsberg gefunden; es enthielt neben einem ganz übereinstimmenden Pygidium, das ich als Encrinurus ef. Seebachi bestimmte, Orthis insolaris Eichw.

Beide Geschiebe stammen aus Ostpreussen; sie sind der Wesenberger Schicht gleichaltrig zu erachten.

Heimat: Weder Estland noch Schweden besitzen eine entsprechende Encrinurusart, die Geschiebe sind daher wohl auf das Balticum zurückzuführen.

\section{d) Schichtengruppe F. Fr. Schmidts.}

\section{a) Lyckholmer Schicht F.}

Gesteine vom Alter der Lyckholmer Schicht F. und zwar die Nötlingsche Varietät $1:^{2}$ ) "weisser dichter kieselreicher Kalk, ähnlich dem Wesenberger, mit wenig Korallen, wohl ident mit Römers Sadewitzer Gestein " sind auch in Westpreussen gefunden, während Nötling sie nur aus Ostpreussen kennt. Geschiebe dieser Art enthalten vornehmlich Asaphus platyrhachis Steinh. und Chasmops Eichwaldi Fr. Schmidt.

Heimat: Estland.

\section{e) Untersilurische Geschiebe unbestimmbaren Alters.}

1. Hellgelber, feinkörniger, zum Teil etwas mergeliger Kalk mit weissen Kalkspathausscheidungen.

Einmal wurde ein derartiges Geschiebe bei Königsberg gefunden. Es enthielt zwei Trilobitenformen, welche nach den vorhandenen Bestimmungen mit keiner der bekannten Arten übereinstimmen; ich nannte sie:

Asaphus obtusus n. sp.

und Holometopus? radiatus n. sp.

Die Schale der Trilobiten ist vollkommen weiss. Das Gestein ähnelt auffallend manchen obersilurichen Kalken; doch das Vorkommen einer Asaphusart lässt es unzweifelhaft erscheinen, dass es untersilurischen Alters ist.

Heimat: Weder aus Estland noch aus Schweden ist mir ein entsprechendes Gestein bekannt, ich kann das vorliegende Geschiebe daher nur auf das Balticum beziehen.

2. Dunkelgelbgrauer, dichter bis körniger Kalk mit farblosen Kalkspathausscheidungen und mit dendritischen Ausscheidungen von Manganoxyden auf den Kluftflächen.

2) Nötling 1. c. pag. 288. 
Mehrere Geschiebe dieser Art lagen vor. Sie enthielten neben

Strophomena sculpta Gagel

und Strophomena pecten Linné

den Abdruck eines kloinen Phacopidenschwanzschildes und reichliche Bruchstücke einer Asaphidenart, für deron Bestimmung ich leider koinen Anhalt finden konnte. Würde das Geschiebe nicht durch die vorhandenen Bruchstücke von As. sp. als untersilurisch charakterisiert sein, so würde das Auftreten der beiden Brachiopodenformen für ein obersilurisches Alter sprechen; wahrscheinlich gehört es einer Grenzschicht zwischen Unter- und Obersilur an.

Fundort: Pr. Holland in Ostpreussen.

Heimat: Weder aus Estland noch aus Schweden habe ich ein ähnliches Gestein erwähnt gefunden, es stammt also wahrscheinlich aus dem Balticum.

3. Braungrauer körniger Kalk von quarzitähnlichem Aussehen.

Nur ein hleines Geschiebe dieser Art liegt mir vor. Es enthielt ein Schwanzschild einer kleinen Illaenusart, die ich mit keiner der vorhandenen Bestimmungen in Einklang bringen konnte. Um der vorzüglich ausgeprägten Merkmale des Schwanzschildes willen habe ich auf dasselbe eine neue Art begründet, für welche ich den Namens Illaenus nuculus vorschlage (cf. pag. 69). Ebensowenig, wie mir eine entsprechende Ilaenidenform aus dem baltischen Silur bekannt ist, habe ich Nachrichten über ein gleichartiges Gestein gefunden.

Fundort: Ostpreussen ohne nähere Ortsangabe.

Heimat: Das vorliegende Geschiebe ist wie dio beiden vorhergehenden auf das Balticum zurückzuführen.

\section{Obersilurische Geschiebe.}

\section{a) Geschiebe vom Alter der unteren Oeselschen Schicht J und der unteren und mittleren Gotländischen Schichten.}

Nötling ${ }^{1}$ ) führt zwei Gesteinsvarietäten dieses Alters, von denen die eine, b, mehrfach gefunden ist; Nötling charakterisiert sie sie „Blaugraue weiche Kalke oder Kalkmergel ${ }^{*}$ mit Encrinurus punctatus und Ptilodictya sp. Derartige Geschiebe enthielten ausser den von Nötling genannten Versteinerungen noch andere, welche einen wesentlicheren Anhalt zur Heimatbestimmung derselben lieferten. Wir können darin unterscheiden:

1. Blaugraue mergelige Kalke mit Encrinurus punctatus, sowohl in Ost- als Westpreussen gefunden.

Heimat: Das Obersilur Estlands wio Schwedens.

2. Blaugrauer, morgeliger Kalk mit Lichas Salteri Fletcher, einmal in Ostpreussen bei Gumbinnen gefunden.

Heimat: Gotland.

3. Grauer, mergeliger Fialk mit Proëtus verrucosus Lindstr.; einmal bei Belschwitz in Westpreussen gefunden.

Heimat: Gotland.

1) cf. Nötling I. c. pag. 294. 


\section{b) Graptolithengestein.}

Zu dem von Nötling ${ }^{1}$ ) nur aufgezählten Graptolithengestein möchte ich bemerken, dass dasselbo keineswegs den höchsten obersilurischen Schichten gleichalterig ist, wie Nütling angiebt, sondern dass es ungefähr der Gotländer Zone $c^{2}$ ) gleichzustellen ist.

Graptolithengesteine sind sowohl in Ost-als Westpreussen gefunden.

Thre Heimat ist das Balticum.

Kiesow erwähnt ${ }^{3}$ ) von Trilobiten aus dem Graptolithengestein allein Calymene Blumenbachi Brongn.

Mir lag nur einmal ein trilobitenführendes Stück dunkel graugrünen Graptolithengesteins von Pr. Holland-Ostpreussen vor, dasselbe enthielt; Acidaspis mutica Emmr. und Cyphaspis sp.

\section{c) Geschiebe vom Alter der Oberen Oeselschen Schicht $\boldsymbol{H}$.}

1. Braunlich grauer, feinkörniger Kalk mit:

Atrypa reticularis Linné,

Strophomena Pompecki Gagel,

Lichas aranea Lindström,

Encrinurus punctatus Wahlenbg.

Einmal bei Marienwerder in Westpreussen gefunden.

Heimat: Das Geschiebe wird durch Lichas aranea als gotländischen Ursprungs bestimmt. Lindström ${ }^{4}$ ) erwähnt die Art Lichas aranea von Fîrö aus seiner Zone d, die den ältesten Schichten der Oberen Oeselschen Gruppe Estlands gleichaltrig ist.

2. Grauer, etwas mergeliger Kalk, an Beyrichienkalk erinnernd, mit:

Encrinurus punctatus Wahlenb.,

Calymene intermedia Lindstr.,

Cheirurus dubius n. sp.

Cybele sp. b., ${ }^{5}$ )

Beyrichia Buchiana var, nutans Kiesow,

Atrypa reticularis Linné,

Ptilodictya sp.

Nur einmal bei Rosenberg in Westpreusssen in einem kleinen Geschiebe gefunden.

Als Heimat dieses Geschiebes muss das Balticum erachtet werden.

3. Rötlicher, sehr harter Kallsstein mit Ausscheidungen von weissem Kalkspath.

Zwei Geschiebe dieser Art liegen vor. Sie enthalten neben zahlreichen Korallenresten und Crinoidenstielen

Atrypa marginalis Dalm.

und Lichas Lindströmi n. sp.

Fundort: Wehlau in Ostpreussen.

1) cf. Nötling 1. c. pag. 305.

2) cf. Lindström: „Ueber die Schichtenfolge des Silur auf der Insel Gotland. Neues Jahrb. 1888. pag. 163.

3) ef. Kiesow 1. c. pag. 19

4) cf. Lindström, „Förteckning på Gotlands siluriska Crustaceer," pag. 94.

5) vergl. Cybele sp. b. pag. 38. Taf. VI, Fig. 35. 
Herr Prof. Lindström, welcher die Liebenswürdigkoit hatte, das betreffende Geschiebe zu begutachten, teilte mir mit, dass auf Gotland auf der Anhöhe Sandarfve ein ganz ähnlicher, doch etwas woicherer Kalk vorküme; es würdo unseren beiden Geschieben, falls sie dem Kalk von Sandarfve gleichaltrig sind, dann das Alter der obersten gotländischon Zone h zuzuschreiben sein. Ihre Hoimat ist wohl das Balticum in der Nähe Gotlands.

Obersilurischen Alters ist ferner ein Geschiobe von Dirschkeim Ost-Prenssen. "Lichtgrüner, sehr harter, dichter Kalk mit Phacops caudata Emmr."

Nötling ${ }^{1}$ ) stellt dieses Geschiebe zu den Gesteinen vom Alter der Wesenberger Schicht. Soweit mir bekannt, gehört Phacops caudata nur dem Obersilur an. Lindström²) erwähnt die Art aus den Mergelschiefern Gotlands vom Alter seiner Zone c. Salter ${ }^{3}$ ) kennt seine Phacops vulgaris auch nur aus dem Obersilur, und zwar dem Wenlocklimestone, welcher ungefähr der Lindströmschen Gotländer Zone d entspricht. Aus welchem Grunde Nötling das betr. Geschiebe der Wesenberger Schicht zuzählt, geht aus seiner Arbeit nicht hervor. Die von Nötling an dieses Geschiebe geknüpfte Bemerkung, dass die Untersuchungen Fr. Schmidts das Fehlen der Phacops caudata in Estland erwiesen haben, schliesst auch aus, dass Nötling durch eine Angabe Nieszkowskis, ${ }^{4}$ ) welcher eine Phacops caudata von Jewe und Wesenberg beschreibt, irre geleitet sein kann. Die Bestimmung Nieszkowski's hat sich nach Schmidt ${ }^{5}$ ) als irrig erwiesen; die betr. Schwanzschilder gehörten keiner Art der im Untersilur Schwedens und Estlands überhaupt fehlenden Untergattung Dalmania, sondern einer Peterygometopusart an. Ist so als unzweifelhaft erwiesen, dass Geschiebe mit Phacops caudata nicht untersilurischen Alters sein können, so fehlt noch die genauere Heimatsbestimmung des vorliegenden Geschiebes.

Wie bereits erwähnt kommt Phacops caudata in der Zone c des gotländischen Obersilurs vor. Die Gesteinsbeschaffenheit des vorwiegenden Stückes schliesst aus, dass es von Gotland selbst herzuleiten ist; es gehört jedenfalls einem der Insel Gotland benachbarten Gebiete des Balticums an.

Von Herrn Konrektor Seydler wurde mir ein Geschiebe ïbersandt, welches unzweifelhaft den echten Phacops latifrons Burm. enthielt. Ein Vergleich des vorliegenden Fossils mit den Exemplaren aus dem Devon der Eifel zeigte eine vollkommene Uebereinstimmung des mir vorliegenden Exemplares mit jenen. Das Gesteinsmaterial unseres Stückes ist dichter, dunkelgrauer nicht sehr harter Kalk, der in seinem Aussehen auffallende Aehnlichkeit mit den eifeler Kalken, in denen Phacops latifrons gefunden wird, zoigt. Die in unseren Provinzen gefundenen devonischen Geschiebe zeigen dagegen stets einen anderen Gesteinscharakter als das vorliegende Stück, es sind meistens Sandsteine, Dolomite und delomitische Kalke. Ebensowenig,

1) cf. Nötling: 1. c. pag. 286.

2) ef. Lindström: Förteckn. pag. 93.

3) cf. Salter: a monograph. pag. 54.

4) cf. Nieszkowski: "Versuch einer Monographie der i. d. sil. Sch. d. Ostseeprov, vork. Trilo-

biten." Arch. fo Naturk. Liv-, Est-, Kurlands. Ser. I. Bd. I. pag. 26.

5) cf. Fr. Schmidt: Rev. I, pag. 92. 
wie ich das Gestein mit dem unserer devonischen Geschiebe übereinstimmend gefunden habe, ist mir eine wirklich authentische Nachricht über das Vorkommen von Phacops latifrons in Russland bekannt. ${ }^{1}$ ) Es bleibt also wohl sehr zweifelhaft, ob das betr. Stück wirklich ein Ostpreussisches Geschiebe ist; dass es in Ostpreussen gefunden ist, muss ich auf die Mitteilung des Herrn Seydler hin annehmen, trotzdem kann es durch irgend welchen Zufall hierher versehleppt worden sein.

Als Fundort gab Herr Konrektor Seidler die Umgegend von Braunsberg an. Steinhardt ${ }^{2}$ ) erwähnt aus der Mascke'schen Sammlung eine schlechte Glabella, die er zu Phacops latifrons stellt. Es ist aus Steinhardt's Beschreibung und Abbildung kaum zu entscheiden, was für eine Art ihm vorgelegen hat.

Im vorstehenden sind 23 Geschiebearten besprochen worden, von denen 11 im Gebiete beider Provinzen neu sind. Die Verteilung und mutmassliche Heimat der neuen Geschiebe erläutert folgende Tabelle:

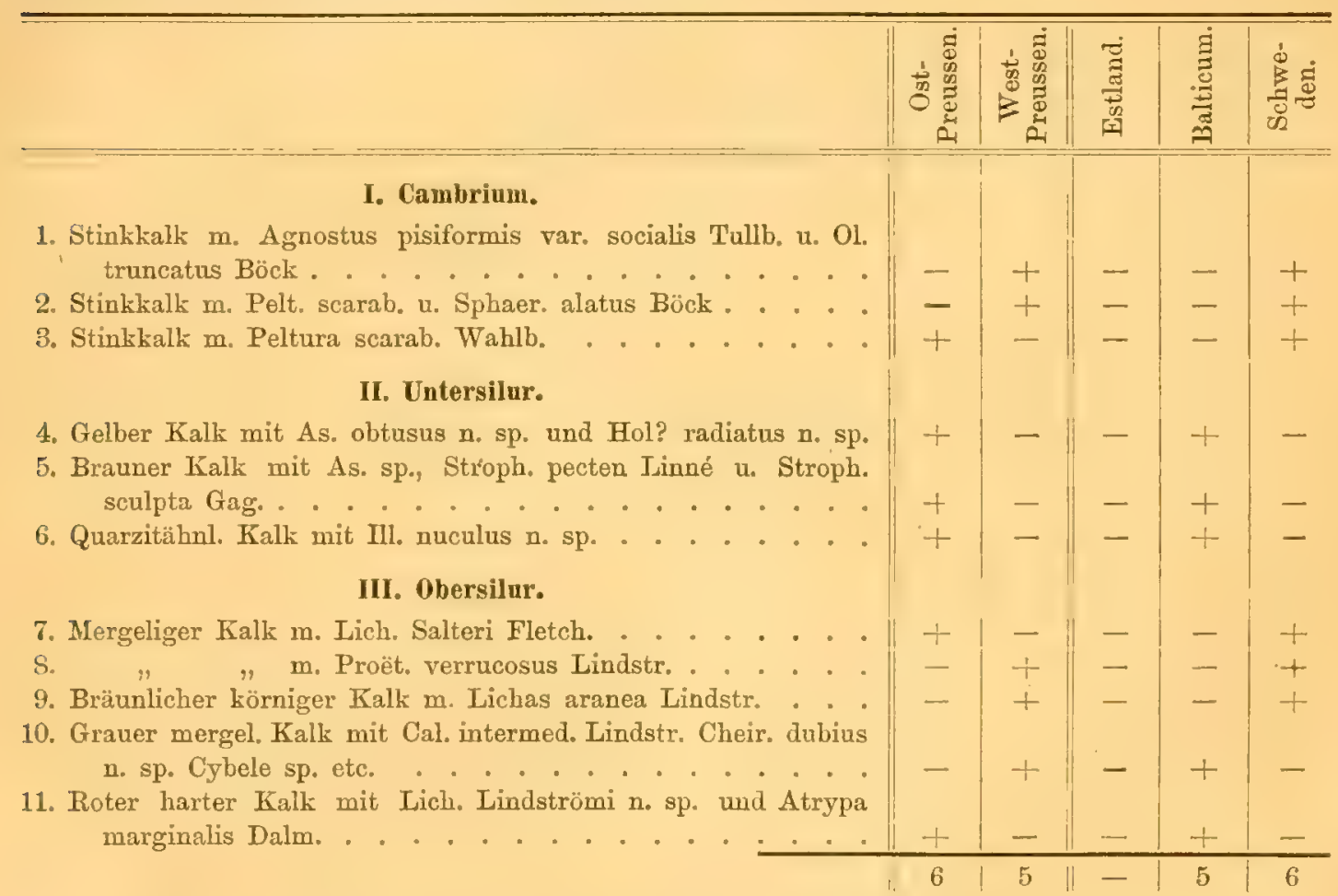

Ausserdem konnten neuere Fundorte nachgewiesen werden für:

1. Typischen Agnostuskalk: Braunsberg Ostpr.

2. Roten Endocerenkalk: Ost- und Westpreussen; Nötling kennt ihn nur aus Westpreussen.

1) Das von Eichwald in Leth. rossica pag. 1428 angegebene Vorkommen von Phacops latifrons in Estland beruht mindestens auf einem Irrtum dieses Autors.

2) cf. Steinhardt: 1. c. pag. 12. Taf. 1. Fig. 1. 
3. Kegelsches Gestein: Ost- und Westprenssen; Nütling liennt derartige Geschiebe überhaupt nicht.

4. Backsteinkalko: Ost- und Westprenssen; Nötling behauptete, sio fehlten in Ostpreussen wahrscheinlich ganz.

Es ergab sich endlich bezüglich des Alters einiger der von Nötling beschriebenen Geschiebe das Folgende:

1. Das Geschiebe mit Phacops Kegelensis Fr. Schmidt gehört nicht der Kogelschen, sondern der Joweschen Schicht an;

2. Das Graptolitengestein entspricht nicht dem obersten Obersilur, sondern den mittleren Gotlïnder Schichten;

3. Das von Nötling citierte Geschiebe mit Phacops caudata gehört keineswegs der Wesenberger Zone E. Fr. Schmidts an, sondern ist der Lindströmschen Gotländer Zone e des Obersilurs als gleichalterig zu erachten.

\section{B. Palaeontologischer Teil.}

Im folgenden reihe ich die Trilobiten nach dem Auftreten und Verlauf der grossen Gesichtsnaht des Kopfschildes aneinander und stelle die Gattungen mit gleichem oder sehr ähnlichem Verlauf dieser Naht in Gruppen, Familien, zusammen. Ich verkenne nicht, dass eine derartige Gruppierung etwas sehr gekünsteltes haben wird, indem oft vielleicht ähnlich aussehende Formen von einander getrennt werden. Ich beabsichtige aber auch durchaus nicht, hiermit ein System der Trilobiten aufzustellen, sondern will nur im Sinne der Aufgabe dieser Arbeit ein bequemes Hilfsmittel geben, die Trilobiten unserer Geschiebe zu bestimmen.

Ein System, wie das von Quenstedt ${ }^{1}$ ) nach der Anzahl der Leibesringe aufgestellte, würde unseren Zwecken kaum gute Dienste leisten. Ebensowenig kann das System Barrandes ${ }^{2}$ ) welcher namentlich die Beschaffenheit der Pleuren zur Klassificierung der Trilobiten benutzt, den Sammlern von Geschiebotrilobiten wesentliche Hülfe leisten, da man die boiden eben genannten Systymo nur daun mit Erfolg anwenden kann, wenn man vollständigo Trilobitenkörper findet: diese sind abor in unseren Geschieben so ausserordentlich selten, dass man kaum Gelegenheit haben wird, sich dieser Systeme zu bedienen. Das System von Goldfuss ${ }^{3}$ ) nach der Ausbildung der Augen allein ist nicht gerado besonders praktisch, da oft nahestehende Gattungen getrennt und umgekehrt fermstehende zusammengestellt werden.

Da man in unseren Geschieben in den allermeiston Fillon uur einzelne 'l'eilo von Trilobiten findet, ernchte ich die Ausbildung des Kopfschildes, insbesondere der Gesichtsnaht als das am moisten praktische Hilfsmittel zur Gruppirung dor Trilobiten

\footnotetext{
1) cf. F. A. Quenstedt: Handbuch der Petrefactenkunde. U. Aufl. 1885. pag, 428 ff.

2) cf. J. Barrande: Systême silurien du centro de la Bohème. Vol. I. prg. 332 ff.

3) cf. Goldfuss: "Sygtematische Uebersicht der Trilobiten und Beschreibung einiger neuen
} Arten." Neues Jahrb. 1813. pag. $537 \mathrm{ff}$. 
und ordne sie danach, indem ich andere Charaktere nur als nebensächlichere Faktoren für diesen Zweck benutze.") So ergiebt sich der folgende Schlüssel zum Bestimmen unserer Trilobitengattungen:

I. Ohne Gesichtsnaht, ohne Augen:

Der Leib besteht aus zwei Segmenten; Kopf- und Schwanzschild sind beinahe gleich gestaltet:

II. Mit Gesichtnaht:

\section{Fam. Agnostidae. \\ Gatt. Agnostus.}

Der Leib besteht aus mehr als zwei Segmenten:

A. augenlose, oder ocellentragende.

a) Die Gesichtsnaht verläuft in ihrer ganzen Länge auf dem Rande des Kopfschildes; die Augen bestehen aus einzelnen, wenigen Linsen:

II. Fam. Harpidae. [Rumpf: 20 u. mehr Segm.]

Gatt. Harpes.

b) Die Gesichtsnaht verläuft auf der Oberseite des Kopfschildes; Augen fehlen vollständig:

III. Fam. Ampycidae. [Rumpf: 5 u. 6 Segm.]

Gatt. Ampyx.

B. Augentragende. Die Augen sind deutlich facottiert, bis sehr fein netzförmig:

a) Die Gesichtsnähte gehen vom Seitenrande des Kopfschildes aus:

a) ohne Schnauzennaht:

Die Gesichtsnähte stossen auf dem Vorderrande zusammen;

Schnauzennaht und -schild fehlen. Augen grob facettiert:

IV. Fam. Phacopidae. [Rumpf: 11 Segm.]

Gatt. Phacops.

ß) Mit Schnauzennaht und -schild:

1. Das Schwanzschild ist weniger als 6 gliederig:

V. Fam. Cheiruridae. [Rumpf: $11(9,18)$ Segm.]

Gatt. Cheirurus, Amphion.

2. Das Schwanzschild ist mehr als $6(-18)$ gliederig.

VI. Fam. Encrinuridae. [Rumpf: 12, 11 Segm.]

Gatt. Cybele. Encrinurus.

b) Die Gesichtsnähte geheī von den Hinterecken aus;

1) Vergl. auch das von Gerstäcker in Bronn's Klassen u. Ordnungen des Tierreichs Bd. V. Arthropoden I, pag. 1238 ff. gegebene System, welches ebenfalls die grosse Gesichtsnaht als erstes Hauptunterscheidungsmittel enthält, bei welchem aber der Autor ausserdem im wesentlichsten die Form der Glabella betont, wodurch er zu einer anderen Gruppierung kommt, als dieses in der folgenden Uebersicht der Fall ist. 
VII. Fam. Calymenidae. [Rumpf: 13 Segm.]

Gatt. Calymene. Homalonotus.

c) Dio Gesichtsnähte gehen vom Hinterrande aus:

a) mit Schnawzennaht und -schild:

1. die Glabella ist ringsum deutlich durch Rückenfurchen begrenzt.

$\dagger$ Schwanzschild fast stots mit Seitenzähnen oder -Stacheln, 2-3gliederig:

* Schwanzschild mit Seitenzähnen, meistens länger als das Kopfschild; Rumpf 11gliederig:

VIII. Fam. Lichidae.

Gatt. Lichas.

* Schwanzschild mit Seitenstacheln, stets kürzer als das Kopfschild; Rumpf 9-10gliederig:

IX. Fam. Acidaspidae.

Gatt. Acidaspis.

t† Schwanzschild meistens ganzrandig, mehr als 3gliederig;

X. Fam. Proëtidae. [Rumpf: 10-17 Segna.]

Gatt. Proëtus, Cyphaspis.

[Phaëtonides].

2. Die Glabella geht nach vorne ohne Begrenzung in die Wölbung des Kopfschildes über.

XI. Fam. Illaenidae. [Rumpf: $(8,9), 10$ Segm.]

Gatt. Illaenus.

B) Ohne Schnauzennaht und -schild:

1. die Gesichtsnähte stossen auf der Oberseite des Kopfschildes zusammon:

† sie gehen von der Mitte des Hinterrandes übor die Augen zum Vorderrande, wo sie in einem Winkel oder Bogen zusammenstossen:

XII. Fam. Asaphidae. [Rumpf: 8 Segm.]

Gatt. Asaphus, Megalaspis, [Niobe], Nilous, Holometopus.

† Sio gehon vom Hinterrande aus den Rückenfurchen aus, begrenzen die Glabella und erroichen den Vorderrand nicht:

XIII. Fam. Remopleuridae. [Rumpf: 11 Segm.]

Gatt. Remopleurides.

2. Die Gesichtsnähte stossen auf der Oberseite des Kopfschildes nicht zusammen, sondern üborschreiten den Vorderrand:

XIV. Fam. Olenidae. [Rumpf: 10 u. mohr Segm.]

Gatt. Olenus. Sphaerophthalmus. Poltura. 
In dieser systematischen Uebersicht sind nur diejenigen Gattungen aufgeführt, welche bis jetzt in ost- und westpreussischen Geschieben gefunden sind; es sind 23 an der Zahl, welche sich auf 14 Familien verteilen.

\section{Fam.: Agnostidae. \\ Gattung: Agnostus Brongniart. \\ (Battus: Dalm. Emmr.}

Agnostus pisiformis Linné. Taf. IV. Fig. 23. 23 a.

1822. Agnostus pisiformis Brongniart: Hist. nat. d., Crustac. foss. pag. 38. Taf. IV. Fig. 4. 1828. Battus pisiformis Dalman: Palaeaden pag. 57. Taf. VI. Fig. $5 \mathrm{a}-$ d.

1869. Agnostus pisiformis Linuarsson: Vestergötl. Cambr. och Siluriska Aflagr. pag. 81.

T'af. II. Fig. 50. 51.

1874. Agnostus pisiformis Steinhardt: Pr. Trilobiten, pag. 61. Taf. IV. Fig. 17.

1882. Agnostus pisiformis Linné in. W. C. Brögger: Sil. Etagen 2 u. 3. pag. 55.

In einem Stück verwitterten Steinkalkes lag mir die typische Form des A. pisiformis vor.

Das Kopfschild zeigt eine durch die vorn zusammenfliessenden Rückenfurchen begrenzte, hochgewölbte zungenförmige Glabella, von deren Vorderende eine Stirnfurche zur Randfurche geht. Nur die ersten und dritten Seitenfurchen sind vorhanden. Die ersten Seitenfurchen, senkrecht zur Axe liegend, fliessen zusammen und schnüren einen vorn abgerundeten Stirnlappen ab. Die dritten Seitenfurchen gehen schräg nach innen zum Hinterrande und begrenzen mit den hinten etwas auseinandergehenden Rückenfurchen die kleinen dritten Seitenlappen. Das ungeteilte Mittelstück der Glabella trägt auf seiner höchsten Wölbung die Andeutung einer kleinen kielförmigen Erhöhung. Die durch die Stirnfurche getrennten Seitenteile sind flacher gewölbt als die Glabella.

Leibesringe habe ich nicht beobachten können.

Das Schwanzschild trägt an seinem Hinterrande jederseits einen kurzen nach hinten gewendeten Stachel. Die Spindel, etwa von derselben Form und Grösse wie die Glabella, ist ungefähr um die halbe Breite der Seitenlappen vom Hinterrande ontfernt, sie zeigt in ihrem vorderen Teile zwei schwache Querfurchen und einen etwas kräftigeren Kiel als die Glabella. Die Seitenteile sind nicht wie boim Kopfschilde durch eine Furche getrennt.

Fundort: Neukuhren, Ostpreussen. Rosenberg, Westpreussen. ${ }^{1}$ )

Nach Linnarsson (Cambr. o. Sil. Aflgr. pag. 81) gehört A. pisiformis dem Olenusschiefer (Cambrium) West-Gotlands an.

Ein von Schettniehnen bei Braunsberg stammendes Stück schwarzen cambrischen Stinklalkes zeigt auf einer Bruchfläche dicht gehäuft Kopf- und Schwanzschilder einer Agnostusart, die von A. pisiformis in bezug auf die Ausbildung des Schwanzschildes ein wenig abweicht, indem die Querfurchen der Spindel sehr undeutich sind, und statt der kurzen kielfömigen Erhöhung eine länglich runde kleine

1) cf. Steinhardt 1, c. pag, 62. 
Warze auftritt. Die Schwanzspindel selbst ist hinten etwas melur zugespitzt als bei der typischen Form des A. pisiformis. Diese Unterschiede schienen mir so unbedentend, dass ich eine Trennung der boiden Formen nicht für angebracht finde.

Agnostus pisiformis Linné. var, socialis Tullberg. Taf. IV. Fig. 24 a b.

1882. Agnostus pisiformis L. var. socialis Tullberg in W. C. Brögger. Dio Silur. Etagen 2 u. 3. pag. 56. Taf. I. Fig. 10 a b c.

Das Kopfschild stimmt mit der vorigen Art fast vollständig überein, es ist im ganzen nur etwas stärker gewölbt, mit einer stärkeren Andeutung des Kieles auf der Mitte der Glabella.

Das Schwanzschild ist durch ganz besonders starke buckelförmige Wölbung der Spindel ausgezeichnet. Nach hinten zu verbreitert sich die Spindel etwas und reicht bis nahe an den Randsaum. Viel deutlicher als bei der Hauptform des A. pisiformis treten zwei paar Querfurchen an der Spindel auf, die bis zu dem recht kräftig ausgebildeten Kiele gehen, welcher in eine kurze warzenförmige Spitze ausläuft, die zugleich die Stelle der höchsten Wölbung des Schwanzschildes ist.

Fundort: Bäckermühle bei Marienwerder, in dunklem, fast schwarzem, sehr bituminösem Stinkkalk zusammen mit Olenus truncatus. Das Gestein gleicht nach einer Mitteilung des Herrı Prof. Lindström dem Alaunschiefer von Westergötland vollkommen. Das Cambrium Schwedens dürfte wohl die Heimat dieser Art sein.

\section{Fam.: IIarpidae.}

Genus: Harpes Goldfuss. Beyr. Barr.

Mir lag kein Vertreter dieser Gattung vor, Steinhardt giebt die Beschreibung und Abbildung der Eichwaldschen Art H. Spaski aus einem Geschiebe von Königsberg (Masckesche Sammlung), welche ich hior citiere:

Harpes Spaski Eichwald. Taf. IV. Fig. 29.

1860. Harpes Spaski Eichwald: Lethaea rossica pag. 1375. Taf. LII. Fig. 27 a b.

1874. Harpes Spaski Steinhardt: Pr. Trilobiten pag. 35. Taf. V. Fig. 6.

Das Kopfschild ist etwa halblireisförmig, im mittleren Teile hochgewölbt. Der flache Randsaum ist weggebrochen, dafür ist die Oberseite des Umschlages, welcher dio den Durchbohrungen des Umschlages ontsprechenden Höckerchen (vergl. Steinhardt, pag. 35) zeigt, blosgelegt. Die hochgewölbto Glabella zeigt die dritten schräg nach hinten gerichteten Seitenfurchen; dio auf den Wangen sitzenden Augen sind weggebrochen. Nach Fr. S'chmidt ${ }^{1}$ ) kommt H. Spasti in Echinosphinritenkalk $C_{1}$ ror.

\section{Fam.: Ampycidae.}

\section{Gattung: Ampyx Dalman.}

Nit Angelin ${ }^{2}$ ) unterscheiden wir folgendo Untergattungen:

1) Fr. Schmidt: Rev. d. Ostbalt. Sil. Trilob. pag. 21.

2) of. Augelin: Pal. Scand. pag. 80. 
1. Ampyx Dalm. s. str.: Die Glabella ist gedrungen mit drehrundem Stirnfortsatz und seitlichen Eindrücken. 6 Leibesringel.

2. Lonchodomas Angel: Die Glabella geht allmählich in einen langen Stirnfortsatz über, der einen mehr oder weniger prismatischen Durchschnitt zeigt. 5 Leibesringel.

3. Raphiophorus Angel: Die Glabella geht plötzlich in einen oft kantigen Stirnfortsatz über. 5 Leibesringel.

\section{Ampyx Dalman, s. str.}

Ampyx foveolatus. Angelin. Taf. IV. Fig. 17. 17a.

1852 (1878). Ampyx foveolatus Angelin: Pal. Scand. pag. 80. Taf. XL. Fig. 2.

Das Bruchstück eines Kopfschildes lag mir vor. Randsaum und Randfurche sind deutlich ausgebildet. Die Glabella ist breit, stark gewölbt, von rechts und links oben etwas zusammengedrückt; nach vorn verjüngt sie sich schnell in eine feine drehrunde etwas nach oben gerichtete Spitze. Jederzeit sind auf der Glabella zwei grubenförmige Vertiefungen vorhanden, die schräg von vorn unten nach hinten oben gehen. Bei ihrer Einmündung in die Nackenfurche sind die Rückenfurchen tiefer eingedrückt.

Fundort: Nasser Garten bei Königsberg.

A. foveolatus wurde in einem dem Echinosphäritenkalk ähnelnden Gestein gefunden. Angelin erwähnt unsere Art aus Dalekarlien.

\section{Lonchodomas Angelin.}

Ampyx (Lonchodomas) rostratus Sars. Taf. IV. Fig. 18. 19. 20. 21. 21a.

1835. Ampyx rostratus Sars: Ueb. einige neue od. unvollst. bek. Tril. - Okens Jsis. pag. 334. Taf. VIII. Fig. 13.

1854 (78). Lonchodomas rostratus Angelin: Pal. Scand. pag. 82. Taf. XI. Fig. 11. 1874. Ampyx (Lonchodomas) rostratus Steinhardt: Pr. Trilobiten pag. 38. Taf. IV. Fig. 10. Taf. V. Fig. 7a. b.

Das Kopfschild ist länglich dreieckig mit ziemlich langen divergierenden Wangenhörnern. Die hochgewölbte Glabella geht allmählich in einen langen geraden Stirnstachel über. Die Glabella ist gekielt, auf ihrem vorderen Teil und auf dem Stirnfortsatz verläuft eine feine Rinne. Am Grunde der Glabella findet sich zu beiden Seiten des Kieles eine kaum vertiefte kreisförmige Zeichnung, die bei fehlender Schale deutlicher hervortritt. Rückenfurchen mit je einem kurzen Schlitz.

Der Leib besteht aus 5 Ringeln mit flacher, schmaler Spindel und längsgefurchten Pleuren.

Das Schwanzschild ist mehr als dreimal so breit als lang. Die Spindel ist flach gewölbt und ebenso wie die Seitenteile undeutlich gegliedert.

Die Schale ist glatt; am Vorderteile der Glabella und am Stirnstachel treten feine längsgestellte Terrassenlinien auf.

A. rostratus ist mehrfach in Ost- und Westpreussen gefunden worden. Nach 
Remelé $\dot{1}^{1}$ ) kommt A. rostratus im Chasmopskalk Westergötlands vor (dem obersten Echinosphreritenkallk entsprechend). Aus dom russischen Silur habe ich unsere Art nicht erwähnt gefunden.

\section{Raphiophorus Angelin.}

Ampyx (Raphiophorus) culminatus Angelin. 'T'af. IV. Fig. 22.

1852 (1878). Raphiophorus ctlminatus Angelin: Pal. Scand. pag. 82. 'laf. XL. Fig. 8. 1874. Ampyx (Raphiophorus) culminatus. Steinhardt: Pr. Trilob. pag. 39. Taf. IV. Fig.11.

Steinhardt beschreibt am angef. Orte eine kleine Glabella, die der Angelinschen Bestimmung von A. culminatus vollständig entspricht und welche ich hier citiere. Die nach vorn plötzlich in einen dünnen Stachelfortsatz verlängerte Glabella trägt am Grunde jederseits eine tief eingedrückte Grube.

Die Abbildung Taf. IV. Fig. 22. ist eine Copio der Steinhardtschen Abbildung nach einem Stück der Sammlung des Herrn Mascke, Ostprenssen.

A. culminatus gehört dem Chasmopskalk Westergötlands an. ${ }^{2}$ )

\section{Ampyx (Raphiophorus) setirostris Angelin.}

1852 (1878). Raphiophorus setirostris Angelin Pal: Scand. pag. 81. Taf. XI. Fig. 6. 174. Ampyx setirostris Kiesow: Sil. u. Devon. Gesch. W.-Pr. pag. 85. Taf. IV. Fig. 13.

Ein kleines Schwanzschild zeigt die dieser Art eigene Ausbildung: die Spindel zeigt 6 undentliche Glieder, während auf den Seitenteilen 4 Pleuren angedeutet sind, welche schwach gefurcht erscheinen.

Länge 4,5 mm, Breite $11 \mathrm{mma}$, Spindelbreite $3 \mathrm{~mm}$.

Fundort: Königsberg Ostpr. [Königsthal Westpr.]

Das Schwanzschild lag in einem Geschiebe vom Alter des Echinosphaeritenkalkes. Seine Heimat ist jedenfalls, wie die der anderen Ampyciden aus unseren Geschieben, in Schweden zu suchen.

\section{Fam.: Phacopidae.}

\section{Gattung: Phacops Emmrich.}

Salter ${ }^{3}$ ) und Fr. Schmidt ${ }^{4}$ ) unterscheiden folgende Untergattungen:

1. Trimerocephalus M.'Coy.

2. Phacops Emmrich s. str.

3. Acaste Goldfuss.

4. Dalmania Emmrich.

5. Cryphaeus Green.

6. Pterygomotopus Fr. Schmidt.

1) cf. Remelé: Unters, üb. d. versteinemungführenden Diluvialgeschiebe I. St. 1883. pag. 50.

2) cf. Remelé: 1. c. pag. 134.

3) cf. J. W. Salter: A. Monograph of. t. Brit. Trilob. pag. $12 \mathrm{fl}^{2}$.

4) cf. Fr. S’chmidt: Revis. d. Ostbalt. sil. Trilob.: I pag. $60 \mathrm{ff}$. 
7. Chasmops M'Coy.

8. Monorakos Fr. Schmidt. $\left.{ }^{3}\right)$

Von diesen 8 Untergattungen kommen 5 in unseren Geschieben vor (Phacops, Acaste, Dalmania, Pterygometopus, Chasmops); Trimerocephalus, Monorakos und Cryphaeus sind im baltischen Silur bisher nicht gefunden.

\section{Phacops Emmr. s. str.}

Bezugnehmend auf das pag. 9 gesagte, gebe ich auf Taf. VI. Fig. 15 u. 15 a. die Abbildungen des Kopf- und Schwanzschildes des von. Herrn Conrector Seydler angeblich bei Braunsberg gefundenen Exemplares von Ph. latifrons Burm.

Phacops prussica. n. sp. Taf. I. Fig. 28. 28 a.

Zwei Kopfschilder lagen mir vor, die dem Ph. elegans Schmidts ${ }^{2}$ ) ziemlich nahe stehen, die ich aber doch einiger besonderer Merkmale wegen nicht mit dieser Art vereinigen konnte.

Das Kopfschild ist abgerundet dreiseitig mit gerundeten Hinterecken. Der Vorderrand ist an den Seiten vor der Glabella etwas eingebuchtet. Der Randsaum ist vorne sehr schmal, nur durch eine feine Furche vom Kopfschilde abgeschnürt, nach den Seiten wird er breiter; er ist hier von einer breiteren, flachen Randfurche begleitet, die sich in den Hinterecken mit der Hinterrandfurche vereinigt. Die Rückenfurchen divergieren sehr stark. Die Glabella ist mässig gewölbt, von abgerundet fünfeckiger Form. Die ersten Seitenfurchen bestehen aus zwei im stumpfen Winkel zu einander liegenden Stücken, welche nicht zusammenstossen. Der vordere, tiefere Ast geht von den Rückenfurchen schräg nach hinten; der zweite Ast bildet einen flachen nach vorn gerichteten Bogen und liegt etwa dem Hinterrande parallel; or bildet einen sehr feinen fadenförmigen Eindruck. Die ziveiten Seitenfurchen sind ebenso ausgebildet, wie die inneren Aeste der ersten und laufen ihnen parallel. Die dritten Seitenfurchen sind tief, sie gehen von den Rückenfurchen aus und schnüren die Glabella so stark ein, dass deren vorderer Teil gestielt erscheint. Die allein deutlich von der Glabella abgeschnürten dritten Seitenlappen bilden einen schmalen, in gestielten Knöpfchen endenden Ring. Von der Vereinigung der dritten. Seitenlappen bis etwa zur Mitte der Glabella geht ein deutlicher Kiel. Die Gesichtsnähte gehen vom Aussenrande aus im Bogen zu den Augen, vor denselben convergieren. sie etwas, überschreiten die Rückenfurchen und laufen auf dem Rande des Stirnlappens entlang, um vor demselben im Bogen zusammenzustossen. Die Augen sind ziemlich gross und ragten, wie das eine der Stücke erkennen lässt, kaum über die Glabella hervor; sie sind am Grunde von einer Furche umgeben.

Der Nackenring ist schmal und kaum höher gewölbt als die Glabella. Die Oberfläche ist fast ganz glatt, nur auf dem Stirnlappen sind flache Grübchen zu erkennen. Der Umschlag bildet ein schmales schräg gestelltes Band mit abgerundeter oberer Kante.

1) cf. Fr. Schmidt: Ueber einige neue ost-sibirische Trilob. u. verw. Tierformen. Bullet. d. l'Acad. imp. d. sc. d. St. Petersbg. XXX. 1886, pag. 506.

2) ef. Fr. Schmidt: Rev. I. pag. 72. 
Maasse des Kopfes: Länge 13 น. $8 \mathrm{~mm}$, Breite 22 น. $14 \mathrm{~mm}$, Breite des Stirnlappens 14 u. $8 \mathrm{~mm}$.

Fundorte: Wehlau und Cranz in Ostpreusscn. Das Gestein ist ein krystalliner gelblich-grauer obersilurischer Kalk.

Von $\mathrm{Ph}$. elegans ${ }^{1}$ ) ist $\mathrm{Ph}$. prussica durch dio abgerundeten Hinterecken sio sind auch auf dem Steinkern abgerundet -, durch den etwas ausgeschweiften Vorderrand, durch don Kiel auf der Glabella und die grösseren Augen verschieden.

Mit Ph. Stokesi ${ }^{2}$ ) hat unsere Art die grösseren Augen gemein, doch divergieren die Rückenfurchen bei Ph. Stokesi stärker, und dann zeigt die Salter'sche Abbildung (Taf. II. Fig. 2a) die Aeste der ersten Seitenfurchen ungetrennt!

\section{Acaste Goldf. ${ }^{3}$ )}

Phacops (Acaste) Downingiae Murchison. Taf. I. Fig. 27. 27a.27 b. $27 \mathrm{c}$.

1862. Phacops Downingiae Murchison in Salter: A. Monograph. pag. 24. Taf. II. Fig. $17-36$.

1874. Phacops dubius Steinhardt: Pr. Trilob. pag. 14. Taf. I. Fig. 7.

1882. Phacops Downingiae Fr. Schmidt: Rev. I. pag. 75. Taf. I. Fig. 2. Taf. XI. Fig. 18. 1885. Phacops Downingiae Lindström: Förteckn. pâ Gotl. Sil. Crust. pag. 42.

1888. Ph. Downingiae Wiegand: Meklenburg. Trilob. in D. Geol. 1885 pag. 4. Taf. VII.

Fig. 2, 3.

Ausser einer grossen Menge von Glabellon und Schwanzschildern liegt mir auch das von Steinhardt a. a. O. als Ph. dubius Nvezk. beschriebene Kopfschild vor, aus dessen genauer Untersuchung ich die Ansicht Schmidt's ${ }^{4}$ ), dass Ph. dubius Steinh. dem Ph. Downingiae Murch. zuzuzählen sei, vollständig bestätigt finde. Wiegand, der ebenso wie Schmidt den $\mathrm{Ph}$. dubius bei Steinhardt von $\mathrm{Ph}$. dubius Nieszkowski ${ }^{5}$ ) trennt, hält ersteren für eine selbständige Art. ${ }^{6}$ ) Die genaue Vergleichung der Steinhardt'schen Abbildung mit der Wiedergabe seines Originals auf 'Taf. I. Fig. 27. zeigt, dass Wiegand durch Steinhardt's undeutliche Zeichnung irregeleitet ist.

Das Kopfschild ist gerundet dreiseitig mit abgerundeten Hinterecken; der Vorderrand ist nach vorne vorgezogen, gerundet (bei Steinhardt bildet or einen stumpfen Winkel). Die Rückenfurchen divergieren nach vorne, sie sind fast vollkommen gerade. Auf der Glabella sind drei Paare von Seitenfurchen vorhanden; die ersten Seitenfurchen bestehen aus zwoi, ein selur stumpfos Knie bildenden Stücken und gehen von den Rückenfurchen aus. Die zweiten Seitenfurchen erreichen die

1) cf. Fr. Schmidt: Rev. I. Ph. elegans pag. 72. Taf. I. Fig. 1. Taf. X. Fig. 10-12. Taf. XI. Fig. 17.

2) cf. J. W. Salter: A. Monograph: pag. 21.

3) Der Auffassung Linüströms, Acaste zu Phacops s. str. zu zählen, weil es bereits eine Cirrhipedengattung Acasta Leach giebt, kann ich mich bei den ausgezeichneten Unterscheidungsmerkmalen zwischen Acasto u. Phacops nicht anschliessen (cf. Lindström: Förteckning pi Gotlands sil. Crust. 1885 pag. 42).

4) cf. Fr. Schmidt 1. c. pag. 75, 76.

5) cf. Nieszkowski: Monographie der Trilobiten: Ph. dudius pag. 19 (533) Tal. I. Fig. 1.

6) cf. Wiegand: 1. c. pag. 42. 
Rückenfurchen nicht; die dritten gehen deutlich von den Rückenfurchen aus. Der Nackenring ist über die Glabella gewölbt. Die Oberfläche ist fast glatt, mit feinen Pünktchen besetzt, auf dem Stirnlappen treten kleine Höckerchen auf.

Das Schwanzschild ist fast halbkreisförmig. Die Spindel trägt bis 9 Glieder, die Seitenteile haben 6-7 schwach gefurchte Pleuren. Um das ganze Schild läuft ein schmaler Saum.

Fundort: In Ost- und Westpreussen sehr häufig in Beyrichien Kalken.

In Estland ist Ph. Downingiae am Okkessare-Pank auf Oesel (Obere Oesel'sche Schicht K) anstehend gefunden; im gotländischen Ober-Silur ist die Art ebenfalls verbreitet.

\section{Dalmania Emmr. $\left.{ }^{1}\right)$}

Phacops (Dalmania) imbricatula Angelin. Taf. I. Fig. 29.

1852 (1878). Phacops imbricatula Angelin: Pal. Scandin. pag. 10. Taf. VIII. Fig. 3.

Ein grosses breit dreieckiges Schwanzschild zeigt auf der Spindel 17 Glieder, auf den Seitenteilen 10 gefurchte, an ihrem äusseren Ende etwas zurückgebogene Pleuren. Das Schwanzschild ist von einem ziemlich breiten gewölbten Randsaum umgeben. Der Hinterrand ist zu einem Stachel ausgezogen.

Länge des Schwanzschildes bis zum Stachel $30 \mathrm{~mm}$, Breite $42 \mathrm{~mm}$, Spindelbreite $10 \mathrm{~mm}$.

Fundort: Ostpreussen ohne nähere Angabe und Marienwerder, Westpreussen. Anstehend ist Ph. imbricatula im Ober-Silur Gotlands gefunden.

Phacops (Dalmania) caudata Brünnich. Taf. I. Fig. 30. 30a.

1852 (1878). Phacops caudatus Brün. in Augelin: Pal. Scand, pag. 10. Taf VIII. Fig. 2. 1874. Dalmania caudata Steinhardt: Pr. Trilobiten. pag. 17. Taf. I. Fig. 8.

1885. Phacops vulgaris Salter in Lindström: Gotlands Crustac. pag. 37. Taf. XII, Fig. 1. 2.5.6

Mehrere kleine Schwanzschilder zeigten die für diese Art charakteristische Ausbildung: sie sind breit dreieckig, mit abgerundeten Vorderecken. Die Spindel besteht aus 12 Ringeln, von denen die vorderen je 2 Knötchen tragen. Auf den Seitenteilen treten 7 gefurchte, geschwungene Rippen auf. Der Randsaum ist schmal und weniger gewölbt als bei Ph. imbricatula. Der Hinterrand ist zu einem Stachel ausgezogen.

Die Stücke lagen zum Teil in graulich grünem Gestein (vergl. pag. 9), zum Teil in gelblichem, krystallinem Kalk.

Fundort mehrfach in Ost- und Westpreussen gefunden.

Anstehend ist $\mathrm{Ph}$. caudata von Gotland bekannt.

1) Dalmania Emmr. ist nicht gleichwertig der Gattung Dalmanites Barr., da Barrande zu Dalmanites alle Phacopsarten zählt, die zur Bildung von Wangenhörnern neigen, so dass dann also auch die Chasmopsarten zu Dalmanites gehören würden. Ferner rechnete Barrande auch Acaste zu Dalmanites (cf. Barrande 1. c. I. pag. 528 ff.). Barrande verwarf den Emmrich'schen Namen Dalmania, da er 1830 von Robineau Desvoidy bereits einer Dipterengattung beigelegt worden ist (cf. Barrande l. c. I. pag. 311). Dalmania bildet jedoch im Emmrich'schen Sinne eine gut umschriebene Gruppe, für die dieser ältere Name beizubehalten ist. 


\section{Pterygometopus Fr. Schmidt.}

\section{Phacops (Pterygometopus) exilis Eichwald. Taf. I, Fig. 15.}

1857. Phacops dubius Nieszkowski: MLonographie pag. 19 (533), Taf. I. Fig. 1. 2.

1860. Acaste exilis Eichwald: Lethaea rossica pag. 1423. Taf. LII. Fig. 28.

1882. Phacops exilis Fr. Schmidt: Rev. I. pag. 86. Taf. I. Fig. 18-21. 'Taf. XII. Fig. 13.

Einige Kopfschilder dieser Art liessen sich noch mit Sicherheit bestimmen. Sie sind ungefähr halbkreisförmig, mässig gewölbt. Der Kopfumschlag ist vorn gerundet, an den Seiten lässt er eine scharfe obere Kante erkennen. Der grosse Stirnlappen ist seitlich zu Flügeln ausgezogen, welche etwa $1 / 2$ der Wangenlänge erreichen. Die vorderen Zweige der Gesichtsnaht sind auf dem Stirnlappen als ganz feine, im Bogen zur Mitte des Vorderrandes gehende eingedrückte Linien zu erkennen.' Die ersten Seitenlappen sind gerundet dreieckig, die zweiten und dritten bilden fast gleich grosse, länglich viereckige, flache Lappen. Der Nackenring ist ziemlich hoch gewölbt, mit einem kräftigen Mittelhöcker verziert. Die Oberfläche der Glabella ist dicht mit Höckerchen besetzt, während die Wangen nur eingestochene Grübchen erkennen lassen.

Maasse des Kopfes: Länge $13 \mathrm{~mm}$, Breite $25 \mathrm{~mm}$.

Fundorte: Soritten bei Memel, Ostpreussen. Marienburg, Westpreussen.

$\mathrm{Ph}$. exilis gehört dem Echinosphaeritenkalk an und ist bisher nur in Estland anstehend gefunden.

Phacops (Pterygometopus) laevigata Fr. Schmidt. Taf. I. Fig. 20 a b c.

1882. Phacops laevigata Fr. Schmidt: Rev. I. pag. 88 u. 235. Taf. I. Fig. 22. Taf. X. Fig. 13. 14. Taf. XII. Fig. 14.15. Taf. XV. Fig. 24.

1884. Phacops laevigata Kiesow: Sil. u. Devon. Gesch. W.-Pr. pag. 75.

Die mir allein vorliegenden Kopfschilder sind etwa $1^{1 / 2}-2$ mal so breit als lang, stark gewölbt, mit gerundeten Hinterecken. Die Rückenfurchen divergieren nach vorne stark, biegen nach aussen um und münden in stumpfem Winkel in die flachen Seitenrandfurchen. Der Stirnlappen ist nach den Seiten in spitzige Hörner ausgezogen, über deren Grund die Gesichtsnähte als feine Eindrücke verlaufen. Drei Paare von Seitenfurchen sind als schmal eingedrückte Rinnen ausgebildet. Der Zwischenraum zwischen den Seitenfurchen auf der Glabella ist breiter als die Seitenlappen selbst. Die Augenhügel sind hoch, in 16 senkrechten Linsenreihen zähle ich je fünf Linsen. Der Nackenring ist breit, hochgewölbt, in der Mitte mit einem Knötchen verziert. Die Oberfläche der Glabella ist glatt, oder mit wenigen Höckerchen besetzt. Im vorderen Teile derselben treten zwei divergierende Grübchenreihen auf; das auf Taf. I. Fig. 20 abgebildete Exemplar trägt merkwürdigerweise statt der Grübchen- zwei Knötchenreihen.

Ph. laevigata gehört der Jeveschen Schicht Estlands an, die Art ist in Geschieben dieses Alters sowohl in Ost- als Westpreussen gefunden. 
Phacops (Pterygometopus) Kegelensis Fr. Schmidt. Taf. I. Fig. 19.

1882. Phacops Kegelensis Fr. Schmidt: Rev. I. pag. 91. Taf. XI. Fig. 8. Taf. XII. Fig. 19. Taf. XV. 25. 26.

Das Kopfschild ist sehr flach, gleichmässig gerundet. Der Stirnlappen ist seitlich zu flachen Hörnorn ausgezogen, die deutlich vom Mittelkörper durch die Gesichtsnähte, abgetrennt werden. Die drei Seitenfurchenpare sind deutlich und tief ausgebildet. Die zweiten und dritten Seitenfurchen laufen etwas schräg nach vorn. Die zweiten und dritten Seitenlappen sind fast vollständig gleichgebildet, sio nehmen etwa ein Drittel der Glabellabreite ein. Die Oberfläche der Glabella ist fein gekörnelt. Ph. Kegelensis kommt anstehend in der Jeweschen Schicht (D) Estlands vor. - Taf. I. Fig. 19 giebt das einzige Bruchstück dieser Art aus einem Ostpreussischen Geschiebe wieder.

\section{Chasmops. H'Coy.}

Phacops (Chasmops) praecurrens Fr. Schmidt. Taf I. Fig. 4. 4a.

1882. Phacops praecurrens Fr. Schmidt: Rev. I. pag. 98. Taf. I. Fig. 14, 15. 17. Taf. XV. Fig. 29.

Einige Kopfschilder dieser Art lagen mir vor. Der Umriss ist beinahe halbkreisförmig; die Hinterecken waren nach Schmidt zu langen Hörnern ausgezogen. Die Rückenfurchen gehen nach vorn stark auseinander und münden in die nicht sehr tiefe Randfurche. Die Glabella ist stark gewölbt, nach vorn steil abfallend. Der Stirnlappen ist oval, seitlich über die ersten Seitenlappen etwas hervorragend. Die ersten Seitenlappen sind rundlich dreieckig, ihre Länge an den Rückenfurchen ist grösser als die des Stirnlappens an den Rückenfurchen. Die zweiten Seitenlappen sind klein, schmal, schräg nach hinten gerichtet, ihre Länge beträgt bis zwei Drittel des Hinterrandes der ersten Seitenlappen; die dritten bilden einen schmalen Ring. Der Nackenring ist stark gewölbt und mit einem kräftigen Mittelhöcker verziert. Die Wangen fallen ziemlich steil ab. Die Oberfläche des ganzen Kopfschildes ist mit Höckern besetzt, die auf der Glabella besonders dicht und stark sind.

Masse: Länge des Kopfes $13 \mathrm{~mm}, 20 \mathrm{~mm}$. Breite $27 \mathrm{~mm}, 38 \mathrm{~mm}$.

Ph. praecurrens gehört dem Echinosphaeritenkalk C1 Estlands an.

Die mir vorliegenden Kopfschilder stammen aus Ostpreussen.

Phacops (Chasmops) Odini Eichwald. Taf. I. Fig. 2. 2a. Taf. VI. Fig. 33.

1857. Phacops conophthalmus Nieszkowski: Monographie pag. 20 (534).

1860. Chasmops Odini Eichwald: Lethaea rossica pag. 1429. Taf. LII. Fig. 32.

1874. Chasmops conicophthalmus Steinhardt: pag. 15 (z. T). Taf. I. Fig. 4.

1882. Phacops Odini Fr. Schmidt: Rev. I. pag. 99. Taf. IJ. Fig. 1-13. Taf. XV. Fig. 30.

Das Kopfschild ist halbkreisförmig mit langen säbelförmigen Wangenhörnern. Der Vorderrand ist an den Seiten der Glabella etwas eingebuchtet. Eine Randfurche umgiebt das ganze Kopfschild; sie bildet vor der Glabella eine ganz schmale Rinue, auf den Wangeu verbreitert sie sich und geht, schwächer werdend, auf die Wangen- 
hörner über. Der Umschlag bildet ein schmales, schräg gestelltes Band, oben und unten mit scharfer Kante. Die Glabella ist kräftig gewölbt, nach vorn steil abfallend. Der Stirnlappen ist nicht ganz so breit, als das Kopfschild lang ist; er bildet ein gleichmässiges Oval. Die ersten Seitenlappen bilden gewölute dreieckige Erhöhungen; alle Winkel des ersten Seitenlappens sind spitz, er nimmt an der Rückenfurche dieselbe Länge ein, wio der Stirnlappen. Die zweiten Seitenlappen bilden lileine deutliche Knötchen; die dritten bilden einen Ring, der etwas schmäler und kürzer ist als der kräftig gewölbte Nackenring. Die Augen sind gross, etwa so lang, wie die ersten Seitenlappen, am Grunde von einer Furche umgeben. Die senkrecht abfallenden. Wangenhöcker sind niedriger als die Glabella. Die Oberfläche ist fast glatt bis fein chagrinartig, die Wangenhöcker sind mit dicht gestellten Grübchen bedeckt.

Die Schwanzschilder sind breit, (Länge: Breite $=3: 4$ ), stark gewölbt, seitlich zusammengedrüclit, hinten etwas abgestutzt. Die Spindel ist hoch gewölbt, breiter als ein Drittel des ganzen Schildes; sie besteht aus 9-11 Gliedern. Die Seitenteile haben bis 10 Pleuren, von denen die orsten 5-6 gefurcht sind, die letzten Pleuren laufen der Are parallel.

In Ost- und Westpreussen ziemlich häufig im Echinosphaeritenkalk gefunden, doch meistens nur Schwanzschilder. Das ejnzige Kopfschild, dass ich mit Sicherheit zu dieser Art stellen kann, ist das auf Taf. VI. Fig. 33 abgebildete aus einem Ostpreussischen Geschiebe.

Heimat: Estland. Echinosphaeritenkalk.

Die var. Itferensis Schmidt ${ }^{1}$ mit kürzeren Wangenhörnern und mehr dreieckigem Schwanzschilde habe ich nicht beobachten können.

Von der nahe verwandten schwedischen Art Ph. conicophthalma Ss. et Boeck - erwähnt Kiesow ${ }^{2}$ ) ein kleines Schwanzschild aus Westpreussen. Ph. conicophthalma zeichnet sich durch ganz kurze Wangenhörner und kürzere erste Seitenlappen aus, das Schwanzschild ist stets 11 gliedrig und gleichmässig gerundet.

Phacops (Chasmops) cf. marginata Fr. Schmidt. Taf. I. Fig. 1. 3. u. 24.

1882. Phacops marginata Fr. Schmidt: Rev. I. pag. 104. Taf. III. Fig.5.6.7. Taf. X. Fig.15.

Mehre Kofschilder zeigen geringe Abweichungen von der Schmidtschen Art. Sie sind mehr als doppelt so breit als lang; der Randsaum ist vor dem Kopfschilde nicht so breit, wie die Abbildungen 5 und 7 bei Schmidt für Ch. marginata angeben, und dann ist der Umschlag bis ziemlich zur Hälfte der Wangenhörner mit einer scharfen äusseren Kante versehen (bei Ch. marginata soll diese Kante nux bis zum Beginn der Wangenhörner gehen). Der grosse Stimlappen ist wie bei Ch. marginata breiter als die ganze Länge des Kopfschildes und zeigt vorn deutlich die divergierenden Grübchenreihen. Die Seitenrandfurche geht deutlich in die Hinterrandfurche über. Der Wangenhöcker ist niedriger als dio Glabella. Dio Oberfläche erscheint auf den mir vorliegenden Stücken (es sind Steinkerne) fast ganz glatt, nur auf den Wangenhöckern sind feine Grübchen eingedrückt.

1) cf. Fr. Schmidt 1. c. pag. 102.

2) cf. Kiesow: Sil. u. Der. Gesch: pag. 77. 
Mit dem einen der Stücke wurde das auf Taf. I Fig. 3 abgebildete Hypostom zusammengefunden; es ist länglich eiförmig, mit stark ausgezogenem Hinterrande. ${ }^{1}$ ) Das Mittelstück ist stark gewölbt, mit wenigen flachen Höckern besetzt, und durch kurze Mittelfurchen in einen grossen Vorderlappen und einen kleinen, schmaleren Hinterlappen geteilt.

Maasse des Kopfes: Länge $19 \mathrm{~mm}$, Breite $42 \mathrm{~mm}$, Breite des Stirnlappens 21,5 mm.

$$
\text { " } 18, \quad 40, \quad \text { " } " \quad \text { " } 419 \quad \text { " }
$$

Das auf Taf. I Fig. 24 abgebildete Schwanzschild stimmt mit dem von Schmidt (Taf. III Fig. 6) abgebildeten ziemlich gut überein, so dass ich dasselbe auch zu Ph. cf. marginata stello: es ist sehr breit, fast halbkreisförmig (12 mm: $20 \mathrm{~mm}$ ) und nicht so stark gewölbt wio die Schwanzschilder von $\mathrm{Ph}$. Odini. Die Spindel nimmt etwa 1/3 der Breite ein (bei Schmidt ist sie etwas breiter) und besteht aus 8 Gliedern; die Seitenteile tragen 7 Pleuren, von denen die ersten 2-3 ganz schwach gefurcht sind; die letzten Pleuren sind sehr undeutlich ausgebildet. Die Schmidtsche Abbildung zeigt die letzten Pleuren auch noch deutlich, und auf den 4 ersten Pleuren Mittelfurchen, während ich bei meinem Stücke nur auf den ersten 2 und 3 Pleuren ganz schwache Furchen beobachten kann.

$\mathrm{Ph}$. cf. marginata ist mehrfach in Ostpreussen gefunden worden. Das Gestein ähnelt dem der Jeweschen Schicht.

Phacops (Chasmops) bucculenta Sjögren. Taf. I. Fig. 16. 17.

1852 (1878). Phacops bucculenta Sjögren in Angelin: Pal. Scand. pag. 9. Taf. VII. Fig. 1 u. 2.

1882. Phacops bucculenta Fr. Schmidt: Rev. I. pag. 105. Taf. III. Fig. 1-4. Taf. X. Fig. 16.

$\mathrm{Ph}$. bucculenta ist eine der $\mathrm{Ph}$. marginata nahe verwandte Form, die sich durch folgende Merkmale auszeichnet: Das Kopfschild ist etwa halblreisförmig, der Vorderrand gleichmässig gebogen bis abgestutzt: die Hinterecken sind in breite säbelförmige Wangenhörner ausgezogen. Der Randsaum ist vor der Glabella ganz schmal, auf den Wangen wird er breiter und ziemlich flach. Der Umschlag bildet ein flaches, oben und unten scharfkantiges Band. Die Glabella ist nach vorne zu sehr kräftig gewölbt, zwischen den Augen ist sie niedergedrückt. Der Stirnlappen ist gross, breiter als die Länge des Kopfschildes, mit flachem Vorderrande. Die ersten Seitenlappen sind klein, rundlich dreieckig und durch tiefe Furchen fast ganz von der Glabella abgeschnürt; die zweiten bilden ganz kleine Knötchen, die dritten einen schmalen Ring. Die Wangenhöcker sind sehr hoch, höher als die Glabella, und steil nach den Seiten abfallend; auf ihrer Vorderseite sind die Gesichtsnähte tief eingedrückt. Die hohen Wangenhöcker und die verhältnismässig kleinen ersten Seitenlappen sind besonders charakteristisch für diese. Art.

Ch. bucculenta gehört der Jeweschen Schicht an und ist anstehend scwohl in Estland als in Schweden gefunden. Unsere Stücke stammen wohl aus Estland.

1) In Bezug auf die Benennung der einzelnen Teile des Hypostoms schliesse ich mich an Novák an. cf. A. Novák: Studien an Hypostomen böhmischer Trilobiten. I u. II. Sitzungsber. d. Kgl. Böhm. Ges。d. Wissenschaften. Prag 1874 (475-483) und 1884 (212-229). 
Bruchstücke dieser Art sind öfters in Ost- und Westpreussen grefunden worden. Das auf Taf. I. Fig. 17 abgebildete Kopfschild giebt die Seitenansicht eines etwas verdrückten Exemplars, das durch die Ausbildung eines breiten vorderen Randsaumes an Ph. Wrangeli Fr. Schmidt ${ }^{1}$ ) erinnert, während der stark gewölbte Stirnlappen und der vorn nur wenig aufgeworfene Rand die Zugehörigkeit zu $\mathrm{Ph}$. bucculenta beweisen.

Phacops (Chasmops) Wesenbergensis. Fr. Schmidt. Tat. I. Fig. 14. 14a. 15.

1882. Phacops Wesenbergensis Fr. Schmidt: Rev. I. pag. 115. Taf. IV. Fig. 10. 12. Taf. V. Fig. 1-7. Taf. X. Fig 20.

1888. Phacops Wesenbergensis Wiegand: Mecklenb. Trilob. pag. 52. Taf. VII. Fig. 3.

Das Kopfschild ist fast halbkreisförmig, mit langen, schräge stehenden Wangenhörnern; der Vorderrand ist etwas emporgewölbt, der Umschlag gerundet. Die ziemlich stark gewölbte Glabella ist nach vorne sehr verbreitert. Der Stirnlappen ist breiter als die ganze Länge des Kopfschildes, sein Umriss ist fast ganz elliptisch; in den Vorderrand geht er in ziemlich starker Wölbung, ohne einen deutlichen Randsaum zu bilden über. Die ersten Seitenlappen sind gross, dreieckig, mit spitzem innerem Winkel; ihre Aussenseite nimmt fast die Hälfte der Rückenfurchenlänge ein. Die zweiten Seitenlappen sind nur als schwache Knötchen ausgebildet; die dritten bilden einen schmalen Ring. Die Glabella ist dicht mit Höckerchen besetzt. Die Gesichtsnaht verläuft vor der Glabella auf dem Aussenrande.

Die nicht sehr stark gewölbten Wangen sind von dem gerundeten Seitenrande durch breite Randfurchen geschieden, die sich mit der Hinterrandfurche vereinigen. Das Hypostom ist länglich eiförmig mit zungenartig ausgezogenem Hinterrande und starken Vorderflügeln.

Das Schwanzschild ist parabolisch mit gleichmässig abfallenden, kräftig gewölbten Seitenteilen. Die Spindel und die Seitenteile tragen bis 14 Glieder.

Maasse: Kopf: Länge $18 \mathrm{~mm}$, Breite $36 \mathrm{~mm}$, Breite des Stirnlappens $19 \mathrm{~mm}$. Schwanzschild: Länge $24 \mathrm{~mm}$, Breice $29 \mathrm{~mm}$, Spindelbreite $11 \mathrm{~mm}$.

Ch. Wesenbergensis ist sowohl in Ost-als Westpreussen in Geschieben vom Alter der Wesenberger Schicht gefunden worden; seine Heimat ist Estland.

Phacops (Chasmops) macroura Sjögren. Taf. I. Fig. 7. 7a. 9. 10 (8. 11?).

1852 (1878). Phacops macroura Sjögren in Angelin: Pal. Scand: pag. 9. Taf. 7. Fig. 3. 4.

1888. Phacops macroura. Wiegand: Mecklenb. Trilob. pag. 49. Taf. VII. Fig. 1. a. b.

Das Kopfschild ist etwa halblreisförmig. Dio Hinterecken sind zu senkrecht stehenden, breiten, säbelförmigen Hörnern ausgezogen. Der Randsaum ist vor der Glabella aufwärts gebogen, an den Seiten ist or durch eine breite Furche von den Wangen getrennt; vor dem Beginn der Wangenhörner biegt diese Furche deutlich zu der Hinterrandfurche um. Die Glabella ist stark gewölbt, deutlich mit Höckern besetzt. Der Stirnlappen ist an seinen Ecken abgerundet, sein Vorderrand ist flach

1) ef. Fr. Schmidt: Rev. I. pag. 107. Taf. XI. Fig. 10. 
gewölbt, doch auch wie die Stücke 7 und 8 zeigen, gradlinig bis ein wenig concav: ${ }^{1}$ ) seine Breite ist nicht ganz der Länge des Kopfes gleich, seine Ausdehnung an der Rückenfurche ist kleiner als die der ersten Seitenlappen. Diese sind gross dreieckig, ihr innerer Winkel ist $90^{\circ}$ und grösser. Die zweiten Seitenlappen sind als kleine Knötchen ausgebildet, die dritten als schmaler Ring.

Zu Ch. macroura sind diejenigen Schwanzschilder zu stellen, deren Spindel, nach hinten stark verschmälert, fast spitz endet, und deren Seitenteile gleichmässig, mehr oder weniger flach gewölbt sind. Der Umriss des Schwanzschildes ist breit dreieckig kis paraboliseh. Spindel und Seitenteile tragen bis 18 Glieder.

$\mathrm{Ph}$. macroura findet sich häufig in Backsteinkalken (typische Exemplare mit vorn convexem Stirnlappen) und in einem dichten, grauen bis braunen, sehr harten kieseligen Kalke mit grossmuscheligem Bruch, Rollsteinkalk (Exemplar Taf. I. Fig. 7.). Die Stücke Taf. I. Fig. 8 und 11 lagen in einem gelbgrauen Kalke mit braunen Kluftflächen, der dem der Kegelschen Schicht ähnlich ist.

Fundorte: Ost- und Westpreussen. Anstehend ist Ph. macroura bisher nur aus Schweden bekannt.

Phacops (Chasmops) maxima Fr. Schmidt. Taf. I. Fig. 12. 13. 13a.

1882. Phacops maxima Fr.Schmidt: Rev. I. pag. 112. Taf. III. Fig. 11. Taf. IV. Fig.1-3, 5-7. Taf.X. Fig.17. 18. Taf.XI. Fig.13. Taf.XV. Fig.34. 35.

Für $\mathrm{Ph}$. maxima giebt Schmidt als Unterscheidungsmerkmal von Ph. macroura an, dass der Stirnlappen vorne gradlinig bis concav sein soll; ferner bilden seine Seitenflügel stumpfe Ecken, und seine Breite ist grösser als die Länge des Kopfschildes; weiter ist der Vorderrand stark aufgeworfen, der Umschlag flach bandartig; die Hinterecken sind zu geraden, schwertförmigen Hörnern ausgezogen, die Oberfläche der Glabella ist glatt bis höchstens chagriniert. Alle diese Merkmale konnte ich bei mehreren Bruchstücken schlecht erhaltener Kopfschilder wohl unterscheiden, und sie daraufhin von $\mathrm{Ph}$. macroura trennen; ohne jedoch ein wirklich gutes Stück zu finden, das annähernd die Grösse der Schmidtschen Exemplare ${ }^{2}$ ) erreicht hätte.

Mit einem der Bruchstücke wurde das auf Taf. I. Fig. 12 abgebildete Hypostom gefunden. Es ist lang eiförmig, stark gewölbt, mit grossen Vorderflügeln; der Hinterrand ist lang ausgezogen. Der Vorder- und Hinterlappen des Nittelstückes ist mit flachen Höckern bedeckt. Das Schwanzschild ist stärker und ungleichmässiger gewölbt als bei $\mathrm{Ph}$. macroura, hinten abgestutzt, die Spindel ist nach hinten weniger verschmälert und endet stumpf. Das Schwanzschild trägt bis 18 Glieder; die Pleuren gehen nicht ganz bis zum Rande; die letzten laufen der Axe parallel.

Bruchstücke von $\mathrm{Ph}$. maxima sind öfters in Ost- und Westpreussen in Geschieben vom Alter der Jeweschen Schicht gefunden worden, deren Heimat Estand ist.

1) Schmidt giebt (Rev. I. pag. 114) für $\mathrm{Ph}$. macroura an, dass der Vorderrand des Stirnlappens nicht geradlinig, sondern convex sein soll; doch der seitlich gerundete Stirnlappen, die geringere Breite desselben und die deutliche grobe Tuberkulierung der Glabella, liessen mich die Stücke 7 und 8 zu $\mathrm{Ph}$. macroura stellen und nicht zu Ph. maxima, für welehe Art der vorn gerade Stirnlappen sprechen würde.

2) Schmidt giebt pag. 114 bei $30-35 \mathrm{~mm}$ Länge $60-75 \mathrm{~mm}$ Breite an, während unsere Stücle bis höchstens $25 \mathrm{~mm}$ Länge bei etwa 40-45 mm Breite zeigen. 
Phacops (Chasmops) Eichwaldi Fr. Schmidt Taf. I. Fig. 21-23.

1882. Phacops Eichwaldi Fr. Schmidt: Rev. I. pag. 117. Taf. IV. Fig. 4. Taf. V. Fig. 8. 9. 10. 16. Taf. X. Fig. 21.

Das Kopfschild ist flach gewölbt, etwa eineinhalb mal so breit als lang. Die Hinterecken sind zu langen, flachen, ziemlich steil stehenden Wangenhörnern ausgezogen. Das ganze Kopfschild ist von einem flachen Randsaume umgeben, der von einer ganz flachen Furche begleitet ist, welche deutlich in die Hinterrandfurche übergeht. Die Glabella ist flach, der Stimlappen vorn convex, nicht so breit, als das Kopfschild lang ist. Vor dem Stirnlappen sind in der Randfurche zwei Grübchen als die Enden der divergierenden Punktreihen zu erkennen. Die ersten Seitenlappen sind gross, abgerundet dreieckig; die zweiten fehlen vollständig. Die dritten Seitenlappen bilden einen schwach gewölbten schmalen Ring. Der Nackenring ist breit, kaum höher als die Glabella. Die Wangenhöcker sind etwas niedriger als die Glabella, die Augen sind sehr klein. Die Oberfläche ist glatt.

$\mathrm{Zu} \mathrm{Ph.} \mathrm{Eichwaldi} \mathrm{stellte} \mathrm{ich} \mathrm{die} \mathrm{Schwanzschilder} \mathrm{auf} \mathrm{Taf.} \mathrm{I.} \mathrm{Fig.} 22$ u. 23. Sie sind nicht sehr stark gewölbt, mehr oder weniger spitz endigend. Die Spindel, aus 13-16 Gliedern bestehend, nimmt etwas mehr als ein Drittel der ganzen Schildbreite ein.

Maasse: Kopf: Länge $16 \mathrm{~mm}$, Breite $24 \mathrm{~mm}$, Breite des Stirnlappens 13,5 mm. Schwanzschild: Länge $16 \mathrm{~mm}$, Breite $17 \mathrm{~mm}$, Spindelbreite $6,5 \mathrm{~mm}$.

$$
" 10, \quad 12, \quad \text { " } " 5,5,
$$

$\mathrm{Ph}$. Eichwaldi ist in Ost- und Westpreussen gefunden. Anstehend ist die Art aus der Lyckholmer Zone $\mathrm{F}_{1}$ Estlands bekannt.

Das auf Taf. I. Fig. 6.6a abgebilete Kopfschild steht seiner Ausbildung nach zwischen $\mathrm{Ph}$. Eichwaldi und $\mathrm{Ph}$. maxima. Es ist fast halbkreisförmig, flach gewölbt mit fast senkrecht stehenden Wangenhörnern. Von Ph. Eichwaldi unterscheidet es sich dadurch, dass die zweiten Seitenlappen als ein ganz schmaler Ring angedeutet sind; während der vorn convexe Stirnlappen, der schmäler als die Länge des Kopfschildes ist, das Stück von Ph. maxima trennen; ausserdem sind sämtliche Furchen des Kopfschildes viel flacher als bei Ph. maxima. Das Stück liegt in einem gelblichen, etwas erdigen Kalkstein aus Ostpreussen.

\section{Anhang:}

Ph. (Chasmops) sp. I. Taf. I. Fig. 5. 5a giebt die Abbildung eines Schwanzschildes, das dem von $\mathrm{Ph}$. bucculenta ${ }^{1}$ ) sehr ähnelt. Die sehr breite Spindel besteht aus 11 Gliedern, deren letzte undeutlich sind; die Seitenteile tragen 12 Pleuren, von denen die acht ersten deutlich gefurcht sind. Steinhardt ${ }^{2}$ ) stellte dieses Schwanzschild zu Ph. latifrons. Es liegt in einem grauen kieseligen Kalk, der dem der Jeweschen Schicht ähnelt, und ist in Ostpreussen gefunden worden.

Ph. (Pterygometopus) sp. II. Das Schwanzschild, Taf. I. Fig. 25, gehört einer Pterygometopusart an. Es ist halbkreisförmig, flach gewölbt, achtgliederig, fast

1) cf. Fr. Schmidt: Rev. I. pag. 106. Taf. III. Fig. 1 d.

2) cf. Steinhardt: Pr. Trilobiten pag. 12. Taf. I. Fig. 2. 
alle Pleuren zeigen eine deutliche Mittelfurche, die grösste Aehnlichkeit hat es mit Ph. Panderi F. Schmidt ${ }^{1}$ ). Das Gestein ist Echinosphaeritenkalk aus Ostproussen. Ph. (Chasmops) sp. III. In einem graubraunen dichten Kalksteine, dem Rollsteinkalk mit Chasmops macroura von Römer ${ }^{2}$ ) entsprochend, lag das Taf. I. Fig. 32 abgebildete Schwanzschild von fust halbkreisförmigem Umriss. Die schmale Spindel lässt noch 15 Ringel erkennen, sie geht bis nahe an den Hinterrand. Die flachen Seitenteile tragen über 15 geschwungene ungeteilte Pleuren. Um das ganze Schild läuft ein flacher schmaler Randsaum. Jedenfalls gehört das Schwanzschild einer flacheren Varietät von $\mathrm{Ph}$. macroura an. Fundort: Ostpreussen ohne nähere Angabe. Die Heimat wird die des Ph. macroura sein, also Schweden resp. Oeland.

Phacops sp. IV. Taf. I. Fig. 26 giebt eine kleine Glabella, die nach der Ausbildung der Seitenlappen zwischen den Arten der Untergattung Pterygometopus und den Verwandten des Phacops (Chasmops) praecurrens steht. Der Stirnlappen ist glatt, der hintere Teil der Glabella ist mit flachen Höckerchen besetzt. Lauth bei Königsberg.

\section{Fam.: Cheiruridae.}

Gattung: Cheirurus. Beyrich. Barr. Salter. Schmidt. Ceraurus: Green. Fr. Römer. Eichw.

\section{Untergattung: Cheirurus s. str.}

Cheirurus exsul Beyrich. Taf. II. Fig. 1. 2.

1846. Cheirurus exsul. Beyrich. : Untersuchungen üb. Tril. II Stück pag. 3. Taf. IV. Fig. 6. 1852 (1878). Cheirurus exsul. Angelin: Pal. Scand. pag. 31. Taf. XXI. Fig. 2.

1860. Ceraurus exsul. Eichwald: Lethaea rossica pag. 1396.

1874. Cheirurus exsul. Steinhardt: Pr. Trilobiten pag. 57. Taf. IV. Fig. 12.

1882. Cheirurus exsul. Fr. Schmidt: Rev. I. pag. 137. Taf. VI. Fig. 5-15. (Taf. XI. Fig. 19-20. Taf. XVI. Fig. 2-4.

Kopfschilder dieser Art sind häufig in Geschieben vom Alter des Echinosphaeritenkalkes gefunden worden. Das Kopfschild ist etwa zweimal so breit als lang, von einem deutlichen Randsaum umgeben; die Hinterecken sind zu langen, divergierenden Hörnern ausgezogen. Der Rand ist vor der Glabella gerade, an den Seiten des Stirnlappens eingebuchtet, in seinem weiteren Verlauf bogenförmig, nach aussen convex. Die tiefen Rückenfurchen verlaufen fast parallel; vorn stossen sie in einer tiefen Grube mit der Vorder- und Seitenrandfurche zusammen. Die Glabella ist flach gewölbt, nach vorn ganz allmählig, zur Nackenfurche steil abfallend, ihr Umriss bildet ungeführ ein Rechteck. Die beiden ersten Seitenfurchenpaare laufen parallel, sie sind ganz wenig gebogen und stehen fast senkrecht zur Axe. Die dritten Seitenfurchen bestehen aus 2 Aesten, deren vorderer breit und tief ist und sich ein wenig nach hinten wendet, während der hintere, schwächere Ast der Axe parallel gerichtet zur Nackenfurche läuft. Der Stirulappen bildet ein Trapez, die Seitenlappen sind ungefähr

1) cf. Fr. Schmidt: 1. c. pag. 85. Taf. I. Fig. 15 d.

2) cf. F. Römer: Lethaea erratica pag. 48. 
quadratisch und etwas kürzer als der Stirnlappen. Der Zwischenraum zwischen den Seitenlappen ist etwa ein einhalb mal so breit, als diese selbst. Die Oberfläche der Glabella ist ziemlich dicht mit runden Höckern besetzt. Die flachen Wangen sind mit feinen Grübchen und stumpfen und spitzen Erhöhungen bedeckt.

Das Hypostom ist breit eiförmig mit hoch aufgeworfenem Seitenrande; Das Mittelstück ist stark gewölbt und mit flachen Höckern besetzt.

Das Schwanzschild ist nach Schmidt ${ }^{1}$ ) viergliederig mit hochgewölbter Spindel. Jederseits sind 3 Pleuren vorhanden, von denen das erste Paar in lang säbelförmige Hörner ausgezogen ist, während das zweite und dritte Paar in sehr viel kürzere, gerade nach hinten gewendete Zacken von gleicher Länge wie der kleine Hinterlappen ausläuft.

Fundorte: Häufig in Ost- und Westpreussen.

Die Heimat unserer Geschiebe mit Ch, exsul. dürfte wohl Estland sein, obwohl die Art auch in Schweden vorkommt. ${ }^{2}$ )

Cheirurus exsul. forma gladiator. Eichwald. Taf. II. Fig. 3. 4.

1860. Cheirurus gladiator Eichwald: Lethaea rossica pag. 1392. Taf. LIV. Fig. 18.

1882. Cheirurus exsul. subsp. gladiator Fr. Schmidt: Rev. I pag. 146. Taf. VI. Fig. 11-15. Taf. XI. Fig. 19.

Von der Hauptform des Ch. exsul. unterscheidet sich die vorliegende Unterart durch die ganz glatte, sehr flach gewölbte Gabella. Der Verlauf der Seitenfurchen entspricht dem der Hauptform, nur sind die inneren Enden der Seitenfurchen durch je eine sehr flache Längsfurche verbunden, die in den zweiten Ast der dritten Furchen übergeht und mit dieser die Nackenfurche erreicht. Die Seitenlappen sind fast ebenso breit wie der Zwischenraum auf der Glabella. Die Wangen tragen breite, kräftige Augenwülste und sind ausser mit flachen Grübchen mit groben flachen Höckern verziert.

Das Schwanzschild zeigt in den Grössenverhältnisson der Pleuren einige Abweichungen von der Hauptform: Die ersten Pleuren sind in sehr grosse, gebogene Hörner ausgezogen; an ihrem Grunde zeigen sie zwischen zwei grossen rundlichen Erhöhungen eine kurze tiefe Furche. Die zweiten und dritten Pleuren sind in kürzere. breit lanzettliche, fast gerade nach hinten gerichtete Zacken ausgezogen. Der kurze dreieckige Hinterlappen erreicht die Länge der zweiten Pleuren, während die dritten darüber weit hinausragen.

Fundorte: Wehlau, Ostpreussen; Rosenberg, Westpreussen.

Ch. exsul. forma gladiator gehört wie die Hauptform dem Echinosphaeritenkalk an und ist bisher nur in Estland anstehend gefunden.

Cheirurus exsul. cf. forma macrophthalma Kutorga. Taf. II. Fig. 5. 5a.

1882. Cheirurus subsp. cf. macrophthalmus Kutorga in Fr. Schmidt: Rev. I. pag. 143. Taf. VII. Fig. 1-5. Taf. XVI. Fig. 4.

Eine gut erhaltene Glabella zeigte deutlich die von Schmidt für diese Unterart angegebenen Charaktere. Ihre äussere Form stimmt mit der der Hauptform des

1) ef. Fr. Schroidt: Rev. I. pag. 141.

2) cf. Angelin: Pal. Scand. pag. 32. 
Ch. exsul. überein; sie ist zum Unterschiede von dieser in der Längsrichtung hochgewölbt, nach den Seiten dachförmig abfallend, die stärkste Wölbung liegt in der hinteren Hälfte; zum Vorderrande ist sie sanft abgedacht, während sie zum Nackenringe ganz steil abfällt. Die ersten beiden Seitenfurchenpaare stehen näher zusammen und sind etwas kräftiger gebogen wio bei der Hauptform, die dritten biegen schneller nach hinten um. Die Oberfläche der Glabella ist ganz glatt, während die Wangen, soweit ein kleines Bruchstück derselben erkennen lässt, nur mit gröberen, dichtstehenden Vertiefungen verziert sind.

Fundort: Rosenberg, Westpreussen.

Ch. exsul. cf. forma macrophthalma ist nach Schmidt ${ }^{1}$ ) in Estland selten, häufiger im Gouvernement Petersburg gefunden; unser Exemplar, in einem Echinosphaeritenkalkgeschiebe liegend, stammt jedenfalls aus Estland.

Cheirurus gotlandicus Lindström. Taf. II. Fig. 9. 10.

1885. Cheirurus gotlandicus Lindström: Förteckning pa Gotlands sil. Crust. pag. 45. Taf. XII. Fig. 9. 10.

In einem Geschiebe weissen, krystallinen Kalkes mit Crinoidengliedern wurden mit Bumastus barriensis, Encrinurus punctatus und Calymene tuberculata zwei Bruchstücke von Glabellen und ein Hypostom gefunden, welche ich zu Ch. gotlandicus stelle. Auf der nicht sehr stark gewölbten Glabella treten drei Paare von Seitenfurchen auf; die beiden ersten sind in schwachen Bogen etwas nach hinten gewendet, während die dritten in fast gleichmässigen Bogen zur Nackenfurche gehen. Die Seitenlappen sind kurz, etwa halb so lang als der Stirnlappen. Der Raum zwischen den Seitenlappen auf der Glabella ist schmäler als die Seitenlappen selbst. Der Nackenring bildet, wie das eine der Bruchstücke zeigt, ein schmales in der Mitte nicht verbreitertes Band. Die Oberfläche der Glabella ist mit feinen Höckerchen dicht besetzt; die Oberfläche der einen vorhandenen Wange zeigt dichte eingedrückte Grübchen.

Das Hypostom, Taf. II. Fig. 10, von einem bedeutend grösseren Individuum herrührend, ist stark gewölbt, von einem breiten gewulsteten Randsaume rimgeben; der Hinterrand ist schwach eingebuchtet. Das sehr kräftig gewölbte Mittelstück zerfällt in einen grossen, ovalen Vorderlappen und einen kleineren, halbmondförmigen Hinterlappen, der durch kurze schwache Mittelfurchen abgeschnürt wird. Die Oberfläche ist mit feinen dichten Kü̈tchen bedeckt, zwischen die einzelne gröbere Hückerchen eingestreut sind.

Fundort: Rosenberg, Westpreussen.

Ch. gotlandicus ist bisher nur in Gotland anstehend gefunden worden; das Gestein entspricht dem der Lindströmschen Zone f (Crinoiden- und Korallenkalk) von Gotland ${ }^{2}$ ).

1) cfr. Fr. Schmidt: Rev. I pag. 145. 146.

2) cfr. Lindström: „Ueb. d. Schichtenfolge d. Sil. a. d. Insel Gotland." N. Jahr 1888. pag. 160. 
Cheirurus speciosus Hisinger. Taf. II. Fig. 6.

1852 (1878). Cheirurus speciosus Hisinger in Angelin: Pal. Scand. pag. 79. Taf. XXXIX.

Fig. 14.

1874. Cheirurus speciosus Steinhardt: Pr. Trilob: pag. 56. Taf. IV. Fig. 13.

Eine am Vorderrande beschädigte Glabella dieser Art lag mir vor. Sie ist nach vorne etwas erweitert, stark gewölbt. Die beiden ersten Seitenfurchenpaare sind lang, etwas nach hinten gebogen; die dritten biegen kurz nach hinten zur Nackenfurche um und schnüren die dritten Seitenlappen vollständig ab. Die ersten und zweiten Seitenlappen sind kurz: der dritte ist etwas länger. Der Abstand zwischen den gegenüberliegendeu ersten und zweiten Seitenlappen ist kaum $1 / 2$ ihrer eigenen Breite, während die dritten ungefähr um ihre eigene Breite von einander entfernt sind. Der Nackenring ist schwach gewölbt, in der Mitte, zwischen den dritten Seitenlappen, etwas nach vorne vorgezogen. Die Oberfläch'e der Glabella ist vollkommen glatt. Die Wangen sind, soweit Angelins Abbildung erkennen lässt, mit dicht gestellten Grübchen verziert.

Fundort: Rosenberg, Westpreussen.

Ch. speciosus ist durch das ganze Ober-Silur Gotlands verbreitet.

Cheirurus dubius. n. sp. Taf. Ir. Fig. 7. 17.

1874. Cheirurus spinulosus Steinhardt: Pr. Trilob. pag. 56. Taf. IV. Fig. 14.

Die beiden vorliegenden Sclhwanzschilder sind durch die hochgewölbte, deutlich viergliederige Spindel und die drei deutlich entwickelten Pleuren, wie den kurzen dreieckigen Hinterlappen, als zu Cheirurus s. str. gehörend charakterisiert. Steinhardt hat a. a. O. beide zu Ch. spinulosus Nieszk. ${ }^{1}$ ) gestellt. Diese Bestimmung Steinhardts ist nicht richtig, da bei $\mathrm{Ch}$. spinulosus die zweiten Pleuren bedeutend kürzer sind als die dritten, während unsere beiden Stücke übereinstimmend das umgekehrte Verhältnis zeigen. Nebenbei gehört Ch. spinulosus dem Echinosphaeritenkalk, resp. der Kucker'schen Schicht an, während das eine Schwanzschild (II. Fig. 17) in einem Beyrichienkalkgeschiobe, das andere in einem blaugrauen, dunklen, dichten Kalke liegt, der dem Chonetenkalke ${ }^{2}$ ) sehr ähnelt. Wir haben es hier also mit einer Obersilurischen Cheirurusart zu thun, und können deshalb die Schwanzschilder kaum auf eine der bekannten Estländischen Arten, welche alle untersilurisch sind, beziehen. Möglicherweise könnten die Schwanzschilder zu einer der gotländischen Cheirurusarten gehören, von denen man bis jetzt nur das Schwanzschild von Ch. bimucronatus Mirch. ${ }^{3}$ ) kennt, dessen Pleuren jedoch alle gleich lang sind. Da aber die otwaige Zugehörigkeit der vorliegenden Stücke zu einer der Arten Ch. speciosus, conformis oder Gotlandicus, oder zu einer bis jetzt noch nicht bekannten anderen Art nicht festzustellen ist, so benenne ich die vorliegende Art Ch. dubius.

Fundort beider Stücke: Westpreussen.

Als Heimat der Art dürfte das jetzt von der Ostsee bedeckte Gebiet zwischen Gotland und Estland anzunohmen sein, vielleicht aber auch Gotland selbst.

1) Vergl. Ch. spinulosus Nieszk. in Fr. Schmidt. Rev. I. pag. $148 \mathrm{ff}$.

2) Nötting: Die Cambr. und Silur. Geschiebe der Pror. Ost- und TVestpreussen. Jahrb. der" königl. geol. Landesanst. 1882. pag. 303.

3) Salter: A Monograph of the Brit. Trilob. pag 63. Taf. VI, Fig. 9-18. 


\section{Untergattung: Cyrtometopus Angelin.}

\section{Cheirurus (Cyrtometopus) clavifrons Dalman. Taf. II. Fig. 11.}

1852 (1878). Cyrtometopus clavifrons Angelin: Pal. Scand. pag. 32. Taf. XXI. Fig. 4. Taf. XXXLX. Fig. 9.

1860. Ceraurus Zembnitzki Eichwald: Lethaea rossica pag. 1400.

1882. Cheir. (Cyrtometopus) clavifrons Dalman in Fr. Schmidt: Rev. II. pag. 153. Taf. VU. Fig. 4-6. Taf. XVI. Fig. 7-12.

Eine ziemlich vollständige Glabella dieser Art lag mir vor. Sie ist länglich eiförmig; ihre grösste Breite (etwa in der Mitte) ist gleich drei Viertel der Länge. Sie ist recht kräftig gewölbt, nach vorn sanft abfallend. Die beiden ersten Seitenfurchen sind schwach eingedrückt (auf dem Steinkerne etwas deutlicher), sie sind ein wenig zurïckgebogen und erreichen noch nicht ein Drittel der Glabellabreite. Die dritten Seitenfurchen sind tief und breit; sie gehen zuerst den vorderen Seitenfurchen parallel und biegen dann, flacher werdend, nach hinten um. Sie schnüren so die dritten Seitenlappen fast vollständig vou der Glabella ab. Die Abstände der Seitenfurchen von einander, und mithin auch die Seitenlappen, sind ungefähr gleich gross; von dem vorn gerundeten Stirnlappen werden sie an Längenausdehnung erheblich übertroffen. Die Schale ist, soweit sie noch vorhanden ist, fein chagriniert, wïhrend der Steinkern fast vollkommen glatt erscheint.

Maasse der Gabella: Länge $19 \mathrm{~mm}$, grösste Breite 14,5 mm.

Fundorte: Königsberg; Marienburg. [Bruchstück einer Glabella.]

Ch. clavifrons kommt in Estland im Glaukonitkalk und Vaginatenkalk, auf Oeland und dem Festlande Schwedens im unteren grauen Orthocerenkalk vor. Die Heimat unserer Geschiebe mit $\mathrm{Ch}$. clavifrons dürfte wohl Estland sein, da das Gestein vollkommen mit estländischem Vaginatenkalke übereinstimmt.

Cheirurus (Cyrtometopus) cf. Plautini Fr. Schmidt. Taf. III. Fig. 8.

[1882. Ch. (Cyrtometopus) Plautini Fr. Schmidt: Rev. I. pag. 159. Taf. XII. Fig. 24].

Auf einem Backsteinkalkgeschiebe von Wehlau befand sich eine kleine Glabella die in der allgemeinen Form mit Ch. Plautini gut übereinstimmt. Sie ist flach gewölbt, vorn abgestutzt. Die Seitenfurchen sind kurz, kaum gebogen; die beiden vorderen Paare sind deutlicher und tiefer ausgebildet, als bei der vorigen Art. Die dritten Seitenfurchen biegen schnell nach hinten um und schnüren die dritten Seitenlappen kaum ganz von der Glabella ab. Auf der einen erhaltenen festen Wange war das Untergattungsmerkmal, die Fortsetzung des Vorderrandwulstes nach dem Auge zu, noch ziemlich deutlich zu erkennen. Der Augendeckel ragt nur ganz wenig aus dem Wangenfelde vor. Der Nackenring ist schmal. Die Oberfläche erscheint ganz fein gekörnelt; die Wange lässt eingestochene Pünktchen erkennen.

Maasse: Länge der Glabella 3,5 mm, Breite 2,5 mm.

Fundort: Wehlau, Ostpreussen. Die Heimat dieses Geschiebes ist wohl der Estland benachbarte Teil des Ostseebeckens.

Cheirurus (Cyrtometopus) pseudohemicranium. Nieszkowski. Taf. II. Fig. 15. 15a. 16. 1859. Sphaerexochus pseudohemicranium Nieszkowski: Zus. zur Monogr. Archiv für Naturk. Livl. etc. Ser. I. Bd. II. pag. 376. Taf. II. Fig. 7. 8. 
1874. Sphaeroxochus pseudohemicranium Steinhardt: Pr. Tril. pag. 60. Taf. IV. Fig. 17. 1882. Ch. (Cyrtometopus) pseudohemicranium. Fr. Schmiảt: Rev. I. pag. 163. Taf. VIII.

Fig. 9. 10. 13-16. Taf. XI. Fig. 29. Taf. XVI. Fig. 18-21.

Neben mehreren, mehr oder weniger unvollständigen Kopfschildern lag mir auch das Original der Steinhardtschen Bestimmung Sphaer. pseudohemicranium vor. Sämtliche Stücke zeigen die Ausbildung der typischen Form dieser Art: Das stark gewölbte Kopfschild ist breit dreieckig, über doppelt so breit als lang; die Glabella bildet ein ganz kurzes Oval. Sie ist sehr stark, fast balbkugelig gewölbt und wird am Grunde von der 'Vorderrandfurche, der Nackenfurche und von den Rückenfurchen stark eingeschnürt. Die beiden ersten Seitenfurchen sind nur als ganz feine kurze, auf dem Steinkern kaum zu erkennende Eindrücke ausgebildet, während die dritten breit und tief sind und die dritten Seitenlappen in Form von kräftig gewölbten ovalen Höckern vollständig von der Glabella abschnüren. Die Oberfläche der Glabella ist auf der Schale mit rundlichen Knötchen bedeckt, auf dem Steinkern erscheint sie fast ganz glatt.

Die festen Wangen (bei meinen Stücken nicht vollständig erhalten) waren in kurze nach aussen gerichtete Hörner ausgezogen; sie sind gross, breit dreiseitig und lassen für die freien Wangen nur kleine stumpfwinklig dreieckige Felder frei. Die festen Wangen sind mit ziemlich grossen Grübchen verziert.

Fundorte: Ostpreussen: Königsberg, Wehlau. Westpreussen: Rosenberg.

Ch. pseudohemicranium gehört dem Silur Estlands an, und zwar kommt die bei uns gefundene typische Form in der Jeweschen Schicht D vor, während die ältere Form Ch. pseudohemicranium var. dolichocephala Fr. Schmidt mit längerer, höher gewölbter Glabella bereits in der Kuckerschen Schicht $\mathrm{C}_{2}{ }^{1}$ ) auftritt.

\section{Untergattung: Nieszkowskia. Fr. Schmidt.}

Cheirurus (Nieszkowskia) variolaris Linnarsson. Taf. II. Fig. 12. 12a.

1869. Cheirurus variolaris Linnarsson: Vestergötl. cambr. o. silur. Aflagr. pag. 60. Taf. I. Fig. 6.

1882. Cheirurus (Nieszkowskia) variolaris Fr. Schmidt: Rev. I. pag. 183. Taf. IX. Fig. 1-8.

1884. Cheirurus variolaris Kiesow: Sil, u. Dev. Gesch. Westpr. pag. 78. Taf. IV. Fig. 7.

Die auf Taf. II. Fig. 12 abgebildete Glabella gehört dieser Art an. Sie ist nicht ganz $1 \frac{1}{2}$ mal so lang als breit, hinten am breitesten, von ungefähr rechteckigem Umriss. Vom Vorderrande steigt sie in ganz allmählicher Wölbung an, hinter der Mitte ist sie am stärksten gewölbt; nach hinten läuft sie in ein drehrundes gerades, spitzes Horn aus. ${ }^{2}$ ) Dieses Horn soll nach Schmidt ${ }^{3}$ ) dicht über dem Nackenringe liegen. Leider ist bei dem vorliegenden Stück der Nackenring weggebrochen, doch die eigentümliche, dichte Verzierung der Glabella mit grossen flachen Höckern von 0,5-1 mm Durchmesser lässt keinen Zweifel, dass hier Ch. variolaris vorliegt. Die

1) cf. Fr. Schmidt: Rev. II. pag, 164, 165.

2) Dieses Horm fehlt der Schmidtschen Varietät Ch. variolaris var. mutica (Fr. Schmidt I. c. pag. 184. Taf. XI. Fig. 25. 26).

3) cf. Fr. Schmidt 1. c. pag. 184. 
ersten beiden Seitenfurchen sind kurz, wenig gebogen und unter etwa $30^{\circ}$ nach hinten gewendet; die dritten Seitenfurchen sind länger, stärker gebogen und gehen unter grösserem Winkel, etwa $45^{\circ}$ nach hinten; wenige Millimeter vor dem Hinterrande der Glabella endigen sie blind. Die ersten beiden Seitenlappenpaare stehen etwa um das doppelte ihrer Breite, das dritte etwa um die eigene Breite von einander $a b$.

Maasse: Länge der Glabella bis zum Anfange des Hornes: $21 \mathrm{~mm}$, mittlere Breite $16 \mathrm{~mm}$.

Fundorte: Wehlau Ostpreussen. Aus Westpreussen beschreibt Kiesow a. a. O. ein Bruchstück einer sehr grossen Glabella unserer Art von Spengawsken.

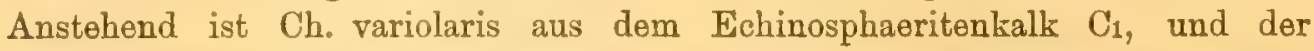
Fuckerschen Schicht $\mathrm{C}_{2}$ Estlands und aus dem Chasmopskalk Westgotlands bekannt. Das Gestein sowohl des Stückes von Wehlau, als des von Spengawsken ist Echinosphaeritenkalk; die Heimat beider Stücke ist sicher Estland.

Cheirurus (Nieszkowskia) cephaloceras Nieszkowski. Taf. II. Fig. 13. 13a.

1857. Sphaerexochus cephaloceras Nieszkowski: Monographie pag. 70 (600). Taf. I. Fig. 4-5.

1860. Zethus triplicatus Eichwald: Lethaea rossica pag. 1406. Taf. LV. Fig. 2a b. 1882. Ch. (Nieszkowski) cephaloceras Fr. Schmidt: Rev. I. pag. 186. Taf. IX. Fig. 9 bis 16. Taf. XI. Fig. 27. Taf. XVI. Fig. 36. 37.

Eine Glabella mit teilweise erhaltener fester Wange liegt mir vor. Sie ist bei ungefähr gleicher Form kräftiger gewölbt als die von Ch. variolaris. Wie bei der vorigen Art läuft die Glabella noch hinten in ein drehrundes, etwas gebogenes Horm aus, das nach Fr. Schmidt ${ }^{1}$ ) etwas über dem Nackenringe liegt. Obwohl der Hinterrand der Glabella und der Nackenring fehlen, so lässt doch das Bruchstück der linken festen Wange, welche zum Hinterrande fast senkrecht abfällt, mit Sicherheit darauf schliessen, dass der Nackenring rom Grunde des Hornes etwa dieselbe Entfernung hat, wie das bei Schmidt Taf. IX. Fig. 10 abgebildete Exemplar von Kuckers.

Ausserdem ist die Glabella, wie die Wange mit den für Ch. cephaloceras charakteristischen kurzen, etwas spitzigen Höckerchen bedeckt. Der Verlauf der Seitenfurchen ist etwa derselbe wie bei $\mathrm{Ch}$. variolaris, nur sind die dritten Seitenfurchen etwas länger und stärker nach hinten gebogen.

Maasse: Länge der Glabella bis zum Grunde des Hornes $16 \mathrm{~mm}$; mittlere Breite $12 \mathrm{~mm}$.

Fundort: Wehlau in Ostpreussen.

Ch. cephaloceras ist anstehend nur in Estland bekannt, und kommt dort im Echinosphaeritenkalk $\mathrm{C}_{1}$ und der Kuckersschen Schicht $\mathrm{C}_{2}$ vor.

Unser Strick liegt in einem Geschiobe von der Beschaffenheit des Echinosphaeritenkalkes.

1) cf. Fr. Schmidt 1. c. pag. 186. Taf. IX. Fig. 10 u. 12. 
Gattung: Amphion Pander.

Als einzigen Vertreter der Gattung Amphion aus unseren Geschieben führe ich die Art:

Amphion priscus n. sp. Taf. II. Fig. 19. 19a.

an, welche mir in 2 Bruchstücken von Schwanzschildern vorliegt. Das besser erhaltene, auf Taf. II Fig. 18 abgebildete Stück zeigt eine nach hinten stark verschmälerte Spindel, welche aus 5, durch tiefe Furchen getrennten Ringen und einem bleinen dreieckigen Endgliede besteht. Die Seitenteile sind in ihrer äusseren Hälfte stark nach unten gebogen und tragen jo 5, durch tiefe Furchen getrennte Pleuren, welche vom Knie ab frei sind und in scharfen Spitzen endigen. Das letzte Pleurenpaare ist gerade nach hinten gerichtet. Die Oberfläche ist, soweit die dünne Schale noch erhalten ist, fein und dicht gekörnelt. - Länge $10 \mathrm{~mm}$, Breite $12 \mathrm{~mm}$, Spindelbreite $5 \mathrm{~mm}$.

Fundort: Westpreussen-Belschwitz.

A. priscus lag in einem Geschiobe buntfarbigen Glaukonitkalkes (cf. pag. 4) vom Alter des Ceratopygekalkes; als Heimat dieses Geschiebes ist Schweden aufzufassen.

Die nächsten Beziehungen hat A. priscus zu A. (Pliomera) primigenus Angel ${ }^{1}$ ) mit welcher Art die vorliegenden Stücke in Bezug auf die Pleurenanzahl übereinstimmen, die verschiedene Grösse aber und das Auftreten der grubenförmigen Vertiefung auf dem Endgliede der Spindel bei A. primigenus trennen beide Arten.

\section{Anhang:}

Cheirurus? sp. Taf. II. Fig. 14.

Das auf Taf. II. Fig. 14 abgebildete Schwanzschild gehört zur Familie der Cheiruriden. Die nach hinten stark verschmälerte Spindel besteht aus drei hochgewölbten Gliedern, die durch tiefe Furchen getrennt sind; auf das dritte Glied folgt ein länglich dreieckiges Endglied mit schwach buckelförmiger Erhöhung in seinem vorderen Teile. Jederseits sind drei, ungefähr gleich lange, stark gewölbte Pleuren vorhanden, die in breite Zähne auslaufen. Diese Zähne, sowie der dem hintersten Spindelgliede folgende breit zahnartig ansgebilrlete Endlappen sind von einem schmalen, flachen, deutlich abgesetzten Randsaume umgeben. Die Pleuron sind ungefurcht und lassen in ihrer Mittellinio je eine Reihe feiner länglicher Höckerchen (auf dem Abdruck als Vertiefungen erscheinend) erkennen. Die Oberfläche ist im übrigen fast ganz glatt. Länge $20 \mathrm{~mm}$, Breite $28 \mathrm{~mm}$, Spindelbreite $10 \mathrm{~mm}$.

Fundort: Kurschitten in Kurland, nahe der Grenze Ostpreussens.

Die meiste Aehnlichkeit zeigt das vorliegende Stück mit dem von Angelin zu Platymetopus lineatus ${ }^{2}$ ) gestellten Schwanzschilde. Platymetopus ist eine Untergattung von Lichas ${ }^{3}$ ) und hat als solche nur Arten, deren Schwanzschilder deutlich gefurchte Pleuren tragen. Das Kopfschild der Angelinschen Art Platymetopus li-

1) ct. Angelin: Pal. Scand. pag. 90. Taf. XLI. Fig. 15.

2) cf. Angelin: Pal. Scand. pag. 75. Taf. XXXVII. Fig. 12 u. 13.

3) cf. Fr. Schmidt: Rev. II. pag. 28 u. 29. 
neatus gehört sicher zur Gattung Lichas, während das mit dem vorliegenden gut übereinstimmende Schwanzschild durch seine ungefurchten Pleuren von Lichas getrennt ist und auf die Zugehörigkeit zur Familie der Cheiruriden schliessen lässt.

Ausser dem von Angelin irrtümlicher Weise zu Platymetopus lineatus gestellten Schwanzschildes kenne ich keines, das mit dem vorliegenden übereinstimmte. Die gleichartige Ausbildung beider Schwanzschilder mit vierteiliger Spindel, 3 freiendigenden ungefurchten Pleuren und dem dreieckigen Endlappen zeigt soviel Uebereinstimmung mit der Gattung Cheirurus, dass ich sie dieser zuzähle; jedenfalls aber gehören sie keiner der bekannten Gruppen von Cheirurus an, sondern bilden eine eigene Untergattung, deren Begrenzung ich nach dem vorliegenden geringen Material nicht wagen darf.

Sphaerexochus? sp. Taf. II. Fig. 18.

In einem harten, sehr dichten, schwärzlichgrauen Geschiebe unbekannten Fundortes (Samml. d. hies. Prov.-MIus.) Jag das Taf. II. Fig. 18 abgebildete Schwanzschild. Es ist ungefähr halbkreisförmig, mit breiter 4 gliederiger Spindel; jederseits sind 3 frei endigende abgerundete Pleuren vorhanden; der Hinterrand ist gebuchtet. Dem Stücke lag eine Bestimmung "Sphaeroxochus ef. minutus Nieszkowski" bei. Ob das vorliegende Schwanzschild in die Verwandschaft dieser Art, die nach Schmidt ${ }^{1}$ ) garnicht zur Familio der Cheiruriden zu zählen ist, gehört, oder ob es zu Sphaerexochus mirus Beyr ${ }^{2}$ ), mit dem es viele Aehnlichkeit hat, zu stellen ist, kann ich nicht entscheiden. Da der Fundort des betreffenden Stückes unbekannt ist - möglicherweise ist es garnicht in unserem Diluvium gefunden, denn das Gestein ist wesentlich von dem unserer Geschiebe verschieden, - habe ich die Gattung Sphaerexochus garnicht weiter erwähnt.

\section{Fam.: Encrinuridae.}

Gattung: Cybele: Lovén. Linnarsson. Fr. Schmidt.

(Zethus. Volb. Pand.)

Cybele revaliensis Fr. Schmidt. Taf. V. Fig. 16 u. 19.

1874. Zethus sp. Steinhardt: Pr. Trilobiten pag. 58. Taf. V. Fig. 8.

1882. Cybele revaliensis Fr. Schmidt: Rev. I. pag. 207. Taf. XIII. Fig. 20. Taf. XIV.

Fig. 6. Taf. XV. Fig. 6. 7. Taf. XVI. Fig. 40.

Eine Glabella und ein teilweise erhaltenes Schwanzschild liegen mir vor. Die Glabella ist wenig länger als breit, flach gewölbt und nach vorn nur wenig verbreitert. Die drei Paare von Seitenfurchen sind kurz, tief, und alle, das erste Paar am stärksten, schräg nach vorn gezogen, ohne die Rückenfurchen zu erreichen. Die Endgrube und einer der Seitentuberkel sind deutlich zu erkennen. Die Oberfläche trägt neben 8 paarig gestellten Höckern noch einige kleinere unregelmässig verteilte. Diese $\mathrm{Be}-$ setzung der Glabella mit Höckern würde gegen die Zugehörigkeit zu C. revaliensis

1) cf. Fr. Schmidt: Rev. II. pag. 189.

2) cf. Beyrich.: Unters, üb. Trilob. II. Stück pag. 5. Taf. I. Fig. 8c. 
sprechen, ${ }^{1}$ ) wenn nicht aus dem Bruchstücke der einen festen Wange die Stellung des Auges gegenüber der dritten Seitenfurche zu erkennen wäre, wie Schmidt sie für diese Art angiebt ${ }^{1}$ ), ausserdem ist die Nackenfurche zu beiden Seiten der Glabella obenso wie bei den estländischen Stücken vertieft und verbreitert.

Das Schwanzschild ist ungefähr ebenso lang als breit. Die Spindel verschmälert sich nach hinten zu allmählich, vorn ist sie sehr stark gewölbt, vom vierten Gliede ab ist sie flach. Bei 15 allmählich undeutlicher werdenden Spindelgliedern hat das Schwanzschild je vier gefurchte, stark nach hinten gebogene Pleuren. Das hintere, breitere Band der Pleuren ist gewölbt und mit feinen Höckerchen verziert. Die Pleuren laufen nach Schmidt ${ }^{2}$ ) in kurze dreieckige Spitzen aus.

Maasse: Länge der Glabella $13 \mathrm{~mm}$, Breite $10 \mathrm{~mm}$. Länge des Schwanzschildes $15 \mathrm{~mm}$, Breite $14 \mathrm{~mm}$, Spindelbreite $7 \mathrm{~mm}$.

Fundorte: Königsberg, Rosenberg.

Ch. revaliensis gehört dem Echinosphaeritenkalk an und ist anstehend nur aus Estland bekannt.

Cybele cf. Grewingki Fr. Schmidt. Taf. V. Fig. 17. 17a.

(1882. Cybele Grewingki Fr. Schmidt: Rev. I. pag. 211. Taf. XIV. Fig. 1.2.)

Ein bei Wehlau gefundenes Kopfschild zeigt nur geringe Abweichungen von C. Grewingki, so dass ich es in die Verwandschaft dieser Art stelle. Die Glabella ist stark gewölbt, auf ihrem Rücken fast dachförmig; der Stirnlappen fällt ziomlich steil zur Randfurche ab. Die Rückenfurchen divergieren nach vorn wenig. Die drei Seitenfurchenpaare erreichen die Rückenfurchen nicht, das erste Paar ist schräg nach vorn vorgezogen. Auf der Glabella sind deutlich die 8 paarigen Knötchen zu erkennen. Der Vorderrand trägt die Bruchstellen von 5 dicht gestellten Randhöckern und der beiden von diesen getrennten „Endtuberkel“". Die festen Wangen sind fast ebenso hoch wie die Glabella gewölbt, in ihrem äusseren Teile sehr stark heruntergebogen, weit kräftiger als es die Abbildung Schmidt's Taf. XIV. Fig. 1a. zeigt. Die Augen liegen gegenüber den zweiten Seitenfurcheu. Die Wangen zeigen neben feinen spitzigen Höckerchen flache Grübchen, die weniger dicht stehen als bei der Schmidt'schen Art. Neben den angeführten geringen Unterschieden in Bezug auf die Wölbung und Verzierung der Wangen unterscheidet sich das vorliegende Stück von der echten Cybele Grewingki noch durch seine geringe Grösse.

Länge des Kopfes $9 \mathrm{~mm}$, Breite $25 \mathrm{~mm}$.

Fundort: Wehlau.

Das Gestein entspricht dem der Jeweschen Schicht; die Heimat unserer Art wäre also in Estland oder einem jetzt vom Meere bedeckten Nachbargebiete zu suchen.

Cybele rex Nieszkowski. Taf. V. Fig. 15. 15 a.

1857. Zethus rex Nieszkowski: Monographie pag. 100 (614) Taf. I. Fig. 3. 1882. Cybele rex Fr. Schmidt: Rev. I. pag. 209. Taf. XIII. Fig. 21-23. Taf. XIV. Fig. 3. 4 .

1) cf. Fr. Schmidt: Rev. I. pag. 207.

2) cf. Fr. Schmidt: lo c. pag. 208. 
Eine kleine Glabella zeigt die für diese Art charakteristischen Merkmale: Sie ist nach vorn wenig verbreitert, schwach gewölbt, der Stirnlappen fällt sonst zum Vorderrande ab. Die Glabella ist mit 8 paarigen, ziemlich nahe stehenden Höckerchen verziert; zwischen den 4 vorderen Höckerchen liegt noch ein kleineres fünftes. Der Stirnrand ist mit 5 drehrunden, gerade nach vorn gerichteten Zähnchen besetzt, von denen die zwei etwas kürzeren "Endtuberkel" durch eine Lücke getrennt sind (in der Fig. 15. Taf. V. sind diese Tuberkel etwas zu gross gezeichnet). Der Nackenring ist schmal, aber hoch gewölbt, mit drei Höckerchen besetzt.

Länge $9 \mathrm{~mm}$, Breite $6 \mathrm{~mm}$.

Fundort: Puschdorf bei Wehlau, Ostpreussen.

C. rex gehört der Kucker'schen Schicht $\mathrm{C}_{2}$ an und ist bisher anstehend nur aus Estland bekannt.

Cybele sp. a. Taf. V. Fig. 18.

Das Schwanzschild Taf. V. Fig. 18 liegt in einem Geschiebe hellgrauen dichten Kalkes vom Alter der Jeweschen Schicht. Seine Spindel besteht aus 4 deutlichen und etwa 10-12 undeutlichen Gliedorn. Dio Seitenteile tragen 4 in stumpfe Spitzen endigende Pleuren, zwischen die sich das spitz dreieckige Endglied der Spindel schiebt.

Fundort: Spittelpark bei Königsberg, Ostpreussen.

Cybele sp. b. Taf. VI. Fig. 35. ${ }^{1}$ )

Ein k]eines Geschiebe von Beyrichienkalk enthielt neben Atrypa reticularis Linné Calymene intermedia Lindstr., Encrinurus punctatus Wahlbg. und Beyrichia Buchiana var. nutans Kiesow anch das auf Taf. VI. Fig. 35 abgebildete Bruchstück einer Glabella von Cybele.

Neben 8 deutlicheren paarigen Knötchen treten noch einige feinere unpaarige auf, namentlich zwischen den ganz kurzen tiefen Seitenfurchen. Diese Besetzung der Glabella mit Knötchen, sowio der vor der Glabella sich hinziehende schmale Randsaum mit den Bruchstelleu einiger Randhöckerchen lassen keinen Zweifel, dass wir hier eine zur Gattung Cybele gehörende Form vor uns haben, die ich mit keiner der bekannten Arten identificieren kann.

Durch die oben aufgezählten Versteinerungen wird das betr. Geschiebe als obersilurisch charakterisiert: Cybele sp. b. gehört mithin dem Obersilur an und ist der erste Vertreter der Gattung in den Schichten dieses Alters. Leider ist das beschriebene Bruchstück anch das einzige vorhandene und so wenig charakteristisch, dass ich darauf hin davon zurückstehen muss, eine neue Art der Gattung Cybele zu begrenzen.

Maasse: Länge der Glabella $6 \mathrm{~mm}$, Breite $4 \mathrm{~mm}$.

Fundort: Rosenberg in Westpreussen. Heimat: das Ostseebecken?

1) Vergl. pag. 12. 


\section{Gattung: Encrinurus Emmrich.}

Encrinurus obtusus Angelin. Taf. V. Fig. 25. 25 a.

1852 (78). Cryptonymus obtusus Angelin: Pal. Scand. pag. 3. Taf. IV. Fig. 9.

1885. Encrinurus obtusus Lindström: Förteckn. pâ. Gotl. Sil. Crust. pag. 53.

Ein grösseres und ein kleineres Schwanzschild aus einem grauen obersilurischen Kalke zeigen die von Angelin angegebenen Charaktere dieser Art. Die Spindel besteht aus 14 Gliedern, welche in der Mitte je ein kleines, rechts und links von einer seichten Einsenkung begleitetes Knötchen tragen. Die stark abwärts gebogenen, gewölbten Seitenteile bestehen aus 10 getrennten, nicht über den Randsaum hervorragenden Pleuren, deren Oberfläche eine ganz feine Körnelung zeigt.

Maasse: Länge $8 \mathrm{~mm}$, Breite $7,5 \mathrm{~mm}$, Spindelbreite $3,5 \mathrm{~mm}$.

Fundort: Wehlau, Ostpreussen.

Anstehend ist E. obtusus bisher nur aus Gotland bekannt.

\section{Encrinurus cf. obtusus Angelin.}

(1882. Encrinurus? obtusus Angelin in Fr. Schmidt. Rev. I. pag. 224.)

Ein kleines Schwanzschild von Pr. Holland zeigt eine mit dem von Schmidt a. a. O. beschriebenen Exemplar aus der oberen öselschen Schicht Estlands übereinstimmende Ausbildung, indem auf der Spindel abwechselnd die zweiten Glieder Knötchen tragen. Die Seitenteile bestehen, wie bei der Hauptform, aus 10 Pleuren. Das von Kiesow ${ }^{1}$ ) als E. cf. obtusus beschriebene Schwanzschild von Königsthal bei Danzig scheint $z$ wischen den beiden mir vorliegenden Formen eine Mittelstellung einzunehmen, indem die Knötchen auf den Spindelringen verschieden verteilt sind; sie fehlen auf dem 5., 6., 8. und 10. Ringe; die Pleurenanzahl ist 11.

Encrinurus cf. Seebachi Fr. Schmidt. Taf. V. Fig. 24. 24a.

(1882. Encrinurus Seebachi Fr. Schmidt, pag. 229. Taf. XIV. Fig. 25. Taf. XV. Fig. 23.)

Das Taf. V. Fig. 24 abgebildete Schwanzschild steht der Schmidtschen Art E. Seebachi sehr nahe. Es ist länger als breit, spitz dreieckig. Die Spindel lässt über 30, in der Mitte undeutlicher werdende Glieder erkennen, während die Seitenteile aus 10, in stumpfen Zähnchen endigenden, Pleuren bestehen, deren Trennungsfurchen tief sind, aber nicht die Breite der Pleuren erreichen, wie Schmidt ${ }^{2}$ ) es für E. Seebachi angiebt.

Maasse: Länge $15 \mathrm{~mm}$, Breite $12 \mathrm{~mm}$, Spindelbreite $4 \mathrm{~mm}$.

Fundort: Nasser Garten bei Königsberg. ${ }^{3}$ )

E. cf. Seebachi wurde in einem Geschiebe vom Alter der Wesenberger Schicht gefunden. Heimat: Ein Estland benachbartes Gebiet des Ostseebeckens.

1) cf. Kiesow: Sil.- u. Dev.-Gesch. pag. 79, Taf. IV. Fig. $\mathrm{Sa}-\mathrm{c}$.

2) cf. Fr. Schmidt. Rev. I, pag. 281. Westpreussen.

3) Kiesow erwähnt 1. c. pag. 80 ein gleichaltriges Stück ebenfalls als E. cf. Seebachi aus 
Encrinurus punctatus Wahlenberg. Taf. V. Fig. 20. 21. 22. Taf. VI. Fig. 32.

1874. Encrinurus punctatus Steinhardt: Pr. Trilobiten pag. 58. Taf. IV. Fig. 15. 1882. Encrinurus punctatus Wahlenberg in Fr. Schmidt. Rev. I. pag. 225 Taf. XIV.

Fig. 11-13. Taf. XV. Fig. 18.

Diese in unseren Geschieben sehr häufige Art zeichnet sich durch die nach vorn stark erweiterte birnförmige Glabella aus, die ziemlich gleichmässig mit nicht zu hohen rundlichen Höckern besetzt ist. Am Seitenrande des hinteren Glabellateiles treten zwischen den kurzen, grubenförmigen Seitenfurchen gröbere Höcker auf.

Besonders charakteristisch sind die Schwanzschilder. Sie sind länglich dreieckig, hinten zugespitzt. Die Spindel besteht aus 24-27 Gliedern, die in der Mitte undeutlicher werden. In der Mittellinie der Spindel treten 6 Höckerchen auf, deren Zwischenräume nach hinten zu enger werden. Die Seitenteile bestehen aus 7 bis 8 Pleuren, die stark abwärts gebogen sind und in rundliche Zähnchen auslaufen. Der Hinterrand läuft in eine mehr oder weniger aufwärts gebogene Spitze aus. Auf den Pleuren treten in der Nähe der Spindel undeutlichere Knötchen auf, welche jederseits eine neben der. Spindel verlaufende Reihe bilden. Das auf Taf. V. Fig. 20a. b. abgebildete Stück ist ein besonders grosses, und breites, leider abgerolltes Exemplar, bei welchem die Knötchen auf den Pleuren des Schwanzschildes jederseits zwei Reihen bilden. Fig. 21 und 22 auf Taf. V. zeigen eine Glabella und ein Schwanzschild der kleineren, sehr häufig gefundenen Form. Taf. VI. Fig. 32 giebt eine freie Wange mit dem gestielten, leider weggebrochenen Auge wieder.

Fundorte: Ost- und Westpreussen, häufig.

E. punctatus geht sowohl durch das ganze Obersilur Estlands als Gotlands.

Encrinurus sp. Taf. V. Fig. 23.23a.

In einem zum Teil bereits in Backsteinkalk umgewandelten Geschiebe fand sich neben Mastopora concava Eichw. das auf Taf. $\nabla$. Fig. 23 wiedergegebene Schwanzschild. Seine Spindel lässt ungefähr 30 ganz ausgebildete Ringel erkennen, während die Seitenteile aus 7 stark abwärts und nach hinten gerichteten Pleuren bestehen, welche durch tiefe, breite Furchen getrennt sind und in stumpfe gerundete Spitzen auslaufen. Die Ausbildung der Spindel erinnert an E. Seebachi, von welcher Art das vorliegende Stück jedoch durch die geringere Pleurenzahl getrennt ist.

Fundort: Mewe in Westpreussen.

Das Geschiebe ist der Jeweschen Schicht gleichalterig. Durch Mastopora concava wird Estland als wahrscheinliche Heimat bestimmt.

\section{Fam.: Calymenidae.}

\section{Gattung: Calymene Brongniart. Emmrich. Dalman (z. T.) Barrandt. Calymene tuberculata Brünnich. Taf. VI. Fig. 19a b c.}

1822. Calymene Blumenbachi Brongniat: Hist. nat. des Crustac. foss. pag. 11. Taf. I. Fig. 1. 1828. Calymene Blumenbachi var. tuberculata Dalman: Palaeaden pag. 35. Taf. I. Fig.2.3. 1874. Calymene Blumenbachi Steinhardt: Pr. Trilob. pag. 11. Taf. V. Fig. 1. 2 a. 1885. Calynumene tuberculata Brünnich in Lindström: Förteckn. på. Gotl. Silur. Crustac. pag. 63. Taf. XVI. Fig. 9. 
Unter dem Namen C. Blumenbachi sind bisher moistens zwei Formen znsammengefasst worlen: C. tuberculata und C. tuberculosa. Dalman unterschied beide Formen noch als Varietäten von C. Blumenbachi. Spätere Schriftsteller zogen beide Formen wieder unter dem alten Brongniartschen Namen zusammen, bis endlich durch die oben citierte Arbeit Lindströms über die Gotlïndischen Silurischen Crustaceen eine genaue Gronze zwischen C. tuberculata und C. tuberculosa gezogen wurde. nachweisen.

In unseren Geschieben komte ich nur die eine der Arten, C. tuberculata,

Das halbmondfürmige Kopfschild ist ringsum von einem sehr stark gewulsteten Randsaume und einer tiefen, aber nicht sehr breiten Raudfurche umgeben; vor der Glabella ist der Randsaum stark anfgeworfen. Die Glabella ist hoch gewölbt, jederseits mit drei Lappen, deren vorderster ganz klein ist, während der dritte, grösste, birnförmig gestielt erscheint. Das charakteristische Merkmal, das unsere Art von C. tuberculosa unterscheidet, ist der Verlauf der Gesichtsuaht hinter dem Auge: sie geht dort zuerst gerade nach dem Seitenrande zu, biegt dann nach der Hinterecke um, überschreitet die Randfurche kurz vor der Ecke, geht anf den Randwulst über, auf dem sie zuerst eine kurze Strecke gerade nach hinten verläuft, um dann in der Ecke nach unten umzubiegen. (Bei C. tubercnlosa geht die Naht in gerader Richtnng über die Raudfurche zur Ecke.)

Der Leib besteht ans 13 Ringen mit hochgewölbter Spindel, die Plenren sind diagonal gefurcht, ihre abgerundeten Enden sind etwas nach vorne gebogen.

Das Schwanzschild ist gemudet dreiseitig, hochgewölbt. Die Spindel besteht aus 6 bis 8 Gliedern, anf den Seitenteilen sind meisten 6 gefurchte Pleuren zu erkennen.

Die Oberfläche ist feingekörnelt (cf. Taf. VI. Fig. 19a), bei den meisten unserer Geschiebeexemplare ist die Körnelung abgerieben.

Die Grösse wechselt, das auf Taf. VI. Fig. 19 abgebildete Stïck zeigt. folgende Maasse:

Kopfschild: Länge $16 \mathrm{~mm}$, Breite $31 \mathrm{~mm}$, hintere Glabellabreite $12 \mathrm{~mm}$.

Breite des Schnauzenschildes $14 \mathrm{~mm}$.

Schwanzschild: Lünge $14 \mathrm{~mm}$, Breite $24 \mathrm{~mm}$, Spindelbreite $8 \mathrm{~mm}$.

C. tuberculata ist häufig in Ost- und Westprenssen. Anstehend kommt sie auf Gotland vor und wird auch jedenfalls im Obersilur Estlands heimisch sein, von wo Fr. Schmidt in der geologischen Einleitung zu seiner Revision der ostbaltischen Trilobiten nur den Namen C. Blumenbachi citiert.

Calymene intermedia Lindström. Taf. VI. Fig. 20.20a.

1885. Calymene intermedia Lindström: Förteckn. pia. Gotı. Crust. prg. 71. Taf. XV. Fig. 5-12.

Das Kopfschild ist etwas mehr doppelt so breit als lang, von einer sehr breiten und tiefen Vorder- und Seitenrandfurche und einer schmaleren Hinterrandfurche umgeben. Der Randsaum ist vor der Glabella besonders hoch anfgeworfen. Die Glabella ist stark gewülbt, bei dem anf Taf. VI. Fig. 20 abgebildeten Stücke sogar schwach gekielt. Drei Paar, nach hinten an Grösse zunehmende Seitenlappen sind vorhanden. Die Augen liegen weit nach hinten, ungefähr gegenüber den dritten 
Seitenfurchen, so dass die festen Wangen hinter den Augen weit schmaler sind als bei C. tuberculata. Die Oberfläche ist ganz fein gekörnelt.

Fundort: Balschwitz, Westpreussen. - Ostpreussen ohne Ortsangabe. Beyrichienkalk. C. intermedia ist anstehend aus Gotland bekannt, doch wird sie jedenfalls auch in Oesel, der Heimat eines grossen T'eiles unserer Beyrichienkalke, vorkommen.

Calymene spectabilis Angelin. Taf. VI. Fig. 21.

1852 (78). Calymene spectabilis Angelin: Pal. Scand. pag. 28. Taf. XIX. Fig. 5. 1884. Calymene spectabilis Kiesow: Sil.- u. Devon.-Geschiebe Westpr. pag. 81.

Einige schlecht erhaltene Schwanzschilder aus ostpreussischem Beyrichienkalk stimmen mit einem Exemplar von Schuddelkau-Westpreussen, aus der Sammlung des Herm Dr. Kiesow, gut überein.

Die Spindel ist hochgewölbt, zebnteilig, von sehr tiefen Rückenfurchen begrenzt. Die Pleuren, von denen nur die vier ersten deutlich zu erkennen sind, sind, wie Angelien angiebt, viermal breiter, als die Furchen zwischen ihnen; bei erhaltener Schale ist das Verhältnis noch grösser. Die Oberfläche ist fein chagriniert.

Fundorte: Ost- und Westpreussen in Beyrichienkalkeu.

Anstehend ist C. spectabilis aus dem Obersilur Gotlands bekannt.

Gattung: Homalonotus: Koenig.

(Dipleura, Trimerus, Geen.)

Mir selbst lag kein Vertreter dieser Gattung vor. Dr. Kiesow erwähut ${ }^{1}$ ) ein Schrwanzschild von

\section{Homalonotus cf. rhinotropis Angelin}

aus Westpreussen (Spengawsken). Nach der von Kiesow gegebenen Diagnose: „Rhachis und Seitenlappen ungefähr gleich breit; die Anzahl der Pleuren beträgt 8, die der Thachisglieder $10^{\prime \prime}$ steht diese Form augenscheinlich dem Angelinschen H. rhinotropis") sehr nahe. Als Heimat giebt Kiesow Gotland an.

\section{Fam. Lichidae.}

\section{Gattung: Lichas Dalman.}

Arges Goldf. Nutlainia Portlock. Metopias Eichw.

I. Arges Goldfuss. (Trochurus Beyrich.)

Die ersten Seitenfurchen endigen blind; die zweiten sind schwach angedentet, die dritten fehlen. Das Schwanzschild hat jederseits zwei Pleuren, deren hinteres Band schmal, aber hoch gewölbt ist, während das vordere flach ist. Die Oberfläche ist mit feinen Wärzchen besetzt.

1) cf. Kiesow: Sil.- u. Devon.-Geschiebe Westpreussens pag. 21 und 82.

2) cf. Angelin: Pal. Scand, pag. 30. Tat. XX. Fig. 1a-9. 
Lichas (Arges) Salteri Fletcher. Taf. VI. Fig. 17.

1854 (1872) Lichas gibbus Angelin Pal. Scand. 71. Taf. XXXVII. Fig. 1. (Schwanzschild!).

1874. Lichas gibba (?) Angelin in Steinhardt: Preuss. Trilobiten pag. 31. Taf. IIT. Fig. 10. 1885. Trochurus Salteri Fletcher in Lindström: Fökteckning png. 60.

Die von Lindström ${ }^{1}$ ) gegebene Beschreibung seines Trochurus Salteri passt, vollständig auf das ron Steinhardt als Lichas gibba beschriebene Schwanzschild. Es ist von fast halblreisförmigem Umriss; die Spindel ist schmal, stark gewölbt, ziemlich lang und besonders am vorderen Teil deutlich geringelt. In der Verlängerung der Spindel läuft eine kräftige Rippe zum. Hinterrande. Jederseits sind zwei Pleurenpare vorhanden, deren hinterer Theil als starke Rippe hervortritt. (Der vordere flache Teil des ersten Pleurenpaares ist weggebrochen). Der Rand ist gewulstet. Ueber den Rand ragen die Fortsätze der hinteren Pleurenteile und der Längsrippe als kurze, stumpfe Fortsätze hinaus. Ausserdem ist der Rand hinter den zweiten Pleuren noch mit je zwei dicht zusammenstehenden kurzen Zacken besetzt.

Die Oberfläche ist mit Höckerchen besetzt.

Fundort: Gumbinnen, Ostpreussen.

Nach Lindström kommt L. Salteri im mittleren mu nördlichen Teile Gontlands vor, sie gehört also dem Ober-Silur an, und zwar den mittleren und oberen Gotländer Schichten.

\section{Leilolichas. Fr. Schmidt.}

Die Furchen treten nur anf dem Steinkern dentlich hervor. Die zweiten Seitenfurchen fehlen. Das Schwanzschild ist ganz randig, ohne Seitenzähne, mit fünf Furchen auf jeder Seite. Gelenkflächen sind vorhanden.

Lichas illaenoildes Nieszkowski. Taf. V. Fig. 12. 13.

1857. Platymetopus illaenoïdes Nieszkowski. Monographie pag. 622. Taf. III. Fig. 3-5. 1874. Lichas convexa? Steinhardt: Preuss. Trilobiten pag. 34. Taf. III. Fig. $7 a-b$. 1885. Lichas illaenoïles Fr. Schmidt. Rev. II. Acid. 17. Jichiden pag. 46. Taf. III. Fig. $27-31$.

Die Glabella ist gleichmüssig, am Vorderrand etwas stärker gewölbt. Die ersten Seitenfurchen endigen blind, die zweiten fehlen, die dritten erscheinen als Fortsetzung des geraden Teiles der Nachenfurche. Die dritten Seitenlappen sind sehr kuxz, aber stark in die Breite gezogen. Bei erhaltener Schale sind die Furchen kaum zu erkennen.

Das Schwanzschild ist breit, halbelliptisch, hochgewölbt, bei erhaltener Schale ohne jede Andentung von Furchen. Auf dem Steinkem tritt die kimze flache Spindel deutlich hervor. Sie trägt an ihrem Vorderende ein Glied. Auf den Seitenteilen sind jederseits fünf Furchen vorhanden. An den Seitenteilen des Vorderrandes tritt eine schmale, riemlich lange Gelenkfläche auf, die die Fähigheit des Tieres, sich einzurollen, beweist. Die Oberfläche ist, ganz glatt.

1) Vergleiche Lindström: Förteckning pă Gatlands Siluriska Crustaceer pag. 60, in Betreft des Namens Lichas gibbus Angelin anch pag. 61 unter Trochurus pusillus. 
Von dieser so wichtigen Art lag mir nur ein kleines Bruchstück einer Glabella vor. Das von Steinhardt als L. convexa beschriebene Stück war mir unzugänglich; - es befindet sich in der Mascke'schen Sammlung. Neben einer Copie nach Steinhardt ${ }^{1}$ ) gebe ich die Copie eines Schwanzschildes nach Schmidt ${ }^{2}$ ). Die Beschreibung ist zum Teil aus Schmidt entlehnt.

Fundort: Umgegend von Königsberg.

L. illaenoïdes gehört der Jewe'schen Schicht an.

Lichas Gageli n. sp. Taf. II. Fig. 333. 33 a.

Ein kleines hochgewölbtes Schwanzschild zeigte eine von den bekannten Lichiden so verschiedene Ausbildung, dass ich mich um seiner deutlich ausgeprägten Merkmale willen veranlasst sah, eine neue Art auf dasselbe zu begründen.

Ausgezeichnet ist das Sohwanzschild dadurch, dass es an dem erhaltenen vurderen Rande des rechten Seitenlappens die Gelenkfläche ziemlich deutlich zeigt (Taf. II. Fig. 33a.). Die Spindel ist schmäler als jeder der Seitenteile und flach gewölbt; in ihrem vorderen Teile trägt sie ein deutlich begrenztes Glied, hinter welchem durch eine zweite, flache Furche ein zweites Glied schwach angedeutet ist. Die Spindel ist kurz, nach hinten undeutlich begrenzt. Auf den Seitenteilen sind jederseits fünf Furchen, also drei Pleuren vorhanden. Die hinteren Grenzfurchen der dritten Pleuren sind undeutlich, der von ihnen eingeschnürte Hinterlappen ist sehr schmal, am Rande etwas eingebuchtet. Die Mittelfurchen der Pleuren erreichen nicht den Rand des Schwanzschildes. Die Enden der beiden ersten Pleuren bilden ganz kurze, den Rand kium überragende, nach hinten gerichtete Zähnchen, doch so, dass das Schwanzschild fast ganzrandig erschoint. Ein ganz schmaler Randsaum umgiebt das ganze Schild. Die Oberfläche ist sehr dicht mit ganz feinen Körnchen bedeckt.

Maasse: Länge $5,5 \mathrm{~mm}$, Breite $8 \mathrm{~mm}$, Spindelbreite $2,5 \mathrm{~mm}$.

Fundort: Cranz, Ostpreussen.

Das mit hellgelber Schale bedeckte Schwanzschild liegt in einem dichten, kieseligen hellgrauen Kalkstein, der dem der Lyckholmer Schicht ähnelt. Heimat: Das „Balticum".

Das Vorhandensein einer Gelenkfläche, die nur ein deutliches Glied tragende Spindel, die fünf Furchen auf den Seitenteilen bestimmten mich, L. Gageli zu Leilolichas zu stellen, obwohl die Schale nicht glatt, und der Rand nicht ganz eben ist, wie bei L. illaenoïdes, auf welche einzige Art Schmidt die Gruppe Leilolichas begründete.

\section{Hoplolichas Dames.}

Die ersten Seitenfurchen münden in die Nackenfurche, oder endigen blind. Der Nackenring ist mit einfachen oder gegabelten Fortsätzen verziert. Das Schwanzschild hat jederseits vier Furchen.

1) ct. Steiuhardt 1. c. Taf. III. Fig. Za.

2) ct. Fr. Schmidt. 1. c. Taf. IL. Fig. 30 b. 
Lichas tricuspidata Beyrich. Taf. II. Fig. 20. 21. 22. 24.

1845. Lichas dissidens Beyrich: Ueb. einige Böhm. Trilob. pag. 30. Fig. 18.

1846. Lichas tricuspidata Beyrich: Unters. üb. Trilobiten. II St. pag. 7. Taf. I. Fig. 7 a b.

1869. Lichas Arenswaldi Karsten: Beitr. z. Landesk. v. Schl.-Holst. I. pag. 66. T'af. XXII. Fig. 6.

1874. Lichas quadricornis Steinhardt: Pr. Trilob. pag. 34. Taf. III. Fig. 4.

1875. Hoplolichas tricuspidata Dames: Hoplolichas u. Conolichas. pag. 795. Taf. XII.

Fig. 1. 2. 3. Taf. XIII. Fig. 1.

Die Glabella bildet ein ziemlich regelmässiges Oval. Der Randsaum vor derselben ist durch eine rinnentörmige Furche vom Stirnlappen gretrennt. Diese Randfurche geht an den Seiten des Stirnlappens in die Rückenfurchen über, die in schwach S-förmigen Bogen zur Nackenfurche gehen. An der Vereinigungsstelle der Vorderrand. und der Rückenfurchen entspringen die ersten Seitenfurchen, die zuerst sehr stark, dann schwächer bis zum mittleren 'T'eil der Glabella convergieren, von wo aus sie schwach divergierend zur Nackenfurche gehen. Die zweiten Seitenfurchen sind als schwache Eindrücke angedentet, die dritten sind schärfer ausgeprägt und bilden die direkten Fortsetzungen des mittleren Teiles der Nackenfurche. Der Stirnlappen steigt steil von der Vorderrandfurche an, biegt damn unter etwa 90 Grad um und geht unter ganz flacher Wölbung, fast horizontal zur Nackenfurche. Die ersten Seitenlappen sind länglich, bohnenförmig; in ihrer Mitte sind sie ebenso breit, als der schmalste Teil des Stirnlappens. Die zweiten Seitenlappen bilden rundliche Höcker; die dritten sind oval, stark gewölbt.

Der Nackenring ist in seinem mittleren Teil sehr breit und trägt hier einen langen seitlich etwas zusammengedrückten, starken, nach hinten gerichteten Stachelfortsatz, an dessen Grunde zu beiden Seiten sich je ein starker, spitziger Höcker befindet. Besonders eigentümlich ist bei L. tricuspidata die Besetzung der Glabella mit Höckern: Der Stirnlappen trägt vorn, an der Stelle seiner stärksten Wölbung, vier nebeneinander stehende grobe Stacheln, in den Ecken seines Hinterrandes wieder je einen Höcker gröberer Art; die kleinen zweiten Seitenlappen sind ebenfalls durch je einen stärkeren spitzigen Höcker ansgezeichnet. Ausserdem ist die ganze Glabella mit ziemlich starken rundlichen Höckern besetzt. Das Bruchstück einer freien Wange (Taf. II. Fig. 24) stelle ich zu L. tricuspidata: es ist grob tuberkuliert, der Augenhöcker ist stark aufgeblasen. Die Seitenrandfurche geht unter einem Winkel von etwa $75 \mathrm{Grad}$ in die Hinterrandfurche über.

Das Schwanzschild ist etwa halbkreisförmig, von einem breiten Randsaum umgeben. Die Spindel ist vorn stark gewölbt, mit zwei deutlichen Ringen versehen; nach hinten fillt sie schräge ab. Die Rückenfurchen konvergieren und reichen nur bis zum Randsaume. Jederseits sind auf den schwachgewölbten Seitenteilen vier Furchen vorhanden, welche zwei deutliche, gefurchte Pleuren abschnüren. Die Mittelfurchen der Pleuren gehen bis in den Randsaum. Die Enden dieser beiden ersten Pleuren bilden breite, nach hinten gewendete Zähne, die weit über den Rand hinausragen. Die dritten Pleuren sind ungeteilt, ganzrandig. Der Hinterrand des Schwanzschildes ist in zwei, nahe aneinanderstehende, breite Spitzen ausgezogen. Die Oberfläche des Schwanzschildes ist mit Höckern besetzt. 
Fundorte: Ostproussen: Wehlau, Königsberg, Pr. Holland; Westpreussen: Langenau bei Danzig.

I. tricuspidata gehört dem Echinosphaeritenkalk $\mathrm{C}_{1} \mathrm{~b}$ an, seine Heimat ist Estland.

Taf. II. Fig. 20 und 22 sind Kopieen nach Schmidt (Rev. II. Taf. II. Fig. 12 und 13 nach Stücken aus der Berliner Sammlung); ich gab diese Abbildungen, da mir bis zur Fertigstellung der Tafeln keine wirklich guten Stücke von I. tricuspidata zur Verfügung standen.

Lichas affin. tricuspidatae Beyr. Taf. II. Fig. 23.

Eine bei Wehlau gefundene Glabella zeigt in ihrer äusseren Form die nahe Zugehörigkeit zu L. tricuspidata; die Besetzung mit Höckern war am Stirnlappen wohl dieselbe, wie bei der vorigen Art: Am vorderen Teil des Stirnlappens sind die Bruchstellen mehrerer grosser, jedenfalls stachelartig ausgebildet gewesener Höcker zu sehen. Von L. tricuspadata ist das vorliegende Stück dadurch verschieden, dass die ersten Seitenfurchen vor der schmalsten Stelle des Stirnlappens plötzlich auf eine kurze Strecke stark verflacht sind - bei L. tricuspidata bleiben sio gleich tief, - und ferner dadurch, dass die ersten Seitenlappen an ihrem Ende zwei grössere spitze Höcker tragen, die hintereinander liegen und durch eine flache Vertiefung (die zweite Seitenfurche?) von einander getrennt sind. Ein kleines spitzes Höckerchen im Verlauf des hinteren Toiles der ersten Seitenfurchen lässt eine Annäherung an I. proboscidea Dames erkennen. ${ }^{1}$ )

Fundort: Wehlau. Gestein: Echinosphaeritenkalk.

Lichas Plautini. Fr. Schmidt. Taf. II. Fig. 32. Taf. VI. Fig. 18.

1874. Lichas tricuspidata Steinhardt: Preuss. Trilobiten pag. 33. Taf. III. Fig. 3 a b. 1874. Lichas dissidens Beyr. in Steinhardt: l. c. pag. 30. Taf. IIT. Fig. 8.

1885. Lichas Plautini Fr. Schmidt: Rev. II. Acidaspiden u. Lichiden. pag. 75. Taf. II.

Fig. $17-24$.

Von L. Plautini lagen mir nur zwei unvollständige Schwanzschilder vor. Die von Steinhardt (Taf. III. Fig. 3) abgebildete Glabella gehört der Masckeschen Sammlung an und war mir nicht zugainglich.

Das Kopfschild²) unterscheidet sich von L. tricuspidata durch folgende Merkmale: Die Seitenfurchen der Glabella sind viel tiefer ausgebildet, die zweiten Seitenfurchen fehlen vollständig. Die ersten Seitenlappen sind broiter als die schmalste Stelle des Stirnlappens. Die Höcker, mit denen die Glabella von I. Plautini besetzt ist, sind spitz kegelförmig, grösser als bei L. tricuspidata, und auf dem ganzen Stimlappen fast von derselben Grösse. Während der mittlere Teil des Stirnlappens bei L. tricuspidata 4-5 kleinere Höckerchen neben einander zeigt, treten hier bei L. Plautini nur immer etwa je zwei Höcker auf.

1) cf. Dames: Hoplolichas u. Conolichas. Zeitsch. d. D. geol. Ges. 1877. pag. 801. Taf. XII. Fig. 4.

2) cf. Fr. Schmidt: Rev. II. Acidaspiden u. Lichiden. pag. 76-78. 
Der Nackenring trägt einen cylindrischen Fortsatz, am Grunde jederseits von einem spitzen Höcker begleitet.

Das Schwanzschild ist flach, halbkreisfürmig. Die Spindel ist mässig gewölbt, stumpt kegelförmig, nach hinten kräftig abfallend. Zwei Segmente sind stets dentlich zu unterscheiden, ein drittes tritt weniger scharf hervor ('Taf. VI. Fig. 18 und Fr. Schmidt 'Taf. II. Fig. 23). Die flachen Seitenteile sind von einem breiten Randsaum umgeben. Jederseits sind vier Furchen vorhanden. Die beiden ersten Pleuren endigen in starke, nach hinten gerichtete Seitenzähne, ihre Mittelfurchen gehen nur bis zum Randsaum. Die dritten Pleuren sind ungeteilt, ihr Aussenrand bildet mit den Zähnen der zweiten Pleuren eine enge tief einschneidende Bucht. Der Hinterrand ist in einen kurzen dreieckigen Zahn ausgezogen.

L. Plautini ist in ost- und westpreussischen ${ }^{1}$ ) Geschieben gefunden worden and gehört dem Echinosphaeritenkalk an.

\section{Lichas proboscidea Dames.}

1874. Lichas quadricornis var. Steinhardt: Pr. 'Trilob. pag. 34. Taf. III. Fig. 5.

1877. Lichas proboscidea Dames: Hoplolichus u. Conolichas pag. 801. T'af. XII. Fig. 4. Taf. XIII. Fig. 23.

Steinbardt erwähnt am ang. Orte eine Glabella aus der Masckeschen Sammling als L. quadricornis variet. Dames hat nach diesem und ähnlichen Stücken seine Art L. proboscidea begründet, die bei naher Verwandtschaft mit L. tricuspidata sich von dieser durch einen sehr starken grossen Stirnstachel unterscheidet. Ausserdem tritt bei L. proboscidea im Hinterende der ersten Seitenfurchen ein Höckerchen auf (vergl. L. aff. tricuspidatae).

L. proboscidea ist bisher anstehend nicht gefunden worden.") Das Steinhardtsche Stück stammt ans Ostpreussen. Seine Heimat dürfte das Ostseebecken sein.

Lichas media. n. sp. Taf. II. Fig. 25. 25 a.

Nehrere Glabellen, die mit einem Fortsntz am Nackenringe versehen sind, zeigten eine ron den anderen Arten der Gruppe Hoplolichas so verschiedene Ausbildung, dass ich sio einer neuen Art zuzähle.

Der vordere Randsaum ist vor dem Stirnlappen schmal, nach den Seiton verbreitert or sich. Die Vorderrandfurche schneidet tief in den Stirnlappen ein, sie geht seitlich in die schwach Sförmig gebogenen Rückenfurchen über, welche deutlich bis zur Hinterrandfurche gehen und auch noch eine schwache Fortsetzung auf den etwas wulstigen Hinterrand entsenden. Die ersten Seitenfurchen convergieren zuerst sehr stark; auf dem Rücken der Glabella gehen sie in gleichmässigen schwachen Bogen zur Nackenfurche; kurz vor der Nackenfurche biegen sie etwas nach aussen und senden von der Umbiegungsstelle eine flachere Fortsetzung in die Nackenfurche. Die zweiten Seitenfurchen fehlen; die dritten bilden die Fortsetzung des geraden Teiles der Nackenfurche. Der Stimlappen steigt vom Vorderrande steil auf, in seinem

1) ef. Fr. Schmidt: Rev. U. pag. 79

2) cf. Fr. Schmidt: Rev. II. pag. 39. 
mittleren und hinteren Teile ist er flach. Die ersten Seitenlappen sind bohnenförmig und ebenso breit wie der engste Teil des Stirnlappens; sie sind etwas niedriger als derselbe. Die zweiten Seitenlappen sind kaum angedeutet. Die dritten Seitenlappen sind länglich eiförmig und liegen erheblich tiefer als die ersten.

Der Nackenring ist in der Mitte schildförmig verbreitert; sein Hinterrand war zu einem rundlichen Stachelfortsatz ausgezogen.

Die ganze Glabella ist mit Höckern besetzt, welche nach hinten zu gröber werden. An den Hinterecken des Stirnlappens liegen zwei besonders grobe, hohe Höcker, ebenso sind die Enden der ersten Seitenlappen durch je einen grösseren spitzen Höcker verziert. ritenkalk.

Fundort: Ostpreussen; Umgegend von Königsberg. Gestein: Echinosphae-

L. media bildet den Uebergang zwischen der Gruppe der Lichas tricuspidata, die durch Stirnstacheln und ungeteilte Nackenfortsitze ausgezeichnet ist, und der Gruppe der L. conicotuberculata ohne Stirnstachel und mit gegabelten Nackenfortsätzen.

\section{Conolichas Dames.}

Der Stirnlappen allein, oder auch die ersten Seitenlappen springen nach vorn konisch gewölbt vor. Nackenring ohne Fortsätze.

Lichas aequiloba Steinhardt. Taf. V. Fig. 14.

1874. Lichas aequiloba Steinhardt: Preuss. Trilobiten pag. 30. Taf. III. Fig. 6. 1886. Lichas aequiloba Fr. Schmidt: Rev.II. Acid. u. Lichiden. pag. 89. Taf. V. Fig.4-10.

Steinhard begründete seine neue Art L. aequiloba auf eine Glabella aus der Sammlung des Herrn Mascke. Mir selbst lag die Art nicht vor, ich citiere sie, als aus preussischen Geschieben stammend, daher nur kurz. Der Stimlappen zerfällt in einen grossen, stark gewülbten vorderen Teil, und in einen schmalen, flachen, niedrigeren hinteren Teil. Die ersten Seitenlappen sind gross, nach hinten verbreitert und hier noch breiter wie der vordere Teil des Stirnlappens. Die zweiten Seitenlappen fehlen, die dritten sind ganz klein, länglich oval, niedrig.

Die Abbildung Taf. V. Fig. 14 ist eine Copie nach Fr. Schmidt Rev. II. Taf. V. Fig. 8a. (Exemplar von Parizy bei Gatschina).

\section{Homolichas Fr. Schmidt.}

Stirn- und Seitenlappen sind mehr oder weniger stark, gleichmässig gewölbt. Nackenring ohne Fortsätze.

Lichas Branconis n. sp. Taf. II. Fig. 26. 26a.

Der Vorderrand ist in der Mitte schmal, kräftig vorgezogen, nach den Seiten verbreitert. Die Vorderrandfurche schneidet tief in den Stimlappen ein. Die Rückenfurchen sind stark Sfürmig gebogen. Die ersten Seitenfurchen convergieren zuerst sehr stark, laufen dann in gleichmässigen Bogen über die Glabella und münden in die Nackenfurche. Die zweiten Seitenfurchen fehlen ganz; die dritten gehen schräg nach innen von den Rückenfurchen zur Nackenfurche; diese ist sehr breit und, wie 
alle Furchen, tief. Der Stirnlappen ist stark nach vorn vorgezogen und steigt von der Vorderrandfurche, dieselbe überwölbend, hoch auf, dann geht er in gleichmässiger, nicht zu starker Wölbung zur Nackenfurche, in die er steil abstürzt. In der Mitte der Glabella ist er stark eingeschnürt und etwa nur den fünften Teil so breit, als vorne. Die ersten Seitenlappen sind sehr gross, fast elliptisch, 4 mal so breit als die schmalste Stelle des Stirnlappens; vorn und hinten endigen sie in stumpfe Spitzen. Die zweiten Seitenlappen fehlen; die dritten sind oval, stark gewölbt und liegen unter den ersten Seitenlappen. Der Nackenring, nach den Wangen zu stark abfallend und verschmälert, zeigte einen geraden Hinterrand.

Die ganze Oberfläche ist mit groben Höckern bedeckt, deren Grösse namentlich auf den Seitenlappen nach hinten zunimmt. Zwischen den groben Höckern liegen kleine feinere Knötchen.

L. Branconis lag mir in einer Glabella aus bräunlichem erdigem Gestein vor, das gut mit einem von Kuckers aus Estland stammenden Handstücke itbereinstimmt. Unsere Art gehört demnach der Kuckers'schen Schicht $\mathrm{C}_{2}$ an.

Fundort: Wehlau, Ostpreussen.

L. Branconis scheint mir eine Vorläuferin dur I. deflexa, die in der Jeweschen Schicht vorkommt, zu sein. Dor stark eingeschnürte Mittellappen und die breiten Seitenlappen sprächen dafür, während der vorn hoch gewölbte und weit vorgezogene Stirnlappen L. Branconis von L. deflexa trennt.

Lichas deflexa Sjögren. Taf. II. Fig. 30. 30a.

1854 (1872). Lichas deflexa Sjögren in Angelin Pal. Scand. pag. 71. Taf. XXXVII. Fig. $3 a-c$.

1874. ? Lichas conicotuberculata Steinhardt: Preuss. Trilob. pag. 28. Taf. III. Fig. 2a-c. 1874. Lichas velata Steinhardt: 1. c. pag. 30. Taf. ПI. Fig.9.

1885. Lichas deflexa Fr. Schmidt: Rev. II. Acid. u. Lichid. pag. 101. Taf. IV. Fig. 24-35.

Mir lag von dieser Art nur eine sehr verdrückte Glabella vor, an deren Stelle ich auf Taf. II. Fig. 30. 30a, Kopieen eines Kegel'schen Exemplars nach Schmidt (Taf. IV. Fig. 24a. b.) gebe.

Der Kopf ist hochgewölbt, nach den Seiten steil abfallend. Der Vorderrand ist schmal, gerade, an den Seiten des Stirnlappen zurückgebogen. Die Vorderrandfurche geht in die Rückenfurchen über. Die ersten Seitenfurchen sind tief, sie convergieren stark :bis zur Mitte der Glabella, nach der Nackenfurche zu divergieren sie wieder. Die zweiten Soitenfurchen fehlen; die dritten sind kurz, tief, sie stehen fast senkrecht zur Längsaxe und liegen etwas vor dem mittleren Teil der Nackenfurche. Der Stirnlappen wird auf der Mitte der Glabella sehr stark eingeschnürt, nach vorne zu wird er stark erweitert, seitlich stumpfe Ecken bildend; zum Vorderrande fällt er ziemlich steil ab. Die ersten Seitenlappen sind gross; oval, fast vier mal so breit als die schmalste Stelle des Stimlappens; die dritten Seitenlappen sind klein, rundlich dreieckig. Die ganze Oberfläche ist mit ziemlich grossen, niedrigen Höckern besetzt. 
Das von Steinhardt ${ }^{1}$ ) als $L$. velata beschriebene Schwanzschild gehört zu L. deflexa ${ }^{2}$ ). Er ist halblrreisförmig, flach gewölbt. Die Spindel ist mässig gewölbt, zweigliederig, nach hinten verschmälert und schräg abfallend. Jederseits sind fünf Furchen tief eingedrückt. Die beiden ersten Pleuren bilden stark nach hinten gerichtete Seitenzähne. Sie sind fast bis zum Ende gefurcht. Der Hinterrand ist in zwei kurze breite Zähne ausgezogen, die durch eine breite flache Bucht getrennt sind.

L. deflexa ist sowohl in Ostpreussen (Königsberg, Wargitten) als in Westprenssen (Gischkau, Langenau) ${ }^{3}$ ) gefunden. Die Heimat unserer Stücke dürfte wohi Estland sein, wo L. deflexa in der Kegel'schen Schicht $D_{2}$ anstehend gefunden ist.

Lichas Eichwaldi Nieszkowski. Taf. II. Fig. 27. Taf. VI. Fig. 16.

1857. Lichas Eichwaldi Nieszkowski: Monogr. d. Trilob. pag. 570. Taf. I. Fig. 16. 17. 1860. Lichas Eichwaldi Eichwald: Leth. rossica pag. 1381.

1874. Lichas Eichwaldi Steinhardt: Pr. Trilobiten. pag. 28. Taf. III. Fig. 1a-c.

1885. Lichas Eichwaldi Fr. Schmidt: Rev. II. Acid. u. Lichiden. pag. 104. Taf. IV. Fig. 10-17.

Eine Glabella und ein Schwanzschild dieser Art lagen mir vor.

Die flachgowölbte Glabella bildet ein breites, hinten abgestutztes Oval. Der Vorderrand bildet einen gleichmässigen, kräftigen Bogen; die Vorderrandfurche geht seitlich in die Rückenfurchen über. Die ersten Seitenfurchen entspringen vorn an den Seiten der Glabella, wenden sich sehr stark nach innen, gehen dann in flachen Bogen, fast parallel über die Mitte der Glabella, um vor der Einmündung in die Nackenfurche wieder nach aussen zu divergieren. Die zweiten Seitenfurchen fehlen ${ }^{4}$ ); die dritten liegen etwas vor dem mittleren Teile der Nackenfurche und stossen senkrecht auf die Rückenfurchen. Der Stirnlappen ist vorn sanft gewölbt, sehr breit, seine Ecken umgeben vorn die Seiteulappen fast ganz. Die ersten Seitenlappen sind gross, vorne spitz, hinten gerade abgestutzt, mit schwach gebuchtetem Aussenrande, sie sind etwas breiter als der schmalste Teil des Stirnlappens. Die dritten Seitenlappen sind ungefähr dreiseitig, flachgewölbt. Der Nackenring ist schmal, wenig gewölbt, sein Hinterrand ist schwach konvex.

Die Oberfläche ist gleichmässig dicht mit rundlichen Höckerchen besetzt.

Das Schwanzschild ist flach gewölbt, etwas über einen Halbkreis ausgezogen. Die Spindel ist bedeutend schmäler als die Seitenteile, vorne trägt sie zwei deutliche schmale Ringel, der hintere Teil fällt sanft ab. Die Rückenfurchen convergieren wenig. Auf den flachen Seitenteilen sind je 5 Furchen vorhanden. Die beiden ersten Pleuren endigen in ganz kurzen Zähnen, die kaum über den Rand vorspringen, so dass dieser fast glatt erscheint. Das vordere Band der Pleuren ist schmäler als das hintere; die Mittelfurchen der beiden ersten Plouren bilden nach vorn convexe Bogen

1) cfr. Steinhardt. 1. c. pag. 30. Taf. III. Fig. 9.

2) cfr. Fr. Schmidt. 1. c. pag. 102. Taf. IV. Fig. 34. 35.

3) cfr. Kriesow: Sil. u. Devongeschiebe, Westpreussen, pag. 80.

4) Die von Fr. Schmidt 1. c. pag. 105 erwähnten Andeutungen der zweiten Seitenfurchen in der Höhe der Augen habe ich bei dem mir vorliegenden Exemplar von L. Eichwaldi nicht beobachten können. 
und endigen in der Nähe der Zähne. Die Hinter- und Mittelfurchen der dritten Pleuren erreichen den Rand nicht. Der Hinterrand des Schwanzschildes ist schwach eingebuchtet. Um das ganze Schild läuft ein breiter schwacher Randsaum. Die Oberfläche ist fein gekörnelt.

Maasse: Länge der Glabella $25 \mathrm{~mm}$, Breite $19 \mathrm{~mm}$. Vordere Breite des Stirnlappens $17 \mathrm{~mm}$, schmalste Stelle desselben: $4 \mathrm{~mm}$. Breite der Seitenlappen $6 \mathrm{~mm}$.

Schwanzschild: Länge $17 \mathrm{~mm}$, Breite ca. $27 \mathrm{~mm}$, Spindelbreite $8 \mathrm{~mm}$.

Fundorte: Belschwitz (Westpreussen). Wehlau (Ostpreussen).

L. Eichwaldi gehört wach Schmidt ${ }^{1}$ ) der Wesenberger Schicht Estlands an.

Lichas cf. Pahleni Fr. Schmidt. Taf. II. Fig. 28. 29. 31.

1885. Lichas Pahleni Fr. Schmidt: Rev. II. Acid. u. Lichiden pag. 97. Taf. IV. Fig. 6-8 (9).

Zwei Glabellen zeigen grosse Aehnlichleit mit L. Pahleni Fr. Schmidt: Sio sind mässig gewölbt, die ersten Seitenfurchen verlaufon in gleichmässigen Bogen über die Glabella, die dritten Seitenfurchen liegen etwas vor der Nackenfurche und stutzen die vorderen Seitenlappen hinten gerade ab, die Oberfläche ist wie bei L. Pahleni fein gekörnelt. Von L. Pahleni sind die beiden Glabellen durch folgende Merkmale unterschieden: Der Stirnlappen ist vorn sehr stark, doch gleichmässig vorgezogen, und fällt zum Rande steiler ab. Die Andeutung der zweiten Seitenfurchen ${ }^{2}$ ) fehlt. Die Augenfurshe auf der einen erhaltenen festen Wange (Fig. 29) bildet ein stumpfwinkliges Knie und nicht wie bei L. Pahleni einen Bogen.

Mit der einen der Glabellen (Taf. II. Fig. 28) wurde ein kleines wohl erhaltenes Schwanzschild gefunden, das den Hinterrand besser erhalten zeigt, als das von Schmidt (Taf. IV. Fig. 8) abgebildete Schwanzschild von L. Pahleni. Die Spindel ist hoch gewölbt, etwas schmaler als die Seitenteile, nach hinten etwas verengt, und schräge abfallend; sie zeigt zwei deutliche Ringel. Die flachen Seitenteile tragen 5 deutliche Furchen. Die beiden ersten Pleuren endigen in spitze breite, nach hinten gerichtete Zähne; ihro gebogenen Mittelfurchen münden in die Bucht zwischen den Zähnen ein. Die Mittelfurchen der dritten Pleuren erreichen den Rand nicht; die Grenzfurchen derselben konvergieren und gehen fast bis zum Rande. Der Hinterrand bildet zwei kurze spitze Zähne, die durch eine enge tiefe Bucht getrennt sind. Die Oberfläche des Schwanzschildes ist sehr dicht und fein gekörnelt.

Maasse: Länge der Glabella $1,8 \mathrm{~mm}$, Breite $14 \mathrm{~mm}$.

$$
" \quad " \quad 11 \mathrm{~mm}, \quad, \quad 9 \mathrm{~mm} \text {. }
$$

Länge des Schwanzschildes $11 \mathrm{~mm}$, Breite 2,2 $\mathrm{mm}$, Spindelbreite $6 \mathrm{~mm}$.

Fundort: Umgegend von Königsberg, in bläulich grauem, feinkörnigem, fast dichtem Kalke, der dem der Jeweschen Schicht ähnelt. ${ }^{3}$ )

1) cf. Fr. Schmidt 1. c. pag. 107.

2) cf. Fr. Schmidt 1. c. Taf. IV. Fig. 6a.

3) L. Pableni selbst gehört der Jewe'schen Schicht $D_{1}$ an; vergl. Fr. Schmidt: Rev. II. Accd. u. Lichid. pag. 100. 
Lichas sp. Taf. II. Fig. 35.

Das auf T'af. II. Fig. 35 abgebildete Schwanzschild aus Wesenberger Gestein scheint in die Verwandtschaft der Lichas Pahleni F. Schm. zu gehören. Die Spindel ist hoch gewölbt, vorn mit 2 schwach angedeuteten Ringeln.

Auf den Seitenteilen sind 5 Furchen vorhanden. Die beiden ersten Pleuren endigen in spitze Seitenzähne. Der Hinterrand fehlt. Der Umschlag des Schwanzschildes ist mit feinen Terrassenlinien verziert.

Fundort: Rippkeim bei Wehlau Ostpreussen, in rötlichem Wesenberger Kalk.

Lichas cf. angusta Beyrich. Taf. II. Fig. 34.

1846. Lichas angusta Beyrich: Unters. üb. Trilobiten. II. St. pag. 6. Taf. I. Fig. 6. 1875. Lichas angusta Beyrichin Fr. Schmidt. Rev. II. pag. 108. Taf. IV. Fig. 18-23.

Eine kleine, schlecht erhaltene Glabella aus Ostpreussen zeigt den in der Mitte stark verschmälerten Stirnlappen, wie L. angusta, doch der Vorderteil des Stimlappens ist nicht stumpfwinklig vorgezogen, sondern gleichmässig aber stark gewölbt. Die Oberfläche ist sparsam mit kleinen Höckerchen bedeckt.

Fundort: Wehlau Ostprenssen.

Das Gestein ist dem der Lyckholmer Schicht ähnlich.

Lichas Lindströmi. n. sp. Taf. F. Fig. 10.

Ein Schwanzschild aus einem Geschiebe von Wehlau lag mir vor, das der schwedischen Art L. triquetrus Lindström sehr nahe steht. Herr Prof. Lindström, der die Liebenswürdigkeit hatte, das betr. Geschiebe zu begutachten, riet mir die vorliegende Art von L. triquetrus zu trennen. Diesen Rat befolgend, erlaube ich mir, diese neue Art L. Lindströmi zu benennen. Das Schwanzschild ist flach, nicht ganz doppelt so breit als lang. Die Spindel ist hochgewölbt und wie bei L. triquetrus ${ }^{1}$ ) hinten durch eine tiefe Furche deutlich begrenzt, ihr vorderer Teil ist nicht erhalten; or trug jedenfalls 2 Ringe. Jederseits sind auf den Seitenteilen 5 Furchen erhalten. Die beiden ersten Pleuren endigen in stark nach hinten umgebogene Zähne; ihre stark gebogenen Mittelfurchen gehen etwa bis zur Bucht eines jeden Zahnes. Die Grenzfurchen der dritten Pleuren convergieren sehr stark, ohne jedoch wie bei L. triquetrus zusammen zu stossen. Die kurzen Mittelfurchen der dritten Pleuren gehen bei L. Lindströmi von den hinteren Grenzfurchen etwas hinter der Endfurche der Spindel aus, während sie bei L. triquetrus in gleicher Höhe mit dieser Endfurche entspringen. Der etwas zerstörte Hinterrand war in zwei kurze, stumpfe, dichtgestellte Zähnchen ausgezogen. Die Oberfläche ist dicht und fein gekörnelt.

MLaasse: Länge $7 \mathrm{~mm}$, Breite $12 \mathrm{~mm}$, Spindelbreite $3,5 \mathrm{~mm}$.

L. Lindströmi gehört dem Ober-Silur an. Nach einer Mitteilung des Herrn Prof. Lindström entspricht das Gestein ungefähr der obersten Gotländer Zone h. (vergl. Seite 12).

1) cf. Lindström: Förteckning på Gotlands siluriska Crustaceer. in. Oefversigt af, K. Vetensk.-Akad. Förhandl. No. 6, pag. 59 (Jahrg. 1885). 


\section{Oncholichas. Fr. Schmidt.}

Die ersten Seitenfurchen münden in hakenförmigen Bogen in die Nackenfurche ein. Am Schwanzschilde sind jederseits 3 vollständig ausgebildete Pleuren vorhanden.

Lichas aranea Lindström. Taf. V. Fig. 11.

1885. Lichas araneus Lindström. Förteckning pa Gotlands Crustac. pag. 58, Fig. 30, Taf. XV.

Ein Bruchstück eines Schwanzschildes ist gut mit der angeführten Lindströmschen Art zu vereinigen. Die Pleuren sind bis zum Ende deutlich gefurcht, die beiden ersten Pleuren endigen in stumpfe Zähne, die dritten in kurze Vorsprünge. Der Hinterlappen zwischen den dritten Pleuren ist schwach eingebuchtet. Trotz einer grossen Aehnlichkeit mit L. Visbyensis Lindström ${ }^{1}$ ) musste ich das vorliegende Stück zu L. araneus stellen, da der Abdruck eines Spindelstückes in demselben Geschiebe, den gleichmässigen Abfall der Spindel nach hintenzu zeigte, während L. Vibyensis im hinteren Teile der Spindel eine buckelförmige Erhöhung mit steilem

- Abfall zeigt. Die Schale ist dicht gekörnelt. L. araneus ist bei Marienwerder gefunden worden (vergl. pag. 12). Nach Lindström kommt L. aranens auf Fă-rö, also im oberen Gotländer Obersilur vor.

\section{IX, Fam, Acidaspidae.}

Gattung: Acidaspis Murch: Barr. Schmidt.

(Odontopleura, Emmr., Burm., Beyr., Römer.)

Acidaspis mutica Emmrich. Taf. VI. Fig. 30.31.

1845. Odontopleura mutica: Emmrich: Ueber die Trilobiten. pag. 44.

1846. Odontopleura mutica: Beyrich: Unters, üb. Trilob. II. Stück. pag. 19. Taf. III. Fig.3. 1888. Acidaspis mutica: Wiegand: Trilob. d. sil. Gesch. Meklenb. pag. 93. Taf. X.

Fig. 19 abc. 20.

Eine Glabella und ein Schwanzschild aus graulich grünem Graptolithengestein stello ich zu dieser Art.

Die Glabella ist breit eiförmig, vorn etwas eingeschnürt. Die ersten Seitenfurchen fehlen, die zweiten biegen bald nach hinten um und erreichen kaum die Umbiegung der dritten Seitenfurchen, welche deutlich bis zur Nackenfurche gehen. Der Nackenring ist breit, hinten convex; die seitlichen Lappen desselben sind ziemlich deutlich ausgebildet. Die Oberfäche ist gekörnelt, in der Mitte des Nackenringes steht ein gröberes Höckerchen.

Der vordere Rand des Schwanzschildes ist gerade, die Vorderecken sind kurz abgerundet. Die Spindel lässt zwei Glieder deutlich, ein drittes undeutlicher erkennen. Dem zweiten Gliede entspricht auf den Seitenteilen ein nach hinten gebogener Wulst, dessen Verlängerung als kräftiger Stachel über den Rand hinausragt. An

1) cf. Lindström 1. c. pag. 5S. Taf. XVI. Fig. 11. 
den Seiten tritt vor diesen Stacheln je oin Zähnchen, am Hinterrande troten vier Zähnchen auf. Die Oberfläche des Schwanzschildes ist fein gekörnelt.

Fundort: Pr. Holland, Ostpreussen, in Graptolithengestein.

Heimat: Das Ostseegebiet zwischen Schweden und Estland.

Anhang:

Das von Kiesow (Sil. und Devon. Geschiebe Westpr. pag. 80 Taf. IV. 9 a b) aus Wesenberger Gestein orwähnte Schwanzschild oiner Acidaspisart, scheint mit der Barrandeschen Art Ac. Hörnesi (Barr. Bd. I. pag. 723. Taf: XXXVIU. Fig. 30) nahe verwandt zu sein.

Was Steinhardt (Pr. Trilob. pag. 62) für eine Art aus der Masckeschen Sammlung vorgelegen hat, kann ich nicht entscheiden. Steinhardt stellt sie in die Verwandtschaft von Ac. Prevosti Barr., doch diese Art hat stets 4-5 Seitenstacheln vor dem eigentlichen Pleurenstachel ${ }^{1}$ ), während Steinhardt nur drei angiebt.

\section{Fam.: Proëtidae.}

Gattung: Proëtus-Steininger. Barrande (z. 'T.).

(Forbesia. M'Coy. Gerastos-Goldfuss.)

Proëtus verrucosus Lindström. Taf. V. Fig. 27.

1885. Proëtus verrucosus Lindström: Förteckn. pâ Gotl. sil. Crust. pag. 81. Taf. XVI. Fig. 15.

In einem dichten grauen, etwas mergeligen Kalke aus Westpreussen liegt eine grosse etwas verdrückte Glabella, welche deutlich die Merkmale der Lindströmschen Art Pr. verucosus besitzt: Sie ist ziemlich kräftig gewölbt, nach vorn verschmälert, mit fast gerade abgestutztem Hinterrade. Die Seitenfurchen, drei Paare an der Zahl,

- sind sehr wonig deutlich; dio dritten sind stark nach hinten gerichtet. Auf dem Nackenringe werden durch tiefe Aeste der Nackenfurche ziemlich grosse, rundlich dreieckige, stark gewölbte Seitenbuckel abgeschnürt. Die Oberfläche ist mit flachen, warzenförmigen Höckern bedeckt, die nach hinten zu gröber werden. Der Randsaum vor der Glabella ist mit sehr foinen parallelen Terrassenlinien verziert.

Länge der Glabella $10 \mathrm{~mm}$, hintere Breite $10 \mathrm{~mm}$, vordere Breite $6 \mathrm{~mm}$.

Fundort: Belschwitz in Westpreussen.

Anstehend ist Pr. verrucosus bisher nur aus den Mergelschiefern Gotlands beliannt.

Proëtas signatus Lindström. 'Taf. VI. Fig. 22.

1884. Proëtus pulcher Nieszk. var. Kiesow: Sil. u. Devon. Gesch. pag. 84. Taf. IV. Fig, 12.

1885. Proëtus signatus Lindström: Förteckn. pâ Gotl. sil. Crust. pag. 80. Taf. XIV. Fig. 16. 17.

Mehrere kleine Glabellen stimmen gut mit der von Lindström a. a. O. für Pr. signatus gegebenen Beschreibung: Sie sind ziemlich kräftig, in der Mitte fast

1) cf. Barrande Bd. 1. Ac. Prevosti pag. 739. Taf. XXXIX. Fig. 33-41. 
dachförmig; gewölbt, nach vorn stark verschmälert. Die Seitenfurchen sind als feine schräg nach innen verlaufende Eindrücke ausgebildet. Die beiden ersten Paare sind kurz, gerade, nach innen etwas verbreitert; die dritten laufen zuerst den vorderen parallel und knicken dann nach hinten um; in der Verlängerung ihres vorderen Astes liegt ein kleiner länglicher Eindruck. Vor den ersten Seitenfurchen sind bei einzelnen Stücken noch kleine kürzere Vertiefungen - je eine auf jeder Seite — zu erkennen.

Die Oberfläche erscheint fein chagriniert. Der vor der Glabella ziemlich stark gewölbte Randsaum ist mit feinen, parallelen Terrassenlinien verziert. Auf dem Nackenringe sind deutlich die länglich dreieckigen Seitenbuckel abgeschnürt; das eine der Stücke (von Belschwitz in Westpreussen) lässt einen feinen Mittelhöcker erkemnen.

Maasse: Länge der Glabella $5 \mathrm{~mm}$, Breite $4 \mathrm{~mm}$.

$$
n \quad n \quad 7 n \quad n \quad 5,5 n
$$

Mit dem einen der Stücke wurde ein kleines Schwanzschild gefunden, das bei $5 \mathrm{~mm}$ Länge und $7 \mathrm{~mm}$ Breite eine hochgewölbte neungliedrige Spindel und sieben längsgefurchte Pleuren zeigte, welche fast bis zum Rande deutlich ausgebildet sind; die Seitenteile fallen in gleichmässiger Wölbung ab. Die Oberfläche ist ebenfalls fein chagriniert.

Fundorte: Pr. Holland, Ostpreussen; Belschwitz: Langfuhr, Westpreussen.

Das Gestein ist ein gelblicher, bröckeliger Kalk mit weissen Kalkspathnestern; seine Heimat ist das gotländische Obersilur.

Proëtus concinnus Dalman. Taf. VI. Fig. 27.

1828. Calymene concinna Dalm: Palaeaden. pag. 40. Taf. I. Fig. 5a-c.

1885. Proëtus concinnus Lindström: Förteckn. pâ. Gotl. Sil. Crust. pag. 78.

Glabellen dieser Art fand ich mehrfach in grauem lionnigem Leperditiongestein. Sie zeichnen sich durch sehr starke Wölbung aus, und sind nach vorn wenig verschmälert. Von den Seitenfurchen sind nur die beiden letzten Paare als ganz schwache, kaum erkenmbare Eindrücke ausgebildet. Die Oberfläche erscheint unter der Lupe kaum chagriniert. Der Nackenring trägt stets deutliche stark gewölbte Seitenbuckel und Mittelhöcker.

Das auf Taf. VI. Fig. 27 wiedergegebene bei Ragnit gefundene Schwanzschild ist ungefähr halbkreisförmig mit hochgewölbter achtgliedriger Spindel, deren erste Ringel besonders kräftig ausgebildet sind. Die flachgewölbten Seitenteile lassen 4-5 gefurchte nicht sehr deutliche Pleuren erkennen, welche bis zu dem, das ganze Schild umgebenden Randsaum gehen.

Fundorte: Ostpreussen, Umgegend von Königsberg, Ragnit (in feinkörnigem gelbgrauem Kalk). Westpreussen, Umgegend von Danzig. Belschwitz.

Pr. concinnus gehört sowohl dem Obersilur Gotlands als Oesels an.

Proëtus affin. concinno Dalman. Taf. VI. Fig. 26.

[1828. Proëtus concinnus Dalman: Palaeaden pag. 40. Taf. I. Fig. 5a-c.]

In einem Geschiebe graulichen, kleinkörnigen, etwas mergeligen Kalkes, der 
In seiner Beschaffenheit dem Leperditiengestein sehr ähnlich ist, fanden sich mehrere kleine Glabellen einer Proëtusart, welche dem Pr. concinnus als nahe verwandt zu erachten ist. Die Glabella ist kurz, ziemlich kräftig gewölbt. Die Seitenfurchen scheinen vollständig zu fehlen. Der Nackenring zeigt bei einigen Bruchstücken dentlich die scharfabgeschnürten Seitenbuckel, wie sie für Pr. concinnus charakteristisch sind, und einen kleinen Mittelhöcker. Von der gotländischen Form des Pr. distans ${ }^{\mathbf{1}}$ ), mit der die vorliegenden Stücke die Form und Ausbildung der Glabella gemein haben, unterscheidet sich unsere Art dadurch, dass die Glabella hart an den aufgeworfenen vorderen Randsaum stösst.

In demselben Geschiebe wurden mehrere Schwanzschilder gefunden, deren hochgewölbte breite Spindel achtgliederig ist, und deren Seitenteile vier deutlich gefurchte Pleuren tragen. Das ganze Schild ist von einem schwächeren undeutlicheren Randsaume umgeben, als die Stammform des Pr. concinnus. - Die Oberfläche ist fast ganz glatt.

Maasse: Länge der Glabella: 2,5 mm, Breite: 2,5 mm.

Länge des Schwanzschildes $3 \mathrm{~mm}$, Breite $5 \mathrm{~mm}$, Spindelbreite $2 \mathrm{~mm}$.

Fundort: Königsberg.

Als Heimat dieser Varietät des Pr. concinnus ist das Gebiet zwischen Estland und Schweden anzunehmen.

Proëtus distinctus n. sp. Taf. VI. Fig. 23.

Mehrexe Glabellen zeigen eine gewisse Aehnlichkeit mit $\mathrm{Pr}$. ramisulcatus Nieszk. ${ }^{2}$ ) in bezug auf den Verlauf der Seitenfurchen, indem die ersten beiden Paare schräg nach innen gewendet sind, während das dritte Paar wie bei Pr. ramisulcatus einen Ast nach hinten zur Nackenfurche sendet. Von Pr. ramisulcatus unterscheidet sich unsere Art durch einen erheblich breiteren Nackenring, auf dem die Seitenbuckel als flache längliche dreieckige Erhöhungen abgeschnürt sind. Nieszkowski giebt ausserdem für Pr. ramisulcatus einem breiten gewölbten Randsaum an, während bei meinen Stücken der Randsaum vor der Glabella nur flach aufgeworfen erscheint.

Die Oberfläche der Glabella ist dicht gekörnelt; der Randsaum zeigt neben feinen eingestochenen Pünktchen ganz schwache runzelartige Leistchen.

Maasse: Länge der Glabella $6 \mathrm{~mm}$, Breite $5 \mathrm{~mm}$.

Fundort: Nasser Garten bei Königsberg. Wehlau. Pr. Holland.

Das Gestein ist ein grobkörniger, krystalliner, graubrauner Kalk, der dem Phaseoluskalk sehr älnlich ist. Die Heimat kann das Ostseebecken zwischen Gotland und Oesel, resp. eine dieser beiden Inseln sein.

Ein mit der anf Taf. 6, Fig. 23 abgebildeten Glabella zusammen gefundenes Schwanzschild, das ich zu dieser Art stelle, ist ziemlich genau halbkreisförmig, von einem breiten flachen Randsaum umgeben. Die hochgewölbte Spindel lässt neun Glieder erkennen, während auf den Seitenteilen sieben deutliche gefurchte Pleuren zu unterscheiden sind.

1) cfr. Lindström: Förteckn. pag. 79. Taf. XV. Fig. 21.

2) cfr. Nieszkowski. Monographie pag. 46 (560) Taf. III. Fig. 1. 
Proëtus sp. Taf. VI. Fig. 25.

Die auf Taf. VI. Fig. 25 abgebildete Glabella ist ausserordentlich hoch gewölbt und zeigt auf der vollkommen glatten Oberfläche einen ähnlichen Verlauf der sehr schwach angedeuteten Seitenfurchen wie Pr. signatus; der Nackenring ist aber verhältnismässig schmäler und mit weniger grossen Seitenbuckeln verziert.

silurischem $\cdot$ Kalk.

Fundort: Belscbwitz, Westpreussen, in gelbgrauem bröckligen ober-

\section{Proëtus sp. Taf. VI. Fig. 24.}

In einem dichten graublanen Kalke, der an Chonetenkalk erinnert, fand ich das anf Taf. VI. Fig. 24 wiedergegebene Schwanzshild. Es ist gleichmässig stark gewölbt, von ungeführ halbkreisförmigem Umriss. Die wulstförmige Spindel nimmt etwa ein Drittel der ganzen Schildbreite ein und zeigt acht deutlich abgesetzte Ringel. Die gleichmässig abfallenden Seitenteile haben sieben längsgefurchte Pleuren, welche fast bis zum Rande des Schildes gehen. Der Rand ist glatt, ohne einen deutlichen Saum. Länge $8 \mathrm{~mm}$, Breite $10 \mathrm{~mm}$.

Fundort: Nasser Garten bei Königsberg.

Gattung Cyphaspis Burmeister. Barrande (z. T.)

[Gonipleura-Angelin.]

Cyphaspis parvula. n. sp. Taf. VI. Fig. 28. 28a.

In einem hellgrauen, foinkörnigen Kalk fand ich mehrere kleine Glabellen und freie Wangen einer Cyphaspisart, welche ich mit keinem der beliunten Vertreter dieser Gattung identifizieren konnte. Die Glabella ist kurz, nach voru stark verjüngt, kräftig gewölbt. Die wenig nach hinten konvergierenden tiefen dritten Seitenfurchen schneiden jederseits längliche Lappen ron der Glabella ab, welche etwas niedriger gewölbt sind als die Glabella selbst. Vor der Glabella fällt das Kopfschild schräge nach vorn zu dem gewulsteten breiten Randsaum ab. Die Entfernung der Glabella vom Randsaum ist etwa gleich der Breite des Saumes. ${ }^{1}$ ) Die Oberfläche der Glabella erscheint fast ganz glatt,") der Randsaum ist fein gestreift. Die erhaltenen freien Wangen sind kräftig gewölbt, in ziemlich lange, spitze Wangenstachel ausgezogen. Die Hinter- und Seitenrandfurche sind sehr tief und stossen in einem Winkel ron ungefähr $45^{0}$ zusammen, die entsprechenden Randsäume sind stark gewulstet. Der Saum des Seitenrandes ist parallel gestreift. Dio Angen sind sehr gross, kugelig anfgeblasen, am Grunde von einer tiefen Furche umgeben.

Maasse: Glabellalänge 3,5 mm, -breite 2,5 $\mathrm{mm}$.

Höhe der Wangen (Entfermung des oberen Augenrandes vom Seitenrande) $4 \mathrm{~mm}$.

Fundort: Königsberg, in hellgrauem, an Phaseoluskalk erinnernden, Kalk-

stein. Weder aus Schweden noch aus Estland ist mir eine ähnliche Art bekannt.

1) Bei der von Nieszkowski aus Estland beschriebenen Art Cy. megalops M'Coy ist diese

Entfernung dreimal so breit als der Randsanm [cf. Nieszkowski: Monographie pag. 50 (5/ $(j)$ )].

2) Bei der einzigen schwedischen Art, C. elegantula Angelin (Pa]. Scand. pay. 23. Taf. XVII. Fig. 7) ist die Oberfliche deutlich gekörnelt. 
Dem Gestein nach dürfte als Heimat das Ostseebecken zwischen Gotland und Oesel anzumehmen sein $\left.{ }^{1}\right)$ vielleicht auch eine dieser beiden Inseln selbst.

\section{Cyphaspis sp. Taf. VI. Fig. 29.}

In graugrünem Graptolithengestein fand sich neben Acidaspis mutica Emmr. das auf Taf. VI. Fig. 29 in dreifacher Vergrösserung wiedergegebene Schwanzschild. Es ist kräftig gewölbt mit hoher siebengliedriger Spindel. Auf den Seitenteilen sind fünf Pleuren vorhanden, welche durch eine Längsfurche in ein vorderes breites und ein schmäleres hinteres Band geteilt werden, und deutlich bis zum Rande gehen. Die Oberfläche ist dicht mit spitzigen Höokerchen besetzt.

Fundort: Pr. Holland. Als Heinat ist das Ostseegebiet zwischen Schweden und Estland anzunehmen.

Inı Anschluss an die Gattungen Proëtus Stein. und Cyphaspis Burm. gebe ich noch eine Charakteristik der im Gotländischen Silur vertretenen Gattung:

\section{Phaëtonides Barrande,}

welche don Uebergang von Proëtus zu Cyphaspis bildet. Unten dem Namen Phaëton fasste Barrande die Formen seiner Proëtidengruppe G. zusammen, deren Schwanzschild mit spitzigen Seitenzähnen verziert ist, und zählte dazu die Formen Pr. Archiaci planicanda und striatus. $\left.{ }^{2}\right)$ Diese Arten sind zugleich dadurch ausgezeichnet, dass die dritten Seitenfurchen, abweichend von denen der ächten Proëtiden, tiefer ausgebildet und stärker nach hinten gewendet sind, und, älnnlich wio bei der Gatturng Cyphaspis, die dritten Seitenlappen fast vollständig von der Glabella abschnüren. Dieselbe Eigentümlichkeit der Glabella weisen auch noch die Barrandeschen Arten Proëtus decorus und Astynax ${ }^{3}$ ) auf, deren Schwanzschild aber nicht gezihnt, sonderm ganzrandig ist.

Angelin ${ }^{4}$ ) stellt aus diesen fünf ebengenannten Arten zusammen mit Phaëtonides Stokesi Murch. die Gattung Phaëtonides Barr. auf und giebt als besonderes Merkmal an: „Frons ovata....... utrinque lobo 1 basali distincto, lineisque 2 obsoletis abbreviatis impressis." Nehmen wir diese Diagnose Angelins als Gattungsmerkmal für Phaëtonides an, so sind nicht nur die oben genannten Arten Barrandes und Angelins zu Phaëtonides zu zählen, sondern auch Cyphaspis novella Barrande ${ }^{5}$ ) und Cyphaspis punctillosa Lindstr., ${ }^{6}$ ) welche beiden Arten je drei Seitenfurchen auf der Glabella tragen, während bei allen anderen Cyphaspisarten nur allein die dritten Seitenfurchen ausgebildet sind. Bei näherer Betrachtung erscheint auch die Stellung der Augen dieser Arten als eine andere wie bei den echten Cyphaspiden.

1) cf. Nötling: Die Cambr. u. Silur. Geschiebe der Provinzen Ost- und Westpr. Jahrb. d. K. Pr. geol. Landesanstalt 1882, pag. 297.

2) cf. Barrande: Syst. sil. Vol. I, pag. 471 ff. Taf. XVII. Fig. 24-31 und 42-49.

3) cf. Barrande: 1. c. pag. 468, Taf. XVII. Fig. 13-21 und pag. 470, Taf. XVII. I'ig. 22, 23.

4) cf. Angelin: Pal. Scand pag. 21.

5) cf. Barrande 1. c. pag. 491. Taf. XVII. Fig. 59, 60.

6) cf. Lindström: Förteckning pả Gotl. Sil. Crust, pag. 77. 
Während nämlich bei letzteren die Augen immer ungefahr in der Mitte der Wangen liegen, rücken sie bei den zn Phaëtonides zu stellenden Arten ganz nahe an die Glabella heran, so dass hieidurch eine Annäherung an die Gattung Proëtus erzielt wird.

Möglicher Weise gehört anch Cyphaspis depressa Barr. ${ }^{1}$ ) zu Phaëtonides. wofur die Stellung der Angen dicht an der Glabella spricht. Allerdings hat Barrande nur bei einigen Exemplaren von Cy. depressa Andentungen der zweiten Seitenfurchenpare gefunden, während die ersten stets fehlen und meistens nur die dritten in der für die Gattung Cyphaspis eigentümlichen Form auftreten.

Fassen wir das vorhin Gesagte zusammen, so können wir die von Angelin gegebene Gattungscharakteristik nur bestätigen, und, vereinigen inter Phaëtonicles diejenigen zur Familie der Proëtiden gehörenden Trilobiten, ,deren Glabella drei Paare von Seitenfurchen zeigt, deren dritte Seitenfurchen die hintersten Seitenlappen. winlich wie bei Cyphaspis in Form länglicher Erhöhungen von der Glabella abschnüren, und deren Augen nahe an der Glabella liegen. Als minderwertiges Merlimal kommt dann noch hinzu, dass der Rand des Schwanzschildes glatit nder gezälint ist."

Aus unseren Geschieben liegt mir nur eine kleine Glabella aus Beyrichienkalk vor, die das für Phaetonides eigentümliche Gattungsmerkmal zeigt, ohne dass sie darauf hin näher zu bestimmen wäre. Der Fundort ist Cranz in Ostpreussen.

\section{Fam.: Illaenidae.}

\section{Gattung: Illaenus Dalman.}

\section{Untergattung: Illaenus s. str.}

A. Augentragende.

Illaenus jevensis Holm. Taf. III. Fig. 1. 1a.2.3.

1856. Illaenus jevensis Holm. in Fr. Schmidt: Rev. III. Illaeniden pag. 57. Taf. X. Fig. 1-7.

Mehrere Bruchstücke von Kopfschildern nud einzelne Schwanzschilder dieser Art lagen mir in Steinkernen ror.

Der Kopf ist breit, von halbelliptischem Umriss. Die Wölbung in der Längsrichtung bildet einen gleichmässigen kräftigen Bogen. Der Vorderrand ist abgerundet. Die breite flache Glabella bildet mit den festen und freien Wangen ${ }^{2}$ ) eine gleichmässige Wölbung. Die auf dem Steinkerne scharf eingedrückten Rückenfurchen erreichen etwas über ein Drittel der Länge des Kopfes (nach der Wülbung gemessen); sie convergieren, aber nur wenig, bis etwa zum Vorderende des Augendeckels mnd gehen dann ein wenig auseinander. Die Augen sind gross, etwa dreiviertel ihrer eigenen Länge vom Hinterrande und etwas mehr als die halbe Glabellabreite von den Rückenfurchen entfernt. Die Gesichtsnaht ist hinter lem Auge beinahe ganz. gerade und ganz wenig nach anssen gerichtet. Die freien Wangen sind nach $\mathrm{Holm}^{3}$ )

1) cf. Barrande 1. c. pag. 492. Taf. XVI, Fig. 38-40.

2) Holm: 1. c. pag. $5 \overline{\mathbf{t}}$.

3) Holm: Illaeniden pag. 58. 
flach gewölbt, nach vorn etwas verschmälert, mit geradem Ausseurande und fast rechtwinkliger Hinterecke.

Der Leib ist zehngliederig. ${ }^{1}$ )

Das Schwanzschild ist etwa $1^{1} / \mathrm{mal}$ so breit als lang, sein Umriss bildet einen Abschnitt einer kurzen Ellipse. Es ist wie das Kopfschild ganz gleichmässig gewölbt. Die Spindel ist breit (über ein Drittel der ganzen Schildbreite), stark gewölbt, und nur in ihrem vorderen Teile deutlich durch die stark convergierenden Rückenfurchen begrenzt. Die Gelenkfläche ist gross, stark nach unten gebogen, ihr Hinterrand etwa doppelt so gross als der Abstand des Knies von der Spindel. Die Furche hinter dem Knie ist breit und tief. Auf den Seitenteilen sind ganz schwache Andeutungen von Rippen zu bemerken. Der etwas gehöhlte Umschlag nimmt nach hinten an Breite zu; in seiner Mittellinie läuft eine schwache Furche, und sein Vorderrand bildet hier einen stumpfwinklig-zungenförmigen Vorsprung, der etwa bis zur Mitte des Schwanzschildes reicht ('Taf. III. Fig. 3).

Die Schale ist glatt. Am Vorderrande des Kopfes und auf dem Umschlage des Schwanzschildes treten Terrassenlinien auf.

Maasse: Kopfschild: Länge (Projection) $19 \mathrm{~mm}$, Breite $32 \mathrm{~mm}$ (des Mittelschildes), Glabella: grösste Breite: $21 \mathrm{~mm}$, geringste Broite: 17,5 mm, Augendeckellänge $6,5 \mathrm{~mm}$.

Schwauzschild: Länge $26 \mathrm{~mm}$, Breite $35 \mathrm{~mm}$, Spindelbreite $13 \mathrm{~mm}$.

$$
" 25 " \quad, \quad 33 \quad \text { " } " 12,
$$

Fundorte: Umgegend von Königsberg.

Illaenus jevensis Holm gehört der Jeweschen Schicht an und ist bisher in anstehendem Gestein nur in Estland gefunden.

Illaenus Chiron Holm. Taf. III. Fig. 4. 4 a. 5.

1848. Illaenus crassicauda Burmoister: „Nene Beobacht. über Trilob." in D'Alton u. Burm. Zeitschr. f. Zool, etc. Bd. I. Heft 10. pag. 79. Taf. I. Fig. 18. 1874. Illaenus centaurus Steinhardt. Preuss. Trilobiten pag. 47. Taf. IV. Fig. 4-6. Taf. V. Fig. $10 \mathrm{a}-\mathrm{d}_{0}^{2}$ )

1883. Illaenus Chiron Holm. Svenska Arterna. pag. 88. Taf. III. Fig. 1-17.

1884. Illaenus Chiron Kiesow. Sil. u. Devon. Geschiebe Westpr. pag. 83.

1886. Illaenus Chiron Holm in Fr. Schmidt. Revision III. Illaeniden pag. 64. Taf. XII. Fig. 13, a. b.

Der kurze, stark nach unten gebogene Kopf zeichnet sich durch folgende Merkmale aus: Die Glabella ist durch kurze tief einschneidende Rückenfurchen begrenzt. Sie übertrifft an Höhe die von den Rückenfurchen stark aufsteigenden festen Wangen un einige Millimeter. Auf dem vorderen Teile der Glabella machen sich namentlich auf dem Steinkern - zwei ziemlich weit nach vorn gehende parallele ganz flache Furchen bemerkbar. Die grossen Augendeckplatten ragen weit aus dem

1) Holm: Illaeniden pag. 58.

2) Die, Tafel V. Fig. 10 a und b, von Steinhardt binzugezeichneten Wangen sind falsch, sio gehören nach Holm (Schmidt: Revision III. pag. 64) einer Megalaspisart an. 
Mittelschilde herror; von denselben geht schräg nach innen und vorn je ein grober Wulst, der zugleich die stärkste Wölbung der festen Wangen in der Längsrichtung angiebt. Der Vorder- und Aussenrand des Kopfschildes bilden einen gleichmässigen flachen Bogen. Der Vorderrand ist mit einer groben Falzlinie versehen.

Die freien Wangen sind nach $\mathrm{Holm}^{1}$ ) stark nach unten gebogen gewölbt, etwa. ron Trapezform, mit kurz abgerundeter Hinterecke.

Der Leib besteht aus 10 Segmenten.")

Das Schwanzschild ist etwas über einen Halbkreis vorgezogen (Länge zu Breite etwa $=2: 3$ ). Bei den meisten Stücken ist die Wölbung nach dem Rande zu gleichmässig, seltener findet sich die Neigung zur Bildung eines Randsaumes mit breiter Randfurche. Holm ${ }^{3}$ ) sieht in dieser verschiedenen Ausbildung des Schwanzschildes örtliche Unterschiede, indem Stücke ohne Randsaum nur Schweden, solche mii Randsaum dem russischen Silur angehören sollen. Die Spindel ist ziemlich lang, bei Stücken mit Schale selten bis zur Spitze dentlich ausgebildet. Die Grelenkfläche ist gross und breit, stark nach unten gebogen, ihr Hinterrand ist grösser als der Abstand von der Spindel bis zum Kniee. Die Furche binter der Gelenkfläche ist breit und tief.

Die Schalenverzierung dieser Art ist sehr charakteristisch: Die sehr dicke Schale ist sowohl auf dem ganzen Kopf- als Schwanzschilde mit groben Terrassenlinien verziert, zwischen denen ziemlich dichtgestellte grobe Punkte eingestochen sind.

Illaenus Chiron ist sowohl in Ost- als Westpreussen ziemlich häufig gefunden. Die Heimat der meisten Stüche scheint mir Schweden zu sein, da Schwanzschilder: mit der Neigung zur Bildung eines Randsaumes recht selten sind.

Illaenus Chiron gehört Geschieben vom Alter des eigentlichen Echinosphaeritenkalkes $\mathrm{C}_{1}$ an.

lilaenus tauricornis Kutorga. 'Taf. III. Fig. 8.9.10. 11.

1860. Illaenus comutus Eichwald. Lethaea rossica pag. 1480. Taf. LUI. Fig. 7.

1874. Illaenus tauricorius Kutorga in Steinhardt. Preuss. Trilob. pag. 51. Taf. VI. Fig. $2 a-c$.

1874. Illaenus Eichwaldi Steinhardt. Preuss. Trilobiten. pag. 49. Taf. IV. Fig. 7a-d. 1886. Illaenus tauricornis Holm in Fr. Schmidt. Revision III. Illaeniden. pag. 74. Tat. VI. Fig. 1-11.

Diese sehr charakteristische Art liegt mir in mehreren Bruchstücken mit zum Teil wohl erhaltener Schale vor.

Der Kopf ist mehr als zweimal so breit als lang, in der Längsrichtung sehr stark gewölbt, in seinem vorderen Teile gerade zum Vorderrande abfallend. Der Vorderrand ist abgertundet, doch ziemlich scharf. Die stärkste Wölbung des Kopfschildes ljegt zwischen den Augen. Die Rückenfurchen sind sehr tief und stark eingedrückt, sie gehen etwa bis zur halben Länge des Kopfschildes. Die Glabella ist.

1) cf. Holm: Svenska Arterna pag. 92. Taf. III. Fig. 10.

2) cf. Holm: Srenska Arterna pag. 92. Taf. III. Fig. 1.

3) Holm: Ilaeniden (Fr. Schmidt. Revision III) pag. 66. 
meistens hochgewölbt und zwischen den Augen sehr stark eingeschnürt, nach vorn und hinten erweitert sie sich fast gleichmässig. Die festen Wangen steigen von den Rückenfurchen hoch auf, so dass die Augendeckel die Höhe der Glabella noch bedeutend überragen. Zum Hinterrande fallen die festen Wangen steil ab. Die Augendeckel sind gross, mehr als einen Halbkreis bildend, kräftig gewölbt, und liegen weit nach hinten; ihr Abstand von den Rückenfurchen beträgt $1 / 2-2 / 3$ der Glabellabreite und mehr. Die Gesichtsnähte sind hinter dem Ange stark nach aussen gerichtet, vor den Augen divergieren sie in schwach Sförmigen Bogen nach vorne.

Die freien Wangen fallen steil ab. Die Hinterecken sind in lange, drehrande, nach aussen gerichtete, geschwungene Hörner ausgezogen. Die freie Wange erhält dadurch die Form eines Dreiecks mit dem Aussenrande als längste Seite. Die Sehfläche der Augen ist schmal, bandartig, am Grunde von einer tiefen Furche becrenzt. Der Aussenrand der freien Wangen neigt zur Gratbildung.

Das Schnauzenschild auf dem fast flachen Umschlage ist gross, bis dreimal so breit als lang.

Der Rumpf besteht aus zehn Ringeln, deren Spindel nicht sehr hoch gewölbt ist. Das Schwanzschild ist gerundet dreieckig bis parabolisch, der mittlere Teil ist flach, die Ränder sind ziemlich stark nach unten gebogen. Die Spindel ist kurz, bis zur Spitze deutlich durch die Rückenfurchen begrenzt. Hinter der Spindel ist oft rer Ansatz eines schwachen Kieles vorhandeu. Der Hinterrand der Gelenkfläche ist kleiner als der Abstand des Kniees von der Spindel. Der Umschlag nimmt nach hinten stark an Breite zu und zoigt in der Mittellinie eine ziemlich tiefe Furche. Schalenverzierung: Ueberall treten Terrassenlinien auf, die namentlich auf dem vorderen Teile des Kopfschildes sehr dicht und grob sind. Ausserdem ist das ganze Kopfschild mit Ausnahme der nächsten Umgebung der Rückenfurchen mit sehr groben dichtgestellten eingestochenen Punkten bedecht. Die Schale des Schwanzschildes zeigt wenige T'errassenlinien, die quer über das ganze Schild hinübergehen.

Maasse: Kopf: Länge (Projektion) $19 \mathrm{~mm}$, Breite ca. $65 \mathrm{~mm}$, Höhe $20 \mathrm{~mm}$. Höhe der Augendeckel über der Glabella 3,5 mm. Glabellenbreite: hinten $17 \mathrm{~mm}$, zwischen den Augen $13 \mathrm{~mm}$, Abstand der Augen von den Rückenfurchen $9 \mathrm{~mm}$, vom Hinterrande 2-3 mm. - Schwanzschild: Länge $23 \mathrm{~mm}$, Breite $42 \mathrm{~mm}$, Spindelbreite $13 \mathrm{~mm}$, Abstand vom Knie bis zur Spindel $9 \mathrm{~mm}$, Hinterrand der Gelenkfäch $6,5 \mathrm{~mm}$.

Illaenus tauricornis Kut. kommt im unteren Echinosphaeritenkalk mit Thoneisensteinlinsen - $\mathrm{C}_{1} \mathrm{a}-$ vor. Die Heimat unserer ost- und westpreussischen Stücke ist Estland.

Der von Steinhardt $t^{1}$ ) beschriebene Illaenus Eichwaldi ist ganz unzweifelhaft ein Illaenus tauricornis von etwas längerer Kopfform. Die anderen für Ill. tauricornis angregebenen Merkmale treffen vollständig für das Steinhardtsche Original (ebenfalls aus dem unteren Echinosphaeritenkalk) zu.

1) cf. Steinhardt: Pr. Trilobiten pag. 49. Taf. IV. Fig. 7. 
Illaenus revaliensis Holm. Taf. III. Fig. 14. 15. 15a.

1874. Illaents Wahlenbergi Eichwald in Steinhardt: Prenss. Tril, pag. 45. Taf. III. Fig. $11 \mathrm{a}-\mathrm{d}$.

1856. Illaenus revaliensis Holm. in Fr. Schmidt: Rev. III. Illaeniden pag. 87. Taf. II. Fig. 1-9.

Der Kopf ist stark gewölbt, die Glabella in der Mittellinie schwach gekielt und hoch über die stark nach aussen abfallenden festen Wangen gewölbt. Die Riickenfurchen sind lang, zuerst schwach konvergierend, um dann etwa vom Vorderende des. Augendeckels ab, ebenso zu divergieren. Die Augendeckel sind mässig gross und stehen etwa um die Hälfte ihrer Länge vom Hinterrande ab, ihr Abstand von den Rückenfurchen kommt ungefähr der halben Glabellabreite gleich. Die Gesichtsnaht hinter dem Auge ist fast gerade nach hinten gerichtet. Eine schlecht erhaltene freie Wange war flach gewölbt, länger als hoch, mit ausgeschweiftem Hinter- und Aussenrande und kurz gerundeter Hinterecke.

Der Leib ist zehngliedrig mit hochgewölbter Spindel, die etwa eineinhalb mal so breit ist, als die Seitenteile. Die Pleuren sind scharf gekniet, ihr äusserer T'eil ist bedentend breiter, als der innere.

Das Schwanzschild ist flach gewölbt, lang, von halbelliptischem Umriss. Die Spindel nimmt vorne ein Drittel der Schildbreite ein, sie ist stark gewölbt, und fast bis zur Spitze durch die stark convergierenden Rückenfurchen deutlich begrenzt. Hinter der Spindel ist ein flacher Längskiel zu unterscheiden. Die Gelenkfläche ist. schwach nach unten gebogen, ihr Hinterrand wenig grösser als der Abstand vom Knie bis zur Spindel. Der Umschlag nimmt nach linten an Breite zu, läuft hier in eine stumpfwinklige Spitze ans und trägt eine schmale Mittelfurche. Die Schalenverzierung besteht ausser sehr foinen, dichten, eingestochenen Punkten, aus feinen wellenförmigen Terassenlinien, die namentlich am Vorderteile des Kopfschildes, auf dem Kopfumschlage und dem Schnauzenschilde deutlicher sind. Die Leibesspindel uud die äusseren Pleurenteile zeigen ebenfalls kräftigere Terassenlinien. Auf dem Schwanzschilde sind die Terassenlinien sehr fein und dicht gestellit; sie sind dem Aussenrande parallel angeordnet, jedoch so, dass die spindel mit ihrer nächsten Umgebung von ihnen freibleibt. (Die Figur 14 zeigt sie zu grob.)

Maasse: Kopf: Länge $28 \mathrm{~mm}$, Breite des Mittelschildes $30 \mathrm{~mm}$, Glabellabreite (hinten) $17 \mathrm{~mm}$. Schwanzschild: Länge $24 \mathrm{~mm}$, Breite $36 \mathrm{~mm}$, Spindelbreite 9,5 mm.

Ill. revaliensis gehört nach $\mathrm{Holm}^{1}$ ) dem Vaginatenkalke $\mathrm{B}_{3}$ an, und ist in anstehendem Gestein bisher nur in Estland gefunden. In Ostpreussen ist diese Art bei Königsberg und Pr. Holland in schmutzig graugrünem Gestein mit kleinen Thoneisensteinlinsen gefunden worden.

Illaenus Schmidti Nieszkowski. Taf. III. Fig. 6.7.

1857. Illaenus Schmidti Nieszkowski: Monographie d. Trilob. pag. 580. Taf. I. Fig. 10. 11. 12.

1857. Illaenus centrotus Nieszkowski: ibid. pag. 582.

1) cf. Holm in Fr. Schmidt Rev. III. pag. 92. 
1960. Mllaenus Parkinsoni Eichwald: Lethaea rossica pag. 147S. Taf. LIV. Fig. 2a-b. 1560. Illaenus Davisi Eichw.: ibidem pag. 1479.

1874. Illaenus Schmidti Nieszkowski in Steinhardt: Pr. Trilobiten. pag. 46. Taf. II. Fig. $1 \mathrm{a}-\mathrm{e}$. Taf. III. Fig. 13.

1883. Illaenus capricornis. Holm: Svenska arterna pag. 96.

1886. Mllaenus Schmidti Holm in Fr. Schmidt: Rev. III. Illaeniden pag. 107. Taf. V.

Mir lagen nur Bruchstücke von Kopf- und Schwanzschildern in Kernversteinerungen vor. Das einzige vollständige ostpreussische Geschiebeexemplar, das Steinhardt in seiner Arbeit Taf. VI. Fig. $1 \mathrm{a}-\mathrm{e}$ abbildet, gehört der Sammlung des Herrn Mascke in Göttingen an, und ist mir leider nicht zugänglich gewesen.

In der Beschreibung dieser Art nehme ich daher zum Teil Rüchsicht auf die betreffenden Steinhardtschen Abbildungen.

Der stark gewölbte Kopf ist von parabolischem Umriss. Die Ruckenfurchen sind tief, sie convergieren fast in ihrer ganzen Länge und erreichen ein Drittel der Länge des Kopfes. Die Glabella ist schwach gewölbt. Die festen Wangen fallen nach vorn, hinten und aussen gleichmässig ab. Die sehr grossen stark aus dem Mittelschilde hervorragenden Augendeckel stehen nahe am Hinterrande, ein Viertel bis ein Trittel ihrer eigenen Länge von diesem entfernt; der Abstand der Augen von den Rückenfurchen beträgt etwa ein Drittel der Glabellabreite. Die Gesichtsnähte hinter den Augen sind ziemlich stark nach aussen gerichtet. Die Form der freien Wangen wechselt stark, da die Hinterecken kurz gerundet, bis in kurze spitzige Ecken ausgezogen sein können.

Der Leib besteht aus 10 Ringeln. ${ }^{1}$ ) Die hochgewölbte Spindel verschmälert sich nach hinten zu recht stark. Der äussere Pleurenteil ist erheblich breiter als der innere.

Das Schwanzschild ist parabolisch (Länge zu Breite etwa $=3: 5$ ), schwach gewölbt. Die Spindel ist kurz, hinter ihr liegt in der Längsrichtung bei unseren Geschiebeexemplaren fast stets ein ziemlich deutlicher Kiel. Der Hinterrand der nicht sehr grossen Gelenkfläche ist ungefähr gleich der Entfernung von der Spindel bis zum Knie.

Die Oberfläche, namentlich am Kopfschilde ist mit dichtgestellten eingestochenen Punkten besetzt. Am Vorderrande des Kopfschildes kommen einige grobe Terrassenlinien vor. Die Glabella trägt nahe dem Hinterrande ein kleines spitziges Höckerchen.

Maasse: Kopf: Länge $40 \mathrm{~mm}$, Breite vorn $46 \mathrm{~mm}$, zwischen den Augen $50 \mathrm{~mm}$. Glabellabreite hinten $25 \mathrm{~mm}$, zwischen den Augen 20,5 mm. Schwanzschild: Länge $25 \mathrm{~mm}$, Breite $44 \mathrm{~mm}$. Spindelbreite $15 \mathrm{~mm}$.

III. Schmidti ist in Ost- und Westpreussen in Geschieben vom Alter des oberen Echinosphaeritenkalkes - $\mathrm{C}_{11}$. - aus Estland gefunden worden.

Illaenus oblongatus Angelin. Taf. I. Fig. 39 (37a.b?)

1504 (1572) Rhodope? oblongata Angelin: Pal. Scand. jag. 41. Tat. XXIV. Fig. 3.3a. 18sti Illaenus oblongatus Holm in Fr. Schmirt: Rev. III. Illaeniden jag. 116. Taf. VIII. Fig. 1-13.

1) cf. Steinhardt: 1. c. pag. 46. Taf. VI. Fig. I. 
Mit Sicherheit kann ich dieser Art nur einige kleinere Schwanzschilder zuzählen, die mit Illaenus tauricornis Kut. zusammen im Linsengestein des Echinospaeritenkalkes gefunden sind.

Das Schwanzschild ist langgestreckt, halbelliptisch, flach gowölbt. Dio Spindel ist kegelförmig, bis zur Spitze deutlich begrenzt; sio ist kräftig gewölbt und nimmt ein Drittel der vorderen Schildbreite ein. Der Umschlag ist nach hinten sehr stark verbreitert, ganzrandig; eine flache aber deutliche Mittelfurche und eine herzförmige flache Einsenkung habe ich bei mehreren Stücken beobachten können (vergl. IIl. oblongatus forma excellens Holm: Rev. III. pag. 119).

Sowohl in Ost- als Westpreussen gefunden. Heimat: Estland.

Ob das Kopfschild - Taf. II Fig. 37a.b.c. - zu dieser Art gehört, kann ich nicht mit Sicherheit feststellen. Es ist stark gewölbt, wie die von Holm erwähnten estnischen Stücke, doch ist die Glabella bei dem vorliegenden Stücke schmäler, und die Gesichtsnaht hinter dem Auge etwas stärker nach aussen gerichtet, als bei den typischen Stücken Holms. Das Gestein des eben angeführten Kopfschildes ist ein harter, heller, dichter Kalk aus Ostpreussen.

lllaenus angustifrons Holm. Taf. III. Fig. 12. 12a.

(Forma typica Holm.)

1861. Illaenus crassicauda. F. Roemer: Sadewitz. Diluv. Gesch. pag. 70. Taf. VIII. Fig. 3. 1886. Illaenus angustifrons Holm. - Forma typica - Holm in Fr. Schmidt: Rev. III. pag. 131. Taf. IX. Fig. 1-3.

Der Kopf ist schwach gewölbt. Soin Umriss ist nach dem vorliegenden Mittelschilde stumpf, halboval. Die Glabella ist hoch gewölbt und zwischen den Augen stark eingeschnürt. Die scharfen Rückenfurchen erreichen die halbe Länge des Kopfschildes; an der Einschnürungsstolle der Glabella bilden sie ein Knie in Form eines stumpfen Winkels und sind hier besonders tief. Die festen Wangen fallen nach hinten und aussen ziemlich kräftig ab; hinter den Augen sind sie sehr schmal, da hier die Rückenfurchen stark nach aussen gerichtet sind. Die Augendeckel sind etwa doppelt so lang als der Abstand der Augen vom Hinterrande. Die Entfernung der Augen von den Rückenfurchen kommt der halben Breite der Glabella zwischen den Augen gleich. Die Gesichtsnähte sind hinter den Augen gerade, nach aussen gerichtet, vor den Augen sind sie stark Sförmig gebogen. Dio freien Wangen sind nach $\mathrm{Holm}^{1}$ ) lang, nach vorn stark verschmälert, mit abgerundeter scharfer Hinterecke.

Der Leib besteht aus 10 Gliedern. $^{\mathbf{1}}$ )

Der vordere Teil des Kopfes ist mit langen, dichton, feinen Terrassenlinien verziert, zwischen die feine, nur durch die Lupe sichtbare Pünktchen eingestochen sind.

Maasse des Kopfes: Länge $21 \mathrm{~mm}$. Breite des Mittelschildes $23 \mathrm{~mm}$. Glabellabreite: hinten $15 \mathrm{~mm}$, zwischen den Augen $11 \mathrm{~mm}$.

Die Stammform des Ill. angustifrons gehört der Lyckholmer Schicht Estlands an. Die Heimat unseres in Ostpreussen gefundenen Exemplars (Taf. III. Fig. 12) ist also Estland.

1) u. 2) cf. Holm in Fr. Schmidt: Rev. III. Illaeniden pag. 181. 
Illaenus Roemeri Volb. Taf. III. Fig. 16.

1861. Illaenus grandis Römer: Sadew. Dil. Geschiebe. pag. 69. Taf. VIII. Fig. 4. 1864. Mllaenus Roemeri Volborth: Neue estl. Illaenen. pag. 7. Taf. II. Fig. 12-15. 1874. Illaenus crassicauda var. Steinhardt: Preuss. Trilobiten, pag. 43 (z。 T.) Taf. III. Fig. 14.

1883. Illaenus vivax Holm: Svenska Arterna pag. 74. Taf. VI. Fig. 1-7.

1886. Illaenus Römeri Holm, in Fr. Schmidt. Rev. III. Illaeniden. pag. 125. Taf. IX. Fig. 4-14.

Das von Steinhardt - Taf. III. Fig. 14a, b, c. - als Illaenus crassicauda var. abgebildete Schwanzschild muss ich seiner äusseren Gestalt und der Form seines Umschlages wegen zu Ill. Roemeri zählen.

Das Schwanzschild ist beinahe halbkreisförnig, gleichmässig, nicht zu starkgewölbt. Die breite Spindel ist fast bis zur Spitze deutlich durch die flachen stark convergierenden Rückenfurchen begrenzt. Die Spindelbreite beträgt am Vorderrande über $1 / 3$ der ganzen Schildbreite. Die Gelenkfläche ist sanft nach unten gebogen, ihr Hinterrand weniger als doppelt so gross wie der Abstand vom Knie bis zur Spindel. Die Furche hinter dem Knie ist breit. Besonders charakteristisch für IIl. Roemeri ist der schmale, stark rinnenförmige Umschlag, der nach hinten an Breite nicht zunimmt.

Maasse: Länge $31 \mathrm{~mm}$, Breite $43 \mathrm{~mm}$, vordere Spindelbreite $18 \mathrm{~mm}$.

Ill. Roemeri ist nahe verwandt mit dem Ill. jevensis Holm. von dem er sich namentlich durch eine breitere Glabella, grösseren Abstand der Augen vom Hinterrande und durch den nach hintenzu nicht verbreiterten Umschlag des Schwanzschildes unterscheidet.

Ill. Roemeri kommt in der Lyckholmer Zone Estlands und im Leptaenakalk Schwedens vor. Das mir vorliegende Schwanzschild befindet sich in einem harten, feinkörnigen graue Kalke aus Ostpreussen.

Illaenus comes. n. sp. Taf. III. Fig. 19.

Zusammen mit Illaenus jevensis wurden in einem Geschiebe bei Spittelpark (Königsberg) mehrere kleine Kopfmittelschilder und Schwanzschilder gefunden, die dem Ill. jevensis sehr nahe verwandt scheinen.

Das Kopfschild ist in allen Richtungen gleichmässig und kräftig gewölbt. Die Augen stehen näher am Hinterrande als bei Ill. jevensis, und die Gesichtsnähte hinter denselben sind stïrker nach aussen gerichtet als bei dieser Art. Die Glabella trägt einen schwachen aber deutlichen Kiel.

Das Schwanzschild, wenig kleiner als der Kopf, stimmt in seiner Form und im Verhältnis seiner Maasse vollkommen mit dem von Illaenus jevensis überein, doch scheinen mir die Andeutungen der Rippen auf den Seitenteilen (bis je 3 an der Zahl) bei Illaenus comes kräftiger zu sein.

Maasse des Kopfes: Länge 9,5 m. Breite des Mittelschildes: ca. $11 \mathrm{~mm}$. Breite der Glabella an Hinterrande: $6 \mathrm{~mm}$. 
Da IIl. comes mit Ill. jevensis zusammen gefunden worden ist, gehört er der Jeweschen Schicht an; seine Heimat müsste in Estland oder in benachbarten Gebieten zu suchen sein.

Illaenus Vanhoeffeni. n. sp. Taf. III. Fig. 17. 17 a.

Mehrere kleine Kopfmittelschilder aus der Sammlung des Herrn Dr. Vanhoeffen (Wehlau) zeigten eine von allen anderen Illaeniden abweichende Ausbildung, durch die ich zur Aufstellung einer nenen Art veranlasst wurde. - Der Kopf ist ziemlich langgestreckt, in soinem hinteren Teile flach, vorn stark gewölbt, und zwar so, dass der Vorderrand des Kopfmittelschildes unten ziemlich weit nach hinten zurückgeschlagen ist. Die Glabella bildet mit den festen Wangen einen gleichmässigen flachen Bogen; sie verschmälert sich nach vorne ziemlich stark. Die scharfen rinnenförmigen Rückenfurchen convergieren etwa bis zum Vorderende des Augendeckels und biegen dann plötzlich noch eine ganz kurze Strecke nach aussen um. Die Augendeckel bilden lange flache Bogen, sie ragen wenig vom Mittelschilde vor und liegen ziemlich nahe am Hinterrande; ihr Abstand von den Rückenfurchen ist etwa $=3 / 4$ der Glabellabreite. Die Gesichtsnaht hinter dem Auge ist schwach nach aussen gerichtet.

Maasse: Länge (Projektion) $10 \mathrm{~mm}$, Breite des Mittelschildes vorn 9,5 mm, zwischen den Augen $11,5 \mathrm{~mm}$, Glabellabreite hinten $7 \mathrm{~mm}$, an der schmalsten Stelle $4,5 \mathrm{~mm}$.

Die Stücke - es lagen mir nur Mittelschilder des Kopfes vor - sind in einem dichten, feinkörnigen, graulichen Kalkstein gefunden, der dem der Jeweschen Schicht sehr ähnelt. Fundort: Wehlau, Ostpreussen.

Der stark wach unten gebogene vordere Teil des Kopfschildes, sowie die zuerst so stark convergierenden Rückenfurchen lassen auf eine Verwandtschaft des IIl. Vanhoeffeni mit Ill. angustifrons schliossen.

Illaenus bisulcatus n. sp. Taf. III. Fig. 18.

Mehrere Kopfmittelschilder zeigten eine gleiche Ausbildung, die sie deutlich von den anderen Illaeniden schied: Der Kopf ist in der Längsrichtung stark gewölbt; sein vorderer Teil ist fast gerade nach unten geboten, so dass der Kopf von oben gesehen sehr kurz erscheint. Der Vorderrand bildet einen flachen Bogen; er ist gerundet, ohne Falzlinie. Die Glabella und die festen Wangen bilden einen sehr flachen Bogen, da die Augendeckel fast die Glabellahöhe erreichen. Der vordere Teil der Glabella zeigt das der Art charakteristische Merlmal: zwei, durch einen flachen Wulst getrennte, flảche Längsfurchen, die mich bestimmten, die Art Ill. bisulcatus zu nennen. Hinter den ziemlich grossen Augendeckeln fallen die festen Wangen stark ab; die Gesichtsuähte sind hier weit nach aussen gerichtet, so dass dio festen Wangen in lange feine Spitzen auslaufen.

Maasse des Kopfes: Länge (Projection) $14 \mathrm{~mm}$, (nach der Krümmung) 22 mm. Glabellabreite: hinten $13 \mathrm{~mm}$, vorn $11 \mathrm{~mm}$, Augendeckellänge $6 \mathrm{~mm}$. Abstand des Auges vom Hinterrande $1,5 \mathrm{~mm}$, von der Rüchenfurche $7 \mathrm{~mm}$ (also mehr als die halbe Glabellabreite).

Fundorte: Wehlau, Königsberg, Westpreussen.

Das Gestein ähnelt dem Echinosphaeritenkalk Estlands. 
Illaenus sp. cf. Dalmanni Volb. (Holm). Taf. II. Fig. 36. 36a.

1874. Illaenus crassicauda form. typ. s. Dalmanni Steinhardt: Preuss. Trilobiten. pag. 42. Taf. III. Fig. 12 a b c.

(18S6. Illaenus Dalmanni Volb. in Holm: Illaeniden [Fr. Schmidt Rev. III.] pag. 93.)

Die vorliegende von Steinhardt als Illaenus crassicauda form. typ. s. Dalmanni beschriebene Art steht dem Illaenus Dalmanni Volb in Bezug auf die starke Wölbung des Kopfschildes in der Längsrichtung und die Form der freien Wangen [vergl. die Furche am Grunde der Sehfläche! - ] sehr nahe, unterscheidet sich aber von ihm durch die viel kürzeren Rückenfurchen und den grösseren Abstand der Augen vom Hinterrande.

Der Leib ist zehngliedrig: die Spindel breit, nicht sehr hochgewölbt. Das Gestein ist ein dunkelgrauer harter Kalk aus Ostpreussen.

Steinhardt giebt zu seiner Art noch die Beschreibung und Abbildung zweier Schwanzschilder. Auf das von mir - Taf. III. Fig. 24 - abgebildete Schwanzschild passt Steinhardts Beschreibung sehr gut, weniger stimmen seine Abbildungen. ${ }^{1}$ ) Das Schwanzschild ist stark gewölbt, sein Aussenrand ist fast senkrecht heruntergebogen. Die Spindel ist kurz, durch tiefe Rückenfurchen begrenzt. - Der Umschlag nimmt nach hinten stark an Breite zu, er ist rinnenförmig gehöhlt, mit einer deutlichen Mittelfurche versehen. Die Oberfläche des Schwanzschildes ist fein punktiert. Jedenfalls ist dieses Schwanzschild auch der vorliegenden Art zuzuzählen.

Es stammt ebenfalls aus Ostpreussen und liegt in einem ganz ähnlichen Gestein wie das auf Taf. III. Fig. 36 abgebildete Stück. Das Gestein ist von ähnlicher Beschaffenheit, wio einzelne dunklere Varietäten des typischen estländischen Echinosphaeritenkalkes.

\section{Illaenus Masckei Holm.}

1855. Illaenus Masclei Holm in Fr. Schmidt. Rer.III. Illaeniden p. 139. Taf. XIr. Fig.1-5.

Holm beschreibt am angef. Orte eine neue Illaenusart, von der ihm das einzige vollständige Stück aus der Mascke'schen Sammlung, die mir nicht zugänglich war, als ostpreussisches Geschiebe vorlag. Ich gebe hier einen kurzen Auszug der Holm'schen Beschreibung:

Der ganze Körper ist sehr flach, niedrig gewölbt.

Die Glabella des niedrigen Kopfes ist flach, lang. Die Rückenfurchen bilden zwischen den Augen je ein stumpfes nach innen gewendetes Knie.

Der Abstand des Auges von der Rückenfurche ist gleich der Glabellabreite.

Die Gesichtsnaht hinter dem Auge geht stark nach aussen. Die Hinterecken der freien Wangen sind spitz.

Der Leib ist 10 gliederig. Die Pleurenenden sind sensenartig zugespitzt.

Das Schwanzschild ist selr flach, halbelliptisch, von einem breiten Randsaum umgeben. Die Spindel ist flach, kurz. Der fast ganz ebene Umschlag nimmt nach hinten stark an Breite zu.

Ill. Masckei gehört der Lyckholmer Schicht Estlands an.

Taf. IIT. Fig. 1 und 3 bei Holm sind die von Mascke bei Königsberg gefundenen Geschiebeexemplare.

1) cf. Steiuhardt 1. c. Taf. V. Fig. 11. 12. 
Illaenus Linnarssoni Holm. I'af. IIT. Fig. 13. (Taf. III. Fig. 23?).

1860. Illaenus Rudolphi Eichwald: Lethaea rossica. I. 2. pag. 1482. Taf. LIII. Fig. 6a-c. 1883. Illaenus Linnarssoni Holm: Svenska Arterna: pag. 103. Taf. IV. Fig. 13-27. Taf. V. Fig. $1-8$.

1884. Mlaenus Linnarssoni Kiesow: Sil.- und Devon-Gesch. Westpr. pag. 83.

1886. Illaenus Linnarssoni Holm in Fr. Schmidt: Rev. III. Illaeniden pag. 146. Taf. X.

Fig. 14-23.

Mit Sicherheit kann ich nur den Steinkern eines Schwanzschildes aus hartem, grauem, kieseligem Kalke dieser Art zuzählen. Sein Umriss bildet den breiteren Teil einer stumpf-eiförmigen Figur. Der Aussenteil des Schwanzschildes ist stark nach unten gebogen: Dio breite Spindel ist nur au Vorderrande deutlich begrenzt, da die Rückenfurchen in ihrem weiteren Verlaufe ganz schwach sind. Der gerade Teil des Vorderrandes ist kurz, kaum $1 / 3$ der Spindelbreite und wenig über $1 / 3$ des Hinterrandes der Gelenkfläche. Der Umschlag ist schmal, in der Mittellinie zu einer kurzen Spitze ausgezogen, im übrigen schwach rinnenförmig gehöhlt, mit wenigen Terrassenlinien. Die ganze Oberfläche ist dicht mit eingestochenen Punkten verziert.

Maasse des Schwanzschildes: Länge $20 \mathrm{~mm}$. Breite $30 \mathrm{~mm}$. Spindelbreite $11,5 \mathrm{~mm}$. Länge des geraden Vorderrandes $3,5 \mathrm{~mm}$, des Hinterrandes der Gelenkfläche $9 \mathrm{~mm}$.

Fundort: Ostpreussen (Umgegend $\nabla$ on Königsberg) aus Lyckholmer Kalk. Westpreussen: aus Backsteinkalk (nach Kiesow).

Anstehend ist Ill. Linnarssoni aus Schweden, wio aus Estland bekannt. Das abgebildete Schwanzschild gehört der typischen Form, die nur in der Lyckholmer Schicht vorkommt, an; die ältere Form aus der Jeweschen Schicht hat einen nach hinten zu verbreiterten Umschlag mit 2-3 stumpfen Zähnen. ${ }^{1}$ ) Das auf Taf. III. Fig. 23 abgebildete Kopfschildbruchstück gehürt müglicherweise Ill. Linnarssoni an. Die schwach convergierenden Rückenfurchen und die nach unten ziemlich kräftig gebogenen Wangen sprechen dafür. Leider fellen die Augendeckel und der Verlauf der Gesichtsnaht, die nach Holm²) hinter dem Auge knieförmig gebogen sein soll. Auf der Glabella ist ein schwacher Längskiel zu bemerken, die Oberfläche ist mit eingestochenen Punkten bedeckt. - Fundort: Wehlau in Ostpreussen, in einem dichten roten Kalkstein von der Beschaffenheit des Wesenberger Kalkes.

Illaenus Limnarssoni Holm hat 9 Leibesringe. ${ }^{3}$ )

Illaenus nuculus n. sp. Taf. VI. Fig. 34 .

1874. Illaenus crassicauda var. Steinhardt: Preuss. Trilobiten pag. 43. Taf. IV. Fig. 3.

In einem bräunlichen, grobkörnigen, mit vielen Quarzkörnchen durchsetzten Gestein fand sich das Taf. VI. Fig. 34 abgebildete Schwanzschild. Es ist gleichmässig, kräftig gewölbt, von halbovalem Umriss. Die Spindel ist besonders hoch gewölbt, nach hinten nicht verschmälert; sie geht allmählich in die Wölbung des

1) cf. Holm: Illaeniden pag. 150. 'Taf. X. Fig. $10 \mathrm{~d}$ u. 13.

2) Holm. Illaeniden pag. 149.

3) Holm. Illaeniden pag. 150. 
Schwanzschildes über. Die Rückenfurchen sind nur vorne deutlich und tief ausgebildet. Die Gelenlfläche ist lang aber ganz schmal, ihr Hinterrand bedeutend grösser als der Abstand vom Knie zur Spindel. Hinter der Spindel liegt ein schmaler scharfer Kiel. Der Umschlag scheint nach dem Durchschimmern durch die Schale ausserordentlich breit zu sein. Die Oberfläche ist nur mit eingestochenen, sehr dicht gestellten Punkten bedeckt.

Maasse: Länge $9 \mathrm{~mm}$. Breite $15 \mathrm{~mm}$. Spindelbreite $4,5 \mathrm{~mm}$.

Fundort: Ostpreussen - ohne nähere Angabe des Ortes.

Illaenus nuculus scheint nahe verwandt mit Illaenus Bowmani Salter ${ }^{1}$ ) zu sein, von dem das Schwanzschild sich nur durch stärkere Wölbung und den feinen Kiel unterscheidet. Gehört Illaenus nuculus hierher, so haben wir in ihm vielleicht eine neungliederige Form vor uns. Die Steinhardtsche Bestimmung als Illaenus crassicauda ist irrig, da einmal bei Ill. crassicauda die Schwanzspindel sehr stark nach hinten verschmälert ist, und dann ist der Aussenteil des Schwanzschildes bei Illaenus crassicauda stark nach unten gebrochen, nicht so gleichmässig abfallend, wio bei der vorliegenden Form. Die typische Form des Illaenus crassicauda Wahlberg fehlt in unseren Geschieben.

\section{B. Augenlose.}

Illaenus caecus Holm. Taf. III. Fig. 21. 21a.

1886. Illaenus caecus Holm in Fr. Schmidt: Rev. III. Mllaeniden pag. 162. Taf. XI. Fig. $11 a-d$.

Der Kopf ist kurz kuglig aufgeblasen. Die Glabella ist kurz, nimmt etwa ein Drittel der Kopfbreite ein. Die nach vorn venig convergierenden Rückenfurchen sind nicht tief. Die festen Wangen fallen von den Rückenfurchen in starker Wölbung ab. Die Gesichtsnähte bilden, von der Mitte des Hinterrandes ausgehend, knieförmig nach aussen gerichtete Bogen bis zur Mitte des Seitenrandes. Der Vorderrand des Kopfes, der nach $\mathrm{Holm}^{2}$ ) eine Falzlinie tragen soll, ist nicht erhalten; ebenso fehlt der Leib und das Schwanzschild. Die Schale ist, so weit sie erhalten, mit sehr feinen Terrassenlinien bedeckt.

Fundort: Belschwitz in Westpreussen; in hellgrauem Kalk, aus der Lyckholmer Schicht. Heimat: Estland.

\section{Untergattung Bumastus Murchison.}

Illaenus (Bumastus) barriensis Murchison. Taf. III. Fig. 26. 27.

1843. Illaenus (Bum.) Barriensis. Burmeister. Org. d. Trilob. pag. 120.

1867. Bumastus Barriensis Nfurchison. Siluria pag. 116.

1885. Illaenus bariensis Lindström. Förteckning. pag. 82.

1886. Illaenus barriensis Holm. in Fr. Schmidt Rev. III Illaeniden pag. 164. Taf. XI. Fig. $12-16$.

Der Kopf ist in der Querrichtung stärker gewölbt, als in der Längsrichtung. Der Vorderrand bildet einen kräftigen Bogen ohne Falzlinie. Die stark gegen ein-

1) cf. Salter: A. Monograph, pag. 185. Taf. XXVIU. Fig. 6-13. Taf. XXX. Fig. 6.

2) of. Holm in Fr. Schmidt. Rev. II. Illaeniden pag. 162. 
ander gewölbten Rückenfurchen schnüren die festen Wangen fast vollständig vom Mittelschildo ab. Dio Augendeckplatton sind gross, flach, nahe am Hinterrande stehond.

Das Schwanzschild ist nur wenig breiter als lang und ganz gleichmässig gewölbt, ohne Randsaum.

Die Oberfläche ist mit sehr feinen Terrassenlinien verziert.

Illaenus (Bum.) barriensis kommt sowohl in Estland (Oesel und Moon) ${ }^{1}$ ) als auf Gotland vor. Die auf Taf. III. Fig. 26, 27 abgebildeten Stücke stammen aus hellem Korallenkalk, der dem der Insel Gotland. (Lindströms Zone f) entspricht. Ein anderes Stück lag in einem mergeligen Kalke, vom Alter der unteren Oeselschen Schicht $\mathbf{J}$ aus Estland.

Fundorte: Ostpreussen: Königsberg, Wehlau; Westpreussen: Rosenberg.

Illaenus (Bumastus), sulcatus Lindström. T'af. III. Fig. 28. 28a, b. 29.

1874. Bumastus sp. c. Steinhardt. pag. 84. Taf. IV. Fig. 8a, b.

1883. Illaenus insignis Holm: Svenska arterna pag. 127.

1885. Illaenus sulcatus Lindström: Förteckning pag. 84. Taf. XII. Fig. 12.

Der Umriss des Kopfes ist parabolisch, der Vorderrand gerundet, ohne Falzlinie. Die stark nach innen gebogenen Rückenfurchen gehen weit nach vorne wnd endigen in kleinen rundlichen Grübchen. Zwischen den Augen werden die Rückenfurchen etwas tiefer und bilden auf dem Steinkern kleine linsenförmige Eindrücke. Die Augen stehen weiter vom Hinterrande ab als bei Illaenus barriensis, doch bei dem mir vorliegenden Stücke nicht so weit als auf der von Lindström ${ }^{2}$ ) gegebenen Abbildung. Die Gesichtsnaht hinter dem Auge geht in schwachem Bogen nach aussen. Das Bruchstück einer freien Wange (Taf. III. 28b) zeigt die zugeschärfte Hinterecke und eine kräftige Furche am Grunde des Auges.

Mit dem Bruchstücke eines vollständig übereinstimmonden Kopfschildes wurden bei Wehlau mehrere Schwanzschilder in einem Geschiebe gefunden, die ich dieser Art zuzähle: sie sind länglich schildförmig, nicht sehr stark gewölbt, von einem flachen Randsaume umgeben. Soweit die Schale erhalten ist, lässt sie feine Terrassenlinien erkennen, die quer über das ganze Schild gehen. Die Gelenkfläche ist ziemlich gross, ihr Hinterrand wulstig aufgeworfen. In dem hinteren Teile trägt das Schwanzschild die Andeutung eines Kieles. Der Umschlag ist schmal, nach hinten nicht verbreitert, schwach gehöhlt und mit wenigen Terrassenlinien verziert.

Fundorte: Wehlau, Ostpreussen. Belschwitz, Westpreussen.

Ill. (Bum.) sulcatus ist nur aus den obersten Gotländer Schichten ( $\mathrm{f}-\mathrm{h}$ Lindströms ${ }^{3}$ ) bekannt.

Die vorliegende Art steht dem Bumastus insignis Hall ${ }^{4}$ ) sehr nahe, ist aber vou ihm durch das Fehlen der Falzlinie am Vorderrande des Kopfes verschieden.

1) cf. Holm in Fr. Schmidt Rev. III. Illaeniden pag. 169.

2) cf. Lindström: Förteckning pag. 81. Holzschnitt.

3) cf. Lindström: Ueber die Schichtenfolge des Silur auf d. Ins. Gotland. Neues Jahrb. 1888 pag. 160, 161 und Lindström: Förteckning pag. 85.

4) cf. Salter: A Monograph, pag. 207. Taf. XXVII. Fig. 6. 7. 
Illaenus (Bumastus) Holmi Lindström. Taf. IIJ. Fig. 30.

1874. Bumastus sp. b. Steinhardt: Trilobiten pag. 54. Taf. VI. Fig. 3ab.

1885. Bumastus Holmi. Lindström: Förteckning pag. 83. Taf. XVI. Fig. 16-20.

Mehrere Schwanzschilder aus den Sammlungen des Mineralienkabinets und des hiesigen Provinzial-Museums gehören dieser Art an.

Das Schwanzschild ist stark gewölbt, von einem schwachen Randsaum umgeben. Am mittleren, der Spindel entsprechenden, Teil des Vorderrandes verläuft eine schmale Rinne, die nach den Seiten hin in den Randsaum übergeht. Die Gelenkfläche ist ziemlich gross, mit gerundeter Ecke und wulstigem Hinterrande. Auf dem Steinkern tritt ein sehr schwacher Längskiel auf, in dessen Verlängerung sich auf dem Randsaum eine kurze schwache Einsenkung befindet. Die Schale ist glatt, nur in der Umgebung des Hinterrandes der Gelenkfläche finden sich feine Terrassenlinien, sonst ist die ganze Schale und auch der Steinkern mit ziemlich groben eingestochenen Punkten bedeckt.

Fundorte: Belschwitz in Westpreussen und Ostpreussen ohne nähere Ortsangabe.

Heimat: Gotland

Das Gestein ist zum Teil ein grobkrystalliner Kalk, dem Gotländischen Korallenkalk ähnelnd, zum Teil ein feinkörniger gelber Kalk.

\section{Anhang:}

1. Taf. III. Fig. 25: Eine sehr hohe freie Wange aus Jeveschem Gestein, welche sich besonders durch den stark gebuchteten Aussenrand auszeichnet. Die Oberfläche ist mit eingestochenen Punkten bedeckt. Fundort: Wehlau, Ostproussen.

2. Taf. III. Fig. 20: Eine Glabella von Wehlau zeigt gewisse Anklänge an III. sulcifrons Holm; doch sind die Augenhöcker nicht über die Glabella vorgewölbt wie bei dieser Art, sondern liegen ein klein wenig tiefer. Echinosphaeritenkalk.

3. Taf. III. Fig. 22: In Vaginatenkalk fand ich mehrfach kleine Schwanzschilder von der Form des auf Taf. III. Fig. 22 abgebildeten: sie sind etwa doppelt so breit als lang, flachgerwölbt, mit kurzer Spindel und schwachem Kiel. Die Schale ist mit wenigen feinen, querverlaufenden Terrassenlinion verziert.

4. Taf. II. Fig. 38ab. Die angeführte Glabella erinnert etwas an das von Holm ${ }^{1}$ ) Taf. II. Fig. 6 abgebildete Exemplar von Illaenus Esmarki Schloth., doch lassen die breitere Glabella und die geringere Biegung des gefalzten Vorderrandes bei Ill. Esmarkii es zweifelhaft erscheinen, ob das vorliegende Stück der Art zuzuzählen ist.

\section{Fam. Asaphidae.}

\section{Gattung: Asaphus Brongniart (z. T.). Angelin.}

\section{Untergattung: Ptychopyge Angelin.}

\section{Asaphus (Ptychopyge) rimulosus Angelin. Taf. IV. Fig. 13.}

1854 (78). Ptychopyge rimulosa Angelin: Pal. Scand. pag. 55. Taf. XXX. Fig. 2. 1884. Asaphus brachyrachis Remelé in Törnquist: Undersökn. om Siljansomrâdets Trilobit fauna -- pag. 67. Taf. III. Fig. 1.

1) cf. Holm: Svenslia artema af Trilobitsl. Illaenus. pag. 58. 
Mehrere Schwanzschilder lagen mir vor: Sie sind etwas über einen Halbkreis ausgezogen, flachgewölbt, von einem sehr breiten flachen Randsaum umgeben. Die Spindel ist ziemlich kurz, bis zum Ende dentlich begrenzt; sie endigt in bedentender Entfernung vor dem flachen Randsaume. 12-13 Spindelglieder sind durch erhabene in der Mitte etwas nach vorn vorgebogene Leistchen angedentet. Auf den Seitenteilen treten 8-9 nicht sehr deutliche Rippen anf, welche ungefähr bis zum Randsaum zu verfolgen sind. Die Gelenkfläche ist sehr breit. Die Schale zeigt mregelmässige, quer über das Schwanzschild verlaufende leistenförmige Jinien. Bei dem abgebildeten Exemplar treten auf der Schale unregelmässig verstreute runde flache Höcker auf, die von einer schmalen Rimne umsäumt sind. Aehnliche Höcker fand ich auch bei einzelnen Stücken anf dem breiten mit Terrassenlinien verzierten Umschlage.

$18 \mathrm{~mm}$.

Maasse: Länge $60 \mathrm{~mm}$, Breite $72 \mathrm{~mm}$, Spindellänge $41 \mathrm{~mm}$, Spindelbreit.e

Fundorte: Ost- und Westpreussen.

A. rimulosus ist nur aus dem oberen granen Orthocerenkalk Schwedens anstehend bekannt.

Das von Türnquist 1. c. als A. brachyrachis Remelé besuriebene ma abgebilçete Schwanzschild gehört wohl ohne Zweifel zu A. rimulosus.

\section{Asaphus (Ptychopyge) multicostatus Angelin.}

1854 (78). Ptychopyge multicostata Angelin: Pal. Scand. pag. 55. Taf. XXX. Fig. 4.

In einom hellgrauen harten Kalk mit grossen Schwefelkieskrystallen liegt ein Abdruck des Schwanzschildes dieser Art. Die Spindel ist bis zu ihrer Mitte von zuerst stärker convergierenden, gegen das Ende hin fast parallel verlaufenden Rïckenfurchen begrenzt; sie endigt abgestumpft und trägt etwa 15-16 Glieder. Auf den Seitenteilen sind elf deutlich begrenzte Pleuren zu erkennen, deren letate ziemlich stark nach hinten gerichtet sind. Um das ganze Schild läuft ein flacher Randsanm.

Fundort: Ostpreussen, ohne nähere Angabe des Ortes.

Angelin erwähnt A. multicostatus aus Dalekarlien und Schonen; die Gesteinbeschaffenheit des vorliegenden Geschiebes liasst es fraglich erscheinen, ob diese Gebiete als die Heimat des betreffenden Stückes anzunehmen sind. In Estland ist die Art bisher nicht gefunden worden.

\section{Asaphus (Ptychopyge) sp. Taf. V. Fig. 4.}

Don Formen des Asaphus rimulosus und multicostatus steht das anf Taf. V. Fig. 4 abgebildete Schwanzschild nahe. Die Spindel ist zehngliederig, die Seitenteile tragen 8 Pleuren. Spindelglieder wie Pleuren sind ebenso wio bei a multicostatus deutlich abgesetzt.

Fundort: Umgegend von Königsberg, in hellgranem, an Echinosphaeritenkalk exinnerndem Kalkstein. 
Asaphus (Ptychopyge) tecticaudatus Steinhardt. Taf. IV. Fig. 10. 11.

1874. Asaphus tecticaudatus Steinhardt: Pr. Trilobiten pag. 26. Taf. II. Fig. 9. 10. 1848. Asaphus sp. Burmeister: „Neue Beobachtungen über die Organisation d. Trilob. in d'Alton u. Burm.: Zeit f. Zool. etc. pag. 80. Taf. I. Fig. 19.

Die erste Nachricht über diese wohl begrenzte Art finden wir bei Burmeister, wolcher a. a. O. eine sehr gename Beschreibung und Abbildung eines Schwanzschildes aus einem Geschiebe von Stettin giebt. Nach Burmeister hat erst Steinhardt wieder die Art aus preussischen Geschieben erwähnt, und nannte sie As. tecticaudatis wegen des. fast dachförmigen Abfalls der Seitenteile des Schwanzschildes. Beiden, Burmeister wie Steinhardt, waren nur Schwanzschilder bekannt. Zum ersten MIale kann ich jetzt das Kopfschild eines allerdings sehr schlecht erhaltenen vollständigen Exemplares beschreiben.

Der Umriss ist etwa halbkreisförmig. Die Hinterecken nicht, wie bei den bekannten skandinavischen Arten der Untergattung Ptychopyge, in Hörner ausgezogen, sondern kurz zugeschärft. Um das ganze Kopfschild läuft ein breiter flacher Randsaum, der anf' den Wangen schwach gehöhlt ist. Die Gesichtsnähte stossen im Vorderrande in einem spitzen Winkel zusammen und umkreisen die flach gewölbte Glabella in ziemlich grosser Entfernung. Zwischen den Augen ist die Glabella sehr stark eingeschuürt und trägt hinter dioser ihrer schmalsten Stelle ein kleines spitziges Höckerchen; in ihrem vorderen Teile zeigt sie eine schwache kielartige Erhöhung. Die grösste Glabellabreite übertrifft den Abstand der Augen von einander um wenige $\mathrm{mm}$. Die Nackenfurche und die etwa bis zur Mitte der Wangen gehenden Hinterrandfurchen sind nur flach angebildet.

Das Schwanzschild liegt mir in sehr vielen Bruchstücken vor. Es ist ron parabolischem Umriss, wenig länger als breit, am Hinterrande schwach eingebuchtet. Die Spindel ist lang, flach gewölbt, bis zur Spitze ziemlich deutlich gegliedert. Die Grenzfurchen der 18-20 Spindelglieder setzen sich auf den Seitenteilen noch eine Strecke fort. Auf den Spindelringen verlaufen unregelmässige Querwülstchen, auf den vordereu je zwei, auf den hinteren je eines, welche die Rückenfurchen nicht erreichen. Die Seitenteile fallen von der Spindel in ungefähr dachförmiger Wölbung ab; sie sind von einer flachee Randfurche umgeben. Der Umschlag des Schwanzschildes zeigt die für die Untergattung Ptychopyge eigentümliche Breite, und ist mit dicht gestellten parallelen T'errassenlinion verziert.

Schalenverzierung: Auf dem Kopfschilde treten nur in der Nähe der Hinterecken neben feinen eingestochenen Punkten ganz feine kurze Terrassenlinien auf. Auf dem Schwanzschilde laufen vom Rande aus lange nach hinten und innen gewendete Terrassenlinien aus, welche sich allmählich mit den aus der Nähe der Rückenfurchen entspringenden feineren erhabenen leistenförmigen Linien vereinigen.

As. tecticaudatus ist nicht selten in Geschieben vom Alter des Echinosphaeritenkalkes in Ost- und Westpreussen. Anstehend ist die Art in Estland bei Reval gefunden worden. 
Asaphus (Ptychopyge) undulatas Steinhardt. Taf. IV. Fig. 12.

1874. Asaphus undulatus Steinhardt: Pr. Trilobiten pag. 26. Taf. II. Fig. 12

1884. Asaplus efr. undulatus Törnquist: Undersökn. öfver Siljansomridets Trilobitfanna pag. 69. Taf. II. Fig. 22.

Wie Steinhardt, so liegen auch mir nur Schwanzschilder dieser Art vor. Sie unterscheiden sich von denen des As. tecticaudatus einmal durch das Fehlen der Randfurche auf den Seitenteilen, und durch sehr undeutliche Gliederung der Spindel, wie der Seitenteile, und dann durch die Schalenverziorung. Die Spindel ist mit sehr feinen wellenförmigen Leistchen verziert, welche auf die Seitenteile übergehen und hier von der Spindel aus schräge nach oben und aussen verlaufen. Vom Anssenrande gehen etwas gröbere und längere leistenförmige Linien zu denen des mittleren Schildteiles hin. Der Hinterrand des Schwanzschildes ist wie bei der vorigen Art gebuchtet.

Fundorte: Ost- und Westpreussen.

As. undulatus ist in unseren Creschieben seltener als As. tecticandatus. Das Gestein, in dem As. undulatus bisher gefunden ist, erinnert sehr an den oberen grauen Orthocerenlalk Schwedons, so dass dieses, orker Nachbargebiete des Ostseebeckens, die Heimat unserer Geschiebe wäre. Törnquist erwähnt seinen As. cfr. undulatus, der dem unsrigen fast vollkommen gleicht ans „Flagkalk" einer dicht über dem oberen grauen Orthocerenkalk liegenden Schicht.

Asaphus (Ptychopyge) cfr. aciculatus Angelin Kiesow muscpt. T'at. V. Fir. 5).

[185̆4 (78). Ptychopyge aciculata Angelin: Pal. Scand. pag. 5̌t. Taf. XXII. Fig. 4.4a.]

Ein Schwanzschild aus der Sammlung des Hern Dr. Kiesow zeigt grosse Aehnlichkeit mit der Ptychopyge aciculata Aug. Die Seitenteile lassen, soweit sie erhalten sind, die Teilung der Pleuren in ein breiteres vorderes und ein schmales hinteres Band deutlich erkemmen. Die Spindel ist riemlich stark verjüngt und zählt ungefähr 16 Glieder. Uober die ganze Spindel laufen zwei convergierende flach rinnenförmige Eindrücke hin. Die Tremungsfurchen der einzelnen Spindelglieder sind nach aussen nicht so stark vertieft und erweitert, wie es die Figur Angelin für Pt. aciculata zeigt. Die Oberfläche ist mit feiner dichtgestellten Wellenlinien verziert.

Fundort: Spengaswken in Westpreussen.

As. cfr. aciculatus ist jedenfalls auf ein Schweden benachbartes Gebiet zurickzuführen. Aus dom estländischen Silur ist keine entsprechende Art bekannt.

\section{Untergattung: Asaphus Brongniart s. str.}

Asaphus oculosus n. sp. Taf. IV. Fig. 1.2.3.4.

1860. Asaphus Weissi Eichwald: Lethrea rossica pag. 1452 (z. T.)

1874. Asaphus expansus Steinlardt: Pr. Trilobiten pag. 22. Taf. II. Fig. 1. 2. 5. 6. 7.8.

1854. Asaphns Weissi Kiesow: Sil. u. Devon. Gesch. pag. 82.

Asaphus expansus Fr. Schmidt: mnserpt.

1852. Asaphus expansus var. incerta Brögger: Sil. Et. 2 u. 3. pacr. 92.

In sehr zahlreichen Bruchstücken lag mir diese Art aus dem typischen oberen Linsengestein [Echinosphaeritenkalk $\mathrm{C}_{12}$ ] vor. Steinhardt hat sie als A.s. expansms 
beschrieben. Ausser der vorzüglichen Beschreibung Bröggers') stauden mir noch mehrere Exemplare des echten As. expansus zu Gebote, so dass ich sehr bald zu der Ueberzeugung gelangte, dass die Bestimmung Steinhardts falsch ist. Brögger selbst nennt die Steinhardtsche Art As. expansus var. incerta. Unter den zahlreichen Stücken dieser Art aus der Sammlung des hiesigen Provinzial-Museums befinden sich einige, die mit der Bestimmung ,As. expansus Fr. Schmidt" versehen sind, von ihnen gilt dasselbe, wie von Steinhardts Bestimmung. Herr Dr. Kiesow endlich bezeiclinete einige Stücke, die ich ihm vorlegte, als seinem, aus westpreussischen Geschieben stammenden As. Weissi identisch.

Asaphus Weissi Eichwald umfasst aber, wie bereits Nieszkowski²)' nachgewiesen, mehrere Arten, den in unseren Geschieben Läufigen As. oculosus, ${ }^{3}$ ) den mit sehr hohen, dünnen Augenstielen versehenen As. Kowalewski Lawrow ${ }^{4}$ ) und den As. cornutus Pand.5) Eichwald glaubt in der verschiedenen Ausbildung der Augenhöcker Geschlechtsunterschiede sehen zu dürfen, indem die Exemplare mit langen dünnen Stielen (= As. Kowalewski) Weibchen, und die mit kürzeren, dickeren Augenhöckern (= As. cornutus und As. oculosus) Männchen sein sollen. Es sind nun aber diese Unterschiede nicht als die der beiden Gesehlechter, sondern als vollgiltige Artunterschiede aufzufassen. Wie erwiesen, sind unter dem Eichwaldschen Namen As. Weissi mehrere wohl unterschiedene Arten zusammengefasst, es ist daher unumgänglich notwendig, diesen Namen aufzugeben. Den von Brögger gewählten Namen As. expansus var. incerta möchte ich, obwohl recht bedeutende Aehnlichkeiten mit dem echten As. expansus vorhauden sind, um der eigentümlich ausgebildeten Augenhöcker willen mit dem Namen As. oculosus vertauschen, da in As. oculosus keine Varietät des As. expansus, sondern eine selbständige Art vorliegt. Zur besseren Unterscheidung von As. expansus stelle ich die Diagnose dieser und unserer Art neben einander:

As. expansus Linné. ${ }^{6}$ )

Das Kopfschild ist in der Längsaxe ziemlich kräftig gewölbt, sein Umriss ist ein gleichmässiger, nicht zu stark gewölbter Bogen. Die Hinterecken sind gerundet.

Die Augenhöcker ragen kaum über die Glabella hervor; die Sehfläche ist nicht deutlich abgesetzt.
As. oculossus n. sp.

Das Kopfschild ist in der Längsaxe sehr stark gewölbt, von parabolischem Umriss. Die Hinterecken sind scharf, oder ganz kurz gerundet, erheblich weiter ansgezogen als bei As. expansus.

Die Augenhöcker erheben sich weit über die Glabella, sie sind sehr kräftig ausgebildet. Die Sehfläche ist nach unten durch eine Zone eingestochener Punkte begrenzt, unterhalb welcher der Augenhöcker etwas eingeschnürt ist.

1) cf. W. C. Brögger: Sil. Et. 2 u. 3. - pag. 85. As. expansus.

2) cf. Nieszkowski: Zus, zur Monogr.-Archiv f. d. Naturk. Liv-, Est- und Kurlands. Ser, I. Band II. pag. 352 .

3) cf. die Abbildung von Eichwald: Taf. LIV. Fig. 7 a b c.

4) cf. Verhandl. d. Mineral. Ges. zu St. Petersb. 1856. Tf. V. Fig. 1.

5) cf. Pander: Beitr. z. Geognosie d. russ. Reiches pag. 137. Taf, VII. Fig. 5.

6) Nach einem russischen Exemplar des hiesigen Mineralogischen Instituts. 
Die Gesichtsuaht iiberschreitot den Hinterraudsaum der Axe ungefihr parallel gerichtet, den Torderrand erreichen die boiden Aeste in einem sehr stumpfen, fast flachen. Winkel.

Die Glabella ist doppelt eingeschnürt, einmal kurz vor den Augen, und dann durch sehr tiefe Gruben zwischen den Augen. Zum Vorderrande fällt sie in kräftiger Wölbung ab; sie ist ungekielt.

Die sehr hohen Augenhöcker, die mehr zugeschärften Hinterecken und die stärkere Wölbung der Glabella unterscheiden unsere Art so gut von As. expansus, dass ich glaube, in As. oculosus eine eigene Art und nicht nur eine Varietät des As. expansus sehen zu müssen. ${ }^{1}$ )

Die Form der 8 Leibesringe unterscheidet sich kaum von denen des As. expansus.

Das Schwanzschild ist ungefähr eineinhalb mal so lang als breit. Die Spindel ist bis zur Spitze deutlich begrenzt und lässt, namentlich auf Steinkernen 9-12 Glieder erkennen, die nach der Mitte zu undeutlicher werden. Die Gliederung der Seitenteile ist sehr undentlich.

Die sehr dicke Schale ist überall mit gröberen, rissigen, kurzen 'Terrassenlinien bedeckt, die namentlich auf den Augenhöckem sehr dicht stehen, auf der Glabella laufen sio dem Umriss derselben parallel. Auf dem Schwanzschilde treten ausser einzelnen (4-5) von der Spindel schräg nach aussen und hinten gehenden längeren Linien kürzere dichter gestellte in der Nähe des Randes auf, welche in umgekehrter Richtung wie die ersten verlaufen.

As. oculosus ist häufig in Ost- und Westpreussen.

Das Gestein, graugrünlicher rotfleckiger Kalk mit grossen Thoneisensteinlinsen dentet auf Estland als Heimat hin.

\section{Asaphus sp. 'T'af. IV. Fig. 7 .}

Ein bei Rosehnen, Ostprenssen, gefundenes Kopfschild zeigt in Bezug auf die Ausbildung seiner Augen nahe Beziehungen zu As. oculosus. Die Augenböcker sind bedentend über die Glabella emporgezogen, jedoch nicht so hoch, wie boi der vorigen Art. Die Sebfläche ist am Grunde von einer Zone oingestochener Punkte begrenzt. Der Vorderrand des Kopfschildes ist in eine kurze stumpfe Spitze ausgezogen, in welche die Gesichtsnähte einmünden. Die Hinterecken sind stärker nach hinten gezogen, wie bei As. oculosus, aber nicht scharf, sondern kurz gerundet. Die Glabella stürzt nach vorne steil ab; zwischen ihr und dem Vorderrande zieht sich ein schmaler, schräg gestellter Saum hin. Zwischen den Augen geht quer über die Glabella eine flache Vertiefung, in die zwei dicht nebeu einander stehende Gruben

1) Der echte Asaphus expansus Linné fehlt jedenfalls ganz in unseren Geschieben, wio or' anch in Fstland, der Heimat des grössten Teiles unserer Geschiebe, fehlt. 
eingesenkt sind. Der Höcker zwischen den Augen ist niedrig und spitz, viel weniger deutlich wie bei As. oculosus. Die Schale der Glabella ist mit sehr feinen Terrassenlinien bedeckt, auf den Wangen sind nur dicht gestellte Pünktchen eingedrückt.

Fundort: Strand bei Rosehnen.

Das Gestein erinnert an Echinosphaeritenkalk.

Asaphus jevensis Fr. Schmidt mnscpt. Taf. IV. Fig. 5. 6.

Mehrere Glabellen und Bruchstücke von Schwanzschildern aus der SammIung des hiesigen Provinzial-Museums zeigten die Aufschriften "Asaphus jevensis Fr. Schmidt;" von diesen Stücken gebe ich die Abbildung einer Glabella und eines Schwanzschildes (Abdruck), ohne auf die genaue Begrenzung der Art eingehen zu hönnen, da Herr Akademiker Schmidt auf eine diesbezügliche Anfrage mitteilte, dass er selbst zur Zeit die Art As. jevensis noch nicht genügend charakterisieren könne.

Die Glabella ist birnförmig, kräftig gewölbt, zum Vorderrande ziemlich steil abfallend. Sie trägt in ihrem vorderen Teile einen deutlichen, aber nicht scharfen Längskiel und gegenüber der Vorderseite der Augenhöcker zwei Paar kurze Querwülstchen (auf den Steinkernen.) Die Rückenfurchen sind von den Augen ab tief, an der breitesten Stelle der Glabella mit einer rundlichen Einsenkung.

Die Schwanzschilder sind ungefähr halbkreisförmig, kräftig gewölbt. Die Spindel lässt auf den Steinkernen etwa 9 Ringel, auf den Seitenteilen 6-7 undeutlich begrenzte Pleuren erkennen. Die Gelenkflüche ist sehr breit, steil nach unten gebrochen. Die Furche von der Spindel bis zum Knie ist selır tief.

Fundorte: Mehrfach in Ostprenssen in Geschieben vom Alter der Jeweschen Schicht gefunden; als Heimat ist Estland zu bezeichnen.

Asaphus Branconis n. sp. Taf. V. Fig. 3a.b.

In einem grossen Geschiebe, welches durch Strophomena tenuistriata Murch. als der Jeweschen Schicht gleichalterig bestimmt wurde, fand ich den auf Taf. V Fig. 3 abgebildeten Asaphiden. Der ganze Körper ist länglich eiförmig. Der Kopf ist etwa $1^{3} / 4$ mal so breit als lang, von parabolischem Umriss. Die Hinterecken fehlen, sie scheinen scharf gerresen zu sein. Der Vorderrand ist an den Seiten der Glabella ganz wenig eingebuchtet. Die Gesichtsnähte münden in sehr flachem Winkel in den Vorderrand. Die Glabella ist kräftig gewölbt, nach vorn steil abstürzend, schwach gekielt. Die Augen sind niedrig, ihre Sehfläche steigt direkt von den Wangen an und ist nach unten nur durch eine feine eingedrïckte Linie begrenzt.

Die Rumpfspindel nimmt etwas mehr als $1 / 3$ der ganzen Breite ein. Der innere Teil der Rumpfpleuren ist sehr schmal.

Das Schwanzschild ist halbkreisförmig, mässig gewölbt. Die Spindel nimmt ungefähr $1 / 4$ der Breite und $3 / 4$ der Länge des Schwanzschildes ein. Eine Gliederung ist nur auf der Spindel durch 9, quer über. dieselbe verlaufende leistenförmige Linien angedeutet. Die Seitenteile sind vollkommen ungegliedert.

Die Schale des ganzen Körpers ist mit feinen Terrassenlinien verziert. 
Iaasse: Kópf: Lünge $7 \mathrm{~mm}$, Breite $12 \mathrm{~mm}$. Rumpf: Lünge $8,5 \mathrm{~mm}$, Breite $11 \mathrm{~mm}$. Spindelbreite $4,5 \mathrm{~mm}$. Schwanz: Länge $6 \mathrm{~mm}$, Breite $10 \mathrm{~mm}$, Spindelbreite $2,5 \mathrm{~mm}$.

Fundort: Craussen bei Königsberg.

Durch das Zusammenvorkommen mit Strophomena tenuistriata wird Estland als die Heimat des As. Branconis bestimmt.

Asaphus Steinhardti n. sp. Taf. V. F'ig. 1a.b.c.

1874. Asaphus raniceps Stoinhardt: Pr. Trilob. pag. 22. Taf. I. Fig. 11.

Das vorliegende Stiick hat Steinhardt als As. raniceps Dalm. beschrieben und abgebildet; diese Bestimmung ist irrig, denn bei As. raniceps Dalm. fehlt der breite Saum vor der Glabella, welcher die vorliegende Form auszeichnet. Ebenso ist das von Steinhardt 1. c. gegebene Synonym As. raniceps Nieszk. ${ }^{1}$ ), welche Art nach einer Mitteilung Schmidt's gleich Ptychopyge globifrons Eichwald ist, ${ }^{2}$ ) unrichtig. Vor dieser Eichwaldschen Art unterscheidet sich die vorliegende durch die nach vorm gleichmässig verbreiterte kolbenförmige Glabella. ${ }^{3}$ )

$\mathrm{Da}$ ich die vorliegende Form mit keiner der bekannten Asaphidenarten vereinigen kann, nenne ich sie nach ihrem ersten Bearbeiter als neue Art As. Steinhardti.

Der Kopf ist fast halbkreisförmig, von einem flachen Saum umgeben. Die Hinterecken fehlen, sie waren wahrscheinlich spitz. Die Gesichtsnaht verläuft in einiger Entfernung von der Glabella: sie mündet in spitzem Winkel in den Vorderrand. Die Augen ragen wenig über die flache kolbenförmige Glabella hervor.

Die Spindel des achtgliedrigen Rumpfos nimmt ein Drittel der Breite ein, sie verschmälert sich allmählich nach hinten.

Das Schwanzschild ist breit parabolisch, mit aufgewölbtem Hinterrande. Die Spindel ist schmal, konisch, und trägt etwa elf undeutliche Glieder. Die Seitenteile sind mässig gewölbt, von einer flachen Randfurche umgeben; in der Nähe der Spindel zeigen sie Andentungen von 4-5 Rippen.

Die Schale ist glatt, nur auf dem Schwanzschilde treten wellenförmige, von aussen schräg nach hinten und innen verlaufende T'errassenlinien auf.

Fundort: Ostpreussen, ohne nähere Angabe.

Das Gestein ähnelt estländischem Echinosphaeritenkalk.

Asaphus cf. raniceps Dalman. ${ }^{4}$ ) Taf. VI. Fig. 10 a.b. 11.

[1828. As. expansts. var. P. raniceps Dalman: Palaeaden. pag. 83. Taf. III. Fig. 4.]

In den auf Taf. VI Fig. $10 \mathrm{a}, \mathrm{b}$ und 11 abgebildeten Stücken liegt eine dom echten As. raniceps sehr nahe stehende Form vor.

1) cf. Nieszkowski: Monographie. pag. 36.

2) cf. Eichwald: Lethaea rossica pag. 1471. Taf. LIII. Fig. 2.

3) Für Ptychopyge grobifrons giebt Eichwald 1. c. an: nle lobe frontal bombé est ronde; die Eichwaldsche Figur zeigt auch den Vorderteil der Glabella in Form einer Kugelcalotte ausgebildet.

4) Der echte As, raniceps Dalm. fehlt in unseren Geschioben wahrscheinlich ebenso wie As. expansus. 
Das Kopfschild ist kräftig gewölbt, vorn etwas vorgezogen, von einem schmalen schräge stehenden Randsaum umgeben. Die Glabella ist nach vorn sehr stark verbreitert; zwischen den Augen zeigt sie, wie As. expansus und As. raniceps, die doppelte Einschnürung. Die Gesichtsnähte münden in spitzem Winkel in den Vorderrand.

Das Schwanzschild ist ungefähr halbkreisförmig, (bei As. raniceps mehr parabolisch). Die Spindel trägt 7-S Glieder; die Seitenteile sind vollkommen ungegliedert.

Häufig in Geschieben vom Alter des Echinosphaeritenkalkes in Ost- und Westpreussen gefunden.

Taf. VI. Fig. 7 zeigt das Hypostom einer zur Gruppe des As. raniceps gehörenden Asaphusart. Der Hinterrand ist in der für die Hypostome der Untergattung Asaphus s. str. eigentümlichen Weise in zwei lange zugespitzt endigende Lappen ausgezogen. Der Mittelkörper ist kräftig gewölbt; an seinem Hinderrande liegen zwei kleine flache Höckerchen, die als die Reste des Hinterlappens aufzufassen sind. Eine genauere Bestimmung, welcher Art das vorliegende Hypostom zuzuzählen ist, ist kaum möglich.

Asaphus ornatus n. sp. Taf. VI. Fig. 3. 4. 5. 6.

Einzelne Bruchstücke dieser Art aus der Sammlung des Mineralienkabinetts hat Steinhardt als As. raniceps bestimmt, jedoch wohl mit Unrecht, da sich die Form ihrer Glabella noch weiter von der des echten As. raniceps entfernt als die des vorherbesprochenen As. cf. raniceps. Vollständige Exemplare lagen mir nicht vor, sondern nur Glabellen mit Leibesringen und Leibesringe mit Schwanzschildern, doch so, dass ich die Zugehörigkeit der auf T'af. VI unter Fig. 3, 4, 5 und 6 abgebildeten Stücke ausser Zweifel stellen konnte.

Die Gesichtsnähte bilden vor der Glabella einen spitzen Winkel. Die Glabella selbst ist mässig gewölbt, gekielt und lässt auf den Steinkernen zwei Paar querliegende, feine Wülste erkennen, die an As. acuminatus Boeck ${ }^{1}$ ) erinnern, bei welcher Art sie jedoch weiter nach vorne liegen, als bei den vorliegenden Stücken. Die Rückenfurchen sind neben der breitesten Stelle der Glabella plötzlich stark vertieft; sie bilden hier eine grössere grubenförmige Einsenkung.

Besonders ausgezeichnet ist die Art dadurch, dass auf der breiten Rumpfspindel zwei parallele Reihen von Höckern - je zwei auf jedem Spindelgliedo verlaufen, welche, wie ich bei einem Stücke von Pr. Holland bemerkte, ganz nale zusammenrücken können. Das Schwanzschild ist parabolisch, flachgewölbt. Auf der Spindel sind zehn Glieder mehr oder weniger deutlich zu erkennen; der Rücken der Spindel ist etwas kräftiger aufgewölbt.

Die Pleuren der Seitenteile, 7-8 an der Zahl sind durch eine feine Längsripke zweigeteilt.

Die Schale ist mit feinen wellenförmigen Terrassenlinien verziert.

Fundorte: As. ornatus ist häufig in Ost- und Westpreussen gefunden.

1) cfr. W. C. Brögger 1. c. pag. 93. Taf. VIII. Fig. 5. 
Asaphus sp. Taf. V. Fig. 2.

Das auf Taf. V. Fig. 2 abgebildete Schwanzschild erimert sehr an As. ornatus, indem die Pleuren der Seitonteile ebenfalls durch eino Längsrippe zweigeteilt sind; seine Form stimmt jedoch wenig mit dieser Art überein: es ist von beinahe halbkreisförmigem Umriss, während das von As. ornatus ausgesprochen parabolisch ist.

Fundort: Königsberg.

Asaphus obtusus n. sp. 'Taf. IV. Fig. 8. 9.

In dem pag. 9. erwähnten neuen Geschiebe lagen neben Holometopus? radiatus m. mehrere Glabellen und Schwanzschilder einer nenen Asaphusart. Dio Glabella ist nach vorn sehr stark erweitert, schwach gekielt; zum Vorderrande stiurzt sie steil ab. Zwischen den Augen wird sie durch eine quer verlaufende Vertiefung vollständig von dem kleinen Nackenhöcker abgeschnürt und fast gerade abgestutzt, ein Merkmal, welches keiner anderen Asaphidenart eigen ist. Die Gesichtsnähte stossen vorn in einem stumpfen Winkel zusammen.

Das Schwanzschild ist etwa halbkreisförmig, hinten schwach abgestutzt. Die Spindel ist stark gewulstet, neungliederig. Die in gleichmïssiger Wölbung abfallenden Seitenteile sind nur ganz in der Nähe der Spindel undeutlich gerippt.

Maasse: Glabella-Länge $10 \mathrm{~mm}$, Breite $8 \mathrm{~mm}$.

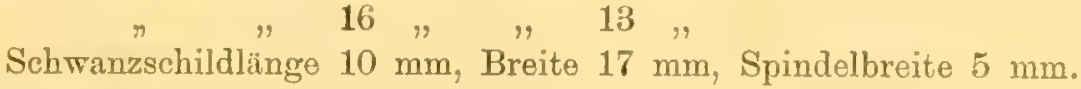

Fundort: Nasser Garten bei Königsberg.

Heimat: Balticum.

Asaphus sp. Tat. VI. Fig. 12.

Ein Schwanzschild (Steinkern) von Kamiontken in Westpreussen zeigt dio auf Taf. VI. Fig. 12 wiedergegebene Form: es ist breit parabolisch, von einem undeutlichen Randsaum umgeben; die Spindel lässt neun undeutlicho Glieder erkennen, die Seitenteile sind vollkommen glatt. Das Schwanzschild zoigt in Bezug auf die undeutlich gegliederte Spindel und die vollkommen glatton Soitentoile Aehnlichkeit mit dem von As. latisegmontatus Nieszk ${ }^{1}$ ). Das Gestein ist Echinosphaeritenkalk.

Asaphus sp. 'Taf. VI. Fig. 13.

Das kleine Schwanzschild zeigt eine von dem der anderen Asaphiden abweichende Form: Es ist fast doppelt so breit als lang, hinten abgestutzt. Die bis nahe an den Hinterrand gehendo Spindel ist undeutlich siebengliederig. Auf den Seitenteilen sind jo fünf Pleuren durch feine leistenfürmige Linien angedeutet.

Fundort: Königsberg.

Das Gestein ist Echinosphaeritenkalk.

1) Nieszkowski giebt für As. latisegmentatus (Monographio pag. 40) an, dass die Spindel nur auf dem Steinkern gegliedert ist, während die Seitenteile auch hier vollkommen glatt bleiben. Einen Randsaum erwähnt Nieszkowski nicht. 
Asaphus devexus Eichwald. Taf. VI. Fig. 9.

1860. Asaphus devexus Eichwald: Lethaea rossica pag. 1458. Taf. LIIr. Fig. 10.

Ein Schwanzschild aus dunkelgrauem Echinosphaeritenkalk stimmte gut mit der Eichwald'schen Art überein: Es ist fast halbkreisförmig, kräftig gewölbt. Die breite Spindel ist durch tiefe Rückenfurchen deutlich begrenzt; sie trägt ungefähr sieben Glieder. Die Seitenteile sind vollkommen glatt. Der Umschlag ist mit sehr groben Terrassenlinien verziert.

Fundort: Ostpreussen (Pr. Holland).

As. devexus ist bisher nur aus Estland anstehend bekannt.

Asaphus cf. platyurus Angelin. Taf. VI. Fig. 8.

[1854 (78) Asaphus platyurus Angelin: Pal. Scand. pag. 54. Taf. XXX. Fig. 1.]

Das auf Taf. VI. Fig. $8^{1}$ ) wiedergegebene grosse Schwanzschild erinnert durch die vielgliederige Spindel, deren einzelne Ringe in der Mitte etwas vorgebogen sind, an As. platyurus Angelin, von dem es sich nur durch die schwache Andentung von Pleuren auf den Seitenteilen unterscheidet.

Fundorte: Königsberg, Marienwerder.

Das Gestein ähnelt dem grauen Orthocerenkalk Schwedens.

\section{Untergattung: Isotelus Dekay.}

Asaphus (Isotelus) platyrhachis Steinhardt. Taf. V. Fig. 7.

1874. Asaphus platyrhachis Steinhardt: Pr. Trilob. pag. 24. Taf. I. Fig. 10.

Die Beschreibung des Kopfschildes dieser Art kann ich nach einem von Dr. Nötling bei Neuenhof in Estland gesammelten Stücke geben. Es ist halbelliptisch, flach gewölbt, von einem flachen Saume umgeben. Die Hinterecken sind weggebrochen, sie waren jedenfalls in kurze Hörner ausgezogen. Die Gesichtsnähte entspringen am Hinterrande, näher an den Augen als an der Ecke, in den Vorderrand münden sie in stumpfem Winkel. Die Augen sind klein und niedrig. Die Glabella ist nur hinter den Augen durch schwache Rückenfurchen begrenzt, vor den Augen tritt sie in keiner Weise aus der Wölbung des Kopfschildes hervor ${ }^{2}$ ).

Der Rumpf besteht aus acht flachgewölbten Gliedern, deren Spindel viel breiter ist, als die Pleuren. Am Hinterrande eines jeden Leibesringes sieht man in der Rückenfurche bei dem Taf. V. Fig. 7 abgebildeten Steinkern deutlich eine etwa stecknadelkopfgrosse Vertiefung, welche den innern Abdruck der zuerst von Burmeister ${ }^{3}$ ) beobachteten Gelenkknöpfe repräsentiert. Die Pleuren endigen schwach gerundet; ihr innerer Teil ist kaum halb so breit als der äussere.

Das Schwanzschild ist parabolisch, gleichmässig sanft gewölbt. Die sehr breite Spindel ist seitlich kaum begrenzt, da die Rückenfurchen auf dem Schwanzschilde

1) Der Umschlag ist nach einem anderen vollkommen gleichgebildeten Stücke gezeichnet.

2) cf. Salters Diagnose für die Untergattung Isotelus in Salter: "A Monograph" pag. 147.

3) cf. Burmeister: "Ueber die Organisation der Trilobiten". pag. 29. 
fast ganz verschwinden. Das Hinterondo dor Spindel tritt als scharf markiorter Buckel horvor. Auf dem Steinkerne erscheint die Spindel undentlich geglichert; ausserdem lässt die Spindel auf Steinkernen noch zwei nach hinten convorgierende ganz flache Lüngsfurchen erkennen. Auf den Seitenteilen sind nur bei schalenlosen Exemplaren ganz flache Rippen zu erkennen, welche undeutlich gefurcht erscheinen. Um das ganze Schwanzschild läuft ein schwach gehöhlter Randsaum.

Westpreussen.

Fundorte: Heiligenbeil, Wehlau, Königsberg in Ostprenssen, Belschwitz in

As. platyrhachis kommt in Geschieben vom Alter der Lycliholmer Schicht vor. Seine Heimat ist Estland.

\section{Gattung: Megalaspis Angelin.}

Megalaspis limbata Boeck. form. typica Brögger. Tat. IV. Fir. 11. Tat. VI. Fier. 1.

1837. Trilobites limbatus Boeck in Keilhau: Gaea norwegica pag. 142.

1852. Megalaspis limbata Angelin: Pal. Scand. pag. 18. Taf. XVI. Fig. 3.

1874. Asaphus (Basilicus) sp. sim. A. tyranno. Steinhardt: Pr. Trilobiten. pag. 25 (z. T.). 'Taf. II. Fig. 11.

1572. Megalaspis limbata Boeck forma typica Brögger: Sil. Etag. 2 u. 3. pag. 77. Taf. IX. Fig. 1-5. Taf. XII. Fig. 10.

Das Bruchstück eines Kopfschildes und eine ganze Reiho von Schwanzschildern lagen mir vor.

Das Kopfschild ist nach Brögger parabolisch, mit zugespitzten Hinterecken. Die Gesichtsnähte verlaufen vor der Glabella im Bogen zum Vorderrande, in welchen sie in ziemlich spitzem Winkel einmünden. Die Glabella ist kurz, zwischen den Augen wenig eingeschnürt. Die Augenhöcker ragen nicht unbedeutend über dio Glabella hervor. Das Schwanzschild ist etwas über einon Halbkrois ausgezogen. Dio von schwach gegeneinander gebogenen Rückenfurchen begrenzte Glabella endet bei den vorliegenden Stücken ziemlich undeutlich; sie trägt 12-14 Glieder. Die Seitenteile zeigen etwa sieben Rippen, die schwach gefurcht sind. Das ganze Schild ist von einem Randsaum umgeben, der hinter der Spindel mässig gehöhlt ist. Die von Angelin und Brögger erwähnte innere Grenzfurche des Randsaumes habe ich bei unseren Geschiebeexemplaren nicht beobachten können; der Saum ist oben nur durch das Aufhören der Seitonrippen geliennzeichnet.

Fundorte: Mehrfach in Ost- und Westpreussen in Geschioben von rotem Orthocerenkalk gefunden, der Ooland oder das Festland Schweden als Heimat der betr. Stücke bezeichnet.

Megalaspis limbata Boeck var. elongata. m. Taf. IV. Fig. 15.

Mehrere Schwanzschilder zeigten bei gloicher Gliedorung der Spindel und Seitenteile eine etwas längliche Form als MLg. limbata forma typica und einen hinter der Spindel krïftiger gehöhlten Randsaum. Ich halte die Form für eine Varietüt der Neg. limbata und nenne sie un ihror Gostalt willen var. elongata. 
Fundorte: Mehrfach in Ost- und Westpreussen in dunkelgraugrünem Kalk mit rereinzelten Glaukonitkörnchen gefunden. Die Heimat der betr. Geschiebe kann sowohl Schwedon als Estland sein.

Megalaspis planilimbata Angelin. Taf. VI. Fig. 2.

1852. Megalaspis planilimbata Angelin Pal. Scand. pag. 18. Taf. XVI. Fig. 2. 1874. As. (Basilicus) sp. Asim. A. tyranno Steinhardt Pr. Trilobiten: pag. 25.

Eine ganze Anzahl von Bruchstücken und einige ganze Schwanzschilder der Art langen mir vor.

Das Schwanzschild ist ungeführ parabolisch, ziemlich kräftig gewölbt. Die Spiudel zeigt ungefähr 14 Glieder. Die Seitenteile tragen 7, durch tiefe Furchen getrennte mehr oder weniger deutlich zweigeteilte Pleuren. Der um das ganze Schild laufende ziemlich breite Saum ist deutlich durch das Aufhören der Seitenrippen begrenzt, er ist meistens ringsum gehöhlt.

Von Meg. limbata unterscheidet sich diese Form durch stärkere Wölbung, durch die deutlicheren Rippen auf den Seitenteilen und durch geringere Breite.

Meg. planilimbata ist häufig in Geschieben von typischem Glaukonitkalk gefunden worden; seine Heimat ist Estland.

Megalaspis gigas Angelin. Taf. V. Fig. 6.

1852. Megalaspis gigas. Angelin: Pal. Scand. pag. 16. Taf. XII. Fig. 3.

Ein Schwanzschild dieser Art lag mir vor. Der Umriss ist ein vorn abgeschnittes Oval. Das ganze, ziemlich kräftig gewölbte Schild ist von einem breiten ebenen Randsaum umgeben. Die stark über die Seitenteile gewölbte Spindel endigt undeutlich; sie lässt bis 25 Ringel erkennen. Die Seitenteile tragen etwa 20 durch tiefe Rinnen von einander getrennte, welche schwach gefurcht sind und bis zu dem oben erwähnten Randsaume gehen.

Maasse: Länge $10 \mathrm{~cm}$, Breite 9,5 cm. Spindelbreite 2,2 cm.

Meg. gigas ist nur einmal im Westpreussen in einem grossen Geschiebe dunkelbraunroten Orthocerenkalkes gefunden worden. Seine Heimat ist Oeland oder das Festland Schweden.

\section{Gattung: Niobe. Angelin.}

Von Niobe lag mir nur ein kleines unbestimmbares Bruchstück eines Schwanzschildes vor (Taf. VI. Fig. 14.). Es zeigt die für Niobe eigentümliche Ausbildung der Pleuren, welche dachziegelartig aneinander gereiht sind.

Fundort: Königsberg.

\section{Gattung: Nileus. Dalman.}

Nileus Armadillo Dalman. Taf. III. Fig. 32.

1828. Nileus Armadillo Dalman: Palaeaden pag. 49. Taf. IV. Fig. 3a-c. 1852. Nileus Armadillo Angelin: Pal. Scand. pag. 19. Taf. XVI. Fig. 5a-c. 1860. Nileus Armadillo Eichwald: Lethaea rossica pag. 1490. 1882. Nileus Armadillo Brögger: Sil. Et. 2 \& 3. pag. 64. 
Die typische Form dieser Art lag mair nur in einem Schwanzschilde vor, wolches ich auf Taf. III. Fig. 32 wiedergebe. Es ist etwa doppelt so breit als lang, in der Mitte hoch gowölbt, mit abgerumdeten Ecken. Die Spindel ist nicht markiert, da die Rückenfurchen fehlen; angedeutet wird sie nur am Vorderrande durch die schmalen, nach unten gebogenen Gelenliflächen. Um das Schwanzschild läuft ein ziemlich breiter Saum, der von dem gewölbten mittleren Teile durch eine ziemlich tiofe und breite Furche abgeschnürt ist. ${ }^{1}$ )

Maasse: Lünge $18 \mathrm{~mm}$, Breite $42 \mathrm{~mm}$.

Fundort: Pr. Holland in Ostpreussen, in grauem körnigem Kalk, der an don schwedischen Orthocerenkalk erinnert. N. Armadillo ist aus Estland bisher nicht mit Sicherheit bekannt, die Heimat unseres Stiickes ist also jedenfalls Schweden.

Nileus sp. Taf. III. Fig. 33.

Das auf Taf. III. Fig. 33 abgebildete Schwanzschild lag in einem Geschiebe grauen Orthocerenkalkes zusammen mit Illaenus chiron Holm. Es ist etwa nur $1 \frac{1}{2}$ mal so breit als lang und ringsum mit einem weniger stark abgesetzten Randsaum umgeben als N. Armadillo.

Fundort: Königsberg.

Nileus? sp. Taf. III. Fig. 31.

1874. Nileus armadillo Steinhardt: Pr. Trilob. pag. 52. 'Taf. IV. Fig. 9.

Steinhardt beschreibt das auf Taf. III. Fig. 31 abgebildete Schwanzschild als N. armadillo Dalm. Diese Bestimmung kann ich ebensowenig für richtig halton, als die der Volborth'schen Stücke, welche eine undeutlich durchschoinende Schwanzspindel haben sollen. ${ }^{2}$ ) Steinhardt giebt a. a. O. an, dass das Schwanzschild keine Spur einer Spindel zeigt; bei genauer Betrachtung bemerkt man jedoch deutlich zwei schwache convergierende Eindrücke, welche die Ausdehnung der breiten Spindel anzeigen; diese Eindrücke fehlen bei N. armadillo Dalm. stets. Ausserdem nennt Steinhardt den Hinterrand der Gelenkfächen nur verdickt, während er in Wirklichkeit eine scharfe, erhöhte Kante bildet, von welchor die Gelenkflächen steil abfallen, was bei N. armadillo nie der Fall ist. Diese Ausbildung der Gelonkflächen, sowie die hinter denselben auftretenden deutlichen Kiniofurchen und das Fehlon dos für $\mathrm{N}$. armadillo so charakteristischen Randsaumes lassen es aussor Zweifel, dass die Steinhardtsche Bestimmung falsch ist.

Fraglich orscheint es, ob das vorliegendo Schwanzschild überhaupt zur Gattung Nileus gehört. Da mir nur dieses eine Stick vorlag, konnte ich es auf die Ausbildung seines Umschlages hiu nicht untersuchen. Die Form des Umschlages würde ja entscheiden, ob hier ein Vertreter der Familie der Asaphiden überhaupt, oder vielleicht eine mit Illaenus verwandte Form vorliegt, an welche Gattung das Schwanzschild lebhaft erinnert.

Das vorliegende Stück wurde in einem grauen, schwach rötlich gefleckten Kalkstein bei Rosenberg in Westpreussen gefundon.

1) Neuerdings mehrfach in rotem Orthocerenkalk gefunden.

2) cf. Volborth: „Ueb. d. m. glatt. IRumpfgliedern versehenen Russ. Trilobiten." Mins. de l'Ac. d. Sc. d. St. Petersb. 1863. pag. 37. Tat. 1V. Fig. 69. 
An die Familie der Asaphiden schliesse ich die Schwanzschilder dreier Formen an, die ich nach den vorhandenen Bestimmungen nur zur Gattung

\section{Holometopus Angelin}

stellen kann. Angelin selbst giebt keine genaue Charakteristik dieser Gattung und hat möglicherweise Formen in ihr zusammengefasst, die garnicht zusammen gehören, wie Hol.? elatifrons, von welcher Art Angelin allein das Kopfschild kennt, auf dem der Verlauf der Gesichtsnähte ganz und gar nicht der Angabe Angelins (Pal. Scand. pag. 58) entspricht. ${ }^{1}$ ) Für die vorliegenden Schwanzschilder wiederhole ich die Diagnose Angelins: ${ }^{2}$ )

„Abdomen, latiusculum, semicirculare, immarginatum, integerrimum, rhachis distincta, angusta, conica, marginem scuti haud attingens." $\mathrm{Zu}$ den Asaphiden stelle ich die folgenden Arten, da der Umschlag (bei dem einen der Stücke freigelegt, bei anderen durch die Schale hindurchschimmernd) eine ähnliche Ausbildung zeigt, wie bei den Arten der Gattung Asaphus.

Holometopus? gracilis n. sp. Taf. V. Fig. 8. 8a.

Zwei Schwanzschilder zeigen einen halbkreisförmigen Umriss, sehr kräftige Wölbung des mittleren Schildteiles und einen verhältnismässig breiten, flachen Randsaum. Die Spindel ist nach hinten stark verschmälert, sie läuft in einen Kiel aus, der bis beinahe zum Rande des Schwanzschildes geht. Auf dem vorderen Teil der Spindel sind etwa drei deutlichere Ringe zu erkennen, auf welche eine Reihe ganz undeutlicher folgt. Die Seitenteile tragen je 6 , ungefähr radial verlaufende, undeutliche Rippen. Der Umschlag, durch die Schale hindurchschimmernd, nimmt etwas mohr als die halbe Schildbreite ein.

Maasse: Länge $6 \mathrm{~mm}$, Breite $10 \mathrm{~mm}$, Spindelbreite $2 \mathrm{~mm}$.

" $10 \quad " \quad 28 \quad " \quad$ " $3 \quad$

Die Oberfläche, auch die der Spindel, ist mit sehr feinen, dichtgestellten Wellenlirien verziert.

Fundort: Bäckermühle bei Marienwerder, Westpreussen, in grauem körnigen Kalk, der an schwedischen Orthocerenkalk erinnert.

\section{Holometopus? laevis n. sp. 'Taf. V. Fig. 9.}

Von der Form der vorigen Art, zeigt die vorliegende auf der ebenfalls in einen Kiel auslaufenden Spindel drei deutliche Ringel, während die Seitenteile vollkommen glatt sind.

Maasse: Länge $8 \mathrm{~mm}$, Breite $12 \mathrm{~mm}$, Spindelbreite $3 \mathrm{~mm}$.

Fundort: Nasser Garten bei Königsberg.

H.? laevis lag in dunkel braunrotem Kalk, der mit dem oberen roten Orthocerenkalk Schwedens vollkommen übereinstimmt. Schweden oder Nachbargebiete des Ostseebeckens sind däher die mutmassliche Heimat unserer Art.

1) ef. W. C. Brögger: Sil. Et. 2 u. 3. pag. 12S. Taf. III. Fig. 13.

2) cf. Angelin 1. c. pag. 58. 
Von den nahestehonden Angelinschen Arten Hol. aciculatus ${ }^{1}$ ) und Hol. limbatus $^{2}$ ) sind die boiden eben angeführten Formen dureh dio kiolartige Verlängerung der Spindel geschieden.

\section{Holometopus? radiatus n. sp. Taf. IV. Fig. 16.}

Das Schwanzschild ist halblireisfürmig, von einem breiten Randsaum umgeben, die Spindel ist schmal, lang, bis zum Ende deutlich geringelt. Die Seitenteile tragen 6, durch ziemlich tiefe Furchen getrennte, radial verlaufende, gewölbto Pleuren.

Der bei dem abgebildeten Stücke blosgelegte Umschlag ist breit, etwa wie bei der Untergattung As. s. str., gehöhlt, mit sehr dicht gestellten parallelen T'errassenlinien verziert.

Maasse: Länge $10 \mathrm{~mm}$, Breite $18 \mathrm{~mm}$. Spindelbreite $3,5 \mathrm{~mm}$.

Fundort: Königsberg.

Hol.? radiatus zoigt in seiner äusseren Form. Aehnlichkeit mit Hol. ornatus Ang. ${ }^{3}$ ) doch das Fehlen der Höckerchen auf der Spindel und den Seitenteilen bei der vorliegenden Form trennt dis beiden Arten.

\section{Fam.: Remopleuridae.}

\section{Gattung: Remopleurides Barrande. Portlock.}

Remopleurides Jentzschi n. sp. Taf. I. Fig. 31a. b.

Aus der Forst Wilhelmswalde bei Skurz in Westpreussen lagen mir mehrere Glabellen vor, welche der des Remopleurides radians ${ }^{4}$ ) ziemlich nahe stehen. Die Glabella ist breiter als lang, flach gerrölbt, nach vorn in einen Stirnfortsatz ausgezogen, der erheblich breiter als bei $R$. radians ist. Droi Paar Soitenfurchen sind angedeutet, das erste Paar nur in Form dunklerer Punkte, die beiden hinteren Paare als deutliche Linien.

Der Vorderrand des Steinfortsatzes ist schwach eingebuchtet, ähnlich wio bei R. emarginatus Törnquist, welche Art von unserer vorliegenden ebenso wie $R$. radians durch die Ausbildung der Seitenfurchen verschieden ist. Der Nackenring ist ziemlich breit, in der Mitte desselben liegt ein kloiner schwacher Höcker. Die Augendeckplatten zeigen, soweit sie erhalten sind, die für Remopleurides charakteristische Sichelform.

Maasse: Länge der Glabella $8 \mathrm{~mm}$, Breite $9 \mathrm{~mm}$, Breito des Stirnfortsatzes $4 \mathrm{~mm}$, Länge desselben 2,5 mm.

Fundort: Forst Wilhelmswalde bei Skurz, Westpreussen.

R. Jentzschi liegt in einem Goschiebe hellgrauen Echinosphaeritenkalkes. Heimat: Das Ostseebecken?

1) cf. Angelin 1. c. pag. 59. Taf. XXX. Fig. 5.

2) cf. Angolin 1. c. pag. 58. Taf. XXX. Eig. 7 a.

3) cf. Angelin 1. c. pag. 58. Taf. IXx. Fig. 6.

4) cf. Berraude: Syst. sil. Bd. I. pag. 359. Tat. ILIII. Yig. 33. 36. 


\section{Fam.: Olenidae.}

\section{Gattung: Olenus: Dalman.}

Olenus truncatus Brünnich. Taf. IV. Fig. 25. 26.

1845. Olenus truncatus Brünn: in Angelin. Pal. Scand. pag. 48. Taf. XXV. Fig. 1.

Eine sehr grosse Anzahl von Bruchstücken dieser Art liegen mir vor, aus denen ich das Kopfschild Taf. IV. Fig. 25 reconstruiert habe.

Das Kopfschild ist etwas mehr als doppelt so breit als lang, mit fast geradem Vorderrande, Ringsum läuft ein schmaler Randsaum neben einer deutlichen Randfurche. Die Hinterecken sind in wenig divergierende Hörner ausgezogen.

Die Glabella nimmt etwa $2 / 3$ der Länge und wenig über $1 / 4$ der Breite des Kopfschildes ein. Sie ist nach vorn wenig verschmälert, abgerundet, von tiefen Rückenfurchen umgrenzt. Drei Paar Seitenfurchen treten auf, die von vorn nach hinten an Länge und Tiefe zunehmen. Sie bilden wenig geschwungene, schräg nach hinten und innen gerichtete Eindrücke. Die Nackenfurche ist tief und tritt deutlicher hesvor als die dritten Seitenfurchen. Der Nackenring ist etwas höher gewölbt als die Glabella und trägt einen ganz schwachen Mittelhöcker.

I) ie festen Wangen sind etwa $3 / 4$ so breit als die Glabella; zu den kleinen halbmondförmigen Augen geht vom Stirnteile der Glabella ein feiner Augenwulst hin. Die Augendeckplatten sind von einer Furche begrenzt, welche sich auf die freien 'Wangen fortsetzt und den Augengrund umgrenzt.

Der Schildteil vor der Glabella ist schräge nach unten gebogen, gewölbt. Als schwache Verlängerung der Rückenfurchen setzt sich auf diesen Schildteil eine ganz flache, breite Vertiefung von beiden Seiten des Stirnteils der Glabella zum Vorderrande fort.

Die freien Wangen sind schwach gewölbt.

Die Oberfläche des Kopfschildes ist fast ganz glatt; nur auf den freien Wangen und auf dem breiten Saume vor der Glabella verlaufen sehr feine, radial resp. parallel angeordnete Runzeln. Leibesringe waren nach Angelin $\left.{ }^{1}\right) 13$ vorhanden. Die Spindel ist deutlich abgesetzt, gewölbt, die Pleuren sind längsgefurcht; sie endigen spitz.

Das Schwanzschild ist dreieckig, doppelt so breit als lang. Die Spindel ist 5-6 gliederig; die Seitenteile tragen 4 breite gefurchte Pleuren. Um das ganze Schild läuft ein schmaler Saum.

Maasse: Kopfschild: Länge $6 \mathrm{~mm}$, Breite $12,5 \mathrm{~mm}$. Glabella: Länge $4 \mathrm{~mm}$, Breite 3-3,5 mm. Schwanzschild: Länge $2,5 \mathrm{~mm}$, Breite $5 \mathrm{~mm}$. Spindelbreite 1,5 $\mathrm{mm}$.

Fundort: Bäckermühle bei Marienwerder in Westpreussen.

Heimat: Durch das Gestein (schwarzer cambrischer Stinkkalk) wird Schweden als die Heimat bezeichnet.

1) Angelin. 1. c. pag. 43. 


\section{Gattung: Sphaerophthalmus. Angelin.}

Sphaerophthalmus alatus Boeck. Taf. IV. Fig. 27. 27 a.

1838. Trilobites alatus Boeck in Keilhau: Gaea norwegica. pag. 143.

18j4. Sphaerophthalmus alatus Angelin: P’al. Scand. pag. 4!. 'T'af. XXVI. Fig. 9.

1880. Sphatephthalmms alatus Bocek sp. in Limnarsson: Om Försteningarne i. 1.

Svenska Lagr. m. Peltura och Sphaer. pag. 97. Taf. I. Fig. 6-10.

Mir lagen nur Mittelschilder des Kopfes vor.

Die Glabella ist hoch gewölbt, cylindrisch, nach vorn wenig verschmälert; sie reicht bis dicht an den eingebuchteten Vorderrand. Nur dio dritten Seitenfurchen sind dentlich ausgebildet; sie fliessen in einen, nach hinten schwach convexen Bogen zusammen. Die vorderen Seitenfurchen sind ganz undeutlich. Der Nackenring ist ebenso breit, wie die dritten Seitenlappen und trägt auf der Höhe seiner Wölbung einen kloinen spitzen Höcker; den langen Nackenstachel, wie ihn Linnarssen 1. c. Taf. I. Fig. 8 abbildet, konnte ich bei meinen Stücken nicht constatieren. Dio festen Wangen sind wenig schmäler als die Glabella und sehr stark gewölbt; in ihrem vorderen Teile ist ein feiner, fadenförmiger Augenwulst zu bemerken.

Die Augen sind nach Angelin kugelig ohne Augendeckel.

Die ungefähr halbkreisförmigen freien Wangen sind am Rande in einen nach hinten gebogenen, feinen Stachel ausgezogen.

Das Schwanzschild ist kloin, keilförmig, mit sehr breiter 3 gliederiger Spindel.

Maasse: Länge des Mittelschildes 2,5 mm, Breite $4 \mathrm{~mm}$.

Fundort: Baeckermühle bei Marienwerder.

Sp. alatus gehört dem oberen Olenusschiefer Schwedens an. Cambrium.

\section{Gattung: Peltura. Milne-Edwards.}

Peltura scarabaeoides Wahlenberg. Taf. IV. Fig. 28.

1821. Entomostracites scaracaeoïdes. Wahlenberg: Petrif. 'Tell. Svec. pag. 41. Taf. I. Fig. 4.

1854. Peltura scarabaeoïdes Angelin: Pal. Scand. pag. 45. 'Taf. XXV. Fig. 8. 1880. Peltura scarabaeoïdes Wahlbg. sp. Linnarsson: Om Försten. i. d. Lagn. m. Pelt. o. Sphaer. pag. 4. 'Tat. I. Fig. 1-5.

Diese Art ist bis jetzt zweimal in unseren Geschieben gefunden worden, einmal bei Marienwerder in Testpreussen und boi Pr. Holland in Ostprenssen. Beido Geschiebe zeigen nur Mittelschilder des Kopfes.

Die Glabella ist mässig gewölbt, vorn abgestutzt, von ziemlich tiefen Rückenfurchen begrenzt. Drei Paar nach hinten gebogene Seitenfurchen treten auf; sie sind jedoch meistens nur undeutlich zu erkennen; in der Mitte der Glabella stossen sio nicht zusammen. Der Nackenring ist ziemlich breit, wenig gowölbt; durch schrïg nach aussen und hinten verlaufende Aeste der Nackenfurcho werden bei einigen

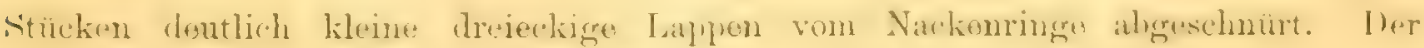
schwache Mittelhöcker auf dem Nackenringe ist selten zu erkennen.

Der Saum vor der Glabella ist sclimal. Dio festen Wangen sind am Hinterrando fünf mal so breit als vorno. Sie sind breit dreieckig, schwach gewölbt. Dio 
Augen sind weit nach vorne gerückt; die kleinen Augendeckel ragen wenig aus den Wangen hervor.

Der Leib besteht nach Linnarsson jedenfalls aus 12 Ringeln.

Das ungefähr halbkreisförmige Schwanzschild zeigt ${ }^{1}$ eine breite dreigliederige Spindel und je drei in Zähne auslaufende Pleuren.

Maasse: Kopfsehildlänge $9 \mathrm{~mm}$, Länge der Glabella $7 \mathrm{~mm}$, Breite $7 \mathrm{~mm}$, hintere Breite der festen Wangen $4 \mathrm{~mm}$.

Fundorte: Marienwerder, Pr. Holland.

In dem Geschiebe von Marienwerder lagen neben Kopfschildern von Pelt. scarabaeoides noch solche von Sphaerophthalmus alatus; durch dieses Zusammenvorkommen wird das Alter des betreffenden Geschiebes als dem oberen Olenusschiefer (Cambrium) Schwedens gleichzeitig bestimmt. Die Heimat ist wohl Schweden.

Es sind somit in der vorliegenden Arbeit 140 Trilobitenformen ${ }^{2}$ ) aus den Ost- und Westpreussischen Diluvialgeschieben behandelt worden; von diesen boten 25 zu wenig Anhaltspunkte zur spezifischen Bestimmung. Von den übrigen 115 Formen waren 75 bereits aus den russischen und skandinavischen Heimatsgebieten, resp. aus den Geschieben des norddeutschen Flachlandes bekannt. 22 Formen zeigten so bestimmte Merkmale, dass ich neue Arten auf dieselben begründen konnte, 18 Formen bildeten Varietäten der bereits bekannten Arten.

Diese 115 bestimmbaren Formen verteilen sich auf die Provinzen Ost- und Westpreussen, auf die einzelnen Formationen und die Heimatsgebiete, wie aus den folgenden Tabellen hervorgeht.

1) Linnarsson. 1. c. pag. 5.

2) Von Phacops latifrons wird abgesehen aus oben angegebenen Gründen. 
Zur Erliuterung der folgenden Tabelle diene nachstehende vergleichende Vehersicht des estländischen und schwedischen Cambrium und Silur:

\section{Fistland:}

1. Cambrium: ${ }^{1}$

Unterer Sandstein

$\left(A_{1}\right)$ Blauer Thon

Zone d. Olenellus Mickwitzi

Fucoidensand

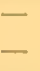

(A2) Ungulitensand

$\left(A_{3}\right)$ Dictyonemaschiefer

II. Untersilur:

$B_{1}$ Glankonitsand
$B_{2}$ Glaukonitkalk . . . . . . . .

$\mathbf{B}_{3}$ Vaginatenkalk .........

C, Echinosphaeritenkalk

$\left.\begin{array}{l}\mathrm{C}_{2} \text { Kuckersche Schicht } \\ \mathrm{C}_{3} \text { Itfersche Schicht }\end{array}\right\} . . . \quad\{$ Mittlerer Graptholithenschiefer u. Chasmopskalk.

D Jeresche Schicht

$D_{2}$ Kegelsche Schicht . . . . . Trinuclenschiefer.

$\mathrm{D}_{3}$ Hemicosmitenkalk

E Wesenburger Schicht

$F_{1}$ Lychholmer Schicht

$F_{2}$ Borkholmer Schicht

III. Obersilur:

$G_{1}$ Jördensche Schicht

$\mathrm{G}_{2}$ Borealis-Bank

$\mathrm{G}_{3}$ Baiküllsche Schicht

II Estonus-Schicht

I Untere Oeselsche Schicht

K Obero Oeselsche Schicht

\section{Schreden:}

Ephytonsandstein.

Fucoidensand.

Zone des Olenellus Kjjerulfi.

Paradoxideszone.

Olenuszone.

Dictyonemaschiefer.

Glaukonitsand

Glaukonitkalk.

Unterer Graptolithenschiefer.

Unterer roter Orthocerenkalk.

Unterer graner

Oberer roter

Oberer grauer

Brachiopodenschiefer.

Oberer Graptolitenschiefer.

Leptaenakalk.

[Gotland.]

(a) Aeltester roter Mergelschieler.

b) Stricklandianamergel.

c) Jüng. Mergelsch. u. Sandst.

d) Kalksteinsch. m. Mergelbänd.-Oolith.

e) Pterygotusschicht.

f) Crinoiden-u. Corallenconglomerat.

g) Megalomusbïnke.

h) Cephalopoden- u. Stromatoporenschicht.

1) cf. Fr. Schmidt: Ueber e. neuentd. Untercambr. Fauna in Estland. Mém, d. l'Ac. d. Sc. d. St. Petersb. 1888. pag. 12-13. 


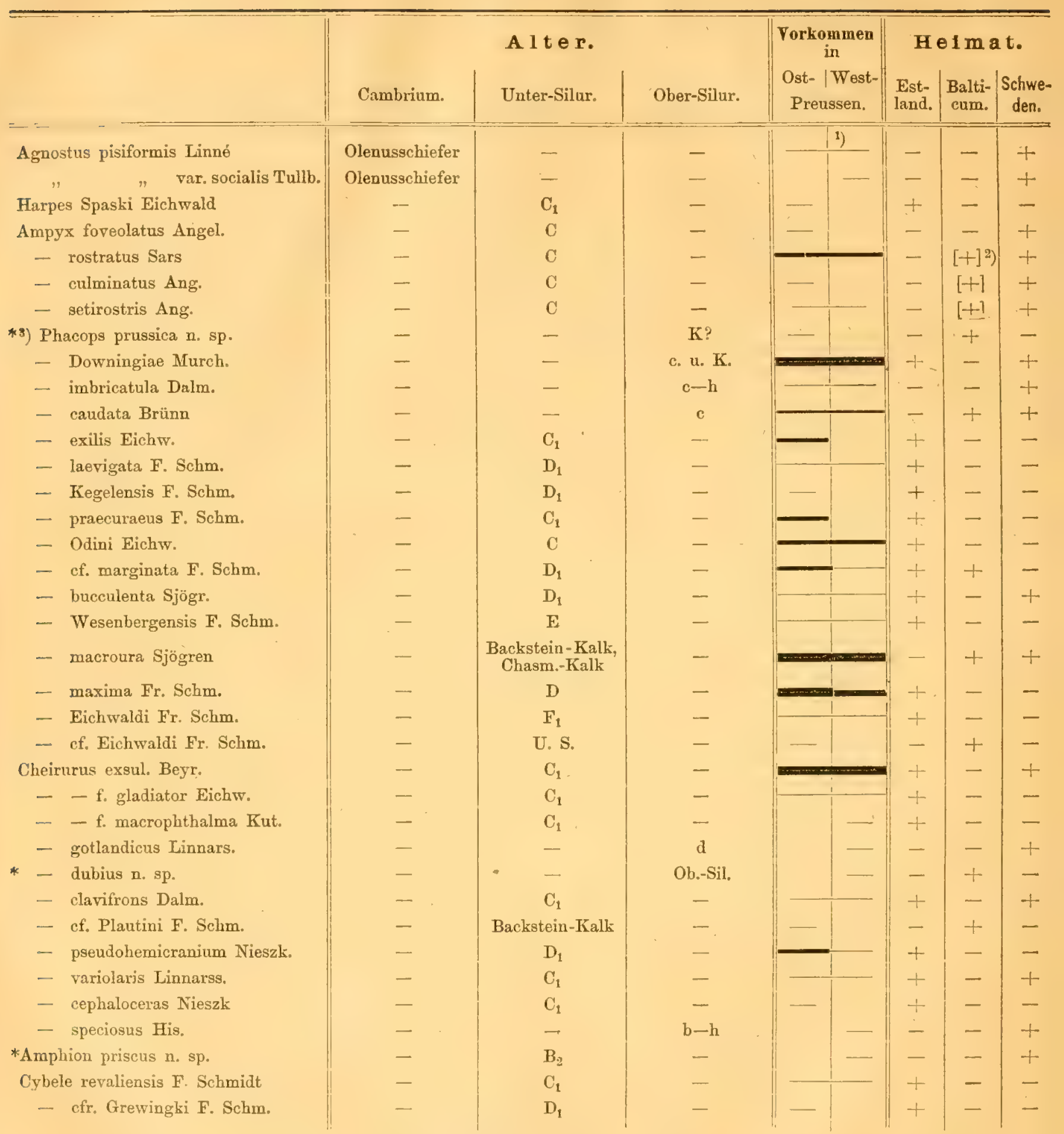

1) Die Lage und Stärke der Striche giebt die Häufigkeit der Art an.

2) $[+]$ bedeutet: Die betr. Art kommt wahrscheinlich auch in dem so bezeichneten Gebiete vor.

3) * bedeutet: Neue Art. 


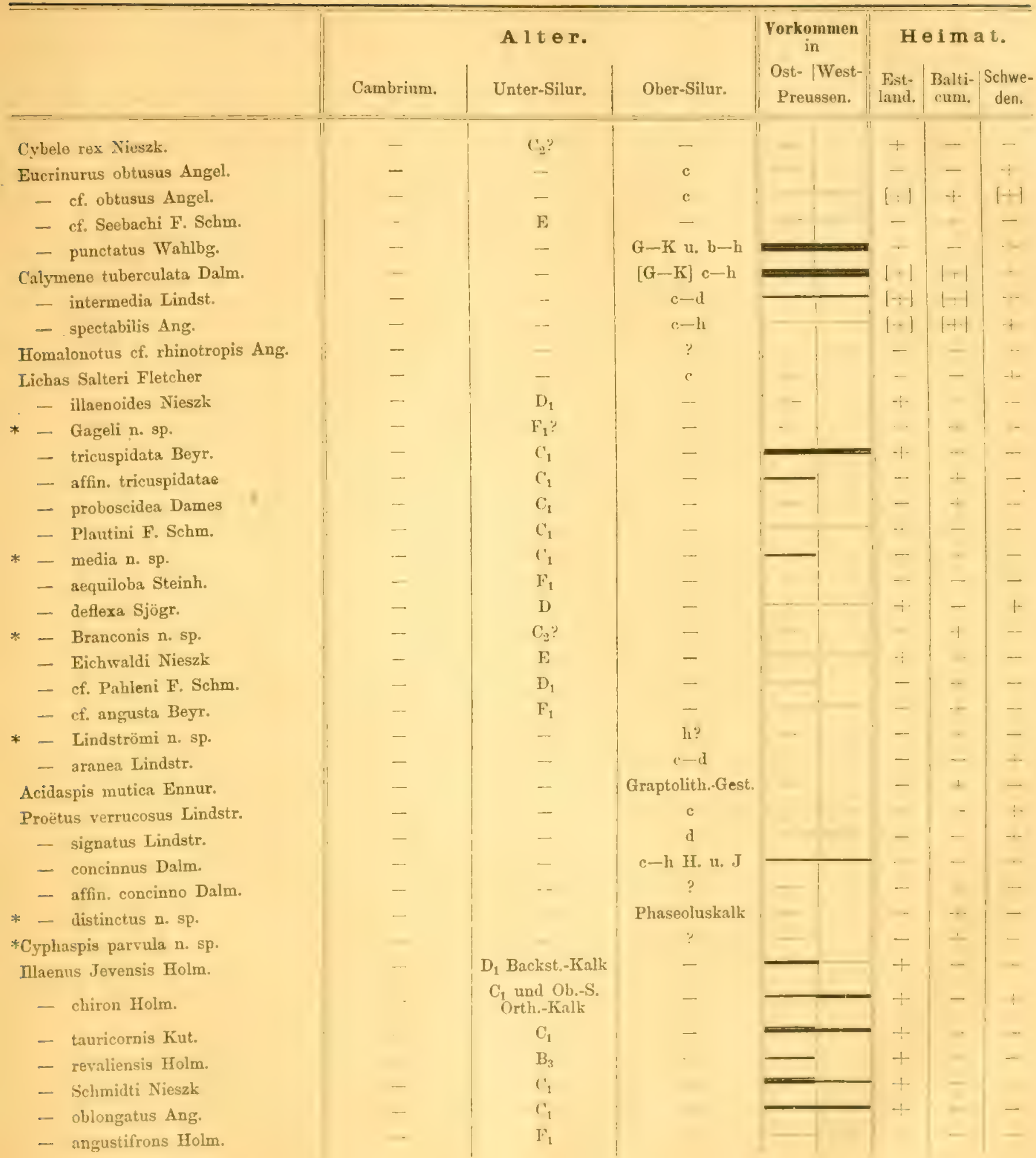




\begin{tabular}{|c|c|c|c|c|c|c|c|c|}
\hline \multirow{3}{*}{ Illenus Römeri Volb. } & \multirow{3}{*}{$\frac{\text { Cambrium. }}{-}$} & \multicolumn{2}{|l|}{ A 1 t er. } & \multirow{2}{*}{\multicolumn{2}{|c|}{\begin{tabular}{|} 
Vorkommen \\
in \\
Ost- / West- \\
Preussen.
\end{tabular}}} & \multicolumn{3}{|c|}{ Heimat. } \\
\hline & & Unter-Silur. & Ober-Silur. & & & $\begin{array}{l}\text { Est- } \\
\text { land. }\end{array}$ & $\begin{array}{c}\text { Balti- } \\
\text { cum. }\end{array}$ & $\mid \begin{array}{c}\text { Schwe- } \\
\text { den. }\end{array}$ \\
\hline & & $\mathrm{F}_{1}$ & - & & & + & - & - \\
\hline * - comes $\mathrm{n} . \mathrm{sp}$ & - & $D_{1}$ & - & & & + & - . & - \\
\hline * - Vanhöffeni n. sp. & - & $D_{1}$ & - & & & - & + & - \\
\hline * - bisulcatus $\mathrm{n} . \mathrm{sp}$ & - & $\mathrm{C}_{1}$ & - & - & & - & + & - \\
\hline - sp. cf. Dalmanni Volb. & - & $\mathrm{C}_{1}$ & - & & & - & + & - \\
\hline _ Maskei Holm. & - & $F_{1}$ & - & $\longrightarrow$ & & + & - & - \\
\hline - Linnarssoni Holm. & - & $F_{1}$ & - & & & + & {$[ \pm]$} & + \\
\hline * _ nuculus $\mathrm{n} . \mathrm{sp}$ & - & $?$ & - & - & & - & + & - \\
\hline - caecus Holm. & - & $F_{1}$ & - & & - & + & - & - \\
\hline - barriensis Murch. & - & - & $\mathrm{J}, \mathrm{b}-\mathrm{h}$ & & & + & - & + \\
\hline - sulcatus Lindstr. & - & - & $d-h$ & & & - & - & + \\
\hline - Holmi Lindstr. & - & - & $c-h$ & & & - & - & + \\
\hline Asaphus riumlosus Angelin & - & Ob. gr. Orth.-K. & - & & & - & - & + \\
\hline - multicostatus Ang. & - & $\mathrm{B}_{3}$ & - & . & & - & + & - \\
\hline _ tecticaudatus Steinh. & - & $\mathrm{C}_{1}$ & - & & & + & - & - \\
\hline - undulatus Steinh. & - & Ob. gr. Orth. $-\mathrm{K}$. & - & & & - & {$[+]$} & + \\
\hline - cf. aciculatus Ang. & - & Ob. gr. Orth.-K. & - & & & - & + & - \\
\hline * - oculosus n. sp. & - & $\mathrm{C}_{1}$ & - & mentances & & + & - & - \\
\hline$*$ - Branconis n. sp. & - & $\mathrm{D}_{1}$ & - & - & & + & - & - \\
\hline - jevensis Fr. Schm. & - & $\mathrm{D}_{1}$ & - & & & + & - & - \\
\hline * - Steinhardti n. sp. & - & $\mathrm{C}_{1}$ & - & 一 & & - & + & - \\
\hline - cf. raniceps Dalm. & - & $\mathrm{C}_{1}$ & - & $=$ & & {$[-+]$} & + & - \\
\hline * - ornatus n. sp. & - & $\mathrm{C}_{1}$ & - & $=$ & & {$[+]$} & + & - \\
\hline * - obtusus n. sp. & - & $?$ & - & - & & - & + & - \\
\hline - devexus Eichwald & - & $\mathrm{C}_{1}$ & - & - & & + & - & - \\
\hline - of. platyurus Ang. & - & Ob. gr. Orth.-K. & - & & & - & - & + \\
\hline - platyrhachis Steinh. & - & $\mathrm{F}_{1}$ & - & & & + & - & - \\
\hline Megalaspis limbata Böck. & - & Ob. rot. Orth.-K. & - & & & - & - & + \\
\hline _ - var. elongata & - & $\mathrm{B}_{3}$ & - & & & {$[+]$} & + & {$[+]$} \\
\hline - gigas Angel. & - & Ob. rot. Orth.-K. & - & & 一 & - & - & + \\
\hline - planilimbata Angel. & - & $\mathrm{B}_{3}$ & - & & & + & - & - \\
\hline Nileus armadillo Dalm. & - & $\begin{array}{l}\text { Ob. roter u. gr. } \\
\text { Orthoc.-Kalk }\end{array}$ & - & & & - & - & + \\
\hline *Holometopus? gracilis n. sp. & - & Gr. Orth,-Kalk & - & & & - & + & - \\
\hline$*$ - laevis n. sp. & - & Roter Orth.-K. & - & & & - & - & + \\
\hline * - radiatus $\mathrm{n} . \mathrm{sp}$ & - & ? & - & & & - & + & - \\
\hline *Remopleurides Jentrschi n. sp. & - & $\mathrm{C}_{1}$ & - & & & - & + & - \\
\hline Olenus truncatus Brünn. & Olenusschiefer & - & - & & & - & - & + \\
\hline Sphaerophthalmus alatus Boeck. & Olenusschiefer & - & - & & & - & - & + \\
\hline Peltura scarabaeoides Wahllbg. & Olenusschiefer & - & - & - & - & - & - & + \\
\hline
\end{tabular}


Unsere Trilobiteufauna bestoht also aus:

5 Arton und Varietäton vom Alter dos Cambrium

83 " $", \quad " \quad$ " $"$ Unter-Silur

$27 " \quad " \quad " \quad, \quad$ " Ober-Silur.

Davon kommen sowohl in Ost- als Westprousson vor . . 54

allein Ostpreussen gehören au . . . . . . . 46

"Westpreussen ",$\quad . . . . . . .15$

Das Verhältnis der Trilobitenfauna der einzelnen Provinzen in Bezug auf Alter und Heimat der Form wird durch folgende Tabello erläutert:

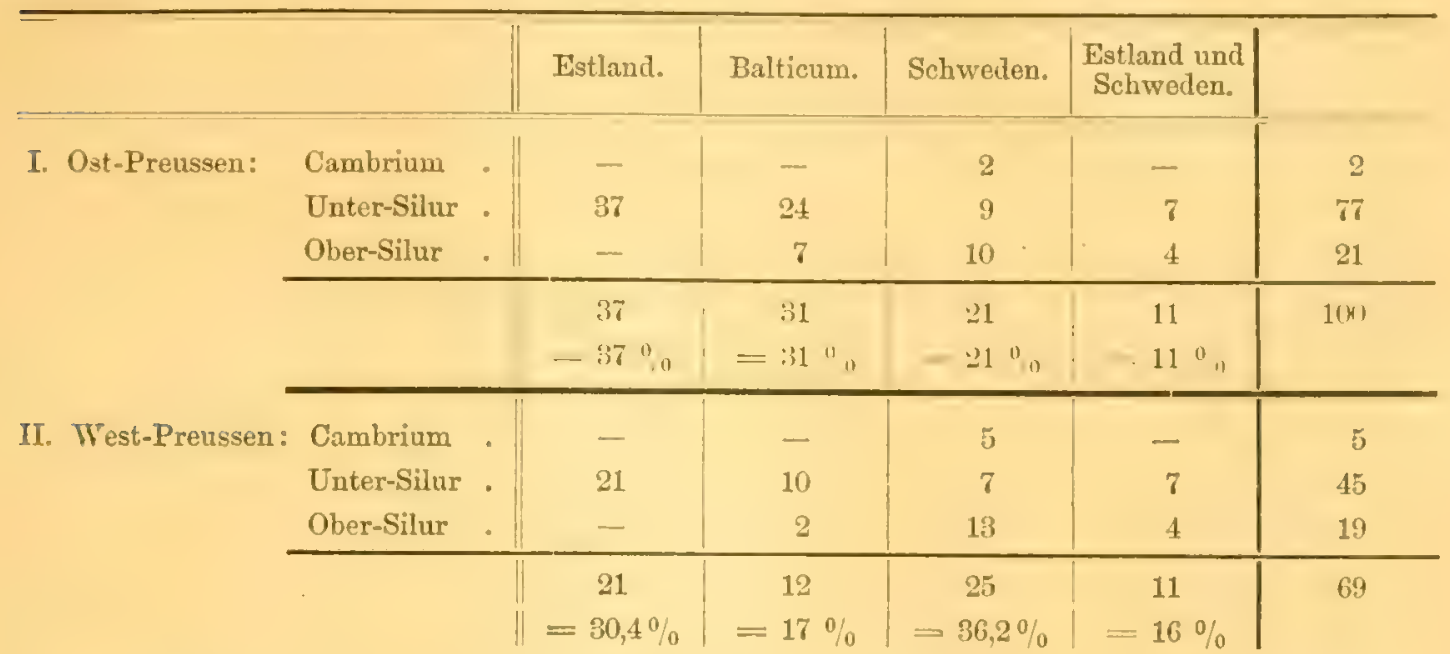

Ein Vergleich dieser Zahlen ergiebt, dass sich die Trilobitenfauna Ostpreussens mehr an Estland, die Wostpronssens mehr an Schwoden anlohnt: Ein abermaliger Beweis für die bereits von Nötling und Kiosow im Allgemoinen und von Gagel ${ }^{1}$ ) in Bezug auf die Brachiopoden gefundene Thatsache. Eigentiumlich ist es ferner, dass wir keine Trilobiten aus dem Estländischen Cambrium und ebenso keine specifisch estländische obersilurische Trilobitenform haben, währond dio Hauptmasse unserer imtersilurischen Trilobiten - 48 resp. $47 \%$ - auf Estland zurückzuführen ist.

Diss. 1890. pag. 71 u. 72.

1) cf. C. Gagel: Die Brachiopoden d. cambr. u. sil. Gesch. d. Prov. Ost- u. Westpr.,

Nach Fertigstellung des Druckes der Arboit orhiolt ich noch mehrere, für das Diluvium unserer Provinzen neue Trilobitonformon: Ampyx sp. aus Glaukonitkalk, Symphysurus sp. aus Ob. rot. Orthocerenkalk, Calymeno sp. aus oinem gelbbraunen, etwas sandigen Kalke, welche ich leider in diese Arbeit nicht mehr aufnehmen konnte. 


\section{Inlaltsserzeiclmis fïr den Palacontologischen Teil.}

Acaste siehe Phacops.

Acidaspis mutica Emmr. . . . 53 VI 30

Agnostus pisiformis Linné . . . 14 IV 23

- - var. socialis Tullb. . . . 15 IV 24

Amphion priscus n. sp. . . . . 35 II 19

Ampyx culminatus Ang. . . . . 17 IV 22

foveolatus Ang. . . . . . 16 IV 17

rostratus Sars. . . . . . . 16 IV 18

setirostris Ang. . . . . . . 17

Arges siehe Lichas.

Asaphus cf. aciculatus Angel. . . 75 V 5

Branconis n. sp.. . . . . 78 V 3

devexus Eichw. . . . . 82 VI 9

jevensis F. Schm. . . . . 78 IV 5

multicostatus Ang. . . . . 73

obtusus n. sp. . . . . . . 81

oculosus n. sp. . . . . . . 75

ornatus n. $\mathrm{sp}$. . . . . . 80 VI

cf. platyurus Ang. . . . . . 82 VI

platyrhachis Steinh. . . . . 82 V 7

cf. raniceps Dalm. . . . . 79 VI 10

rimulosus Ang. . . . . . . 72 IV 13

tecticaudatus Steinh. . . . . 74 IV 10

Steinhardti n. sp. . . . . . 79 V 1

undulatus Steinh. . . . . 75 IV 12

Bumastus siehe Illaenus.

Calymene intermedia Lindst. . . 41 VI 20 spectabilis Ang. . . . . . 42 VI 21 tuberculata Dalm. . . . . 40 VI 19

Chasmops siehe Phacops.

Cheirurus cephaloceras Nieszk. . . 34 II 13 clavifrons Dalm. . . . . . 32 II 11 dubius n. sp. . . . . . . 31 II 7 exsul Beyr. . . . . . . . 28 II 1 gladiator Eichw. . . . . 29 II 3 macrophthalma Kut . . . . 29 II 5 Gotlandicus Lindstr. . . . . 30 II 9 cf. Plautini F. Schm. . . . . 32 III 8 pseudohemicranium Nieszk. . 32 II 15 speciosus His. . . . . . . . 81 II 6 variolaris Linnrs. . . . . 93 II 12
Conolichas siehe Lichas.

Cybele cf. Grewingki F. Schm.. . 37 V 17 revaliensis F. Schm. . . . . 36 V 16 rex. Nieszk. . . . . . . 37 V 15

Cyphaspis parvula n. sp. . . . 57 VI 28 Cyrtometopus siehe Cheirurus.

Dalmania siehe Phacops.

Encrinurus obtusus Ang. . . . 39 V 25 punctatus Emmr. . . . . 40 V 20 cf. Seebachi F. Schm. . . . . 39 V 24

Harpes Spaski Eich. . . . . . 15 IT 29

Homalonotus ef. rhinotropis Ang. 42

Homolichas siehe Lichas.

Holometopus gracilis n. sp. . . $86 \mathrm{~V}$ s laevis n. sp. . . . . . . 86 V 9 radiatus n. sp. . . . . 87 IV $10^{\circ}$

Hoplolichas siehe Lichas.

Isotelus siehe Asaphus.

Illaerus angustifrons Holm . . . 65 III 12 barriensis Murch . . . . 70 III $26^{\circ}$ bisulcatus n. sp. . . . . . 67 III 18 caecus Holm . . . . . . 70 III 21 chiron Holm . . . . . . 60 III 4 comes n. sp. . . . . . . . 66 III 19 cf. Dalmanni Volb. . . . . 68 II $36^{2}$ Holmi Lindstr. . . . . . . 72 III 30 jevensis Holm . . . . . . 59 III 1 Linnarssoni Holm . . . . 69 III 13 Mascliei Holm . . . . . 68 nuculus n. sp.. . . . . . . 69 VI 34 oblongatus Holm . . . . . 64 II 39 revaliiensis Holm . . . . . 63 III 14 Roemeri Volb. . . . . . 66 III 16 Schmidti Nieszk. . . . . 63 III 6 sulcatus Lindstr. . . . . 71 III 28 tauricornis Kut . . . . 61 III 8 Vanhöffeni n. sp. . . . . . 67 III 17

Lichas aequiloba Steinh. . . . 48 V 14 cf. angusta Beyr. . . . . 52 II 34 aranea Lindst. . . . . . 53 V 11 Branconis n. sp... . . . . 48 II 26 


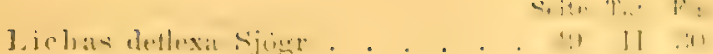

Fichwaldi Nieszk。 . . . . it $\because 1$ it

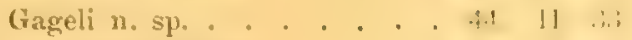

illaenoides Nieszk. . . . 4:; $\because$ 1:2

Lindströmi n. sp. . . . . . .2 Y 16

znedia n. spo....... . 47 I1 25

cf. Pahleni F. Schm. . . . . 51 II

Plantini F. Schm. . . . . Ni VI 1 is

proboscilea Dames . . . . 46

tricuspilata Beyr. . . . . 45 II 201

atfin. tricuspidatae Beyr. . . 4t; I1 2:?

Salteri Fletch. . . . . . 13 VI 17

Megalaspis gigas Angel. . . . . i $\mathrm{T}$

limbata Boeck . . . . . A IV 1.1

- var. elongata . . . . F:3 IV I.,

planilimbata Ang. . . . . is $\mathrm{VI} 2$

Nieszkowskia siehe Cheirnms.

Nileus armadillo Dalm. . . . \& III :

Olenus truncatus Brimn. . . . \&4 IV 2:

Phacops bucculenta Ang. . . . 24 T 11;

candata Emmr. . . . . 20 I 30

Downingiae Murch. . . . . $19 \quad 19$

Fichwaldi F. Schm. . . . . 25 I 21

ct. Eichwaldi Schmidt * . . 25) 1 is

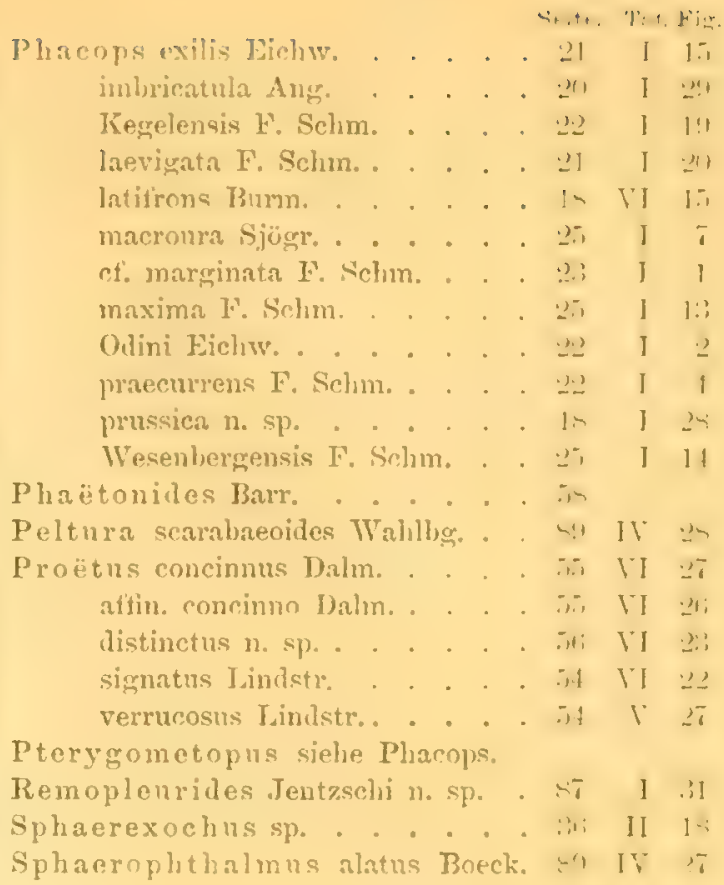

\section{Tafel-Erklärungen.}

['r. ‥ K. $\mid=$ Samml. d. Prov.-Ann. Königsberg.

[M. I. K.] $=$, d. Min.-Inst. Königsberg.

[s. K. D.] = " d. Herrn Dr. Kiesow-Danzig.

|s. V. W. .. - " d. Herm Dr. Vanhüffen-Wehlat.

[S. Z. H.] = " d. Herm Lehrer Zinger-Pr. Holland.

|S. S. P. $\mid="$ d. Herm Konrektor Seydler-Bramaberg.

[S. P. K. . = meine Sammlung. 


\section{Erklärung der Tafel I.}

Fig. 1. a. v. Phacops cf. marginata $\mathrm{F}_{\mathrm{l}}$. Schmidt, Königsberg. [Pr. M. K.] . . . . Seite 23

Fir. 2. a. Phacops Odini Eichw. Ostpr. [M. I. K.] . . . . . . . . . . . . . . " 2 "

Fı. 3. Phacops ct, marginata Fr. Schinidt. Königsberg. [Pr. M. K.] . . . . . . ., 23

Fig. 1. a. Phacops praecurrens. Fr. Schmidt. Wehlau, [Pr. M. K.] . . . . . . . . , 22

Fig. 5. Phacops sp. [? bucculenta]. Wehlau. [Pl. M. K. . . . . . . . . . . . . " 2 ?

Wig. 6. Phacops sp. [? Eichwaldi]. Ostpr. [M. I. K.] . . . . . . . . . . . . . 27

Fi... 7. 7a. Phacops macroura Sjögr. Detmitten. [Pr. M. K.] . . . . . . . . . . " 25

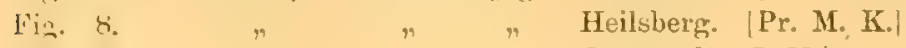

Fin. 3. $\quad " \quad n \quad$ Ostpr. [M. I. K.]

Fig. L11. " " $"$ "Ostpr. [M. I. K.]

Fig. 11. " " $\quad$ " Königsberg. [Pr. M. K.]

Fig. 12. Phacops maxima Fr. Schmidt. Hypostom. Cranz. [Pr. M. K.]. . . . . . , ¿6

Fir. 1:i, 13a. $" \quad n \quad$ Schwanzschild. Wargitten. [Pr. M. K.]

Fi... 14.14a. Phacops Wesenbergensis Fr. Schmidt. Wehlau. [Pr. M. K.] . . . . . " 洪

Iis. 15. " " " Kruglanken. [Pr. M. K.]

Fi. 16. Phacops bucculenta Ang. Wargitten [Pr. M. K.] . . . . . . . . . . . . " 21

Fin. 16. " " "ranz. $\mid$ Pr. M. K.

Hi... 18. Phacops exilis Eichw. Soritten. [Pr. M. K.]. . . . . . . . . . . . . . " 21

Fin. 1\%. Phacops Kegelensis. Fr. Schmidt. Kaidau |Pr. M. K . . . . . . . . . . , . 2

Fi... 20. a. b. c. Phacops laevigata Fr. Schmidt. Gr. Schönau. [Pr. M. K.] . . . . . . " 2:

lic. 21. Phacops Eichwaldi Fr. Schmidt. Wehlau. [S. V. W.] . . . . . . . . . . " 27

Fig. 22. 23. " " ",$\quad$ Königsberg. [Pr. M. K.]

Fi... 2. Phacops sp. [? marginata]. Königsberg. [Pr. M. K.] . . . . . . . . . . . " .";

Fi... 2., Phacops sp. [? Panderi]. Königsberg. [Pr. M. K.] . . . . . . . . . . . . 26

Fi... 26. Phacops sp. Lauth bei Königsberg. [Pr. M. K.] . : . . . . . . . . . . . 24

Ti.. 27. a. b. c. Phacops Downingiae Murch. Belschwitz. [M. I. K.] . . . . . . . . " 1 ,

Jig. 2S. 28a. Phacops prussica n. sp. Cranz. [S. P. K.] . . . . . . . . . . . . " 14

Fin. ... Phacops imbricatula Ang. Kamiontken, |Pr. M. K.l. . . . . . . . . . . " 20

Fin. 30. 30a. Phacops caudata Emmr. Dirschkeim. [M. I. K.] . . . . . . . . . . " 20

Fig. 31. a. b. Remopleurides Jentzschi n. Sp. Wilhelmswalde. [Pr. M. K. ] . . . . . . 97

Fi... 22. Phacops sp. [cf. macroura]. Ostpr. [M. I. K.] . . . . . . . . . . . . . . . 25 

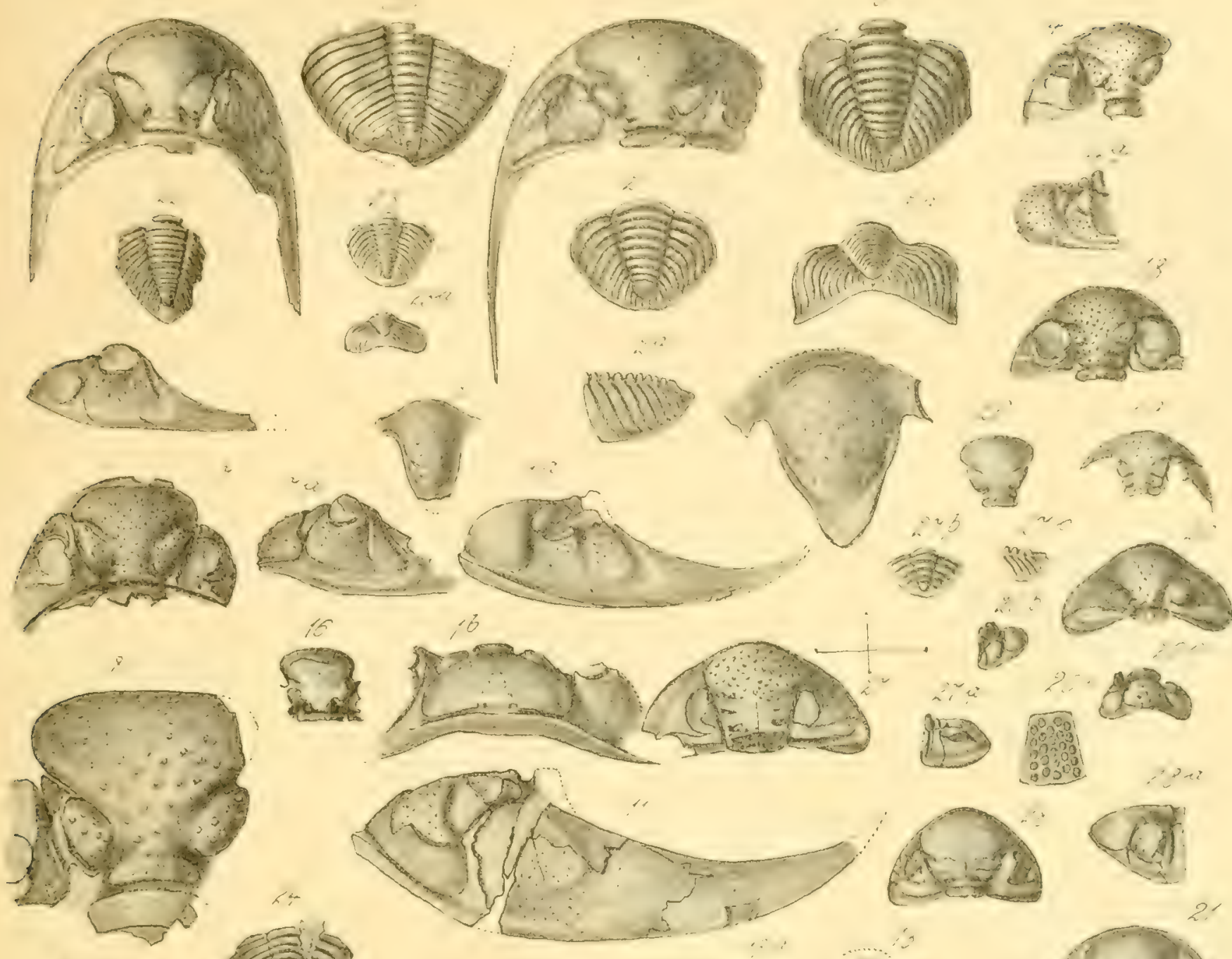

(6)

(2)
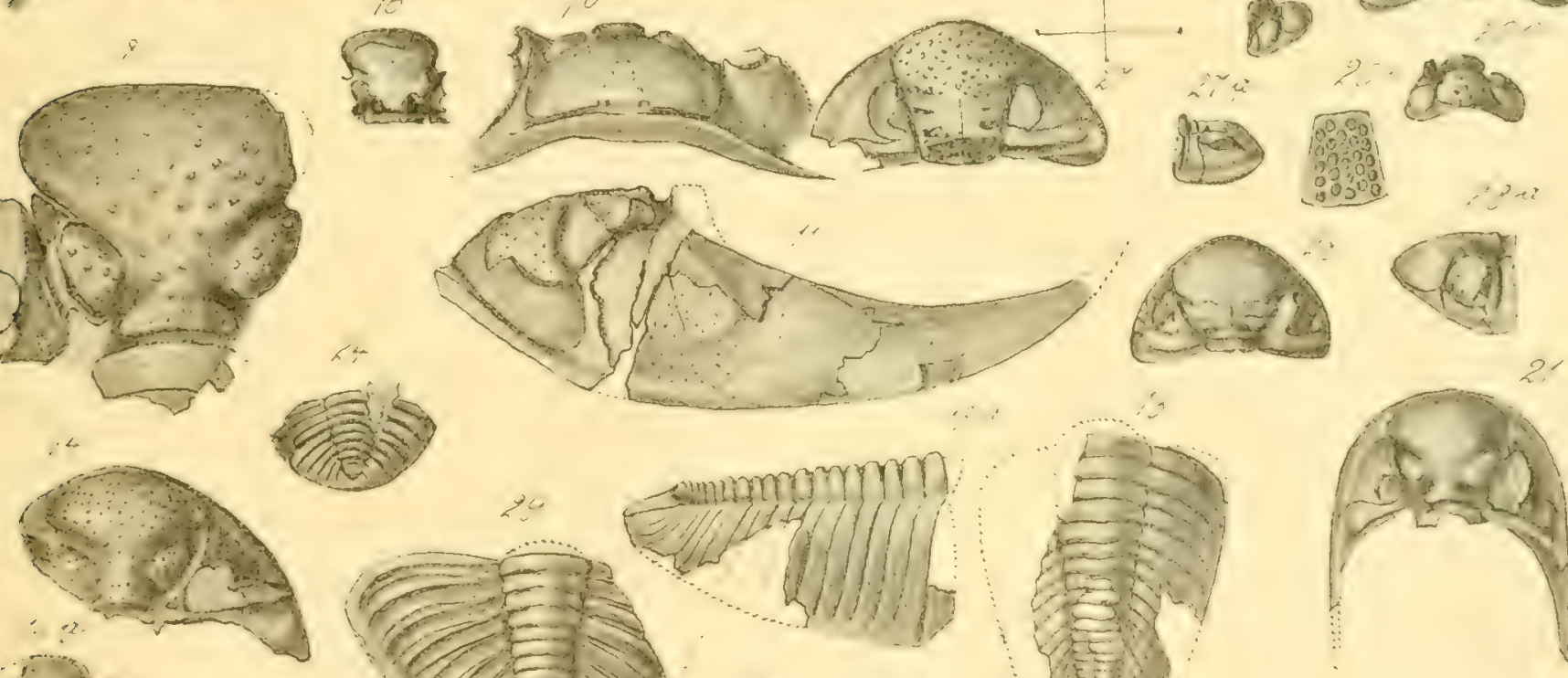

$y^{-2}$

$4-$

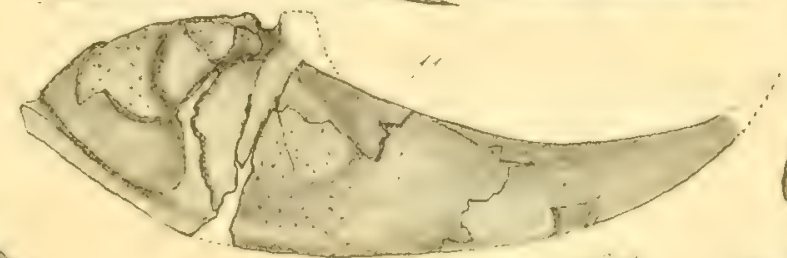

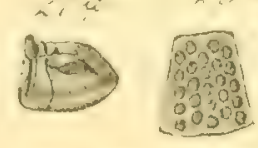

(1):in
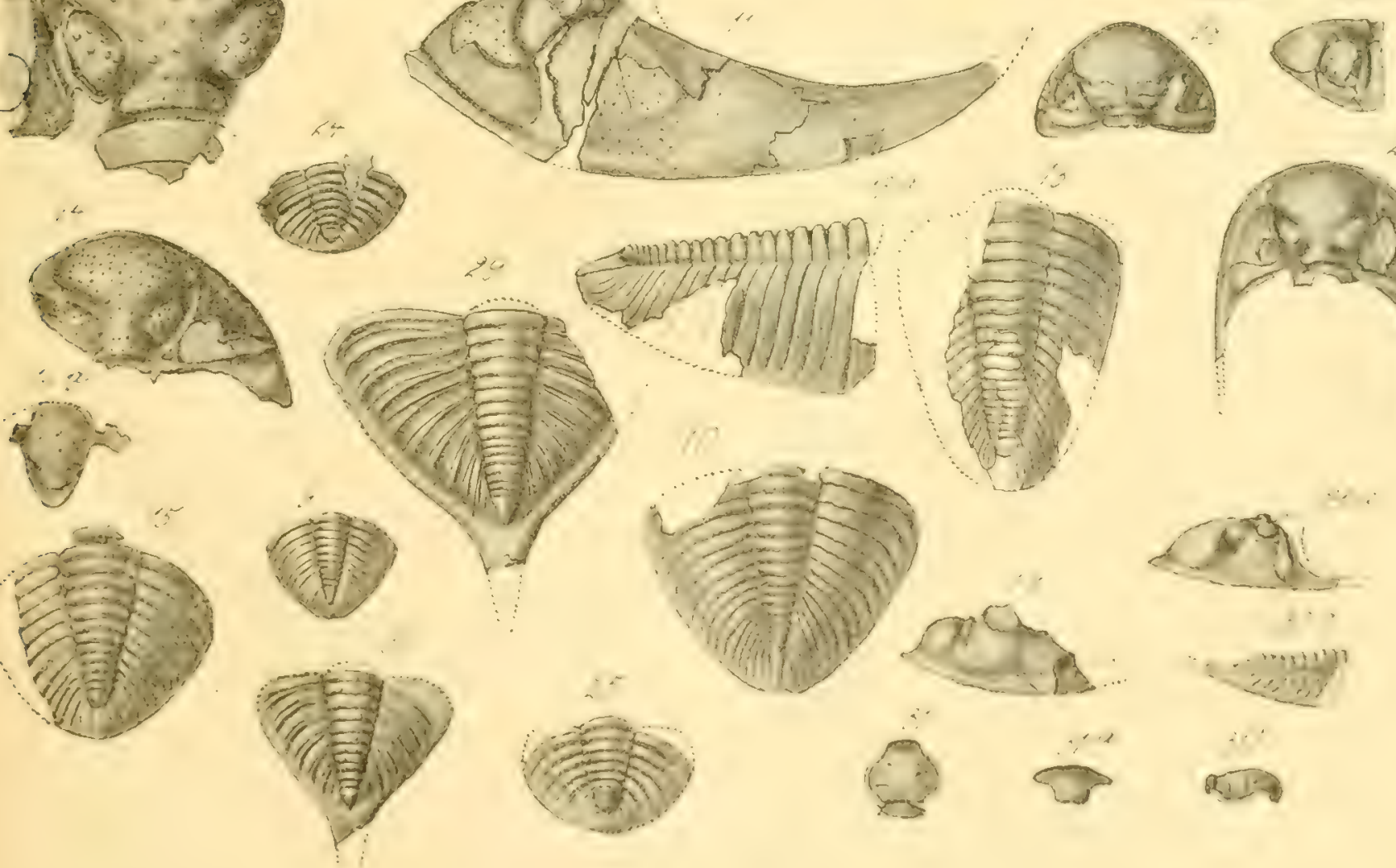

y. commongming
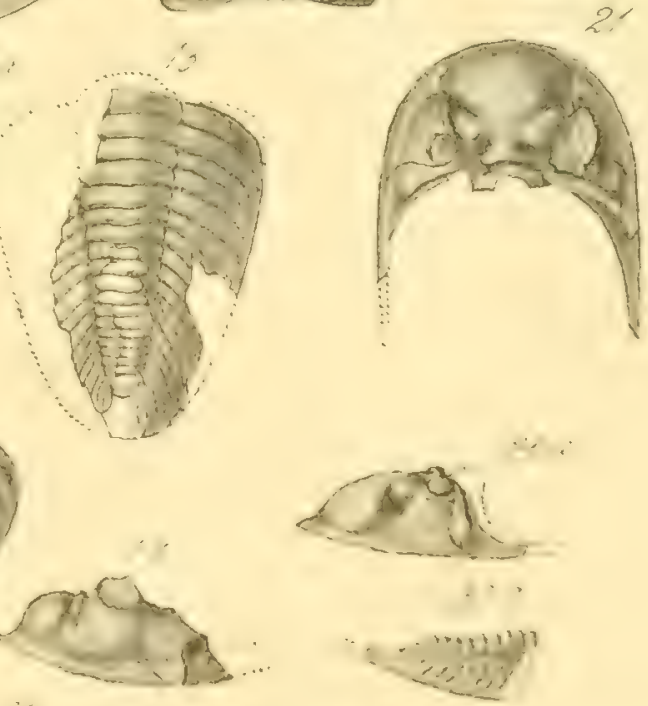


POMPECKI: TRILOBITEN.

Belträge zur Naturkunde Preussens VII. 1890

50 \&
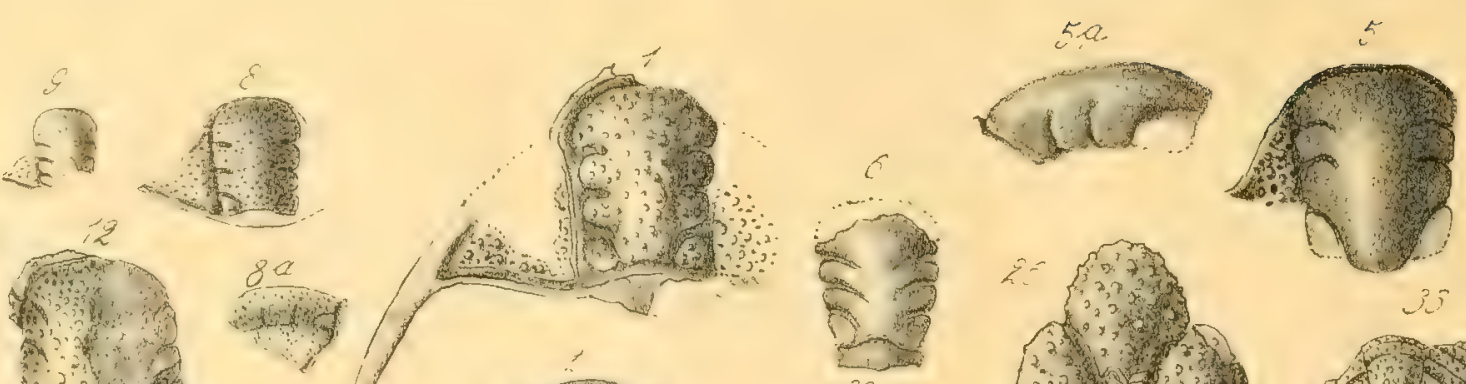

6..1.1.

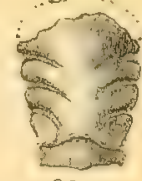

(3)

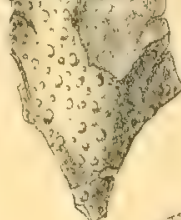

row

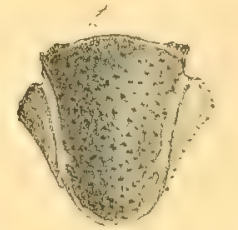

$200 \quad 4(-1)$

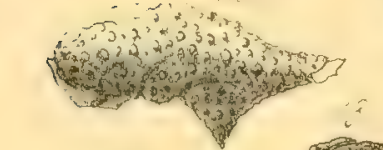

1,2

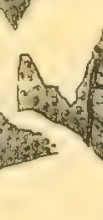

.

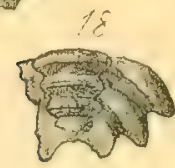

(find

$10 \quad 100$

Eिक्रो से
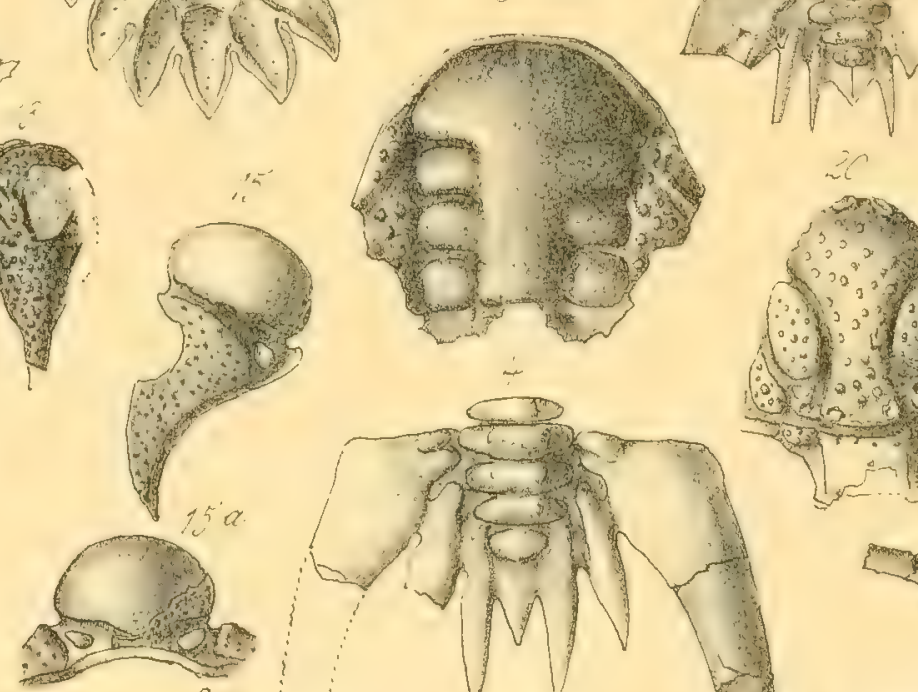

A.
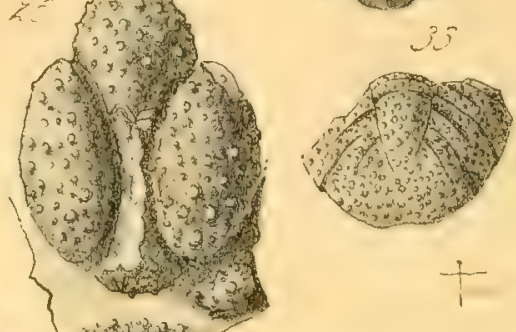

$$
\text { : } 26 a
$$
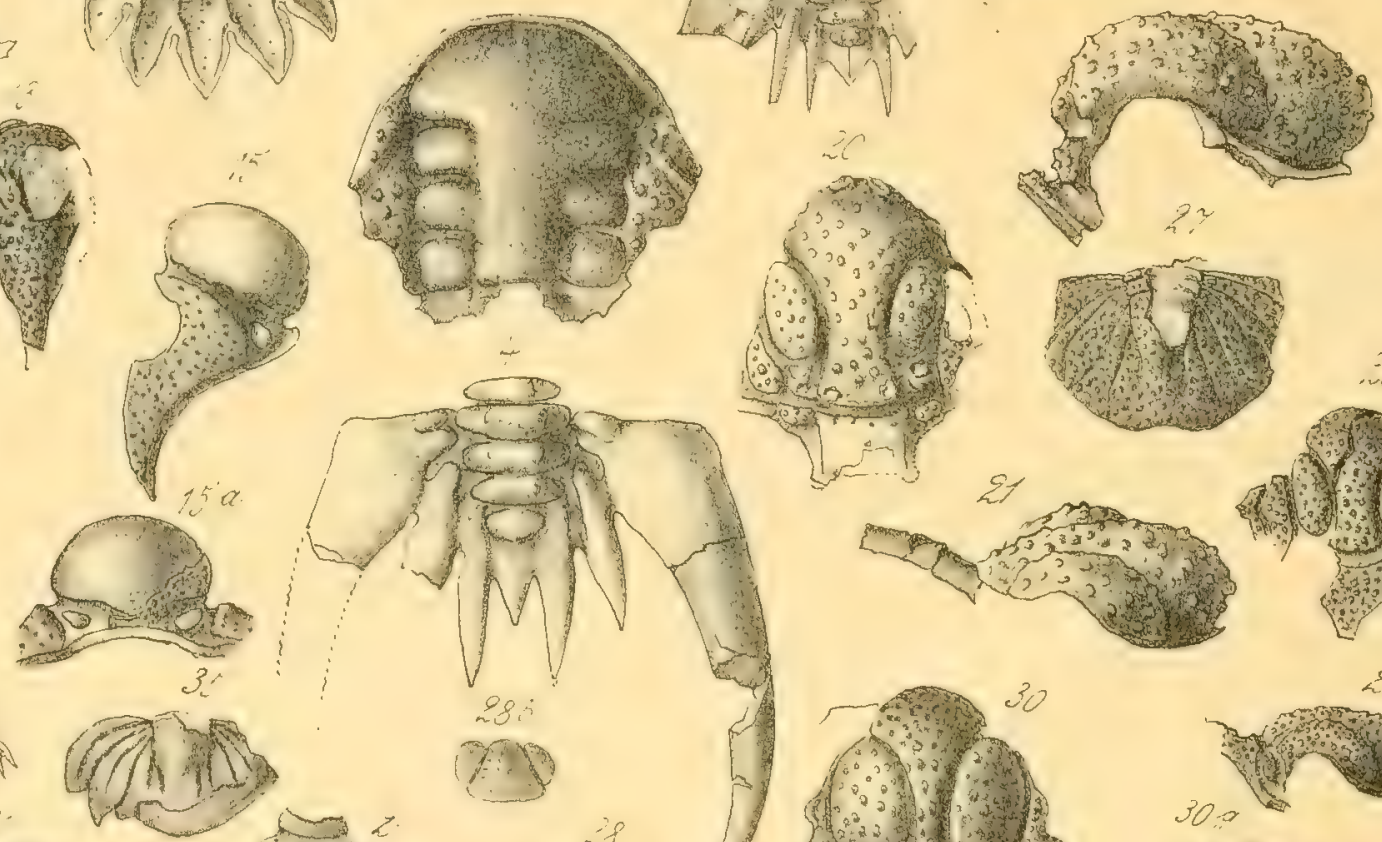

$\therefore 6$
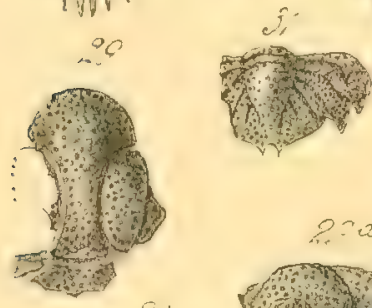

9.
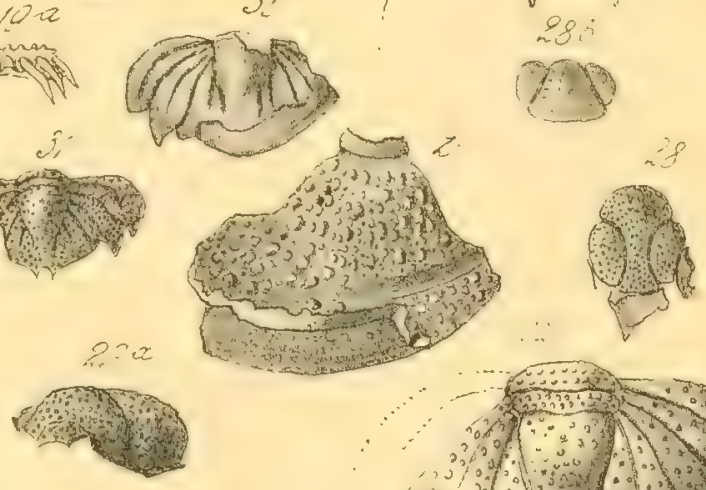

(1)
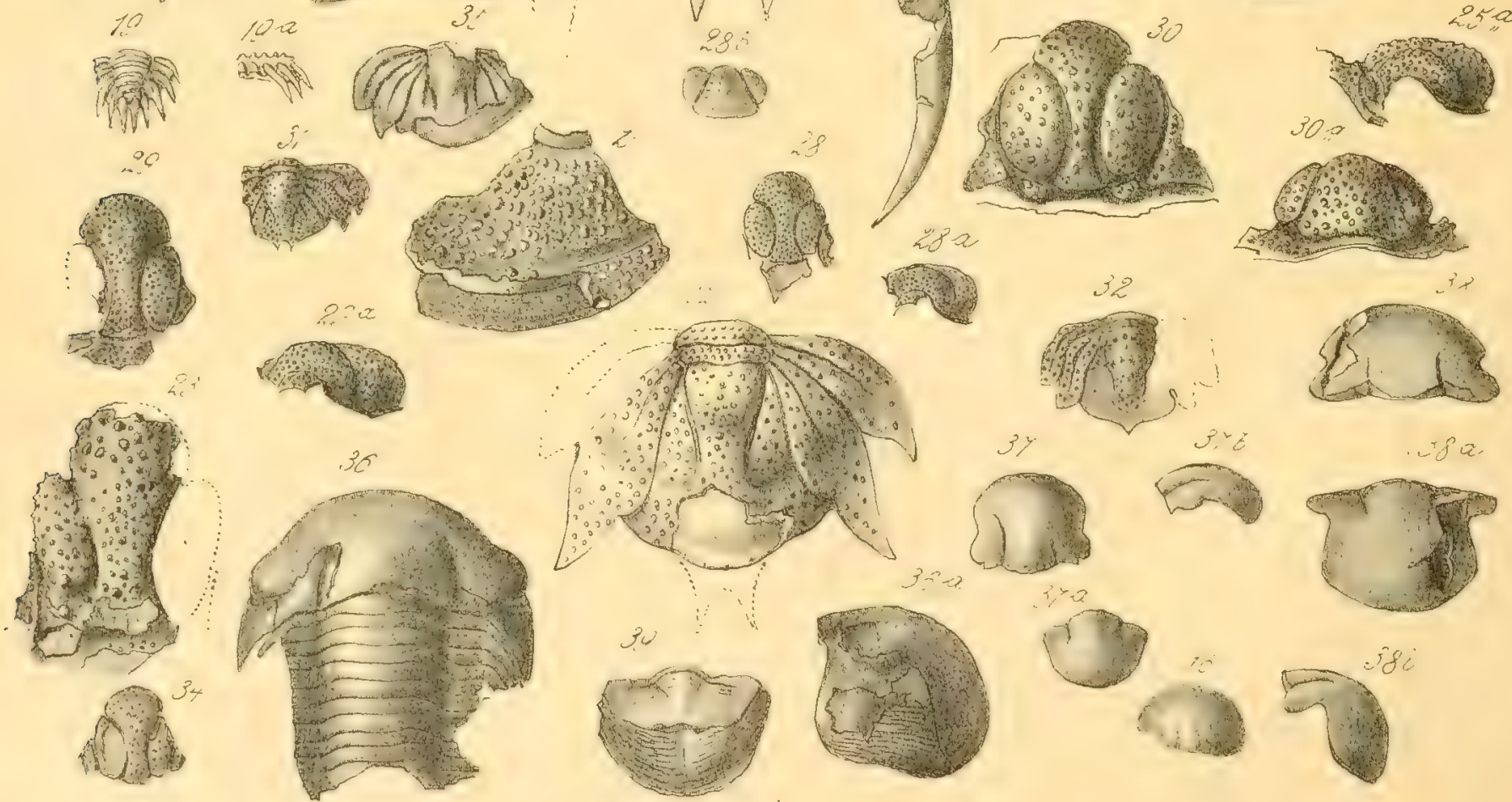

. fo.

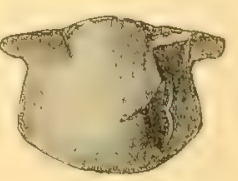




\section{Erklarrung der 'Tafel II.}

Fig. 1. Cheimms exsul. Beyr. Königsberg. [Pr. M. K.] - Das Wangenhnrn nach einem anderen Stiick . . . . . . . . . . . . Seite 28

Fig. 2. Cheirums exsul. Beyr. Itypostom. Königsberg. [Pr. M. K.]

Fig. 3. " " forma gladiator Eichw. Rosenberg. [M. I. K.] . . . . . . n 29

Fig. 4. " $"$ " $"$ Wehlau. [S. V. W.

Fig. 5. อง. " " torma macrophthalma. Rosenterg. [M. I. K.]. . . . . . . , 29

Fig. 6. Cheirurus speciosns His. Rosenberg. [M. I. IK.] . . . . . . . . . . . . . 31

Fig. 7. Cheirums dubius n. sp. Rosenberg. [M. I. I..] . . . . . . . . . . . . . " ?

Fig. 8. 8a. Cheirurns of. Plantini Fr. Schmidt. Wehlan. [S. V. IV.] 4/1 . . . . . $\quad$ n 32

Fig. 9. 10. Cheirums gothuticus Lindstr. Rosenherg. [Pr. M. K.] . . . . . . . , 3

Fig. 11. Cheirums clavifons Dalm. Königsberg. [Pr. M. K.] . . . . . . . . . . ${ }^{9} \quad 82$

Fig. 12. 12ณ. Cheirmus variolaris Limm. Wehlan. [S. V. W. . . . . . . . . . . . " $, 3: 3$

Fig. 13. 13a. Cheirurus cephalocerns Niesz. Wehlau. [M. I. K.] . . . . . . . . . . 34

Fig. 14. Cheirurus? sp. Kurschitten (Kurland). [Pr. M. K.] . . . . . . . . . . . 9 35

Fig. 15. Cheirurus psendohemicraninm Nieszk. Ostpr. |M. I. K.|. . . . . . . . . 9, 32

Fig. 16. " " $"$ Königsb. [Pr. M. K.]

Fig. 17. Cheirums dnbins n. sp. Rosenberg. [M. I. K. . . . . . . . . . . . . . ${ }_{n} 31$

Fig. 18. Sphaerexochus? sp. Fundort mbek, [Pr. M, K. . . . . . . . . . . . . " ni

Fig. 19. 19a. Amphion priscus n. sp. Belschwitz. \{M. I. K. . . . . . . . . . . . "

Fig. 20. Lichas tricuspidata Beyr. [Kopie nach Schmidt Rev, II, Taf. II, Fig. 12.] . . " 45

I.ig. 21. " " $"$ Wehlan. [M. I. K.]

Fig. 22. " " " "Kopie nach Schmidt Rev. II, Tat. II, Fig. 13.]

Fig. 23. I. affin. tricnspiatac Beyr. Wehlan. [S. V. W.I . . . . . . . . . . . . n 46

Fig. 24. I. sp. [? tricuspichata|. Königsherg. [Pr. M. K.] . . . . . . . . . . . . " ti

Fig. 2i. 25a. Lichas media n. sp. Königsberg. [Pr. M. K.] . . . . . . . . . . . 9 47

Fig. 26. 26ia. Lichas Brnconis n. sp. Wehlnn. |M. T. K.] . . . . . . . . . . . . " . 18

Fig. 27. Lichas Eichwaldi Nieszk, TVehlau, [Pr. M. K.] . . . . . . . . . . . . 19

Fig. 28. a b. 29. 31, Lichas of. Pahleni Fr. Schmidt. Königsherg. [Pr. M. K.] . . . " 5l

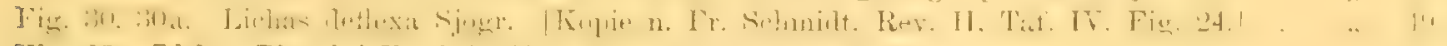

Fig. 32. Lichas Plautini Fr. Schmidt. Königsberg. [Pr. M. K.]. . . . . . . . . . 4 46

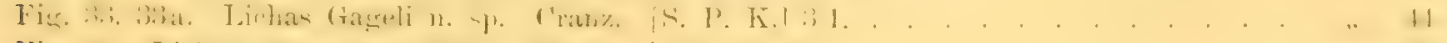

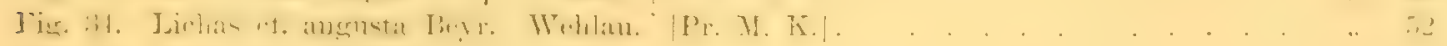

Fig. 35. Lichas sp. Wehlan. [Pr. M. K. . . . . . . . . . . . . . . . . n 52

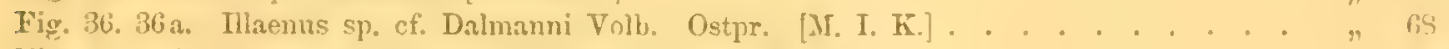

Fig. 37. a. b. Illaenus oblongatus? Holm. Ostpr. [M. I. K] . . . . . . . . . . . , (i4

Fig. 38. a. b. Illaenus sp. Künigsberg. [Pr. M. K.] . . . . . . . . . . . . . ., 72

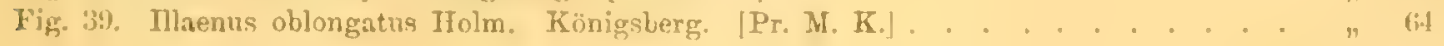




\section{Exklärung dex Tafel III.}

Fig. 1. 1a. Illaenus jevensis Holm. Königsberg. [Pr. M. K.] . . . . . . . . . Seite 5í

Fig. 2. $", \quad, \quad$ Königsberg. [Pr. M. K.]

Fig. 3. " " " (auf Backsteinkalk). Königsberg. [Pr. M. K.]

Fig. 4. 4a. Illaenus chiron Ilohn. Marienwerder. [P1. M. K.] . . . . . . . . . " 60

Fig. 5. " " " Marienwerder. [Pr. M. K.]

Fig. 6. Illaenus Sehmidti. Nieszl. Pr. Holland. [M. I. K.] . . . . . . . . . . . . " 63

Fig. 7. $" \quad$ " Wilhelmswalde. [Pr. M. K.]

Fig. 8, Illaenus tauricomis Kut. Königsberg. [Pr. M. K.] . . . . . . . . . . . " „ ti1

Fim. 9. " " ". " Ostpr. [M. I. K.]

Fị. 10. "

Fig. 11. " " Rosenberg. [M. I: K.]

Fig. 12. 12a. Illaenus angustifrons Holm. Ostpr, [M. I. K.] . . . . . . . . . . . . . (i.

Fig. 13. Illaenus Linnarssoni Holn. Ostpr. [MI. I. K.] . . . . . . . . . . . . . . , (i.)

Fig. 14. Illaenus revaliensis Hlolm, Ostpr. [MI. I K.] . . . . . . . . . . . . . . . (i,i

Yim. 15. 15a. $" \quad "$ Pr. Holland. [MI. I. K.]

Fig. 16. Illaenus Roemeri Volb. Ostpr. [M. I. K.]. . . . . . . . . . . . . . . " " tifi

Fig. 17. 17a. Illaenus Vauhocticni 11. sp. Wehlau. $\mid$ S. V. W. . . . . . . . . . . " , lif

Fig. 18. Illacnus bisulcatus n. sp. Wehlat. . [M. I. K.] . . . . . . . . . . . . . " " (i7

Fig. 19. Illaemus comes n. sp). Königsherg. [Pr. M. K.] . . . . . . . . . . . . . . , tit;

Fig. 20. Illaerus sp. Wehlatr. $[$ S. V. W. . . . . . . . . . . . . . . " 72

Fig. 21. 21 a. Illaenns caecus Holn. Belschwitz. [M. I. K.] . . . . . . . . . . . " Ti

Fig. 22. Illacnus sp. Königsberg. [Pr. M. K.] . . . . . . . . . . . . . . . " . 72

Fig. 23. Illacnus sp. |? Linnarssoni]. Wehlau. [MI. I. K.] . . . . . . . . . . . . " "

Fig. 24. Illaenus sp. cf. Dalmanni Volb. Ostpr. [M. I. K.] . . . . . . . . . . . " " lis

Fig. 25. Illaenus sp. Wehlau. [M. I. K.] . . . . . . . . . . . . . . . " .2

Fig. 26. Bumastus barriensis Murch. Kosenberg. $[\operatorname{Pr}$. M. K. $]$. . . . . . . . . . " T()

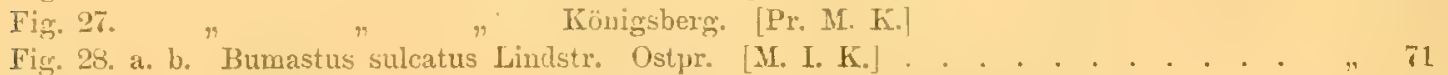

Fig. 28. a. b. Bumastus sulcatus Lindstr. Ostpr. [M. I. K.] . . . . . . . . . " "

Fig. 30. Bumastus" Holmi Lindstr. Rosenberg. [M. I. K.] . . . . . . . . . . . . " i:

Fig. 31. Nileus? sp. Rosenberg. [M. I. K.] . . . . . . . . . . . . . . . . " " s

Fig. 32. Nileus armadillo Dalm. Pr. Holland. [M. I. K.] . . . . . . . . . . . . " \&4

Fig. 33. Nileus sp. Múrienwerdcr. $[$ Pr. M. K.] . . . . . . . . . . . . . . . . . 85 
POMPECKI: TRILOBITEN.
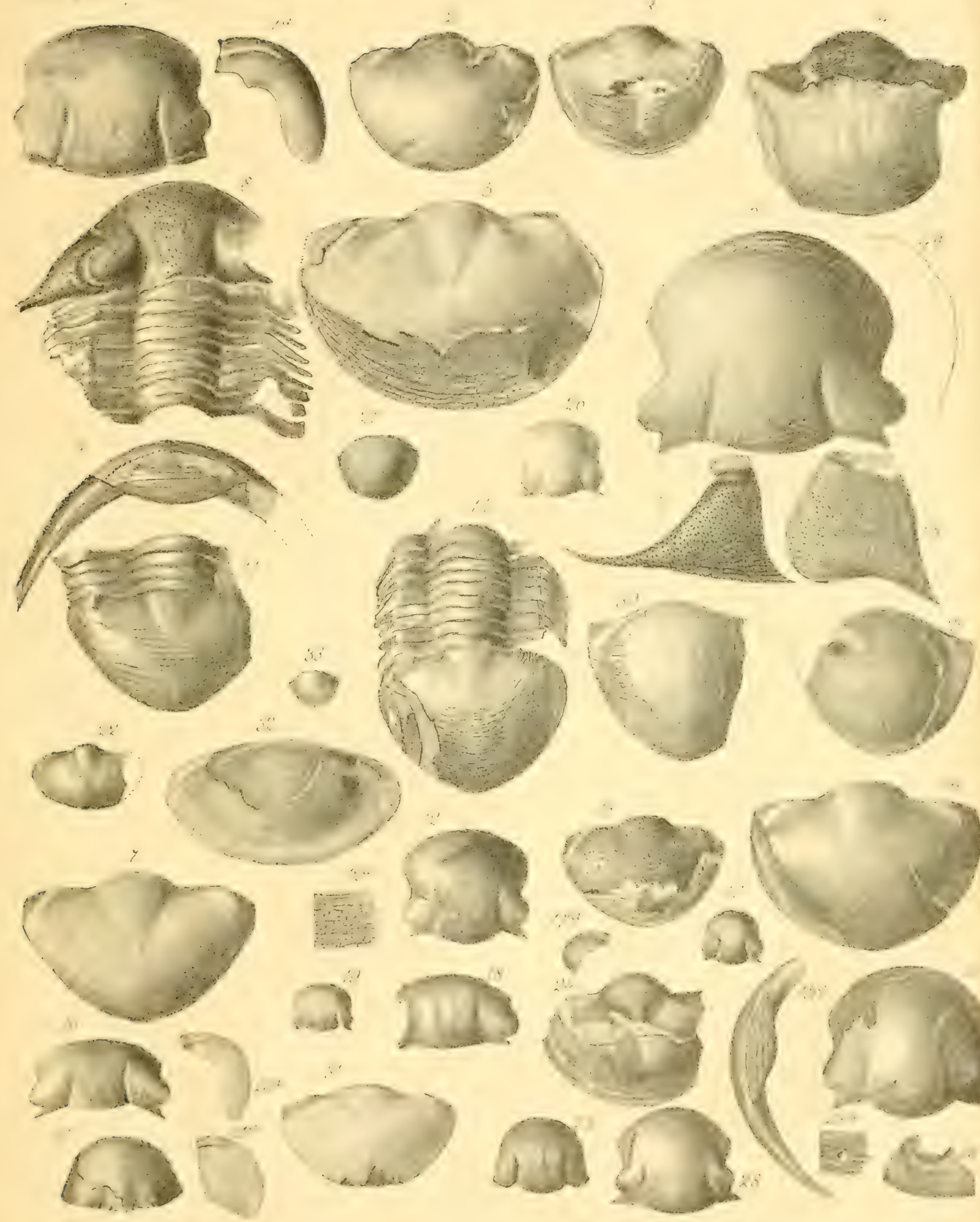


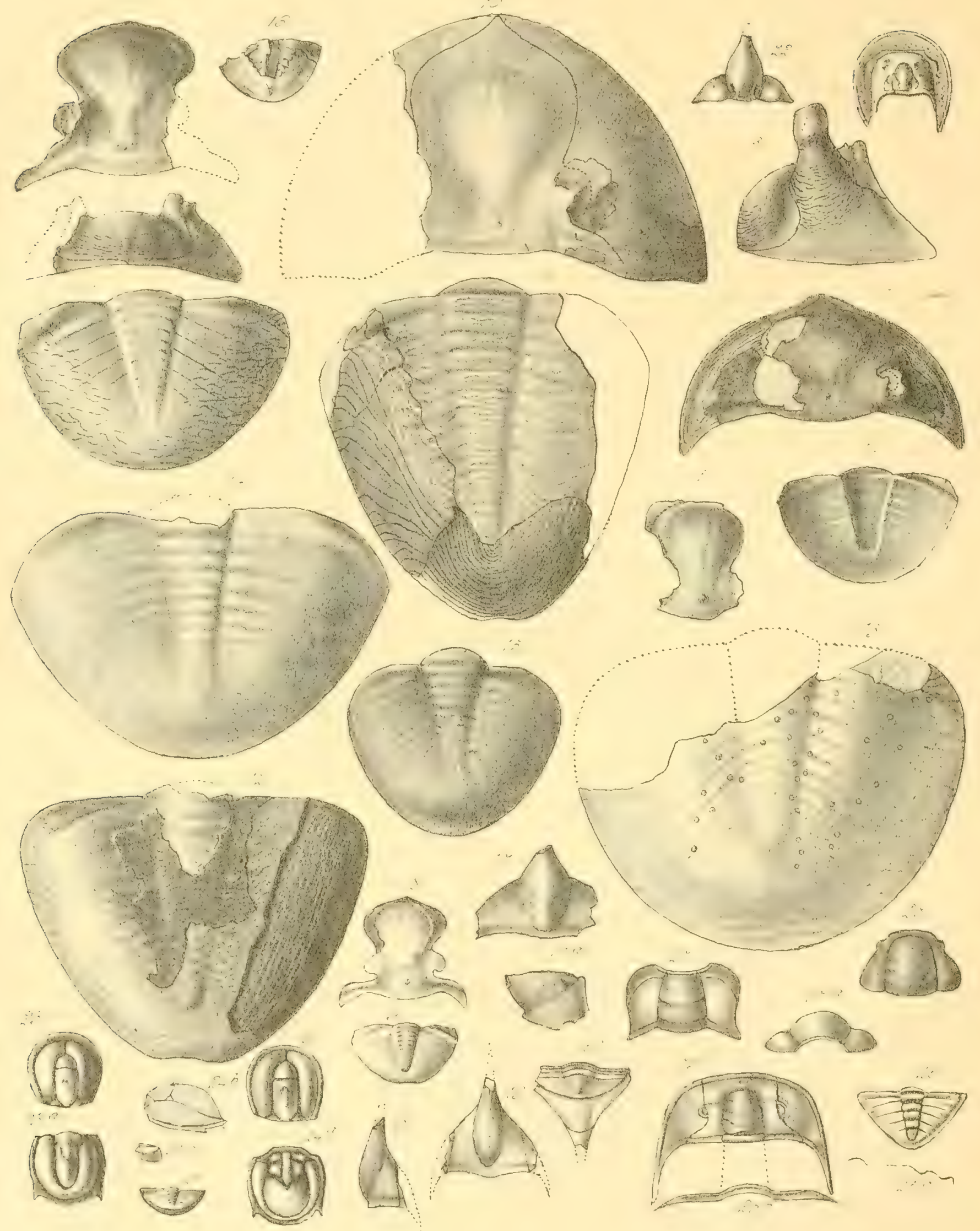




\section{Erklärung der Tafel IV.}

Fig. 1. Asaphus oculosus n. sp. Königsberg. [Pr. M. K.] . . . . . . . . . tirit. it

Fig. 2. " " $"$ Künigsberg. [Pr. M. K.]

Fig. 3. $", \quad$ Königsberg. [Pro M. K.]

Fig. 4. $" \quad$ " $"$ Künigsberb. [Pr. M. K.]

Fig. 5. Asaphus jerensis Fr. Schmidt. Gr. Schönau. [Pr. M. K.] . . . . . . . . . Th

Fig. 6. " " " $\quad$ "Trömpau. [P1. M. K.

Fig. 7. Asaphus sp. Strand bei Rosehnen. $[\mathrm{Pr} . \mathrm{M}, \mathrm{K}.] \ldots$. . . . . . . . . . . .

Fig. 8. 9. Asaphus obtusus n. sp. Künigsberg. $[$ Pr. M. K. . . . . . . . . . . $\rightarrow 1$

Fig. 10. Asaphus tecticaudatus Steinh. Königsberg. [Pr. M. K.] . . . . . . . . . †

Fig. 11. " " $"$ Königsuerg. [Pr. M. K.]

Fig. 12. Asaphus undulatus Steinh. Pr. Holland. [M. J. K.] . . . . . . . . . . . †

Fig. 13. Asaphus rimulosus Ang. Königsberg. $[\mathrm{Pr}$. M. Kr.] . . . . . . . . . . iz

Fig. 11. Megalaspis limbata Boeck. Künigsberg. $[\operatorname{Pr} . \mathbf{M} . \mathbf{K}$.$] . . . . . . . . . . " " "$

Fig. 15. Megalaspis limbata Boeck. var, elongata n. var. Kosenberg. [M. I. K.] . . . . 4 \..

Fig. 16. Holometopus? radiatus n. sp. Königsberg. [Pr. M. K.] . . . . . . . . . . -

Fig. 17. 17a. Amprx foreolatus Aug. Künigsberg. [Pr. M. K. . . . . . . . . . " . 1 .

Fig. 18. 19. 20. Ampyx rostratus Sars. Wehlau. $[\mathrm{Pr} . \mathrm{M} . \mathrm{K}$.$] . . . . . . . . . . 1$.

Fig. 21. 21a. " " " Königsberg. [M. I. K.]

Fig. 22. Ampyx culminatus Ang. 4/1. Königsberg. [Kop. n. Steinh., 'Tat: IV, Fig. 11.] . I 1:

Fig. 23. 23a. Agnostus pisiformis Linné. Nenkuhren? [Pr. M. K.] . . . . . . . . n 1 :

Fig. 21. 24a. 2tb. Agnostus pisiformis L. var. socialis Tullb. Marienwerder. |I'r. M. K.| n is

Fig. 25a. b. 26. Olenus truncatus Brünn. 3/1. Marientwerder. [Pr. 2L. K.|. . . . . . r r n

Fig. 27. 27 a. Sphaeroplthalmus alatus Boeck。 4/1. Marienwerder. [Pr. M. K.] . . . . n

Fig. 28. Peltura scarabaeoildes Wahlbg. 2/1. Marienwerder. [Pr. M. K] . . . . . n -

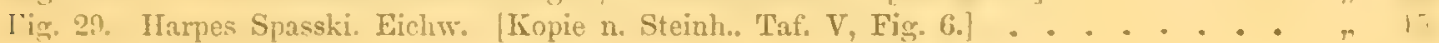




\section{Erklärung der Tafel V.}

Yig. 1. a. b. Asaphus Steinhardti n. sp. Ostpr. [M. I. K.] . . . . . . . . . . . Seite 73

Fig. 2. Asaphus sp. [? ornatus]. Königsberg. [Pr. M. K.]. • . . . . . . . . . . , 80

Fig. 3. a. b. Asaphus Branconis n. sp. Craussen. [Pr. M. K.]. . . . . . . . . , Ts

Tig. 4. Asaphus sp. Königsberg. [Pr. M. K. . . . . . . . . . . . . . . . . .

Fig. 5. Asaphus ef, aciculatus Ang. Spengawsken, [S. K. D.] . . . . . . . . . . " 75

Fig. b. Megalaspis gigas Aug. Westpr. [M. I. K.] . . . . . . . . . . . . . . . .

Iig. 7. Asaphus platyrhachis Steinh. Ostpr. [M. I. K.] . . . . . . . . . . . . . S

Iig. \&. 8a. Holometopus? gracilis n. sp. Marienwerder. [Pr. M. K. . . . . . . . " sij

Fin. !. Holometopus? laevis 12. sp. Königsberg. [M. I. K.] . . . . . . . . . . . . sis

Fis. 10. Lichas Lindströmi n. sp. 3/1. Wehlan. [S. V. W.] . . . . . . . . . . . . . . . 3

Fis. 11. Lichas aranea Lindstr. Marienwerder. [Pr. M. K.] . . . . . . . . . . . 9 5 5

Fig. 12. Lichas illaenoirles Nieszk. [Kopie nach Steinh., Taf. III, Fig. 7a.j. . . . . . , , 13

Fir. 13. " " "Kopie n. Schmidt Rev. II, Taf. III, Fig. 30a.]

Fig. 11. Lichas aequiloba Steinh. [Kopie n. Schmidt Rev. II, Taf. V, Fig. 8a.] . . . . . . 1.5

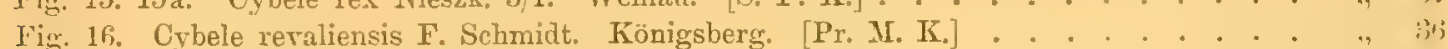

Fig. 17. 17a. Cvbele cf. Grewingki Fr. Schmidt $(2 / 1)$. Wehlau. [S. V. W.] . . . . . . . 37

Fig. 1s. Cybele sp. a. Königsberg. [Pr. M. K.]. . . . . . . . . . . . . . . . . 35

Fin. 19. Cybele revaliensis Fr. Schmidt. Westpr. [M. I. K.] . . . . . . . . . . . " it?

Fir. 20, a. b. Encrinurus punctatus Wahlbg. Wormditt. [Pr. M. K.] . . . . . . . , 4)

Yis. 21. 22. " " " " Königsberg. [Pr. M. K.]

Fig. 23. 23a. Encrinurus sp. Mewe. |Pr. M. K.] •. . . . . . . . . . . . . . . 40

Fig. 24. 24 a. Encrinurus cf. Seebachi. Fr. Schmidt. Königsberg. [S. P. K.] . . . . . . . 39

Fig. 25. 25a. Encrinurus obtusus Ang. Wehlau. [S, V. W.] . . . . . . . . . . . . $\quad 39$

Iiv. 2t. Phacops sp. Ostpr. [M. I, K.]

I"ig. 27. Proetus vermeosus Lindstr. Belschwitz. [M. I. K.] . . . . . . . . . . . .. .4 


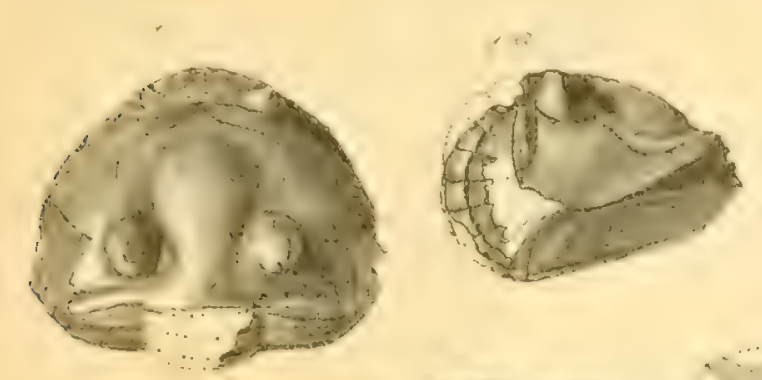

13
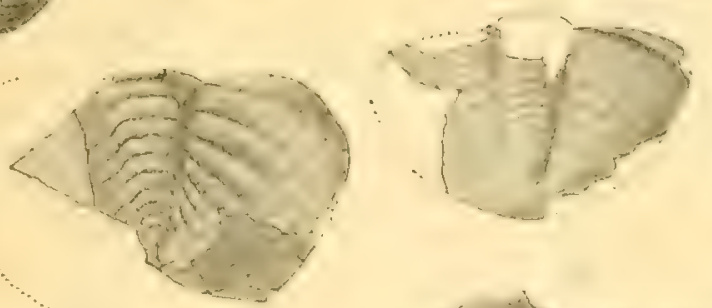

(c)

val
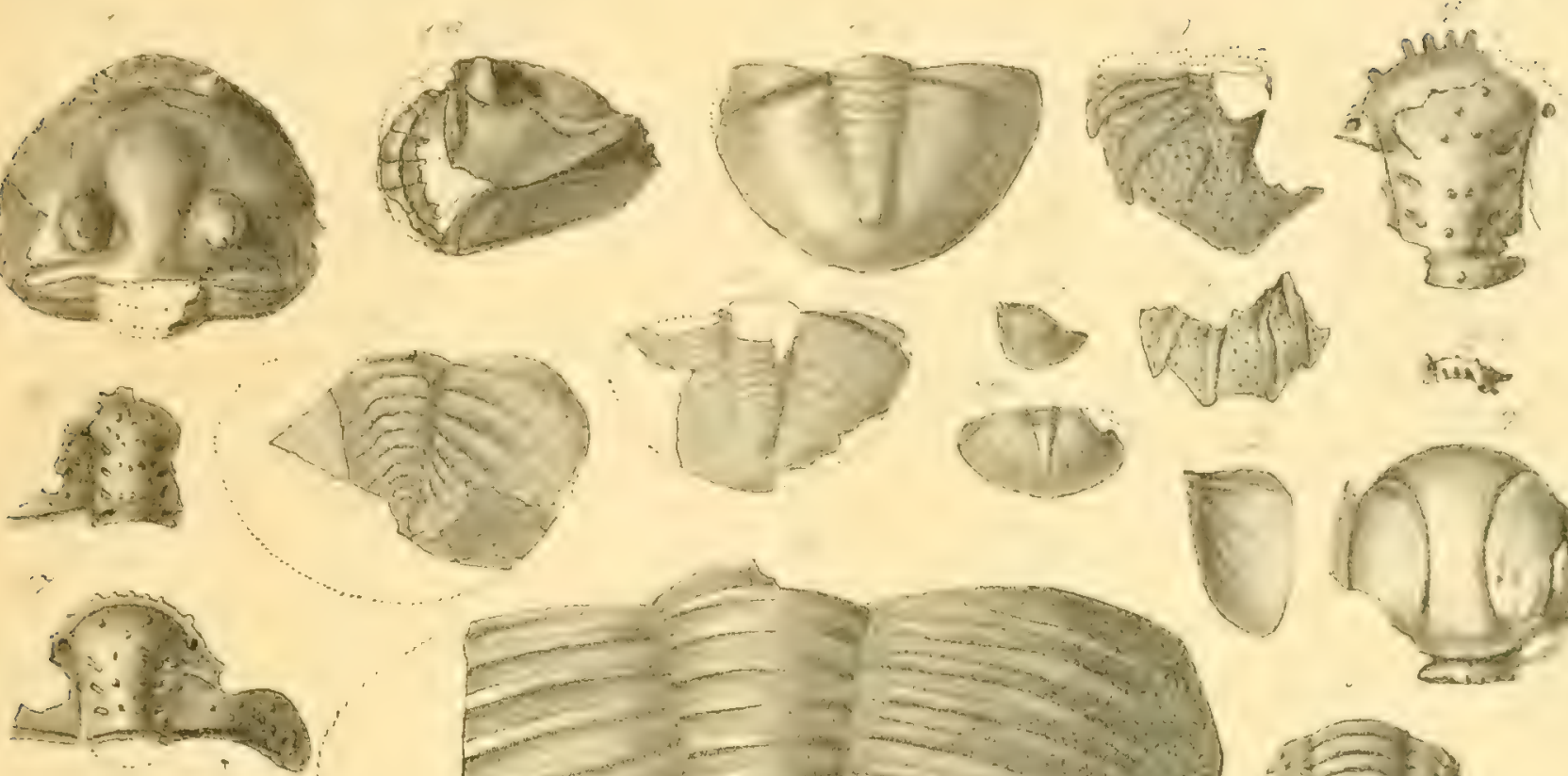

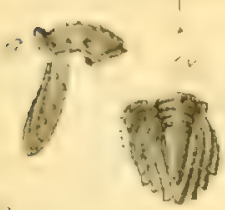
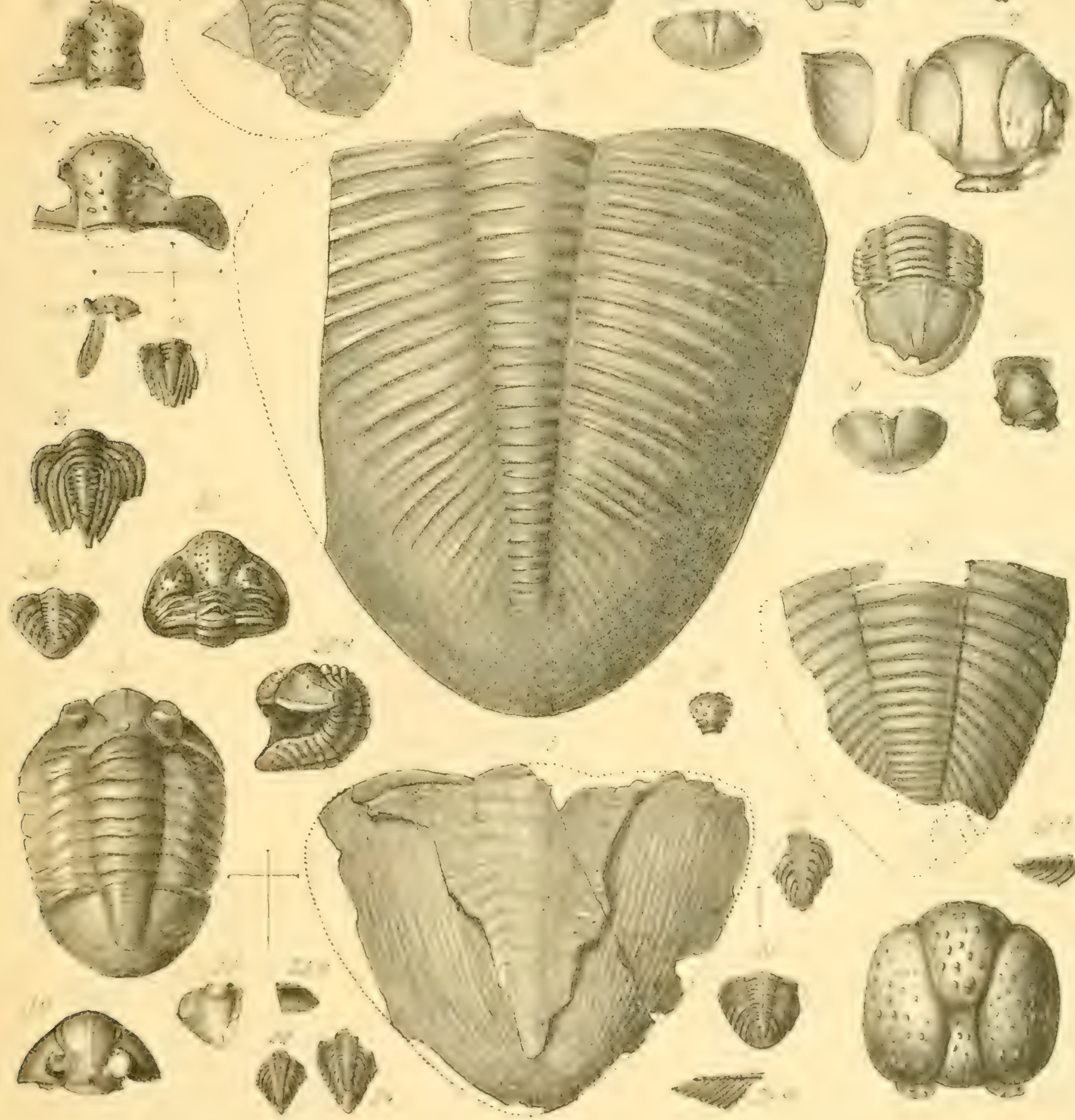



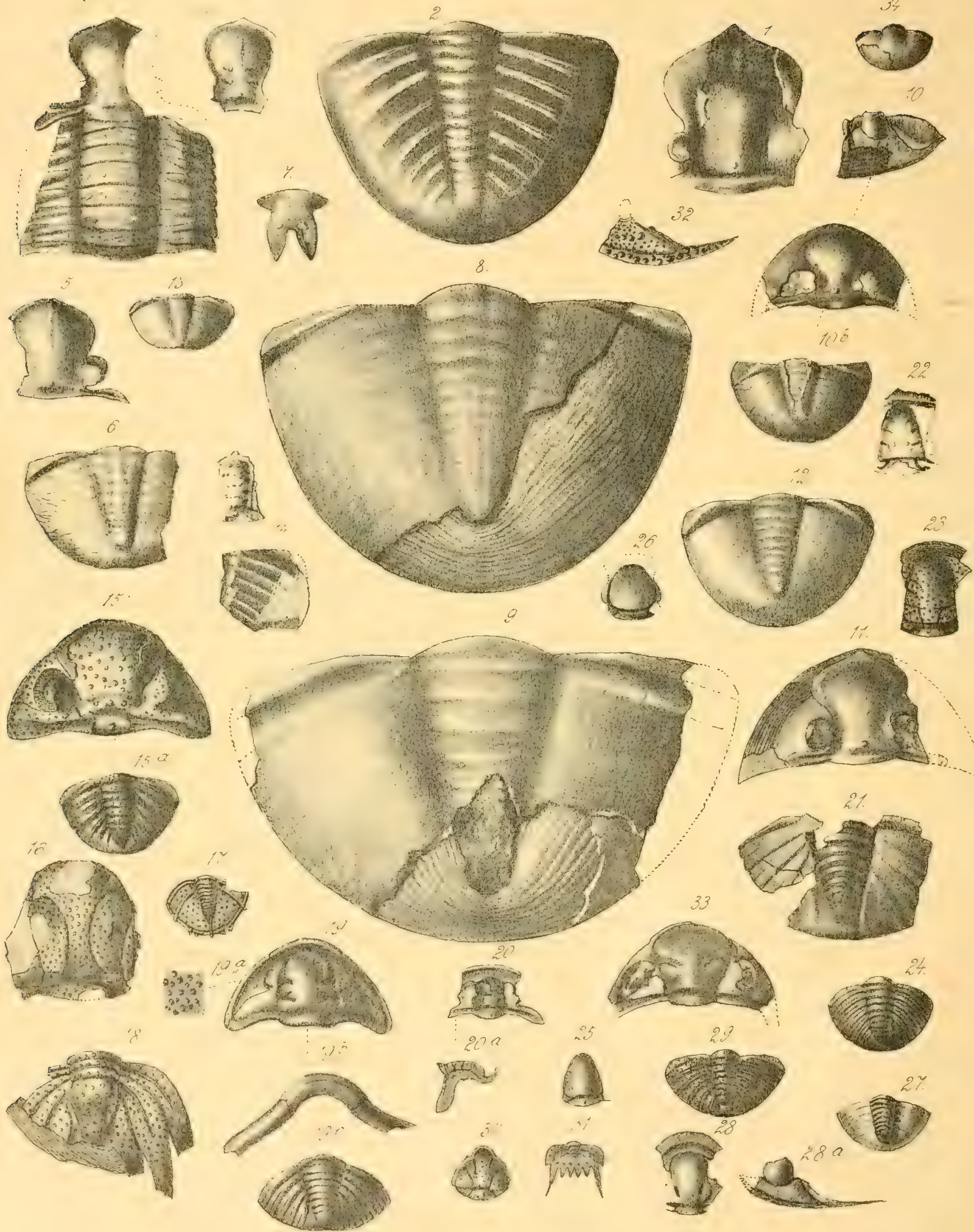


\section{Frklärung der Tafel VI.}

Fig. 1. Megalaspis limbata Boeck. Rosenberg. [M. I. K.] . . . . . . . . . . . Seite 83

Fig. 2. Megalaspis planilimbata Angel. Braunsberg. [S. S. B.] . . . . . . . . . ,

Fig. 3. Asaphus ornatus n. sp. Ostpr. [M. I. K.] . . . . . . . . . . . . . . ,

Fig 4. " " " $\quad$ Königsberg. [Pr. M. K.]

Fig. 5. " " " " Ostpr. [M. I. K.]

Fig. 6. " " " $\quad$ " Königsberg. [Pr. M. K.]

Fig. 7. Asaphus sp. Bischofswerder. [Pr. M. K.] . . . . . . . . . . . . . . . . 87

Fig. 8. Asaphus ef. platyurus Ang. Marienwerder. [Pr. M. K.] . . . . . . . . . " 8 ?

Fig. 9. Asaphus devexus Eichw. Pr. Holland. [M. I. K.] . . . . . . . . . . . . $\quad$, 82

Fig. 10. 10a. 10b. Asapbus ef. raniceps Dalm. Königsberg. [Pr. M. K.] . . . . . . . 7 .

Fig. 11. " " " " " Marienwerder. [Pr. M. K.]

Fig. 12. Asaphus sp. [? latisegmentatus]. Marienwerder. [Pr. M. K.] . . . . . . . . , 81

Fig. 13. Asaphus sp. Königsberg. [Pr. M. K.] . . . . . . . . . . . . . . . . " , 81

Fig. 14. Niobe sp. Königsberg. [P1. M. K.] . . . . . . . . . . . . . . , 84

Fig. 15. 15a. Phacops latifrons Burm. ? Braunsberg. [S. S. B.] . . . . . . . . . . . 18

Fig. 16. Lichas Eichwaldi Nieszk. Belschwitz. [M. I. K.] . . . . . . . . . . . . , 50

Fig. 17. Lichas Salteri Fletch. Gumbinnen. [M. I. K.] . . . . . . . . . . . . . , 45

Fig. 18. Lichas Plautini Fr. Schmidt. Ostpr. [M. I. K.]. . . . . . . . . . . . . " 46

Fig. 19. a. b. c. Calymene tuberculata Dalm. Marienburg. [Pr. M. K.] . . . . . . " , 40

Fig. 20. 20a. Calymene intermedia Lindstr. Belschwitz. [M. I. K.] . . . . . . . . , 41

Fig. 21. Calymene spectabilis Ang. Wargitten. [Pr. M. K.] . . . . , . . . . . . , 42

Fig. 22. Proëtus signatus Lindström. 21. Pr. Holland. [Pr. M. K.] . . . . . . . . . . 54

Fig. 23. Proëtus distinctus n. sp. 2/1. Königsberg. [M. I. K.] . . . . . . . . . . . 56

Fig. 24. Proëtus sp. 2/1. Königsberg. [Pr. M. K.] . . . . . . . . . . . . . . . . 57

Fig. 25. Proëtus sp. Belschwitz, [M. I. K.] . . . . . . . . . . . . . . . . . , 57

Fig. 26. Proëtus affin. concinno Dalm. 3/. Königsberg. [Pr. M. K.] . . . . . . . . , , 55

Fig. 27. Proëtus concinnus Dalm. 2/1. Ragnit. [Px. M. K.] . . . . . . . . . . . , 55

Fig. 28. 28a. Cyphaspis parvula n. sp. 3/1. Königsberg. [Pr. M. K.] . . . . . . . . . 57

Fig. 29. Cyphaspis sp. 3/1. Pr. Holland. [S. Z. H.] . . . . . . . . . . . . . . " 58

Fig. 30, 31. Acidaspis mutica Emmr. 2/1. Pr. Holland. [S. Z. H.] . . . . . . . . " 5 ,

Fig. 32. Encrinurus punctatus Wahlbg. Detmitten. [Pr. M. K.] . . . . . . . . . . , 40

Fig. 33. Phacops Odini Eichw. Ostpr. [M. I. K.] . . . . . . . . . . . . . " 22

Fig. 34. Illaenus auculus n. sp. Ostpr. [M. I. K.] . . . . . . . . . . . . . 69

Fig. 35. Cybele sp. b. 2/1. Belschwitz. [M. I. K.]. . . . . . . . . . . . . . 38 


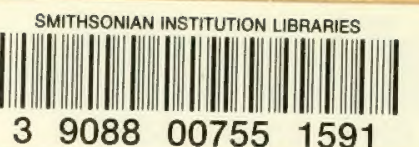


